The United Nations University Press is the publishing arm of the United Nations University. UNU Press publishes scholarly and policy-oriented books and periodicals on the issues facing the United Nations and its peoples and member states, with particular emphasis upon international, regional and trans-boundary policies.

The United Nations University is an organ of the United Nations established by the General Assembly in 1972 to be an international community of scholars engaged in research, advanced training, and the dissemination of knowledge related to the pressing global problems of human survival, development, and welfare. Its activities focus mainly on the areas of peace and governance, environment and sustainable development, and science and technology in relation to human welfare. The University operates through a worldwide network of research and postgraduate training centres, with its planning and coordinating headquarters in Tokyo. 
Broadening Asia's security discourse and agenda 



\section{Broadening Asia's security discourse and agenda: Political, social, and environmental perspectives}

Edited by Ramesh Thakur and Edward Newman

United Nations
University Press
TOKYO. NEW YORK • PARIS 
(C) United Nations University, 2004

The views expressed in this publication are those of the authors and do not necessarily reflect the views of the United Nations University.

United Nations University Press

United Nations University, 53-70, Jingumae 5-chome,

Shibuya-ku, Tokyo, 150-8925, Japan

Tel: +81-3-3499-2811 Fax: +81-3-3406-7345

E-mail: sales@hq.unu.edu general enquiries: press@hq.unu.edu

http://www.unu.edu

United Nations University Office at the United Nations, New York

2 United Nations Plaza, Room DC2-2062, New York, NY 10017, USA

Tel: +1-212-963-6387 Fax: +1-212-371-9454

E-mail: unuona@ony.unu.edu

United Nations University Press is the publishing division of the United Nations University.

Cover design by Joyce C. Weston

Printed in Hong Kong

UNUP-1094

ISBN 92-808-1094-4

Library of Congress Cataloging-in-Publication Data

Broadening Asia's security discourse and agenda : political, social, and environmental perspectives / edited by Ramesh Thakur and Edward Newman.

p. $\mathrm{cm}$.

ISBN 92-808-1094-4 (pbk.)

1. National security-Asia. 2. Security, International. 3. Asia-Economic conditions-21st century. 4. Asia-Politics and government-21st century. 5. Globalization-Economic aspects-Asia. 6. Asia-Social conditions-21st century. 7. Globalization-Environmental aspects-Asia. 8. Human ecologyAsia. I. Thakur, Ramesh Chandra, 1948 - II. Newman, Edward, 1970-

UA830.B76 2004

$355^{\prime} .03305-\mathrm{dc} 22$

2003025284 


\section{Contents}

List of figures $\ldots \ldots \ldots \ldots \ldots \ldots \ldots \ldots \ldots \ldots \ldots \ldots \ldots \ldots \ldots \ldots \ldots \ldots \ldots \ldots \ldots$, vii

List of tables ..................................... viii

Acknowledgements $\ldots \ldots \ldots \ldots \ldots \ldots \ldots \ldots \ldots \ldots \ldots \ldots \ldots \ldots \ldots \ldots \ldots \ldots \ldots, \quad$ ix

List of abbreviations................................. $\quad \mathrm{x}$

Introduction: Non-traditional security in Asia .................. 1 Ramesh Thakur and Edward Newman

Part I Social and economic perspectives.................... 17

1 Globalization and human development: The cases of Pakistan

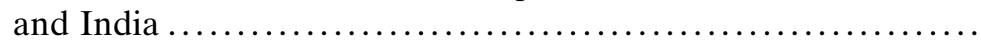
Jennifer Bennet

2 Southeast Asia's embedded mercantilism in crisis:

International strategies and domestic coalitions ............... Kanishka Jayasuriya

3 Poverty as a non-traditional security issue: Experiences of China's partnership with multilateral donor institutions on

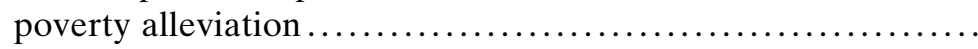
Qingxin K. Wang and Melissa G. Curley 
Part II Governance

4 Security and governance in South Asia: Their linkages ........ P.R. Chari

5 Governance in plural societies: Sri Lanka.................. Paikiasothy Saravanamuttu

Part III Environment

6 Sustainable development and human security: Lessons from South Asia .......................................... Adil Najam

7 How critical is "environmental security" as a non-traditional security issue in Northeast Asia? .......................... M. Shamsul Haque

8 A cultural theory perspective on environment and security issues in Nepal... Ajaya Dixit and Dipak Gyawali

9 The hydro-politics of the Mekong River Basin: regional cooperation and environmental security.... Evelyn Goh

Part IV Institutional security perspectives

10 Alternative security models: Implications for ASEAN William T. Tow

11 Seeking non-traditional security in "traditional" ways: Northeast Asia and emerging security challenges............. Richard W. Hu

12 Cooperation and institutional transformation in ASEAN: Insights from the AFTA project. Helen E.S. Nesadurai

13 Non-traditional security cooperation in Northeast Asia........ 306 Tsuneo Akaha

Contributors 


\section{Figures}

2.1 A structural model of coalitions, crisis, and policy outcomes .. 67

6.1 Organizing the environment and security discussion ......... 157

8.1 Map of the Mahakali River ........................... 198

9.1 Geographical importance of the Mekong Basin to riparian states....................................... 213 


\section{Tables}

1.1 Selected macro-economic and social indicators............

1.2 Expenditure on education and health as a percentage of GDP ........................................... 31

2.1 Asia: Ratio of FDI inflows to gross domestic capital formation, 1971-1993 (annual averages) ................ 55

6.1 Environment and security: an "obvious" connection? ...... 149

6.2 South Asia's many roots of insecurity ................. 160

9.1 Geographical control of the Mekong River Basin.......... 212

9.2 Selected socio-economic indicators for Mekong riparian states ..................................... 214

9.3 Summary of the relative geopolitical and resource positions of the Mekong states ............................. 217

10.1 Selected alternative security models.................. 259

10.2 Traditional and "alternative" security: Areas of comparison 266

12.1 The three stages of the AFTA Project ................. 282

12.2 Framework of institutionalization ..................... 285

12.3 The nature of the constitutional documents............... 290

13.1 Trade in Northeast Asia, 1996 (in US\$million) ............ 316

13.2 Trade in Northeast Asia, 1998 (in US\$ million) ........... 317

13.3 Main characteristics of multilateral cooperation institu-

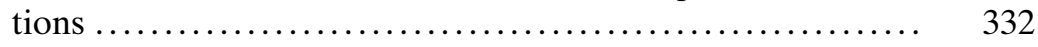




\section{Acknowledgements}

The origins of this book lie in a research project on Non-Traditional Security in Asia, generously supported by the Ford Foundation. Our first thanks therefore go to the Ford Foundation for supporting this important initiative. The objective of the project was to deepen understanding of non-military and non-state centric dimensions of security. Work was divided into three sub-regions: Northeast Asia, Southeast Asia, and South Asia. The institutions which directed the research in these three sub-regions were, respectively, United Nations University (under the supervision of Ramesh Thakur); the Institute of Defence and Strategic Studies, Singapore (Barry Desker); and the Regional Centre for Strategic Studies, Sri Lanka (Dipankar Banerjee).

This volume brings together some of the results of the project and we would like to thank these institutions and individuals for cooperating in its publication. We would also like to thank the three institutions that worked with the UNU in the research on Northeast Asia: Hong Kong University (under the supervision of James Tang), the Chinese Academy of Social Sciences (Zhang Yunling), and Korea University (In-Taek Hyun). We would also like to thank the publishers in the instances where material in this volume has already been published locally elsewhere: Institute of Defence and Strategic Studies (Singapore), Manohar publishers (Delhi), Academic Press and Publishers Ltd. (Dhaka), and the Regional Centre for Strategic Studies (Colombo). Finally, we would like to thank the people who helped to support the project work and the publication of this volume at the UN University, particularly Yoshie Sawada and Lysette Rutgers. 


\title{
Abbreviations
}

\author{
ADB Asian Development Bank \\ AEM ASEAN Economic Ministers \\ AFTA ASEAN Free Trade Area \\ AIA ASEAN Investment Area \\ APEC Asia Pacific Economic Cooperation \\ ARF ASEAN Regional Forum \\ ASEAN Association of Southeast Asian Nations \\ ASEAN+3 ASEAN plus Three (China, Japan and South Korea) \\ AusAID Australian Agency for International Development \\ BJP Bharatiya Janata Party, India \\ BoP balance of payments \\ CAD current account deficit \\ CASS Chinese Academy of Social Sciences \\ CCF1 China Country Cooperation Framework \\ CEPT Common Effective Preferential Tariff \\ CICETE China International Centre for Economic and Technical \\ Exchanges \\ CPI consumer price index \\ CSCAP Council for Security and Cooperation in the Asia-Pacific \\ DID Development International Desjardins (Canada) \\ DSM Dispute Settlement Mechanism \\ EAC Economic Commission for Africa \\ EAEC East Asia Economic Caucus
}




$\begin{array}{ll}\text { ECSC } & \text { European Coal and Steel Community } \\ \text { EEC } & \text { European Economic Community } \\ \text { EFF } & \text { extended fund facility } \\ \text { EFTA } & \text { European Free Trade Area } \\ \text { EGAT } & \text { Electricity Generating Authority of Thailand } \\ \text { EIAs } & \text { environmental impact assessments } \\ \text { ESCAP } & \text { Economic and Social Commission for the Asia-Pacific } \\ & \text { Region } \\ \text { FCPMC } & \text { Foreign Capital Management Centre (China) } \\ \text { FDI } & \text { foreign direct investment } \\ \text { GATT } & \text { General Agreement on Tariffs and Trade } \\ \text { GLCs } & \text { government-linked companies } \\ \text { GNP } & \text { gross national product } \\ \text { IGOs } & \text { international government organizations } \\ \text { IMF } & \text { International Monetary Fund } \\ \text { INGOs } & \text { international non-governmental organizations } \\ \text { INTERFET } & \text { International Force for East Timor } \\ \text { IOs } & \text { international organizations } \\ \text { JETRO } & \text { Japan External Trade Organization } \\ \text { JVP } & \text { Janata Vimukthi Peramuna (People's Liberation Front, Sri } \\ & \text { Lanka) } \\ \text { LDP } & \text { Liberal Democratic Party } \\ \text { LEDCO } & \text { Langjung Electricity Development Company (Nepal) } \\ \text { LGPR } & \text { Leading Group for Poverty Reduction (China) } \\ \text { LTTE } & \text { Liberation Tigers of Tamil Eelam } \\ \text { MDRN } & \text { Mekong Development Research Network } \\ \text { MFN } & \text { most-favoured nation } \\ \text { MOFTEC } & \text { Ministry for Foreign Trade and Economic Co-operation } \\ & \text { (China) } \\ \text { MRC } & \text { Mekong River Commission } \\ \text { NAFTA } & \text { North American Free Trade Agreement } \\ \text { NATO } & \text { North Atlantic Treaty Organization } \\ \text { NEACD } & \text { Northeast Asia Cooperation Dialogue } \\ \text { NEAEF } & \text { Northeast Asia Economic Forum } \\ \text { NEATIC } & \text { Northeast Asia/Tumen Investment Corporation } \\ \text { NEP } & \text { New Economic Policy (Malay) } \\ \text { NET } & \text { natural economic territory } \\ \text { NGOs } & \text { non-governmental organizations } \\ \text { NICs } & \text { newly industrializing countries } \\ \text { NTB } & \text { non-tariff barriers } \\ \text { OECD } & \text { Organisation for Economic Co-operation and Develop- } \\ \text { ment }\end{array}$


OSCE Organization for Security and Cooperation in Europe

PA Peoples Alliance (Sri Lanka)

PA poverty alleviation

PADO Poverty Alleviation and Development Office (China)

PECC Pacific Economic Cooperation Council

PPLG Provincial Poverty Leading Group (China)

PPP purchasing power parity

R\&D research and development

SAARC South Asian Association for Regional Cooperation

SAL structural adjustment loan

SEOM Senior Economic Officials Meeting

SIDDs Self-Financing Irrigation and Drainage Districts (China)

SPC State Planning Commission (China)

SPI sensitive price indicator

TRIMs Trade Related Investment Measures

TRIPs Trade Related Aspects of Intellectual Property Rights

TULF Tamil United Liberation Front

UMNO United Malays National Organization

UNDP United Nations Development Programme

UNEP United Nations Environment Programme

UNICEF United Nations Children's Fund

UNP United National Party (Sri Lanka)

WPI wholesale price index

WSSD World Summit on Social Development

WTO World Trade Organization 


\title{
Introduction: Non-traditional security in Asia
}

\author{
Ramesh Thakur and Edward Newman
}

In recent years both the theory and practice of national and international security have undergone evolution. While basic physiological human needs have changed little, our conceptualization of security and our approaches to achieving and maintaining security have changed considerably. International security is no longer conceived of solely as defence of national territory against "external" military threats under state control. The security agenda, as this volume demonstrates, incorporates political, economic, social and environmental dimensions as well as the many linkages between them. An established literature now exists to support this broad approach, and non-traditional security perspectives have taken their place in academic and, to an extent, policy circles. ${ }^{1}$ But this has not been without controversy in terms of academic rigour and policy relevance. This volume applies non-traditional security perspectives - an approach that goes beyond military threats and state centric analysis - to a range of human challenges across the Asian continent. It explores the potential practical and conceptual benefits of non-traditional security thinking in a region beset by both conventional and non-traditional security challenges.

The underlying premise and starting point of this volume is that traditional security has failed to deliver meaningful security to a significant proportion of the people of Asia - who between them comprise more than half the world's total population. This is an empirical reality. For most people in the region, the greatest threats to security come from 
disease, hunger, environmental contamination, crime, and unorganized violence. For many indeed a still greater threat may come from their own state itself, rather than from an "external" adversary. Attitudes and institutions that privilege "high politics" above disease, hunger, or illiteracy are embedded in international relations and foreign policy decisionmaking. This volume aims to present a fresh approach to human security in a region that is beset by critical welfare concerns but is often preoccupied with orthodox notions of national security at the policy level. In combining empirical and normative approaches, this volume aims to highlight the magnitude of security threats in Asia and the impact that these threats have upon individuals and communities in the region. It also attempts to demonstrate the analytical advantages that non-traditional security approaches can offer, while attempting to highlight policy implications where possible.

\section{Non-traditional security and the state}

The non-traditional security approach is not necessarily in opposition to state sovereignty and national security; the state remains the central provider of security in ideal circumstances. The approach does, however, suggest that international security as traditionally defined - the defence of territorial integrity by military means - does not necessarily correlate with all the dimensions of the security of people, and that an overemphasis upon statist security can be to the detriment of human security needs. Therefore, while traditional conceptions of state security may be a necessary condition, they cannot be a sufficient one of human survival. The narrow definition of security also presents a falsified image of the policy process. The military is only one of several interest groups, alongside environmental and social groups, competing for a larger share of the collective goods being allocated by the government. Rational policymakers will allocate resources to security only so long as the marginal rate of return is greater for "security" than for other uses of the resources. The citizens of states that are "secure" according to the abstract and remote concept of traditional security can be perilously insecure in terms of the threats to the lives of individual human beings in everyday reality. A number of countries in Asia are cases in point. A nontraditional security approach attempts to redress this asymmetry of attention and resources.

The fundamental purpose of a state is to protect the security and promote the welfare of its citizens. In return, the state and state sovereignty are given primacy as the ordering unit and organizing principle of world affairs. $^{2}$ But the capacity of many states to fulfil this double purpose is 
often severely limited. The changing security discourse has thus moved beyond protection of a state's territorial integrity, political independence and sovereignty to embrace such issues as plight of children in armed conflict; terrorism; trafficking in arms, narcotics and people; the spread of infectious diseases; and cross-border environmental depredations. Security analysts today have to grapple simultaneously with problems of external threats, internal social cohesion, regime capacity and brittleness, failed states, economic development, structural adjustment, gender relations, ethnic identity, and transnational and global problems like AIDS, drug trafficking, terrorism, and environmental degradation.

The human and non-traditional security agenda is clearly both broad and deep. These issues are often neglected by traditional security thinking, but they shorten the life expectancy of millions and have repercussions beyond their immediate impact that are only now beginning to be understood. And when the degradations reach the point where they become life-threatening on a large scale, it would seem ridiculous to insist that this is not a "security" issue. These challenges are pressing concerns across Asia.

\section{Applying the non-traditional security approach}

The non-traditional security approach is necessarily a multidisciplinary and comprehensive approach to critical welfare issues and questions of survival. Challenges and solutions are not phenomena that can be addressed in isolation from each other; they are interconnected, and even sometimes interdependent. Non-traditional and human security must be approached in an inclusive and "holistic" manner - not only examining the symptoms or manifestations of human insecurity, but also seeking to produce recommendations that address root causes.

However, can there be a methodology for approaching non-traditional security challenges? What issues are included and which excluded from the approach, and on what basis is this determined? It is essential to develop a sound rationale for bringing a diverse range of issues together within a single, unifying theme of "non-traditional security" in order to demonstrate the meaningfulness and policy relevance of approaching diverse issues under a single conceptual umbrella. Non-traditional security must clearly demonstrate its distinctiveness from issues of welfare and governance. It does not include all health, welfare, and development challenges. But these issues become security concerns when they reach crisis point, when they undermine and diminish the survival chances of significant proportions of the citizens of society, and when they threaten the stability and integrity of society. 
A further important analytical point: why are non-traditional security issues "international" issues? Deepening understanding of interlinkages helps to answer this. Non-traditional security challenges can and do spill over territorial borders and cause a range of wider security threats and sources of instability - such as refugee flows, illegal trafficking in narcotics and humans - or otherwise disrupt international markets. Human security threats are therefore interdependent and very much an international concern that require international cooperation among a range of actors. There are gaps in understanding and acceptance regarding this critical issue.

Adherents and analysts of non-traditional and human security are familiar with the difficulties of defining security and developing a sound methodology through which to approach non-traditional security concerns. Defining human security is conceptually and practically troublesome. But the field of International Relations is full of essentially contested concepts. And the very exercise of constructing boundaries of exclusion and inclusion can itself be problematized. ${ }^{3}$ The definition used by the United Nations University is:

Human security is concerned with the protection of people from critical and lifethreatening dangers, regardless of whether the threats are rooted in anthropogenic activities or natural events, whether they lie within or outside states, and whether they are direct or structural. It is "human-centered" in that its principal focus is on people both as individuals and as communal groups. It is "security oriented" in that the focus is on freedom from fear, danger and threat.

Thus, the referent of human security must be human beings, whether as individuals or as social and political groups. Human security reflects the concern that contemporary security, if it is to be relevant to changing conditions and needs, must focus on the individual or groups. This does not exclude the importance of traditional ideas of security, but it does suggest that it may be more effective to reorient the provision of security around people: wherever the threat comes from.

The human security approach specifically holds the individual as the referent of security concerns and policies. The approach of the nontraditional security perspective of this volume is looser. A non-traditional security approach can be a human security approach, but it can also be a broader framework for analysis. In the approach of this volume, the nontraditional security element can refer to the source of security threats, the referent object of security analysis, or the means of achieving security. Thus, the source of security threats can be non-traditional (non-state centric and non-military), including poverty, environmental degradation, sectarian tension, and organized crime. The referent object can be nontraditional (i.e. non-state), such as the individual or the natural environ- 
ment. Finally, whatever the source of the security threat and the referent object of security analysis, the response to security challenges can be non-traditional, for example, through non-governmental organizations (NGOs) and international cooperation. Thus, the chapters in this volume imply a number of foundational questions concerning the security discourse: regarding the unit of analysis, or object, of security; the tools for achieving security; the relationship between development and security; and the place of ideas such as dignity and equity in security.

By way of illustration, health and security converge at three intersections. Being wedded still to "national security" may be one reason why half the world's governments spend more to protect their citizens against undefined external military attack than to guard them against the omnipresent enemies of good health. ${ }^{4}$ First, faced with domestic economic crises and shrinking foreign assistance, many developing countries have had to make difficult budgetary choices to reduce the level of public services. But the failure of governments to provide the basic public health services erodes governmental legitimacy and encourages the spirit of "self- help" and "beggar thy neighbour" among citizens at the expense of the public interest. Often the competition degenerates into violence. Thus the withdrawal of the state from the public health domain can be both a symptom and a cause of failing states. Second, there has been an increasing trend in recent internal armed conflicts to manipulate the supplies of food and medicine. Indeed the struggle to control food and medicine can define the war strategies of some of the conflict parties. And third, the use of biological weapons represents the deliberate spread of disease against an adversary.

A further example is terrorism. Recent experience of Afghanistan, before 11 September 2001, showed how corrupt, unstable, ineffective, and repressive governance is a cause of misery for millions in that country: human rights, development, and education (amongst other things) all ranked around the worst in the world. At the same time, such a state of affairs can also be a breeding ground and haven for violent grievance and terrorism, the effects of which have a far wider impact upon international peace and security, both traditional and non-traditional. The war on terror has reinforced the need to go beyond the traditional security framework; terrorism must be dealt with at the nexus between development and security. This suggests a broad, multifaceted approach to security that embraces the social, economic, political as well as military dimensions.

\section{Social and economic perspectives}

The social and economic perspectives of human security and nontraditional security are now well established. Poverty and material depri- 
vation - and related threats such as illiteracy, vulnerability to ill health, malnutrition - are a direct and clear threat to the security of individuals and communities. Furthermore, deprivation can represent a threat to states: poverty and inequality can undermine social cohesion and cause instability, undermining the provision of public services, and making societies vulnerable to a range of other threats. Alternatively, the persistence of traditional types of conflict, whether within or between states, can pose significant obstacles to the eradication of extreme poverty.

The chapter by Jennifer Bennett presents a worrying picture of human security threats in South Asia. She investigates the processes of globalization and its impact on social development, especially in poorer countries. She explores the major question of who will benefit from such transnational processes and focuses on Pakistan and India to determine the impact of globalization. According to Bennett, the expanding processes of globalization, administered through international financial institutions, are posing an alarming threat to the marginalized and poor. She argues that structural adjustment conditionalities have reduced the state's role in the economy, lowered barriers to imports, removed restrictions on foreign investment, eliminated subsidies for local industries, reduced spending for social welfare, cut wages, devalued the currency, and emphasized production for export rather than for local consumption. In this context the masses are clearly neglected, widening the gaps between the rich and poor, and between the most affluent and impoverished nations, in the interests of achieving competitiveness internationally. She draws a number of conclusions: applying a unitary set of policies across the entire developing world, regardless of an individual country's social and economic level of development or its local needs and priorities, is flawed; the assumption that higher growth rates will produce a trickledown effect to ameliorate the socio-economic conditions of the general population of a nation has not been borne out; and the unequal international division of labour, wide disparities in wages and labour costs between developed and developing countries, and the wide technological gap between the two worlds do not allow the developing countries to be on a level playing field in the arena of global market system.

Kanishka Jayasuriya takes a different approach by focusing on the internal political economy dynamics of states. Jayasuriya argues that the foreign economic and security policies pursued in East Asia before the 1997 economic crisis depended on the existence of a set of domestic coalitions that enabled the protection of politically linked cartels and business groups. At the same time, this permitted the pursuit of an open economic policy which had the approval, until the crisis, of the international financial institutions. This domestic configuration - which the author calls "embedded mercantilism" - created the distinctive forms of 
multilateralism in the Asia Pacific Economic Cooperation (APEC) and the Association of Southeast Asian Nations (ASEAN) Regional Forum (ARF) in the Asia-Pacific. In the wake of the Asian crisis, the chapter argues, these domestic foundations have become more brittle and diverse, producing significant fissures between those states dominated by reform-oriented coalitions and others where nationalist coalitions still remain deeply entrenched. Thus, the form and structure of international economic policies and security policy in East Asia are contingent upon power and interests in the domestic and external economy. The breakdown of domestic coalitions therefore has important implications for the future course of East Asian multilateralism.

Melissa G. Curley and Qingxin K. Wang begin their chapter by making the case that poverty is a security issue in international relations. They observe that poverty is a clear human security challenge; but it can also be related to traditional security concerns by threatening and undermining regime legitimacy and stability, and thus threatening international peace. The consequences of poverty upon and within populations can also escalate to the international level to cause cross-border and interstate tensions. Upon this basis they explore the interaction between different actors in poverty alleviation by emphasizing the importance of forming partnerships between state actors and international actors. To illustrate their hypothesis, Curley and Wang analyse the case of China's cooperation with international organizations on poverty alleviation programmes. The case study shows that institutional cooperation between the state, international organizations, and NGOs has provided an effective solution to tackling poverty in China, and of improving the human security of millions of China's poor. But they conclude by arguing that effective collaboration between the state and multilateral donor organizations is central in the global campaign to eradicate poverty. In the case of China, at least, NGOs are not on an equal footing in terms of importance.

\section{Governance}

Part II addresses the role of governance in the non-traditional security debate. It is now widely accepted that domestic governance is related to security among and within states, as well as a broad range of human rights and welfare needs. There is also much support for the idea that democratic governance is conducive to sound development and stable, plural societies, and that it correlates to peaceful relations between and within societies (although democratic transition can increase instability). The corollary, of course, is that unstable, inefficient, undemocratic governance is the source of insecurity both to individuals and communities. 
The provision of public services, the protection of human rights, the maintenance of a stable and productive economy all largely rest ultimately upon the shoulders of national governments. It goes without saying that when governments are unable or unwilling to meet these responsibilities, individuals are vulnerable to deprivation and human rights abuse. This can, in turn, have repercussions across national borders.

P.R. Chari addresses some of these issues and argues that South Asia is noteworthy for examples of poor governance: scarce resources are inefficiently deployed or frittered away, government administrations are getting increasingly divided on ethnic and sectarian lines, law enforcement is arbitrary and political leadership is obviously inadequate. According to Chari, this situation derives largely from a lack of a participatory government accompanied by - and connected to - a rapid erosion of government effectiveness. The common causes underlying this crisis of governance are the decay of political parties and democratic institutions; the indifference of the ruling elite to social needs; resistance to devolution and decentralization of powers to the people; and the nexus between criminals and corrupt bureaucrats, politicians, and businessmen. Therefore, there is a pressing need for greater transparency, access to information, and oversight mechanisms to regulate the functioning of the state.

Traditional security contains an inherent and unresolvable paradox at its very core. As every campaign for national self-determination by groups within existing states shows afresh, one "nation's" security is another "nation's" insecurity. While there is no solution to this particular security dilemma from within the analytical framework of the traditional security paradigm, there may be a solution through an emphasis on "good governance". Paikiasothy Saravanamuttu's chapter illustrates the challenges of providing stable and efficient governance in Sri Lanka. In that country, the growth of a more assertive majority Sinhala nationalism after independence fanned the flames of ethnic division until civil war erupted in the 1980s with the Tamils pressing for self-rule. Saravanamuttu argues that the problem of governance in Sri Lanka stems in large measure from the failure to acknowledge the pluralism inherent in society through constitutional guarantees and through the propagation of this value in the political culture. Consequently, there is a crisis of legitimacy of the state. He observes that in Sri Lanka, and in South Asia in general, governmental structures still bear the hallmarks of the colonial legacy and social relations those of pre-colonial influences. At the same time, state and nation building processes are still underway. Consequently, in Sri Lanka the state, essentially the colonial state, preceded nation and has become the principal institutional agency in the creation of the nation through strategies of assimilation, integration, and coercion. These cen- 
tralizing tendencies of the state have bedevilled the objectives of developing socio-political harmony and an overarching national consciousness. Rather, the inability and/or unwillingness of the state to accommodate social diversity and provide democratic "space" to a variety of groups has in turn nurtured and intensified centrifugal tendencies. Saravanamuttu describes the painful history of negotiations and peace processes that culminated in the hopeful Norwegian initiative of 2002.

If we accept the thesis that the roots of armed conflicts in Indonesia and Sri Lanka can be traced to the lack of good governance that defines and mediates relations between the political centre and distinctive regions, then the logic of looking beyond the traditional security paradigm, even for threats to the territorial integrity of states, is compelling.

\section{The natural environment}

Part III demonstrates how the natural environment has multifold implications for security. Environmental degradation can represent a direct threat to individuals - through the effects of pollution, ill health, and vulnerability to natural disasters, for instance. It can represent a threat to the coherence and stability of communities - by undermining their capacity to operate as productive communities, or their capacity for the provision of public services. It can also potentially lead to conflict between communities and states, as a result of the spill-over effects of pollution and competition over resource scarcity.

Adil Najam's chapter begins with an exploration of the non-traditional and human security debates. As he observes, exactly what is being "secured", for whom, by whom and how, have long been in contention. Within this, environmental issues require new ways of thinking about policy, including security policy. At the same time, the environment is among the earliest and most pervasive sources of human conflict - and therefore of security concerns. Linkages between the natural environment and security are clear. Water has been and remains one of the most persistent sources of conflict at every level: international, national, community, and even individual. Energy is similarly one of the most potent motifs of environmental as well as security issues at every relevant level, from supranational to individual. Looking at environment and security links from a different perspective highlights the deep relationship between the deterioration of environmental quality - whether it is in the form of urban pollution, water contamination, soil degradation, deforestation, or biodiversity loss - and human well-being. Ultimately, a threat to human well-being can be seen as a threat to human security. Najam makes a number of observations: environmental stress can and does 
translate to human insecurity, but it does not necessarily take the form of violent conflict; the absence of sustainable human development can lead to environmental degradation, thereby triggering social inequity and injustice; poverty is, and is likely to remain, the most important source of environmental vulnerability and insecurity in many Asian countries; an atmosphere of insecurity can be created when environmental stresses interact with societal vulnerability, disruptive development, and perverse markets - it is this volatile mix, rather than the environmental stress alone, that can become a trigger for insecurity or violence; the environment-security nexus is integrally tied to the cultural and institutional robustness of societies; structures of governance and policy - rather than natural endowments alone - are critical to enhanced energy security.

M. Shamsul Haque also argues that the natural environment should be considered as a (non-traditional) security issue and applies this reasoning to Northeast Asia. Haque examines the relationship between the environment and traditional security issues and presents his analysis in the context of broader political and security factors. The environmental challenges that confront Northeast Asia - such as greenhouse gas emissions, chlorofluorocarbons emissions, marine pollution, deforestation, diminishing biodiversity - are worsened by the "fetish for economic accumulation", reckless industrialization, urbanization, population pressure, and poverty and inequality. Haque argues that there is the potential for conflict over environmental issues, in particular as a result of resource scarcity and the "spill-over effect" of one country's environmental disorders on other countries. Finally, he argues that existing regional mechanisms for addressing environmental issues are inadequate: current environmental conventions and institutions at the international level often lack the authority and power of enforcement; traditional security perceptions based on state-centric and militaristic assumptions still dominate in the region; past legacies and history continue to obstruct meaningful cooperation, which is not made better by the hegemonic military presence of the US preventing regional cooperation. On this basis, Haque suggests that Northeast Asian countries need to rethink their current agenda of further economic growth based on environmentally hazardous industrialization, and the economically poorer countries in Northeast Asia, especially China, Mongolia, and North Korea, must address poverty and inequality. It is also essential to build interstate cooperation to achieve environmental security, which, in turn, requires states to overcome traditional conflicts and security perceptions. After completing this groundwork - examining negative perceptions, putting behind past rivalries, reassessing the US factor, and building mutual confidence - the stage may be set for Northeast Asian countries to get involved in adopt- 
ing mutually binding conventions and treaties based on equality and transparency.

Ajaya Dixit and Dipak Gyawali's chapter illustrates how, in Nepal, natural disasters interact with societal vulnerability, disruptive development interventions, and perverse market exchanges to generate insecurity. Their chapter presents a cultural/anthropological approach to environmental issues in the context of deprivation. It identifies three scenarios of decision-making structures in this area. Hierarchies would seek additional security through procedural rationality; their technological and developmental choices are biased toward the large scale and therefore require additional expertise and control. Those in the individualistic mode would seek security through innovation and networking; their choices veer towards the path that provides the most substantive benefits. Egalitarians will seek social justice as the foundation of human security; they are suspicious of choices not easily controlled by the community.

Evelyn Goh explores the relationship between the exploitation and management of the Mekong River basin and the national and regional security of its riparian states. Interstate tensions may result from a number of problems. Conflicts over upstream/downstream interstate allocation, where upper-stream abstraction, impoundment or pollution reduces the quantity and quality of water available to downstream users; where land or water use in one part of the basin has unintended consequences on the resources in general; and socio-environmental conflict deriving from the direct and indirect impact of resource utilization and development. Goh argues that there are two key concerns here: sustainability, which is the ability of the ecological system to support indefinitely human development aims, and security, which refers to the relationship between the integrity of the environmental system and the integrity of human socio-political systems. Her analysis demonstrates that "environmental security" in the Mekong context represents a mixture of traditional and non-traditional security issues. In the process, it has thrown up three complex and difficult questions, which should guide the development of institutional capacity to ensure environmental security in the region: How can the asymmetries of power that exacerbate the innate geographical disadvantage of downstream states be redressed? How can the dependent, newly developing riparian states be strengthened against their economic vulnerability? How can socio-environmental "externalities" be incorporated into economic cost-benefit analyses in water development projects? Finally, Goh considers the prospects for building greater institutional capacity for cooperative approaches to managing the environmental resources of the Mekong River. 


\section{Institutional perspectives}

The final section of the volume considers institutional perspectives and, in particular, prospects for the development of regional institutions for addressing non-traditional security challenges. William T. Tow's chapter analyses ASEAN and the ARF as non-traditional approaches to regional security politics. He suggests that they clearly function in a developingregional context rather than in a European or Western setting, where centuries of diplomatic and legal precedent shape the form and parameters of institutional interaction. Unlike traditional security alliances, moreover, they try to advance strategic reassurance in the region through transparency and confidence-building rather than by perpetuating more traditional modes of security behaviour, such as power-balancing, deterrence, and crisis manipulation. Yet the security behaviour of ASEAN states often belies this idealistic image. Intra-ASEAN consultation is becoming more difficult to sustain as Southeast Asian polities are consumed with domestic political crises and economic survival. Tow employs three alternative security approaches, including constructivism, securitization and human security. He concludes by considering what "mix" of these alternative security models might be best applied to strengthen Southeast Asia's regional security future.

Helen Nesadurai discusses prospects for institutional cooperation in Southeast Asia. She observes that ASEAN is best known as a regional diplomatic community that works on the basis of a limited form of institutionalization, which stresses processes of socialization and consensus building and employs minimal rules. ASEAN member states arguably prefer such institutional forms owing to their preoccupation with national sovereignty and domestic policy autonomy, and ASEAN institutions are assumed to remain weak and informal. This chapter challenges these views and shows that partial institution building involving rule-based institutional forms has taken place throughout the 1990s in ASEAN in the field of regional economic cooperation through the ASEAN Free Trade Area (AFTA) project. Nesadurai suggests that the presence of politically and economically significant non-state constituencies, as well as distributional concerns between domestic social groups, will alter the dynamics of cooperation and could well make rule-based institution building necessary to advance cooperative processes. Institutions are as much about attempting to influence the behaviour of non-state actors, including business actors, as they are about influencing national governments to cooperate through the informational and distributional functions that institutions perform. Rules and procedures can play a significant role in this regard, and the chapter argues that there are prospects for institution building in non-traditional security issue areas in the region. 
Tsuneo Akaha's chapter provides a wide-ranging analysis on nontraditional security cooperation in Northeast Asia. After discussing the relationship between human security and non-traditional security, the chapter opts to employ the concept of non-traditional security for three reasons. First, the distinction between traditional and non-traditional security is important in the context of contemporary Northeast Asia. Second, the state plays such a dominant role in both domestic and foreign affairs in this region - as both a source and target of security threats and as a means of combating those threats - that many security problems can more appropriately be defined and addressed through the dichotomy between traditional and non-traditional security. Third, an exclusive focus on "human security" would ignore many non-traditional security issues that affect in important ways the interests of the state and its institutions as well as their response to those issues. As Akaha observes, in Northeast Asia traditional and non-traditional security issues exist side by side, demanding parallel attention from the policy makers and analysts in all the countries of the region, both large and small. He offers an explanation for why multilateral cooperation has been limited in Northeast Asia by making some comparisons with regional economic cooperation in other parts of the world, namely, in Western Europe, North America, Southeast Asia, and Asia-Pacific. On this basis, the chapter explores the prospects of multilateral regional cooperation in non-traditional security matters. As examples, the chapter focuses on the Tumen River Area Development Programme, the Northeast Asia Economic Forum, the Northeast Asia Cooperation Dialogue, the Council for Security Cooperation in the Asia-Pacific and the ASEAN plus Three (China, Japan and South Korea).

The chapter concludes with an assessment of the prospects for multilateral regional cooperation in non-traditional security areas in the foreseeable future. The most realistic approach to multilateral decisionmaking in Northeast Asia would resemble the procedural rules practiced by ASEAN, i.e. consensual decision-making based on the least common denominator. Given the strong national sensitivities and political sensibilities in the region, security cooperation can only begin in areas that do not threaten national sovereignty but which offer promises of mutual benefits. Promising issues include environmental protection, resource conservation and development, coordination of migration policy, and effective management of cross-border flows of goods and people. Finally, cooperative schemes must employ non-threatening rules and procedures, allowing for gradual building of consensus, eschewing, at least initially, demanding political compromises or major resource commitments.

Richard $\mathrm{Hu}$ asks if there are sociological reasons for different ideas of 
security in different regions. He starts with a number of key questions: How should nation-states address non-traditional security issues in their national strategies in the contemporary era? Have states changed their strategies to address non-traditional security issues? Have states begun to deal with non-traditional security issues in "non-traditional" ways or still in "traditional" ways? In addressing these issues Northeast Asian states still view security problems more "traditionally" than Southeast Asia and other developing countries. The external environment has a strong shaping effect on Northeast Asia's security conception and threat perception. In Northeast Asia, the state is still considered the primary referent of security as well as the means to achieve security goals, including nontraditional security goals. This is because the state still plays the dominant role in society and people look to the state for solutions of security problems, traditional and non-traditional. This security practice is largely attributed to the external environment and its shaping effect on Northeast Asia's security conception and threat perception, as well as cultural and societal factors such as state-society relations.

\section{Conclusion}

The three sets of unconventional security issues relevant to the security architecture can be summarized as follows:

i. Damage to and destruction of peaceful relations, stability and order of the state-based system of international relations caused by the persistence of extreme poverty, environmental decay and resource scarcity, malgovernance and so on;

ii. Threats to human security rooted in subhuman poverty, tyrannical government, environmental decay and resource scarcity, etc.; and

iii. Damage to and destruction of livelihoods, ethnonational groups and environmental integrity caused by instability and conflict.

The multidimensional concept of security introduces extra elements of complexity (that is, a greater number and variety of elements and interactions) and uncertainty (due to lack of knowledge and information). The more complex the social reality, the greater the need for analytical parsimony in social science. The multidimensional approach to security sacrifices precision for inclusiveness. Realists could legitimately argue that only a "lean" conception of security can provide an honest and effective policy tool to cope with the "mean" enemies of the international jungle. For example, most of the Greens' agenda, while entirely legitimate and proper items of public policy, is better conceptualized in economic rather than security frameworks. Broadening national security to include environmental concerns could have the effect, not of demilitarizing traditional security thinking, but the opposite one of militarizing the environment. 
One possible solution to the dilemma is to focus on security policy in relation to crisis, short of which it is more accurate to assess the situation in terms of welfare gains and losses. Security policy can then be posited as crisis prevention and management, both with regard to institutional capacity and material capability. Even when so limited in meaning, many non-traditional concerns merit the gravity of the security label and require exceptional policy responses: environmental threats of total inundation or desertification, political threats of the total collapse of state structures, population inflows so large as to destroy the basic identity of host societies and cultures, structural coercion so severe as to turn human beings into de facto chattels, and such like. This volume documents, largely although not exclusively through voices from within the continent, the new emerging reality of many such non-traditional security concerns in Asia and the Pacific. What the volume does not do, but points to the urgency of the task as a future research project, is to grapple with the challenging question of the securitization of issues. By what processes and through which gate-keeping individuals and mechanisms do some issues get put on the table of national security planners while others are excluded? We hope this will mark a major start to the research agenda of non-traditional security debates - not, by any means, the end.

\section{Notes}

1. See, for example, Human Security Now, Report of the Commission on Human Security, New York, 2003; Kanti Bajpai, 'Human Security: Concept and Measurement', Kroc Institute Occasional Paper no. 19, August 2000; Astri Suhrke (1999) "Human Security and the Interests of States", Security Dialogue 30(3); Edward Newman (2001) "Human Security and Constructivism", International Studies Perspectives 2(3); Ramesh Thakur (2001) "Threats Without Enemies, Security Without Borders: Environmental Security in East Asia", Journal of East Asian Studies 1(2); Ramesh Thakur (1997) "From National to Human Security", in Stuart Harris and Andrew Mack, eds., Asia-Pacific Security: The Economics-Politics Nexus, Sydney: Allen \& Unwin; William Tow, Ramesh Thakur and In-Taek Hyun, eds. (2000) Asia's Emerging Regional Order: Reconciling Traditional and Human Security, Tokyo, UNU Press; and S. Neil MacFarlane and Yuen Foong-Khong, A Critical History of the United Nations and Human Security, Indiana University Press for the UN Intellectual History Project, forthcoming.

2. For a powerful statement of state sovereignty deriving from and being conditional on the responsibility of states to protect the security and promote the welfare of their citizens, see The Responsibility to Protect: Report of the International Commission on Intervention and State Sovereignty (Ottawa: International Development Research Centre for ICISS, 2001). The report is available also on the website at www.iciss.gc.ca.

3. See R.B.J. Walker (1993) Inside/Outside: International Relations as Political Theory, Cambridge: Cambridge University Press.

4. See Contagion and Conflict: Health as a Global Security Challenge. A Report of the Chemical and Biological Arms Control Institute and the CSIS International Security Programme, Washington DC, Centre for Strategic and International Studies, January 2000. 

Part I

Social and economic perspectives 



\title{
Globalization and human development: The case of Pakistan and India
}

\author{
Jennifer Bennett
}

There are deep concerns and apprehensions worldwide about the ongoing processes of "globalization". The phenomenon of globalization cross-border flows of capital, trade, information, technology, and sociocultural exchanges - have been occurring for centuries. Why are the recently expanding processes of globalization posing such an alarming threat - especially to the marginalized and poor - and instigating fierce debates at the national and international levels? The seeds of the new globalization process were sown in Bretton Woods, New Hampshire, USA, with the creation of the World Bank (WB) and the International Monetary Fund (IMF). These institutions were primarily created with a twofold intertwined task: first, to reconstruct worn-torn Europe and, later, guarantee interest-bearing loans for specific projects in developing countries; second, to create multilateral institutions that could enforce rules favouring free movement of capital internationally, and to ensure a liberal, capitalist world by promoting economic reform, financial stability, and promotion of free trade. For development purposes, these institutions were meant to keep intact the world market and benefit all trading countries, to reduce global imbalances and establish global prosperity.

Loans to developing countries follow a standard policy. Every loan granted (called Structural Adjustment Loan, SAL) is accompanied by a set of mandatory conditionalities that stipulate market-oriented changes in the recipient's overall economic structure. The key elements of the structural adjustment programme include: reducing the state's role in the 
economy, lowering barriers to imports, removing restrictions on foreign investment, eliminating subsidies for local industries, reducing spending for social welfare, cutting wages, devaluing the currency, and emphasizing production for export rather than for local consumption. Conditionalities, it was argued, were imposed to ensure that debt repayments were met beyond the short term. Unable to gain access to further bilateral and private bank financing without the IMF/WB seal of approval, many governments surrendered. Hence the loaning policies of the IMF/WB laid the basic foundation for open economies, especially in the developing world. Through these reforms and the conditionalities, developing countries moved a long way from medium-term plans and centrally planned economies to relatively more open market economies, and towards greater integration with the global market economies at the dawn of the twenty-first century.

To steer the mechanism of economic integration, the World Trade Organization (WTO), was established in 1995 as the legal and constitutional element of an integrated global economy. While the organizational structure of WTO may be different from that of the Bretton Woods institutions, it is a mere extension of the Bretton Woods mandate to incorporate and standardize the strategies for global economic integration. In this sense, in many developing countries, the WTO clauses are already a fait accompli. What has consequently emerged is a triangular division of authority between the WTO, the IMF, and the World Bank in a system of global surveillance of developing countries' economic and social policies. ${ }^{1}$ This means that enforcement of IMF-World Bank policy prescriptions will no longer hinge upon the ad hoc country-level loan agreements which are not legally binding documents. For poor countries, WTO clauses and concessions have already been implemented under the IMF conditionalities.

However, under these clauses, as will be seen later, the interests of the masses are clearly neglected because these policies demand competitiveness internationally, through freeing of markets and curbing the role of the state, including public expenditure on social welfare. The nature of interaction between this new phenomenon and economies at different levels pose critical questions for prosperity or marginalization of developing countries and their poor. There is a growing belief that the processes of globalization are resulting in widening gaps between the rich and poor, and between the most affluent and impoverished nations. Although the enormity of these problems may vary from one nation to another, there is a general downward socio-economic and human development pattern afflicting the majority of the people in the developing world. Many countries, such as India, may have experienced a higher 
growth rate under the Structural Adjustment policies, but this growth is widely believed to mark an unsustainable pattern.

This chapter investigates the processes of globalization and its impact on social development, especially in developing countries. The chapter explores the major question of who will benefit from such transnational processes, be they economic, social, political, scientific, or otherwise. It considers whether benefits will accrue to the poor or the marginalized the majority in the developing countries - or whether it is a process which will further exclude them from the mainstream development agenda and opportunities of well-being. In doing so, the chapter will focus on Pakistan as a case in point and will present a comparative analysis with India to determine the impact of these processes in light of differences in national policies. The chapter concludes with a discussion on the main issues relating to the enhancement of human development the principal engine of the national growth and development - and makes some recommendations for Pakistan, specifically, suggesting strategies for survival and human well-being against the backdrop of the iniquitous global integrating trends.

\section{The dynamics of global integration}

Under the global economy phenomenon, the primary focus of the reform of trade and investment, and the reform programme in general, is to promote a greater integration of the developing economies with the global economy. With the reduction of impediments to free trade, production in developing countries would be based on their comparative advantage to a much greater extent than before. This would encourage the expansion of production and export of those goods and services which could be produced at relatively low cost in developing countries. As a result, the rate of growth would be higher due to improved efficiency of resource use. A further impetus to higher growth would come from an increased flow of Foreign Direct Investment (FDI). The attraction of this to developing countries is that it not only adds to the scarce investments in these countries, but also provides access to other scarce resources, notably technology, management and marketing. Greater integration with the global economy is also expected to improve the distribution of income and reduce poverty. Quite apart from the increased scope for poverty reduction that higher growth would provide, an increased dependence on comparative advantage would promote specialization in goods and services that would use the abundant resources and labour of the developing countries more intensively. This would increase 
the rate of growth of productive employment as the most effective and efficient instrument for poverty reduction. ${ }^{2}$

Theoretically, these global trade rules appear to promote an equitable development model. However, the implementation of these principals under WTO has raised inherent shortcomings and generated intense controversy. To begin with, the processes of globalization are based on the assumption of fair trade and economic transactions where all actors are considered equal, regardless of the level of development and technological advancement of individual countries. This assumption is not tenable and has negative implications, specifically for the developing and least developed countries in view of their comparative low technological capacities and trading powers. The issues that need to be debated in setting out rules and entitlements for global trade practices are the kind of rules, the nature of free trade, and the inequity embedded in the international trade agreements that form an important part of globalization. ${ }^{3}$

The debate on the international trade agreements has emerged from the impacts of globalization that promote neo-liberalism through the implementation of policies emphasizing less government intervention and a shift towards a more defined and central role of markets and private interest groups. Under such agreements complicating factors include the involvement of strong multinational actors and transnational corporations, many of which exceed the economic strength of nation-states as well as countries at different stages of industrialization. This has also been acknowledged within the WTO where adjustments for the least developed countries have been made in principle. However, in practice the role and relevance of such adjustments remain disputed and have been of limited interest in the context of the actual negotiations. ${ }^{4}$

In view of the inequitable stages of development, the crucial question of human security and the factors associated with implementation of social policies and human welfare take precedence. In the WTO, social and health policies are simply assumed to benefit from economic growth. ${ }^{5}$ Such an assumption does not take into account the issues of social redistribution nor the level of development in individual countries. Instruments for rectifying macroeconomic imbalances through the imposition of policies such as currency devaluation, privatization, trade liberalization, and cuts in government spending, have far-reaching and wide-ranging socio-economic consequences and exacerbate inequity. These conditionalities are tantamount to an assault on the living standards of the poor. Cutting consumer subsidies and raising producer prices for agricultural goods, charging user fees for social services such as health and education, are all aimed at regulating privatization in order to create incentives to attract foreign capital and to allow the MNCs to flourish. 
One important example of entitlement of global trade is the implementation and enforcement of Trade Related Aspects of Intellectual Property Rights (TRIPs) through which the patent systems can have adverse affects in critical sectors such as food production, poverty alleviation, health care and disease prevention. At best, one would have expected the TRIPs agreement to be designed in a manner where barriers to market entry, created by "exclusive rights" granted to the owners of intellectual property, would fall; principles relating to national sovereignty and freedom to adopt lower standards of intellectual property protection would be preserved; and the market to which entry could be afforded would be global. Further it was expected that the concerned WTO rules would promote R\&D in developing countries and improve their technological capabilities, by gaining access to innovations made elsewhere. But that is not the way it has worked out. Instead, the systems of the protection of IPRs as laid by the WTO rules are by nature monopolistic and favour large multinational actors only. In the past it was possible for firms in developing countries to buy technology. Today technology comes embodied as capital or as goods. Without allowing open trade and investment and conforming to global regimes on IP, protection cannot be obtained.

These issues and concerns regarding the WTO agreements first surfaced at the Seattle Ministerial Conference held in late November 1999 and were raised again at the World Economic Forum in Davos, Switzerland, in January 2003. The opponents to WTO agreements demanded a moratorium on further liberalization under WTO auspices including the holding of an audit to be undertaken on the impacts of globalization. Strong opposition was expressed towards TRIPs in view of their impact on the marginalized communities, development, democracy, environment, health, human rights, labour rights, and the rights of women and children. More importantly, the articles of WTO were declared to be in contradiction with the pre-existing national and international laws and at variance with the Universal Declaration of Human Rights.

\section{Human development and global integration}

Human development can be defined in relation to all those sectors which contribute to the enhancement of human well-being. According to Rosen, "human capital refers to the productive capacities of human beings as income producing agents in the economy and may be defined as the "stock of skills and productive knowledge embodied in people". ${ }^{6}$ Since the onset of comprehensive SAPs in the 1980s, accompanied by 
conditionalities, to the establishment of the WTO in 1995, the very question of human development remains challenged in the face of global economic integration - which was meant to enhance economic growth, especially that of developing countries and as a consequence promote human well-being. Three major inherent anomalies in the WTO agreements clearly reflect the bogusness of it: first, economic growth does not mean that benefits will directly or automatically translate into human capital; second, the prioritization of economic and trade policies and concomitant lack of consideration of redistribution issues have, in practice, resulted in promoting social inequity; and, third, the economic liberalization, as guided by the WTO social policies, are in practice forced towards providing restricted safety-net policies rather than broader government measures which promote the redistribution of resources or policies which recognize linkages between economic, trade, and social policies.

As a matter of fact, the entire processes of global economic integration are lop-sided when seen from the viewpoint of the developing world. After more than two decades of persistence with reforms leading to greater integration with the global economy, most developing countries today find themselves marginalized in terms of national growth of output and trade and run the risk of further marginalization. Most of the poorest and least developed countries are largely bypassed by the intensified circuits of trade, capital flows, foreign investment, technology transfers, or activities of transnational enterprises. ${ }^{7}$ Estimates show that the least developed countries, with 10 per cent of world population, account for only 0.3 per cent of the world trade; half of their share two decades ago. ${ }^{8}$ Similarly, the share of Africa in global agricultural exports and imports is around 3 per cent to 4 per cent. ${ }^{9}$ Foreign investment, frequently considered as the engine of growth, takes place mostly between North America, Europe, and Japan and, together with China, these receive more than 90 per cent of all Foreign Direct Investments. The rest of the world, with 70 per cent of the population, receives less than 10 per cent. ${ }^{10}$ The share of multinational corporations in global trade is expected to grow, and it has been estimated that intra-company trade now accounts for about 40 per cent of world trade. ${ }^{11}$

The developing world today, under the garb of the structural adjustment policies and debt, whirls in an accelerated spiral of economic and social decline, marking massive redistribution of financial resources from the South to the North. To achieve this, developing world economies underwent a painful transformation: state intervention in the national economy was drastically curtailed to make internal economies more tightly integrated into the capitalist world-market. Subsequently, a comparative analysis of the period before and after the structural reforms in developing countries shows that between 1984 and 1990 net transfers of 
resources from South to North amounted to $\$ 155$ billion. ${ }^{12}$ Though Western economists claimed that these policies would reduce debt burdens, by 1992 Africa's external debt had reached $\$ 290$ billion, about 2.5 times greater than it was in $1980 .{ }^{13}$ Similarly, Bello's ${ }^{14}$ findings reveal that the average Gross National Product for nations in sub-Saharan Africa fell by 2.2 per cent per year in the 1980s; by 1990, per capita income of the continent was back down to its level at the time of independence in the 1960s. Such reverse financial flows were also experienced in Latin America, the Caribbean and Asia. In Latin America, per capita income in 1990 was virtually at the same level as ten years earlier. The former Soviet Union and Eastern Europe, where the process of reform and integration with the global economy began later, also experienced a reduction in per capita income, often at very high rates. By and large, in most countries in these regions the distribution of income worsened and/ or the incidence of poverty increased. Needless to say, there are isolated cases of countries in these regions which have achieved outcomes that are different from the regional trends. ${ }^{15}$ Structural reforms for global integration have thus resulted not as a transition to prosperity but a permanent condition of economic suffering of the South. According to the United Nations report of 1999, the income gap between the fifth of the world's people living in the rich countries and the fifth in the poorest was 74 to 1 in 1997, up from 60 to 1 in 1990 and 30 to 1 in $1960 .{ }^{16}$

Ironically, the OECD and World Bank estimates have highlighted general global gains, but define sub-Saharan Africa, as a case in point, as a loser. The major complicating factor to the case of sub-Saharan Africa was the debt crisis where the funds that governments transferred to Northern creditors was four times more than what they spent on the health of their people, while aid levels stagnated or declined. ${ }^{17}$ The overall gains during 1995-2001 as a result of the Uruguay Round of the GATT were expected to increase global income by an estimated US\$212-US\$510 billion; the overall gains, however, obscured the relative winners and losers. While projected gains may have outweighed losses, the losses were concentrated in the least developed countries - a group of countries losing an estimated US $\$ 1.2$ billion. ${ }^{18}$

In the process of global integration during the last twenty years, the pace of human development has clearly demonstrated the inequity experienced by the populations, both within and between countries, despite economic growth. Given these facts, it seems no longer possible to assume that economic growth alone will be beneficial for health and human welfare. According to the UN Economic Commission for Africa (EAC) drastic cuts in social expenditures have led to a 50 per cent decline in health expenditure and a 25 per cent decline in the education sector in most southern regions undergoing WB/IMF/WTO structural reforms. ${ }^{19}$ 
Figures obtained from various annual publications of the United Nations Children's Fund (UNICEF) shows that at least six million children under five years of age have died each year since 1982. About 1.3 billion people in the South now live in poverty - twice the number of 15 years ago - as a result of wage levels plummeting, often to levels half as low as those at the beginning of the $1980 \mathrm{s.}^{20}$ Statistics show that in many developing countries, wages have declined by more than 60 per cent since the beginning of the $1980 \mathrm{~s}^{21}$ The situation of the informal sector and the unemployed is even more critical, while the North reaps the benefits of wealth drawn from the South. Susan George reminds the world that every single month, from the outset of the debt crisis in 1982 until the end of 1990 , debtor countries in the South remitted to their creditors in the North an average of US $\$ 6.5$ billion in interest payment alone. If payments of the principal are included, then debtor countries have paid creditors at a rate of almost US $\$ 12.5$ billion per month, as much as the entire third world spends each month on health and education. Despite these payments, these countries are about 61 per cent more in debt than in $1982 .{ }^{22}$

Given these realities, there is no effective machinery at the international level to coordinate the macro-policies of individual countries. In effect, markets hold a veto on the macro-economic policies of governments, with countries having become prisoners of global markets. It can be argued that increased efficiency, greater competition, and the creation of a hospitable environment for business activities are likely to spur investment, enterprise, and technological progress, thereby contributing to faster growth, as seen in some Asian countries. ${ }^{23}$ However, in the long run, it is unlikely that in the absence of effective and equitable mechanisms for coordinating policy at the world level, the new environment and global market forces can counteract the contradictory influences mentioned above. The unfolding consequences of these trends have led the poor countries to slip into escalating poverty with worsening nutritional, health, and educational outcomes that affect their productive capacities, both at the individual and national levels. The structural adjustment problematic is focused on prices, budgets, payments and savings rather than on the real structures of production, consumption, distribution, technology, trade and power.

\section{The case of Pakistan}

Pakistan has long been reforming its economic policies and institutions to promote greater openness. It was in the late 1970s that Pakistan first committed itself to accepting structural reforms to liberalize its economic 
policies and to accelerate the pace of integration with the global economy. The impetus for the process came from the need to make adjustments to the unsustainable imbalance in the external account that many other developing countries also experienced in the aftermath of the oil shocks of the 1970s and the declining demand for their exports due to the recession in the OECD countries during the 1980s. Since then some form of conditionality, in return for loans, has become a permanent feature of the country's economy with the aim of reforming the protectionist trade regime of the country.

Chronologically, the first IMF structural adjustment programme was brought in by the military dictator Ziaul Haq in 1978/79, followed by a Trust Fund Loan for the period 1979/80 for removing the fiscal and payment crises. In November 1980, a new long-term Extended Fund Facility (EFF) was signed to cover the period 1980/81 to 1982/83. The Structural Adjustment Loan (SAL) offered for the period 1983/84 was declined by the then government which instead accepted a series of sectoral loans for agriculture, industry, energy, and the financial sectors. Interestingly, analysts believe that the SAL offered in 1983/84 was refused because the country's foreign exchange reserves had recovered to over US $\$ 2$ billion. ${ }^{24}$ The SALs signed subsequently were accompanied with stringent conditionalities associated with the policies of the IMF, WB, and the Asian Development Bank. After having signed an SA agreement for the period 1987/88 to 1990/91, there was a gap of almost two years. Hence, a one-year standby agreement was signed in September 1993 followed by the signing of a more extensive agreement in February 1994 and a softer EFF programme with the IMF/WB in October 1997.

These programmes were implemented to improve the financial internal and external balances, to increase average savings rates, and to promote private sector investment by reforming the fiscal policy, foreign trade policy, and the financial sector. These objectives were to be met by bringing about an overall reduction in the budgetary deficit, containing the rate of inflation, reducing the external current account deficit, reducing the civilian external debt service ratio, increasing gross official foreign exchange reserves, containing the growth of domestic credit and money supply, and sustaining real GDP growth at about 5.2 per cent (and to 5.5 per cent by 1989/91). Estimates drawn from various Pakistan Economic Surveys show that since the implementation of these reforms, growth has substantially slowed down and that not only do the earlier economic crises for which SAPs were implemented persist but the socioeconomic situation has worsened significantly.

Historically, Pakistan has managed to maintain a respectable average economic growth rate exceeding 5 per cent per annum. Since 1960 onwards, the GNP of the country vacillated between 5.4 per cent and 6.8 
per cent, except during the period 1969/70 to $1974 / 75$ when it was 4.4 per cent. Estimates derived from various yearly Pakistan Economic Surveys indicate that the GNP of the country touched the lowest figure, 4.4 per cent, during the period 1989/90 to 1994/95. No substantive improvements in removing the budgetary deficits (fiscal deficits and BoPs) has taken place in spite of the conditionalities of reducing the overall GDP expenditures (development expenditure declined from 6.8 per cent in 1987/ 88 to 6.5 per cent in 1990/91). On average, the net current account deficit has remained above US\$1 billion, which had in effect risen to 2.1 per cent and 3.6 per cent in the fiscal years 1990/91 and 1992/93 respectively. The decline in the GNP is well reflected in the major industrial and agricultural sectors. The overall declining economic trends triggered high rates of inflation, unemployment, and substantially scaled-up poverty levels. (Selected macro-economic and social indicators are given in table 1.1).

The following are the overall impacts that Pakistan experienced:

- In Pakistan, the rate of growth fell significantly in the period since the adoption of the reform programmes in the late 1970s. The decline in the rate of growth substantially exacerbated poverty and distributional inequity;

- The stabilization programmes led to drastic reductions in public expenditure. As a result, the poor faced a reduced access to basic education, health, and human capital;

- Social expenditure as a proportion of total public expenditure fell after the adoption of the reform programme in 1978/79.

\section{The present scenario}

In October 1997, Pakistan signed a softer EFF programme with the IMF/ WB to shore up the fragile economy of the country. However, a series of nuclear tests soon after in May 1998 led to an immediate imposition of stringent sanctions which further jolted the economy of the country. As a consequence, foreign investment was drastically reduced leading to a tight fiscal and monetary policy: the fall in revenues resulted in a 25 per cent hike in petrol prices and a cut in annual public sector development. Consequently, the growth in real GDP and manufacturing was lowered by 3 per cent and 6 per cent, respectively, while the current account deficit increased by 2.5 per cent of the GDP. ${ }^{25}$ Scholars are of the opinion that the dwindling macro-economic scenario of Pakistan since then has had a more or less permanent adverse impact on some key social dimensions such as poverty, employment, wages, and health and education sectors. ${ }^{26}$ They characterize Pakistan's current economic situation as having the following features: serious loss of industrial development; weak export sector resulting in trade imbalance; inadequate social services; increased 
Table 1.1 Selected macro-economic and social indicators

\begin{tabular}{|c|c|c|c|c|c|c|c|}
\hline Indicator/Year & $1991-1992$ & $1992-1993$ & 1993-1994 & 1994-1995 & 1995-1996 & 1996-1997 & 1997-1998 \\
\hline Growth $\%$ of per capita income & 13.6 & 7.2 & 13.3 & 16.9 & 10.7 & 7.5 & 11.9 \\
\hline G. rate in $\%$ GNP at MP & 1.64 & 3.32 & 5.28 & 3.54 & -0.72 & 5.26 & \\
\hline G. rate in $\%$ GDP at MP & 1.87 & 3.74 & 4.87 & 4.47 & -0.35 & 5.06 & \\
\hline \multicolumn{8}{|l|}{ Fiscal indicators (as \% of GDP) } \\
\hline Total revenue & 19.1 & 18.0 & 17.3 & 17.2 & 17.6 & 16.1 & 16.1 \\
\hline Tax revenue & 13.6 & 13.3 & 13.2 & 13.7 & 14.1 & 13.5 & 12.9 \\
\hline Non tax revenue & 4.3 & 4.6 & 4.0 & 3.2 & 2.9 & 2.6 & 3.2 \\
\hline Direct taxes & 2.5 & 2.8 & 2.8 & 3.4 & 3.7 & 3.7 & 3.9 \\
\hline Indirect taxes & 11.1 & 10.5 & 10.4 & 10.3 & 10.4 & 9.8 & 9.6 \\
\hline \multicolumn{8}{|c|}{ Exports, imports and trade balance in Rs (million) } \\
\hline Total exports & 171,728 & 177,028 & 205,499 & 251,173 & 294,741 & 325,313 & 276,226 \\
\hline Total imports & 229,889 & 258,643 & 258,250 & 320,892 & 397,575 & 465,001 & 333,157 \\
\hline Balance & $-58,161$ & $-81,615$ & $-52,751$ & $-69,719$ & $-102,834$ & $-139,688$ & $-56,931$ \\
\hline \multicolumn{8}{|c|}{ Debt servicing (as \% of GDP at market price) } \\
\hline Interest on domestic debts & 4.2 & 4.7 & 4.9 & 4.1 & 4.7 & 4.8 & 5.6 \\
\hline Interest on foreign debt & 1.2 & 1.3 & 1.2 & 1.2 & 1.2 & 1.2 & 1.1 \\
\hline Repayment of foreign debt & 2.4 & 2.2 & 2.8 & 2.8 & 2.8 & 4.2 & 3.6 \\
\hline Total debt servicing & 8.0 & 8.3 & 9.3 & 8.8 & 9.0 & 10.4 & 10.3 \\
\hline \multicolumn{8}{|l|}{ Rate of inflation (\%) } \\
\hline CPI & 10.6 & 9.8 & 11.3 & 13.0 & 10.8 & 11.8 & 8.2 \\
\hline CPI food & 10.6 & 11.9 & 11.1 & 16.7 & 10.1 & 11.9 & 8.2 \\
\hline CPI non-food & 10.5 & 7.8 & 11.5 & 9.3 & 11.5 & 11.7 & 8.2 \\
\hline \multicolumn{8}{|c|}{ Expenditures under annual development programme (\%) } \\
\hline Agricultural & -6.67 & -59.93 & -7.98 & -28.37 & -29.00 & -5.76 & \\
\hline Industry & -21.39 & -33.51 & 12.31 & 63.78 & -22.61 & -29.42 & \\
\hline Population planning & -8.53 & 36.09 & 2.91 & 4.06 & 6.04 & 34.56 & \\
\hline Social welfare & 12.10 & -20.76 & -4.83 & 25.30 & -58.09 & -1.94 & \\
\hline
\end{tabular}

Source: Economic Survey, 1997-1998

* CPI refers to the "Consumer Price Index". In Pakistan four types of price indices are used to measure the changes in the price

level. These are: CPI (Consumer Price Index), WPI (Wholesale Price Index), SPI (Sensitive Price Indicator) and the GDP deflator. Amongst all four, CPI is generally considered to be a better indicator of inflation in Pakistan. 
incidence of poverty; breakdown of law and order; and loss of confidence of the foreign investors.

Pakistan, as it stands today, has an economy that is not only fragile but is rocked by any slight internal or external shock. Since its subjection to the structural adjustment programmes, Pakistan's exchange rate has increasingly been determined by market forces, the rates of tariff have been brought down, and the discrimination against exports relative to domestic production has been drastically reduced. There is also a sharp reduction in restrictions on Foreign Direct Investment as compared to the period before the onset of SAPs. These reforms are accompanied by conditionalities or other reforms such as: a general reduction of direct regulation of prices, production, and distribution; greater dependence on market forces; reduction in public ownership to promote the private sector; and strangulating government spending cuts in the social sector.

Sustained depreciation of exchange rate as part of the structural reforms has, over the two decades, led to substantial inflation, unemployment, and higher poverty levels. Depreciation of the exchange rate has raised the costs of debt servicing leading to an increase in fiscal deficit and also of inflation and higher poverty. Domestically, prices of goods have risen, leading to more inflation and thereby reducing the purchasing power of the average person. Likewise, with the rise in prices of imported capital goods, private investment has declined, leading in turn to a decline in employment and income with a resultant rise in the level of poverty. Other factors contributing to an increase in poverty include the unfavourable effects of broadening of the GST, rise in energy tariffs, withdrawal of consumer subsidies, cuts in development expenditure, and the scaling down of the Social Action Programme (SAP).

\section{Social development in Pakistan}

In the past, Pakistan has managed to sustain a respectable economic growth, averaging well over 5 per cent per annum. Despite this, Pakistan is among the few countries where the gap between economic growth and human development is widening. Literacy and health levels are among the lowest in the world, while unemployment and underemployment have increased to over 15 per cent. ${ }^{27}$ More than 34 per cent of the population now live in poverty, ${ }^{28}$ which is a sharp rise from 20 per cent in $1990,{ }^{29}$ while inequality in income distribution - the ratio of highest 20 per cent to lowest 20 per cent income group - worsened from 5.5 in 1987/ 8 to 7.8 in $1992 / 3 .^{30}$

Human development has continued to remain neglected, although the recent efforts of the government are encouraging. Social sector expenditure since the late 1970s oscillated between 2 per cent and 3 per cent and 
Table 1.2 Expenditure on education and health as a percentage of GDP

\begin{tabular}{lccc}
\hline Year/Expenditure & Education & Health & Total \\
\hline $1987-1988$ & 2.4 & 1.0 & 3.4 \\
$1988-1989$ & 2.4 & 1.0 & 3.4 \\
$1989-1990$ & 2.2 & 0.9 & 3.1 \\
$1990-1991$ & 2.1 & 0.7 & 2.8 \\
$1991-1992$ & 2.2 & 0.7 & 2.9 \\
$1992-1993$ & 2.2 & 0.7 & 2.9 \\
$1993-1994$ & 2.2 & 0.7 & 2.9 \\
$1994-1995$ & 2.4 & 0.7 & 3.1 \\
$1995-1996$ & 2.4 & 0.7 & 3.1 \\
$1996-1997$ & 2.6 & 0.7 & 3.3 \\
\hline
\end{tabular}

Source: Pakistan Economic Surveys, 1994-1995 and 1996-1997

has stayed roughly constant since then regardless of the needs of the rapidly growing population. However, during the period 1987/88 to 1990/ 91, the social expenditure declined from 3.4 per cent in 1987/88 to 2.8 per cent in 1990/91. It increased marginally from 2.8 per cent in 1990/91 to 2.9 per cent during the period 1991/92 to 1993/94. The total social expenditure increased further to 3.1 per cent, in 1994/95 and to 3.3 per cent in 1996/97. This increase in the social expenditure is still lower than that in 1987/88. Table 1.2 above gives the GDP expenditure on social sectors with percentage allocation to education and health during the ten-year period $1987 / 8$ to $1996 / 7$. It also shows that the health sector fared even worse than did the education sector. The percentage of social expenditure on health did not exceed 1.0 per cent during the entire structural adjustment period. In fact, the 1.0 per cent expenditure in $1987 / 88$ declined to 0.7 per cent in 1990/91. Thereafter, it remained constant in spite of a slight increase in the overall social expenditure. The outlay on education, on the other hand, was 2.2 per cent during the period 1991 to 1994 which, with a marginal increase of 0.2 per cent for the year 1993/94, increased slightly to 2.4 per cent during the period 1994 to $1996 .$. However, by 1998/99, the figure had once again declined to the level of 2.2 per cent of the GNP despite initiation of the Social Action Programme (SAP) for ameliorating the social conditions of the people. Overall, the total expenditure on the education sector in the country is far below the UNESCO-recommended level of 4 per cent of the GNP for developing countries.

The increase in social expenditure, mentioned above, came about as part of the overall increase in the GNP and the Social Action Programmes (SAPs) accompanying the SALs. These programmes, begun in 1993, were initiated in order to improve the social conditions of the general population. The federal and provincial governments, with the 
cooperation of donors - the World Bank was in the forefront of these reallocated some of their public expenditures for key social services, namely, primary education (for girls), basic health (rural areas), clean water, sanitation, and population planning. It is interesting to note that in 1997 the original target for SAP (II) expenditure was 2.4 per cent of the GDP, but in the aftermath of the nuclear explosions of May 1998 this was scaled down to 2.1 per cent in October 1998. The total SAP (II) expenditure was further reduced to 1.8 per cent of the GDP for 1998/99, and still continues at the same level.

In economic terms, the actual and overall increase in the social sector allocation of the government can be termed as mere compensation for an increase in user charges and the imposition of sales taxes for revenue enhancement - all to comply with the WB/IMF conditionalities. Ironically, but nonetheless a reality, the entire development structure of Pakistan seems to rely on loans and conditionalities of the donors and any non-compliance with WB/IMF conditionalities can crumble and cripple further progress. Thus SAPs suffer from inherent setbacks in terms of their impact and long-run sustainability both socially and monetarily. The basic problem with the programmes is that they rely solely on accelerated development funding without any obvious source of revenue for financing the downstream operation and maintenance expenditures. This specifically refers to the provision of recurring expenditures. In other words, schools and basic health centres are being constructed without due consideration to the ongoing need for teachers, books, doctors, nurses, medications, and so forth.

Statistics also show that the overall expenditure is not adequate to reduce the congestion for both boys and girls at primary and middle-school levels. For example, the student-teacher ratio for girls at both primary and middle-school levels for the last year of SAP (I) was 56:1. Moreover, figures reveal that over the last three years of SAP (I) (1993-1996) there was an increase in gross enrolment rates of rural girls, but the net rural primary enrolment rate actually declined during the SAP years from 50 per cent to 43 per cent for boys and 31 per cent to 30 per cent for girls. ${ }^{31}$ Many such programmes were designed in the early years, and their failures are self-explanatory, but in designing new programmes, the existing infrastructure is still totally ignored with no attempt to make them functional and optimize utilization. Other than the implementation of SAPs, there are nine other social safety-net programmes implemented for mitigation of poverty in the country. These programmes account for a total of 0.8 per cent of the total GDP expenditure and relate to cash transfers, consumer subsidy, social security, micro-credit programmes, and housing finance. These public safety nets reach out to only about 1.9 million beneficiaries against an estimated 33 million poor in Pakistan. Moreover, 
targeting efficiency is low in most of these transfers. Owing to demonstrated corruption, cutbacks and scaling-down is felt in almost all the transfers. ${ }^{32}$

A similar pattern of low priority to human resource development is felt across the board in every other sector associated with human development as a process of economic development. Past and present scenarios show apathy and lack of political will and commitment, unequal and biased utilization and distribution of resources in favour of monetary-instigated goals. Moreover, bad governance and inept and inadequate administrative and management systems have crippled the entire service delivery mechanism and its functional capacity. It should be admitted that there has been some progressive improvement in the overall social development of the population, but the progress is hampered by unevenness. This unevenness has been further exacerbated under the reformist policies whereby imposition of taxation, withdrawal of consumer subsidies, rising unemployment, decreasing per capita income and inflation have negatively impacted upon the ability of the poor to attain human development. Furthermore, Pakistan continues to follow the lop-sided development paradigm which is skewed heavily in favour of urban development while the majority of the population (67 per cent) still lives in the rural areas.

The critical social issue in Pakistan continues to hover around attaining good health. Although, some improvement in overall health, nutrition, and education has been felt, the progress continues to be uneven. The poor still continue to suffer from sickness, malnutrition, and early death. Health statistics show that most of the diseases and deaths in the country are caused by preventable illnesses while the majority of the health facilities cater for curative measures. Most of the diseases in Pakistan are caused by inadequate and contaminated sources of water, which results in a widespread prevalence of typhoid, cholera, and most intestinal infections. Figures show that more than 40 per cent of the overall deaths, and 60 per cent of infant deaths, result from diarrhoea and other waterborne diseases. ${ }^{33}$ Given such conditions, attempts at making Social Action Programmes a success will be marginal unless social development is made an integral part of the overall development of the country, including raising budgetary allocations to the social sector, the provision of basic health facilities, and eradicating unemployment and poverty.

\section{The case of India}

India is considered to have resisted US pressures to liberalize trade and investment policies until 1991, when it first signed a comprehensive 
SAL with the IMF/WB to correct its balance of payments $(\mathrm{BoP})$ crisis in 1990/91. Indian economic history, however, shows that India's BoP crisis did not arise suddenly in 1991 but goes as far back as the late 1970s, in the wake of the second oil crisis in 1979. As in the case of many other developing countries, India too had succumbed to the debt-financing way of solving the crisis by taking its first ever IMF loan of US\$5 billion in 1980. ${ }^{34}$ This loan, however, had a mild IMF conditionality pertaining to imports. Relatively favourable circumstances allowed India to forego most of the IMF loans, but the BoP crisis worsened as a result of increased imports, including consumer goods. This combined with a sharp increase in short-term external debt to trigger the eventual BoP crisis in 1990/91 and opened the road to increased foreign borrowing. India's external debt (excluding defence debt) during this period increased to as high as US\$70.35 billion. The all-inclusive estimate of India's external debt had touched nearly US $\$ 87$ billion at the end of $1992 .{ }^{35}$ And according to the recent estimates given in the 1999 Annual Report of the Reserve Bank of India, India owed international agencies such as the WB/IMF a debt of US\$98 billion.

Before the imposition of SAPs, India had long followed an inward policy, as opposed to the outward policies pursued by Pakistan. During the mid-1960s to the mid-1970s, more than in the 1950s, self-reliance came to be increasingly defined in terms of greater inward-orientation of economic activity and the protection of domestic enterprise. ${ }^{36}$ Admittedly, this created an indigenous base in many industries and this was a major gain for the economy and its stability. Figures show that India's real GDP growth increased to an average of 3.5 per cent during the years 1950 to 1980 and to 5.5 per cent in the period 1980 to 1991 . As against an average 5.5 per cent growth during the $1980 \mathrm{~s}$, GDP growth in the postreform period of 1992 to 1997 was around 6.0 per cent, ${ }^{37}$ which was not much of a consolation given the fact that the GDP itself had been swollen by an inflation rate of over 11 per cent. Exhibiting a marked tilt to accommodate the stringent IMF conditionalities in the post-1991 period, figures in the Indian budget for 1995/96, for example, show that the planned development budget for 1994/95 was slashed to Rs 48,500 crores as against the initial figures of Rs 48,761 crores. Given the inflation rate of over 11 per cent, this reduced development expenditure was considerably less when seen in real terms. Contrarily, the non-development expenditure was increased from Rs 113,510 crores in 1994/95 to Rs 123,650 crores, a major share of which was to be used for interest payments. ${ }^{38}$ This shows that India had reached a stage where the purpose of new borrowings was not contributing to capital expenditure but was largely used for paying interests on outstanding liabilities.

Using statistics from various Indian budget reports, Nair's ${ }^{39}$ compara- 
tive analysis shows that in the first five years of liberalization and openness of economy starting 1991, the trade gap had widened along with the widening of the external current account deficit (CAD). He argues that "as a proportion of GDP, the CAD in 1994/5 may be only 0.5 per cent. But in absolute terms as compared to 415 million dollars of CAD in 1993/ 4, the CAD in 1994/5 was about 1,000 million dollars". Regarding the external debt, statistics show that the increase in external debt was reduced to less than one billion dollars compared to the external debt at the time of the crises, which rose at the rate of US\$8 billion a year. However, the total stock of external debt in 1994/95 reached US\$90 billion involving a rising annual interest liability of US\$10 billion.

Overall, under the IMF/WB conditionalities, statistics show that the key parameters to be monitored constantly and kept within reasonable limits, from the viewpoint of ensuring economic security in India, include the fiscal and revenue deficits, the current account deficit, and external and internal debt. While the external economic indicators have been improving for India, particularly the GDP ratio, debt-servicing ratio, and external debt indicators, the internal fiscal threats facing the economy arise from an inability to finance essential developmental expenditure and the inability to ensure a truly efficient banking system. Productive investment is being held back by the inability to reduce unproductive subsidies, mobilize adequate direct tax revenues, and generate returns to existing public investment. ${ }^{40}$ Under the slogan of free trade and liberalization, distorted pricing and trade, internal and external, have also discouraged productivity growth and have repressed rural incomes, requiring massive public investment in irrigation, rural infrastructure, and bio-technology, as well as the pursuit of economic policies that shift resources from wasteful subsidies into productive investment. ${ }^{41}$ According to the Indian Economic Survey Reports, in 1990/91 the capital expenditure was 6 per cent of total expenditure. It steadily came down to reach 4.3 per cent in 1994/95 and about 3.4 per cent in subsequent years.

Putting the onus on the ruling Indian government, Ghosh contends that "in the first fifteen months that the BJP-led government has been in power, it has done perhaps more in terms of liberalizing imports and furthering the interests of international capital, and done it faster, than any previous government". ${ }^{42}$ One glaring concern is food, the greatest common denominator after life itself. In India, freeing the wheat trade, for example, allowed the giant grain traders such as Cargill and Continental to, first, monopolize the market and, second, amass exorbitant profits with consequent losses to India. According to estimates, Cargill and Continental buy wheat at US\$60-US\$100 per tonne from India and sell it at US\$230-US\$240 per tonne on the international market. These monopolistic traders make a profit of about US\$130-US\$170 per tonne, 
while India loses US\$100 million in exports because of the concentration of power in the hands of five grain merchants. ${ }^{43}$ Simultaneously, abiding by the market reforms, there have been cuts in public services, rising prices of food and other necessities, stagnating employment opportunities, and growing economic inequalities.

Many economists have found that liberalizing imports and furthering the interests of international capital has led to the promotion of the economic interests of the trading class, both large and small, and that the interests of the domestic producers have actually been adversely affected. This has had an unfavourable effect on employment which, in turn, creates negative multiplier effects. Since 1991, there has been a significant shift towards the production of "white goods" which is targeted at satisfying elitist consumption and which is capital intensive. As such, people now speak of "jobless growth", which is a distinguishing feature of the post-reform economy. ${ }^{44}$ These trends certainly do not suggest equitable distribution of resources for the overall welfare of its people as GDP may grow even if goods and services for satisfying basic human needs are not produced. Though globalized trade is an opportunity in a trade perspective, treating countries as economic units in free trade by replacing them by corporations will have serious impacts on the entitlements of already vulnerable groups. Shiva is of the opinion that free trade and trade liberalization both play with the words "free" and "liberation". ${ }^{45}$ She argues that "by their association with trade, they rob the Third World peasants of their basic freedoms - to have livelihoods, to have access to land and water, to be free to select, breed and conserve their genetic diversity according to their own needs and the needs of their ecosystems". ${ }^{46}$

Analysis reveals that the correlation of the adoption of reforms with GDP growth was rather superficial as the 3 per cent growth in agricultural production, with food-grain output reaching a record high at 185 million tonnes, was not a result of the economic reforms but because of the good monsoons. Furthermore, growth has been largely confined to non-commodity sectors and, in spite of these gains, food prices have risen further, diminishing the purchasing capacity of a large proportion of the poor population, especially those living below the poverty line.$^{47}$ This is supported by the fact that the growth rate is largely demand-led growth, where the demand has been artificially stimulated by public expenditure, fiscal deficit, and inflow of foreign exchange. Nor does higher growth rate of GDP ensure jobs for millions of the unemployed, as indicated by the declining trend in unemployment elasticity. Although figures indicate that India's employment expanded by 2 per cent a year during the 1980s, its labour force growth rate averaged 3 per cent a year, leading to an increase in both unemployment and under-employment despite a rise in 
GNP growth rate. The number of unemployed, as registered in June 1992, had already risen to an exorbitant level of 37.1 million, ${ }^{48}$ and this figure has since been exacerbated by the structural adjustment policies. The facts and figures under the reformist policies indicate that pursuance and continuation of these policies is bound to cause further deterioration in the socio-economic conditions of the existing poor, which comprise about half of the total population of India.

\section{Social development in India}

As in the case of Pakistan, the major concern in India revolves around attaining good health and lowering the levels of rising poverty in the country. These common concerns are associated with the government's mode of financing, the importance given to the social sectors in the overall national plans, and the overall health policies pursued. In India, of the 6 per cent of the GDP spent on health, 4.7 per cent comes from the private sector households, while only 1.3 per cent is from government, both federal and state. ${ }^{49}$

Until 1991, state health budgets accounted for between 5 per cent and 6 per cent of the total revenue budget. In the 1990s, when SAPs were formally accepted, India's social sector investments underwent successive cuts, with the health sector being the worst affected. In line with the new liberalization process, medical care was opened up to the private sector, user fees were introduced along with private investment in public hospitals. These reforms resulted in a direct negative impact on the primary health care. The first massive cuts in health sector expenditure were part of the 1992/93 budget. The decrease in the overall amount for health as a percentage of total revenue expenditure fell from 5.45 per cent to 4.61 per cent by 1994/95. ${ }^{50}$ The impact of such cuts in public spending on health was felt most by the poor. Further, since the reform process in 1991, the central budget has been tightened by reducing its fiscal deficit. This has resulted in the unloading of the centrally assisted programmes onto the federal states. The estimated impact on the federal states was a 16 per cent cut in their recurring budgets, affecting the availability of funds and seriously affecting the quality and credibility of health care. Moreover, statistics show that investments available for infra-structural resources were drastically shifted to be spent exclusively on population control.

As a result, the infectious disease control programme was disrupted by the reduction in investment and medical care was handed over to the private sector without any mechanisms to ensure the quality and standards of treatment and access to services. ${ }^{51}$ The allocation to family planning rose from 15 per cent of overall spending on health to 24 per 
cent during the sixth Five-Year Plan (1980-1985), and was further increased to 35 per cent in the seventh (1985-1990) and eighth (19921997) Five-Year Plans respectively. ${ }^{52}$ Thus, public health care suffered further as a result of a weakening of the food security system, massive unemployment, and loss of subsistence for the poor.

Although, the per capita consumption of food has increased over the past half century in India by a modest 0.5 per cent per year, the interclass distribution of this growth has been highly skewed. Consequently, there are serious inter-regional, inter-class/caste and inter-gender imbalances in food consumption. Food and energy malnutrition is widespread. Protein and calorie deficiencies, malnutrition, and lack of access to potable water are some of the major problems for more than a third of the approximate one billion population of India. ${ }^{53}$ Although the government of India has announced various schemes as new initiatives for funding agricultural infrastructure, expanding rural housing, and introducing social assistance and insurance, along with other anti-poverty programmes, the major question is how to sustain these measures given that there is no extra provision for them in the budgets, as seen in the 1995/96 budget. The Asian Development Bank (ADB), in its own publication entitled Asian Development Outlook: 1993, wrote about the uncertainty of employment while the labour force was expected to grow at 2 per cent per annum. It mentions that "the ongoing structural reforms particularly technological upgrading and the development of a firm exit policy in industry and the public sector may check the emergence of sufficient employment opportunities, thus exacerbating the problem of underemployment and unemployment". ${ }^{54}$ Such a situation is further worsened, especially after the signing of the GATT agreement, which violates the national sovereignty by curtailing the power to decide policies not only in relation to foreign trade but also decisions concerning areas of agriculture, investment, and social welfare.

Recent figures show that about 50 per cent of the total population of India survives below the poverty line, with an income of less than one US dollar a day. About two-thirds of the population do not get the opportunity to receive even the minimum level of education and health care to form the basis of human development. Statistics show that around 50 per cent of the people are illiterate; 70 per cent of the people survive in villages with practically no public infrastructure - notably safe drinking water, basic sanitation facilities, and primary health care. ${ }^{55}$ The minuscule allocation to the social sectors and the overall human development is of grave concern, especially in view of the nuclearization status of India in 1998, followed by increasing percentage allocation of the total GNP to military expenditure, the current figure being 3 per cent.

Thus, there are several conflicting undercurrents in India's macro- 
economic and social scenarios. Whilst economic development has been encouraging in terms of growth in agriculture, industry, capital market, and in foreign exchange and foreign investment, the economy is slipping down in terms of real investment and income inequalities. India's domestic economy hinges on fragility and warning signals are imminent, given the IMF/WB conditionalities. Like any other developing country undergoing structural reforms as a condition for further loans, India needs to reconsider its economic policies before reaching a point of no return, as in the case of Pakistan. Of immediate concern is lack of investment in people, and in the social and overall economic infrastructures. To repeat, the importance of investment in education and the creation of domestic skills makes the domestic economy stable and sustainable, and thus cannot be over-emphasized.

\section{Globalization-human security linkages}

A poor nation's economic, political, and social security rests on the pursuit of a balanced and sustained economic growth and equitable distribution of resources, especially to the social sectors. Promoting human development, in turn, could be gainfully used to promote economic development and the overall development and security of the country. The primary requirement of economic security, therefore, is human security attained through the well-being of the people defined in terms of their longevity, access to education and other skills that enable them to seek gainful employment and access to food, energy, housing, clothing, and other necessities of a civilized life. Any form of development, whether viewed internally or in terms of globalization, primarily needs to focus on the notion of human development: the idea of providing equal opportunities to all humans to enable them to realize their potential. Admittedly, there is no escaping from the globalization process and it has a lot to offer to countries that are well equipped to benefit from it.

To enter the global market, it is imperative to have a skilled labour force, efficient macro-economic management, regional cooperation, and, above all, efficient institutions of governance. The East Asian miracle, which saw these economies take on the global market before the economic debacle, was the outcome of strategic planning. These states not only invested in their labour force but also ensured well-functioning institutions, rule of law, and macro-economic policies. Yet globalization is not a guaranteed solution for the alleviation of poverty as increased economic growth does not automatically transform into reduced poverty. In countries such as Pakistan and India, where the base economy still hinges on agriculture, measures such as land reform, labour-intensive means of 
production, investment in agriculture, and access to credit have to be taken into account to ensure equitable distribution of gains. The Latin American and East Asian crises have shown, from the perspective of "protecting" domestic markets against entry of or competition from multinational firms, that excessive dependence on external debt makes the domestic economy susceptible to external pressures to open up the domestic market. This is because a financial crisis triggered by such excessive debt exposure can end up forcing a country to go to the International Monetary Fund and accept its aid conditionally which, in turn, involves liberalizing trade and investment policies. ${ }^{56} \mathrm{~A}$ crisis in the stock market, banking sector, external trade, and payments can even pose a serious challenge to national sovereignty and the very survival of governments. Further, ignoring economic problems can create social tensions with serious consequences for national survival and sovereignty. Any system built upon a foundation of structural inequities "is ultimately unsustainable in the sense that it will result in increasing conflict and struggle along the lines of class, gender, and ethnicity", ${ }^{57}$ which is now a widely spread phenomenon in most developing countries undergoing IMF/WB structural reforms.

As argued earlier, reducing poverty or competing in the global market are not purely economic problems; they are more issues of political economy. The political structure and the institutions that run the system have a key role in improving any country's performance. More importantly, in order to face the challenges of entering the competitive global market, developing nations should have the ability to pursue an independent national policy without becoming critically dependent on external support and resources. This notion of self-reliance emphasizes autonomy of decision-making at all levels. In a country such as Pakistan, for example, lack of political will and the continuity of economic planning and its implementation has seriously marred the potential it has to achieve its economic goals.

Regional cooperation in this age of globalization is critical for both Pakistan and India. Realizing the significance of regional strengths, countries all across the world are regrouping on the basis of economic blocs. Europe is one of the most prominent examples of regional grouping for economic gains. Various studies, long before the emergence of the recent economic blocs, have documented the huge benefits that can accrue through regional trade in South Asia. For self- and mutual benefits, both India and Pakistan seriously need to consider lifting trade barriers between their two countries in order to enter the global market competitively. Simultaneously, the enormous potential that SAARC (South Asian Association for Regional Co-operation) can provide for regional cooperation needs to be realized and strengthened. Further, India and 
Pakistan should seriously cast off their political differences which have, in their chequered histories, exposed them to internal and external vulnerability and threats. Since early 1998, India and Pakistan have both acquired a nuclear status as the ultimate weapon for national security. For their own survival, these countries need to internalize the fact that national security is largely dependent on, and is an outcome of, the social and economic well-being of its people. History has shown that military security alone cannot assure national security and that a weakening economy can jeopardize national security. If India and Pakistan do not curtail and limit their military expenditure, their governments will soon be faced with the problem that the former Soviet Union met after investing exorbitantly in defence and thereby destroying the rest of its economy.

\section{Conclusions}

Evidence in almost all developing countries shows that the ongoing structural reforms form the basis of creating linkages to promote the processes of globalization. Trade and other exchanges within and amongst countries are clearly important and potentially mutually beneficial. The problem lies in the nature of restructuring in the form of industrial policy reforms, public sector reforms, agricultural reforms, trade and exchange rate reforms, and reforms in regulation. The most stringent of these relate to cuts in social spending as a condition for the assurance of the socalled financial aid. Accumulatively, these reforms create limitations on the state's sphere of activities in a nation's economic progress and the enhancement of human development conditions.

The problem is manifold: first, that the global model of development follows a developed world perspective which is essentially marketoriented. Applying a unipolar set of policies in the entire developing world, regardless of an individual country's social and economic level of development or its local needs and priorities, is flawed. Second, in implementing reforms in developing countries for integration in the global process specifically to correct the imbalances in the macro-economics, human welfare and human values are deliberately kept in abeyance under the false assumption that higher growth rates will have a trickle-down effect to ameliorate the socio-economic conditions of the population of a nation. It is now clear in almost all countries undergoing such reforms that reduction in public investment in agriculture and social services has accentuated unemployment, poverty, and gross marginalization of the overall productive forces, and has led to social conflict. It is also evident that despite all the controls and regulations and import substitution, for- 
eign trade deficit and foreign debt service payments have strangulated the economies of most of the borrowing countries. To say the least, it should now be clear that by making exports cheaper and imports costlier, and by keeping demand inelastic, the balance of payment (BoP) deficit cannot be corrected. On the contrary, the pattern has been quite the reverse as interest-bearing loans have added to the BoP deficit. Third, the unequal international division of labour, wide disparities in wages and labour costs between developed and developing countries, and the wide technological gap between the two worlds will not allow the developing countries to be at par in the arena of the global market system. These inequities will be perpetuated given the SAP, WTO, and GATT policies which, by design, clearly promote capital monopolies by creating new impetus in the fields of production, marketing, services, and research and development. Lastly, deciphering the interdependence on trade and development aid, the developing countries must recognize that developed countries are motivated to sustain their own interests. In this sense, the developing countries must protect their own national interests of development too - individually and collectively - and design their own import-export trade and other policies accordingly.

Focusing on human welfare and human development in the era of market liberalization raises important issues of public policy. One of the issues relates to the identification of core needs for which public authorities need to assume responsibility. How do these vary with social and economic structures and the level of economic development? There is also the important question of the relationship between the methods of financing social support programmes and their effects on incentives to save, invest, and work. It would seem desirable that wherever possible social support programmes should encourage socially and economically productive work and facilitate the acquisition of skills and capabilities that enhance the recipients' potential contribution to the economy and the society. In the light of market liberalization over the past two decades national strategies need drastic revamping. In the division of responsibilities for this, public accountability is critical. The concept of accountability must operate within the framework of democracy and participation. An important aspect of the issues concerns the mechanisms and procedures for ensuring public accountability of institutions, private and public, at different levels.

Specifically, taking the case of Pakistan, a number of issues need to be addressed. First, it is necessary to take control of its internal problems and acquire social and economic stability to be able to face the international arena competitively in a manner which leads the country towards overall well-being and social and economic development. The sustainable alternative for a country like Pakistan is to prioritize - and work on levels of priorities - with regard to the multiple problems which confront it 
today. The model presented here does not ring new bells, but it does provide a methodological framework for the overall efficient functioning of the nation-state.

The major issues are to deal with poverty, development, and the productive deployment of human resources while moving towards efficient infrastructure within the dictates of the macro-economic stability. This development must centre on people, and be decentralized and participatory in nature. It must also be sustainable and in harmony with the environment. Two very critical and cross-cutting elements in this entire process will have to be catered for: first, gender equity and equality and free exercise of human rights and advocacy; and, second, a high standard of educational and health facilities.

To attain this model of development, concurrent actions need to be streamlined by four major players: the government, the private sector, the NGOs, and the local communities. This will set the new premise of relationships between the four actors with each actor's role clearly identified and complementary. The entire process will have to strike the required balance of forces. The new equation needs to be developed between the government and the government-run institutions, on the one hand, and the private sector, the NGOs, and communities, on the other, with people as the beneficiaries. Simultaneously, a collaborative equation also needs to be struck between and within each sector in order to match capacity with expectations, savings with investment, development with equity, and effort and enterprise with reward.

At present the government is the provider, regulator, and enforcer. Its new role should be that of a facilitator. This new system can be built on the existing system which has an enormous potential for absorbing the new transformative initiatives. The following are the essential steps in this direction: devolution of authority from the top to the lowest echelons of the hierarchy that is, from federation down to local government institutions, which will help link the government machinery to the local communities, reflecting a participatory approach; development of efficient market mechanisms; evolution of a mature civil society; and academia capable of self-regulation In addition, a smaller but more efficient government machinery will be necessary with prudent macro-economic management, efficient government structures, human resource development and good transparent governance. Skills will have to be upgraded and reoriented to cater to specialized needs. An enabling legal environment with freedom of interaction and free exercise of human rights is essential. To attain this, strong democratic political sovereignty of nations and economic democracy need to be evolved collectively for embedding a people-centred development paradigm to ensure equitable growth and distribution of resources across the entire spectra of the civil society. Concurrently, democratic movements must evolve on a large 
scale to hold the national leaders accountable for pursuing policies that foster development for alleviation of poverty and deteriorating human conditions. ${ }^{58}$

\section{Notes}

1. M. Chossudovsky (1998) The Globalization of Poverty: Impacts of IMF and World Bank Reforms, London and New Jersey: Zed Books.

2. World Trade Organization (WTO) (1995) Trading for the Future, Geneva: World Trade Organization.

3. M. Koivusalo (1999) "World Trade Organization and Trade-Creep in Health and Social Policies", GASPP Occasional Papers, No. 4.

4. OEDC (1998) "Multilateral Agreement on Investment", draft, DAFFE/MAI/NM, (98)2.

5. World Trade Organization (WTO) (1995) Trading for the Future, Geneva: World Trade Organization.

6. S. Rosen (1989) "Human Capital", in J. Eatwell, M. Milgate, and Peter Newman, eds., The New Palgrave Dictionary of Economics, Vol. 2, London: Macmillan Press.

7. UNCTAD (1996) “The Least Developed Countries”, 1996 Report, Overview, Geneva, UNCTAD.

8. United Nations Development Fund (UNDP) (1997) Human Development Report 1997, New York: Oxford University Press.

9. World Trade Organization (WTO) (1995) Trading for the Future, Geneva: World Trade Organization.

10. United Nations Development Fund (UNDP) (1997) Human Development Report 1997, New York: Oxford University Press.

11. P. Cook, and C. Kirkpatrick (1996) "Globalization, Regionalization and Third World Development", in UNCTAD, Least Developed Countries, 1996 Report, UNCTAD, Geneva.

12. J. Gershman (1994) "The Free Trade Connection”, in Kevin Danaher, ed., 50 Years Is Enough: The Case Against the World Bank and the International Monetary Fund, Boston, MA: South End Press.

13. K. Danaher (1994) "Introduction", in Kevin Danaher, ed., 50 Years Is Enough: The Case Against the World Bank and the International Monetary Fund, Boston, MA: South End Press.

14. W. Bello (1994) "World Bank/IMF: 50 Years Is Enough", in Kevin Danaher, ed., 50 Years Is Enough: The Case Against the World Bank and the International Monetary Fund, South End Press, Boston, MA; W. Bello (1994) "Global Economic Counterrevolution: How Northern Economic Warfare Devastates the South", in Kevin Danaher, ed., 50 Years Is Enough: The Case Against the World Bank and the International Monetary Fund, Boston, MA: South End Press.

15. A.R. Khan (1997) "Globalization, Liberalization and Equitable Growth: Some Lessons for Pakistan from Contemporary Asian Experience", paper presented at the Thirteenth Annual General Meeting, Islamabad, 15-17 December, Pakistan Institute of Development Economics (PIDE).

16. United Nations Development Fund (UNDP) (1999) Human Development Report 1999, New York: Oxford University Press.

17. United Nations Development Fund (UNDP) (1997) Human Development Report 1997, New York: Oxford University Press. 
18. M. Koivusalo (1999) "World Trade Organization and Trade-Creep in Health and Social Policies", GASPP occasional Papers, No. 4.

19. Economic Commission for Africa (ECA) (1989) "The African Alternative Framework to Structural Adjustment Programmes for Socio-Economic Recovery and Transformation (AAF-SAP)", Addis Ababa.

20. United Nations Development Fund (UNDP) (1997) Human Development Report 1997, New York: Oxford University Press.

21. M. Chossudovsky (1998) The Globalization of Poverty: Impacts of IMF and World Bank Reforms, London and New Jersey: Zed Books.

22. S. George (1994) "The Debt Boomerang", in Kevin Danaher, ed., 50 Years Is Enough: The Case Against the World Bank and the International Monetary Fund, Boston, MA: South End Press.

23. D. Ghai (1992) Structural Adjustment, Global Integrating and Social Democracy, Geneva, Switzerland: United Nations Research Institute for Social Development.

24. T. Banuri, A.R. Kemal, and M. Mahmood (1997) "The Policy Framework and Structural Adjustment”, in Tariq Banuri, Shahrukh Rafi Khan, and Moazam Mahmood, eds., Just Development: Beyond Adjustment with a Human Face, Karachi: Oxford University Press.

25. H.A. Pasha, A.G. Pasha, S. Akhtar, and Ismail Zafar (1999) Impact of Economic Adjustment on Social Development in Pakistan, Karachi, Pakistan: Social Policy and Development Centre.

26. H.A. Pasha, A.G. Pasha, S. Akhtar, and Ismail Zafar (1999) Impact of Economic Adjustment on Social Development in Pakistan, Karachi, Pakistan: Social Policy and Development Centre.

27. A.R. Kemal (1995) "Poverty and Growing Unemployment in Pakistan: Where and Why Pakistan Failed", in Sabur Ghayur, ed., South Asia Employment Generation and Poverty Alleviation, Islamabad: Friedrich Ebert Stiftung/Pakistan Administrative Staff College.

28. Various sources give different estimates of poverty in Pakistan. In the Poverty Seminar Report of the UNDP (1996), the paper "Poverty and Debt" quotes a figure of 40.57 per cent based on the head count ratio. In the latest supplement of the World Bank Report for the year 1998, the total percentage of the population living in poverty was 46.2 per cent for the year $1989 / 90$. Poverty stricken population was defined as those with an income of below US $\$ 2$ per day.

29. Mahbub ul Haq (2000) Human Development Report in South Asia 2000: The Gender Question, Mahbub ul Haq Human Development Centre, Karachi: Oxford University Press.

30. Government of Pakistan (1997) Economic Survey 1996-97, Islamabad: Finance Division, Economic Adviser's Wing.

31. S.R. Khan (1999) "An Overview of Basic Education Under the Social Action Plan in Pakistan", Research Paper No. 22, Islamabad: Sustainable Development Policy Institute.

32. H.A. Pasha, A.G. Pasha, S. Akhtar, and Ismail Zafar (1999) Impact of Economic Adjustment on Social Development in Pakistan, Karachi, Pakistan: Social Policy and Development Centre.

33. Mahbub ul Haq (1997) Human Development Report in South Asia, Mahbub ul Haq Human Development Centre, Karachi: Oxford University Press.

34. D.P. Barooah (1994) "Structural Adjustment Policies: Policy Options Before the Developing Nations with Special Reference to the Situation in India", in Pam Rajput and Hem Lata Swarup, eds., Women and Globalization: Reflections, Options and Strategies, New Delhi: Ashish Publishing House. 
35. D.P. Barooah (1994) "Structural Adjustment Policies: Policy Options before the Developing Nations with Special Reference to the Situation in India", in Pam Rajput and Hem Lata Swarup, eds., Women and Globalization: Reflections, Options and Strategies, New Delhi: Ashish Publishing House.

36. S. Baru (1999) "National Security in an Open Economy", Indian Council for Research on International Economic Relations, New Delhi, India: India Habitat Centre.

37. Mahbub ul Haq (1997) Human Development Report in South Asia, Mahbub ul Haq Human Development Centre, Karachi: Oxford University Press.

38. K.R. Nair (1995) “The Union Budget - 1995/96: A Critical View”, in B. Mohanan, ed., Globalization of Economy: Vision for the Future, New Delhi: Gyan Publishing House.

39. Idem.

40. S. Baru (1999) "National Security in an Open Economy", Indian Council for Research on International Economic Relations, New Delhi, India: India Habitat Centre.

41. Idem.

42. J. Ghosh (1999) "Economic Challenges Facing the New Government", Focus Files: India Programme, Mumbai, India: Focus on the Global South.

43. V. Shiva (1996) "Globalization and Food Security", briefing paper for the FAO Fourth International Conference on Plant Genetic Resources, Leipzig, 17-23 June, unpublished.

44. K.R. Nair (1995) "The Union Budget - 1995/96: A Critical View", in B. Mohanan, ed., Globalization of Economy: Vision for the Future, New Delhi: Gyan Publishing House.

45. V. Shiva (1996) "Globalization and Food Security", briefing paper for the FAO Fourth International Conference on Plant Genetic Resources, Leipzig, 17-23 June, unpublished.

46. V. Shiva (1996) "Globalization and Food Security", briefing paper for the FAO Fourth International Conference on Plant Genetic Resources, Leipzig, 17-23 June, unpublished.

47. K.R. Nair (1995) "The Union Budget - 1995/96: A Critical View”, in B. Mohanan, ed., Globalization of Economy: Vision for the Future, New Delhi: Gyan Publishing House.

48. S. Kumar (1995) "New Economic Policy and the Dwindling Role of Parliament in Indian Polity", in B. Mohanan, ed., Globalization of Economy: Vision for the Future, New Delhi: Gyan Publishing House.

49. Ministry of Health and Family Welfare (2000) "South Asia Regional Consultation on Globalization and Human Development: A Note on the Health System in India", Indian Council for Research on International Economic Relations, New Delhi, 6 June.

50. Government of India, Five Year Plans 1980, 1985, 1992, 1994, 1999, New Delhi: Planning Commission.

51. I. Qadeer (2000) "Health Care Systems in Transition III. India, Part I: The Indian Experience", Journal of Public Health Medicine 22(1): 25-32.

52. Government of India, Five Year Plans 1980, 1985, 1992, 1994, 1999, New Delhi: Planning Commission.

53. United Nations Development Fund (UNDP) (1997) Human Development Report 1997, New York: Oxford University Press.

54. Asian Development Bank (1993) Asian Development Outlook 1993, New York: Oxford University Press.

55. Mahbub ul Haq (1997) Human Development Report in South Asia, Mahbub ul Haq Human Development Centre, Karachi: Oxford University Press.

56. S. Baru (1999) "National Security in an Open Economy", Indian Council for Research on International Economic Relations, New Delhi, India: India Habitat Centre.

57. P.L. Allen, and C.E. Sachs (1991) "The Social Side of Sustainability: Class, Gender and Race", Science as Culture 2(13): 569-590.

58. J. Bennett (2001) "Structural Adjustment and the Poor in Pakistan", in Imrana Qadeer, Kasturi Sen and K.R. Nayar, eds., Public Health and the Poverty of Reforms: The South Asia Predicament, New Delhi: Sage Publications, (also SDPI's Research Report No. 17). 
2

\section{Southeast Asia's embedded mercantilism in crisis: International strategies and domestic coalitions}

Kanishka Jayasuriya

\section{Introduction}

This chapter has at its core a simple thesis: the foreign economic and security policies pursued in East Asia before the 1997 economic crisis depended on the existence of a set of domestic coalitions that enabled the protection of politically linked cartels and business groups, while at the same time permitting the pursuit of an open economic policy, which gained the plaudits (until the crisis) of the purveyors of economic orthodoxy in the World Bank and other institutions. This domestic configuration - which can be called "embedded mercantilism" - created the distinctive forms of multilateralism as exemplified by the Asia Pacific Economic Cooperation (APEC) and the Association of Southeast Asian Nations (ASEAN) Regional Forum (ARF) in the Asia-Pacific.

The chapter suggests that in the wake of the Asian crisis, these domestic foundations are more brittle and more diverse, producing significant fissures between those states dominated by reform-oriented coalitions and others where nationalist coalitions still remain deeply entrenched. In conclusion, the chapter discusses the possible scenario of the development of new forms of multilateralism that reflect the reality of a region where the diversity of domestic coalitional structures is now clearly evident in the heterogeneity of economic strategies being pursued.

In summary, the argument is that the form and structure of international economic policies (open regionalism) and security policy in East 
Asia were contingent on a particular configuration of power and interests in the domestic and external economy (embedded mercantilism). This system of embedded mercantilism depended on a set of domestic coalitions between tradeable and non-tradeable sectors of the economy. The non-tradeable sector in Southeast Asia was entrenched within a particular system of political patronage - a form of nomenklatura capitalism. ${ }^{1}$

The Asian crisis and other structural changes in the international economy have made these domestic coalitions less sustainable. Moreover, there is now a greater diversity of economic strategies within the region, which has important implications for the future course of East Asian multilateralism.

\section{Domestic coalitions and embedded mercantilism}

One of the key theoretical concerns of this chapter is to address an important lacuna in the literature on multilateralism in East Asia; that is, its neglect of the domestic foundations of foreign economic and security policies. ${ }^{2}$ Much of the literature - whether realist, liberal or constructivist - employs an "outside in" methodology to understand foreign economic and security policies. In contrast, this chapter seeks to develop an "inside out" framework to understand the dynamics of regional economic order. More specifically, it attempts to explore the role of domestic coalitions in underpinning a range of outward-oriented policies. However, it must be made clear that this does not exhaust all the different modalities of domestic influences on foreign economic policy; indeed, this chapter complements my earlier work with Mark Beeson ${ }^{3}$ on the role of political rationality - or the contribution of the East Asian normative order - in shaping the distinctive configuration of regionalism in East Asia.

Therefore, the argument developed here is based on the assumption that markets are embedded in politically contested constellations of power and interests. This stands in sharp contrast to the underlying assumptions of the orthodox neoclassical approach that sees markets and economic strategies as somehow independent of the broader institutional context. For this perspective, all that is needed is the right economic fix or strategy to correct market failure; hence, economic strategies are seen to depend on the strategic choices of individual agents. This strategic understanding of markets points to deeper ontological disagreements over the nature of markets. For example, the neoclassical perspective takes a static and abstract view of markets and cognizes economic behaviour as independent of historical experience, institutional context and informational or knowledge deficits. In another, more political perspec- 
tive, the market is seen as a structure determined by a complex historical past and one in which economic outcomes are strongly coloured by the texture of the institutional environment. J. Zysman ${ }^{4}$ neatly encapsulates this institutionalist logic when he notes that:

Each market economy is defined by the institutions and rules that permit it to function, or to put it differently, each national system can be defined by the "institutional structure" of the economy, that which shapes how buying, selling and the very organisation of production takes place. ${ }^{5}$

These theoretical debates over the proper constitution of markets and "economic time" have important ramifications for the way we comprehend economic reform and policies. By adopting a dynamic conception of economic time, it becomes simply untenable to think in terms of one single correct set of economic strategies. Rather, we need to understand the way different economic strategies are linked to different configurations of power and interests. Therefore resorting to a dynamic conception of markets demands recognition that markets cannot be disconnected from the wider ensemble of political and economic power. A comprehensive understanding of economic reform is possible only within the context of the wider set of political and institutional structures.

The point here is that it is rather problematic to understand economic strategies - both domestic and international - as rational responses to the imperatives of market forces. But, if the argument that is proposed is correct, domestic and international economic strategies are intrinsically political because any given set of economic strategies needs to be underpinned by a coherent dominant coalition, the member of which benefits from the pursuit of a given economic policy regime. We discuss these elements in more detail below, but what needs to underlined here is the fact that economic reform implies a dramatic change in previously dominant or influential configurations of interests, institutions, and ideas, and therefore any shift in economic strategies will bring forth serious resistance from political and social forces that have benefited from previously dominant economic strategies. For this reason, while the crisis has unsettled previously dominant coalitions, this is a necessary - albeit not a sufficient - cause to challenge the prevailing structures of interests. ${ }^{6}$

Central to our analysis is a consideration of the role of domestic coalitions in shaping economic policy trajectories. Coalition analysis of this sort has a long tradition in political science. There are a number of important studies ${ }^{7}$ that have used a coalitional framework to explain and account for a range of political outcomes and events. Barrington Moore, ${ }^{8}$ in a ground-breaking study of the sources of democratic change, used a 
coalitional analysis to explore the varying social foundations of dictatorship and democracy. Indeed, this study follows the classic work of A. Gerschenkron ${ }^{9}$ on the marriage of iron and rye in laying the foundations of German authoritarianism.

More recently, Etel Solingen ${ }^{10}$ has sought to extend this coalitional framework to encompass international, as well as domestic, economic, and security strategies. She has suggested a basic and underlying cleavage between international- and nationalist-oriented coalitions, and argues that, while international coalitions favour economic liberalization, nationalist coalitions will seek to protect and insulate the economy from global influences. These coalitional cleavages pivot around preferences towards economic liberalization. As she points out:

external liberalisation affects individuals and groups in different sectors through changes in employment status, labour incomes, and returns on assets, through changes in prices of goods and services consumed, and through the provision of public services. ${ }^{11}$

However, a clear-cut distinction between nationalist and internationalist coalitions was much more problematic in Southeast Asia during the boom years. Indeed, what is striking in Southeast Asia is the presence of a strong internationalist orientation that is conjoined with a politically protected domestic economic sector. In fact, rather than a cleavage, Southeast Asian political economies seem to accommodate both nationalist and internationalist coalitions. This is the critical point of our thesis: domestic coalitions in Southeast Asia were structured around a series of trade-offs between the domestic and international economies, which in turn were nested within certain types of international strategies. In a nutshell, it is proposed that the international strategies of Southeast Asian states were based on a political economy of embedded mercantilism.

We borrow the term "embedded mercantilism" from T.J. Pempel ${ }^{12}$ who uses a coalitional framework to understand the dynamics of regime shifts in Japan. In an insightful analysis of institutional and coalitional transition in advanced industrial societies, he defines a "regime" as consisting of three key elements: a set of dominant socio-economic coalitions, a set of institutional arrangements, and a stable set of policy strategies. As he notes:

A regime is composed of three essential elements: socio-economic alliances, political economic institutions and public policy strategies. These three overlap and reinforce one another; they resemble the three legs of a tripod that collapses when anyone is removed. They interact in complex ways, developing and responding to a discrete internal logic. ${ }^{13}$ 
He goes on to suggest that shifts in regimes are prolonged and may involve, as in the case of Japan, a period of long-term transition where the old regime is dying but a new regime struggles to find its coalitional and institutional anchors.

For Pempel, one of the defining characteristics of the post-war Japanese regime was a system of embedded mercantilism. In other words, embedded mercantilism captures the way in which a set of coalitional and institutional structures entrenches a form of political capitalism at home while pursuing a relentlessly internationalist strategy abroad. He observes that

equally integral to the conservative regime's economic policy profile were policies that had a political rather than economic rationale. These involved side payments to the country's less economically advanced sectors: rice farmers, the small business sector, geographical regions lacking high growth industries, and, increasingly industries in decline. ${ }^{14}$

In essence, embedded mercantilism relied on a series of trade-offs and compensation for the domestic sector, thereby creating a kind of dualistic economy.

While much of this analysis of embedded mercantilism in Japan is dictated by the nature of Japanese institutions as well as by the key strategic role of the Liberal Democratic Party (LDP), it is nevertheless a model that can be very useful in seeking to understand the role of domestic alliances and coalitions in Southeast Asia. Abstracting from its "Japanese distinctiveness", the system of the embedded mercantilist model has the following characteristics:

- a segmentation between the export oriented and domestic economic sector, creating a kind of dualistic economy;

- an overlapping of these divisions with distinctive sections of capital; and

- a set of public policies to ensure that side payments from the more efficient export sectors facilitate a broad set of alliances between the two segments of the dual economy.

Over and above these elements, but equally important for the operation of the system of embedded mercantilism, was a permissive set of regional and international economic structures. Bruce Cumings ${ }^{15}$ has drawn attention to the role of Cold War structures in creating the kind of developmental states that emerged in East Asia. However, it needs to be added that there was a more specific set of international forces entrenched in embedded mercantilism in Southeast Asia. In particular, the expansion of Japanese foreign direct investment and the very distinctive open regionalism favoured by APEC helped to consolidate the politically 
protected domestic economic sector. In fact, the whole gamut of economic reform policies pursued in the late 1980s and 1990s served to consolidate the political economy of embedded mercantilism. From this perspective, domestic and international strategies are mutually constitutive of domestic coalitions and alliances around a system of embedded mercantilism.

In this context, the system of embedded mercantilism in East Asia may well be the counterpart of J. Ruggie's notion of "embedded liberalism". Ruggie, ${ }^{16}$ in a highly influential article, introduced the notion of embedded liberalism as a way of understanding the emergence and development of internationalization of political authority in the post-war period. He starts off with two key assumptions, that international political authority requires the fusion of power and authority and that the explanation of the nature, emergence and functioning of international regimes ${ }^{17}$ requires that equal attention be given to the roles of power ${ }^{18}$ and social purpose. For Ruggie, ${ }^{19}$ the essence of the post-war economic order lay in the fundamental reconciliation of two distinct objectives: the need to provide a framework for a liberal international trading order, as well as the conditions for domestic social stability. For example, the restrictions, exceptions, and safeguards of the General Agreement on Tariffs and Trade (GATT) were designed in such a manner so as to allow for the protection of domestic stability, while at the same time benefiting from the advantages of liberal free trade. At the global level, embedded liberalism reflected the dominance of a kind of social liberalism. The essence of this embedded liberal compromise was twofold: that

unlike the economic nationalism of the thirties, it would be multilateral in character; [and] unlike the liberalism of the gold standard and free trade, its multilateralism would be predicated upon domestic interventionism. ${ }^{20}$

In part, Ruggie argues that this reconciliation of domestic stability and liberal free trade was at the cost of inflation because the reduction of domestic adjustment it permitted "had inflationary consequences by sacrificing economic efficiency to stability". ${ }^{21}$ Another crucial factor that has been essential to the sustenance of the regime of embedded liberalism is that it was able to combine a liberal trade system with the regulation of capital markets. ${ }^{22}$ In retrospect, it appears that the regulation of capital structure played a major role in protecting domestic, social and economic programmes. It is the removal of these capital controls that has unleashed a fundamental restructuring of all forms of the welfare as well as the developmental state.

The mode of global governance that has been identified as embedded liberalism has been crucial to the organization and structure of the "wel- 
fare state", broadly defined to include not only social programmes but also particular patterns of economic governance. For example, Philip Cerny ${ }^{23}$ uses the term "welfare state" not only in terms of social programmes but also to include such core features as the pursuit of full employment, the use of Keynesian techniques of macro intervention and regulated labour markets.

Analogously, I would argue that the East Asian variants of embedded mercantilism - though, most emphatically not welfare-type states - were able to prosper within this particular framework of internationalization. Embedded liberalism and mercantilism were specific domestic strategies that were nested within a particular framework of international order that enabled certain kinds of domestic coalitions and political projects to prosper.

Finally, embedded mercantilism enabled the East Asian developmental states to put together policies that compensated non-export sectors of the economy, and compensatory policies were critical in securing the political coalitions required for the pursuit of export-oriented industrialization strategies. One of the principal features of the political economy of the developmental state has been the construction of a segmented market. On the one hand, there are internationally competitive export industries, and, on the other hand, key elements of the domestic economy are inefficient and politically entrenched through close relationships with the political and bureaucratic elite. In the Japanese context, Pempel and Calder $^{24}$ have argued that compensatory public policies for farmers, small businesses, and domestic industries, such as construction, have coexisted, and indeed provided the political wherewithal for efficient competitive export industries. In fact, it has been pointed out that there exist two distinct forms of states in Japan: ${ }^{25}$ one, a developmental and the other a clientalist state. In this context, political clientalism is:

an interaction characterised by the selective allocation of distributive benefits by public sector elites in exchange for the promise of solidarity and mutually beneficial inputs from private sector interests. This exchange may involve governmental subsidies, official price supports and import quotas, targeted tax breaks, regulatory favours in the allocation of trucking routes, and other policy benefits. ${ }^{26}$

Similar examples of compensatory policies may be found in other East Asian developmental states; for example, Korea, like Japan, grants extensive subsidies to its farm sectors. ${ }^{27}$

However, these rent-seeking or clientalist structures are widespread in much of Southeast Asia. In Malaysia, for example, a relatively efficient export sector exists alongside industries characterized by widespread patronage and rent seeking. For instance, the heavily protected national 
car industry provides direct benefits to the Malay elite closely associated with the ruling party. ${ }^{28}$ In this instance, industry policy is a means of ensuring the political survival of the Malay-dominated United Malays National Organization (UMNO) coalition so that the rent-seeking structures have been central to the political consolidation of the developmental state in Malaysia.

Embedded mercantilism permitted these kinds of segmented markets because, by and large, it failed to monitor non-competitive non-tariffrelated market practices in the domestic market. This permitted the development of the kind of compensatory policies that became the norm in much of East Asia, and which in turn, allowed a degree of latitude over domestic policies. However, one significant change that occurred through both multilateral and bilateral pressures was the increasing use of competitive rules and other instruments as a means of monitoring foreign trade, thereby blurring the boundary between domestic and international economic policy. This has meant that entrenched rent-seeking practices are now the subject of international regulation. There is no doubt that these policy changes have had wide-ranging implications for the maintenance of the compensatory policies that provide the necessary political foundations of the developmental state.

The value of Ruggie's work ${ }^{29}$ is to illustrate how international economic order is sustained by a complementary domestic order. In this regard, there is symmetry between embedded liberalism and mercantilism. Both provided a set of compensatory policies and benefits that are crucial to the pursuit of liberal trade policies. Of course, the distributional effects and the normative assumptions of citizenship that sustained these state strategies were vastly different, but it remains the case that both were compensatory policies linked to a particular kind of international trade order. We turn now to consider in more detail the precise manner in which the system of embedded mercantilism operated in Southeast Asia - in particular, the distinctive characteristic of the Southeast Asian variant - was the consolidation of a kind of nomenklatura capitalism.

\section{Embedded mercantilism in Southeast Asia}

A critical feature of the Southeast Asian political economy during the boom period was the presence of two distinct economic segments: one, an international segment that is export-oriented and predominately driven by foreign direct investment (FDI) and the other, a highly cartellized domestic segment. These economic segments or sectors were also composed of distinct capitalist groupings with differing linkages to the state; the tradeable sector was predominantly driven by foreign investors 
while the non-tradeable sector was largely in the hands of enterprises or corporate groups closely linked to the apparatus of political power. The growth generated by the tradeable sector was effectively compensated through an implicit and explicit set of bargains between the capital in the tradeable sector and the non-tradeable sector. Of course, how this was achieved depended on the precise institutional configuration of the state. An elaboration of this is beyond the brief of this chapter, but for the purpose of the present argument it would suffice to underscore the fact that these domestic coalitions were structured through a set of bargains that in the final analysis rested on the economic growth generated by the tradeable sector of the economy.

In this context, there can be no doubt that the formation of the dual economies of Southeast Asia was accelerated by the rapid growth in Japanese FDI. From 1987, Japanese investment in Asia increased dramatically, particularly after the Plaza Accord ${ }^{30}$ that raised the value of the yen, prompting Japanese manufacturers to seek overseas manufacturing plants. Singapore and Thailand were the initial beneficiaries of these investments, but Japanese FDI shifted to Malaysia and Indonesia over the next few years. ${ }^{31}$ As table 2.1 indicates, Malaysia and Singapore remained heavily dependent on the inflow of FDI.

Japan was not the only major source of FDI; other East Asian newly industrializing countries (NICs) were also important investors in Southeast Asia. Just as appreciating currency forced Japanese manufacturers to relocate, a similar set of pressures were being felt in some NICs, such as South Korea and Taiwan. Taiwan, for example, is a significant investor

Table 2.1 Asia: Ratio of FDI inflows to gross domestic capital formation, 19711993 (annual averages)

\begin{tabular}{lccccc}
\hline Country & 1971-1975 & 1976-1980 & 1981-1985 & 1986-1990 & 1991-1993 \\
\hline China & 0.0 & 0.1 & 0.9 & 2.1 & 10.4 \\
Hong Kong & 5.9 & 4.2 & 6.9 & 12.9 & 5.7 \\
India & 0.3 & 0.1 & 0.1 & 0.3 & 0.4 \\
Thailand & 3.0 & 1.5 & 3.0 & 6.5 & 4.7 \\
Korea & 1.9 & 0.4 & 0.5 & 1.2 & 0.6 \\
Malaysia & 15.2 & 11.9 & 10.8 & 11.7 & 24.6 \\
Philippines & 1.0 & 0.9 & 0.8 & 6.7 & 4.6 \\
Singapore & 15.0 & 16.6 & 17.4 & 35.0 & 37.4 \\
Taiwan & 1.4 & 1.2 & 1.5 & 3.7 & 2.6 \\
Indonesia & 4.6 & 2.4 & 0.9 & 2.1 & 4.5 \\
\hline
\end{tabular}

Source: K.S. Jomo, Chen Yun Chung, Brian C. Folk, et al., (1997) Southeast Asia's Misunderstood Miracle: Industrial Policy and Economic Development in Thailand, Malaysia and Indonesia, Boulder: Westview Press. 
in Malaysia, and South Korea made substantial investments in Indonesia. ${ }^{32}$ In addition, the emergence of the growth triangle linking Singapore with the Malaysian state of Johor and the Indonesian province of Riau underlined significant Singaporean investment in its neighbours. In short, from the late 1980s Southeast Asia was the beneficiary of significant FDI from Japan and other East Asian NICs.

However, this was not simply a question of market forces creating a "flying geese" model of investment. This investment was driven by a set of political forces that served to entrench the dominant coalitions in East Asia. It was political in a number of ways: first, it was driven by domestic pressures to move offshore in order to internationalize production strategy; second, these strategies were underpinned by export markets in the United States, which, in turn, were dependent on the broader relationship between the United States and Japan; and third, Japanese FDI was enmeshed in the political strategies of local dominant coalitions through equity investment or joint ventures. For example, significant Japanese investment in Proton, the Malaysian automobile company, helped cement an enterprise that was both economically and ideologically pivotal to dominant sectors of the Malaysian political economy. The growth of FDI in Southeast Asia was driven not just by market forces but also by a complex array of political pressures, particularly the economic and political interests of domestic coalitions.

Japanese foreign investment has been supplemented by significant flows of bilateral aid. In this connection, Richard Stubbs points out that:

during the 1970s and 1980s the four ASEAN states of Indonesia, Malaysia, the Philippines, and Thailand consistently received about one third of Japanese bilateral aid and disbursements. In the wake of the new wave of investment in the late 1980s Japanese aid rose in absolute terms from \$914 million in 1986 to $\$ 2.3$ billion in $1990 .^{33}$

In essence, the rapid flow of investment was also reinforced by Japanese bilateral aid, a proportion of which - particularly in infrastructural projects - helped sustain the domestic economic cartels.

However, this growth in foreign investment was also accompanied by rapid growth of the political and economic power of the non-tradeable sector in Southeast Asia. As will be argued, much of this growth was helped by the policies of deregulation and liberalization introduced in the late 1980s. Far from helping to curtail the growth of powerful politically linked domestic cartels, these policies only served to consolidate the considerable shift of power to politically linked cartels. In fact, in Southeast Asia, outward-oriented economic policies helped to entrench a dual economy and its mainsprings, the constellations of power and interests. 
The economic success of the export-oriented sector served to underpin the growing economic and political power of the non-tradeable sector. This growth was reflected, for example, in the rapid growth of infrastructural development in countries such as Malaysia, which was fuelled by the export-oriented sector. ${ }^{34}$ Moreover, the high capital inflows generated by the rapid growth of Southeast Asian economies fed directly into the politically connected non-tradeable sector. ${ }^{35}$ In fact, much of the recent discussion of capital inflows overlooks the fact that most of the debt incurred has been with politically connected domestic cartels. In addition, the increased assertiveness of domestic cartels in the nontradeable sector has been clearly illustrated in the pegging of local currencies to the US dollar prior to the crisis, an action that effectively overvalued most local currencies. For example, one of the main triggers of the Thai crisis was the failure of Thai economic authorities to make effective downward adjustments to the baht. ${ }^{36}$ However, these policies cannot be simply dismissed as policy failures just because the distributional benefits of an overvalued currency accrue to the non-tradeable sector; they must be seen as a reflection of the relative political dominance of the non-tradeable as against the tradeable. ${ }^{37}$

More significantly, the distinctive character of embedded mercantilism in Southeast Asia is reflected in the growth of a type of regional nomenklatura capitalism. The term "nomenklatura capitalism" is used to highlight the close connection between the political elite and insulated domestic cartels. In the Southeast Asian context, the connections are stronger than the clientalism of Northeast Asian developmental states because the management and control of business groups are closely intertwined with the state and party apparatus. Nomenklatura capitalism here points to an important shift in Southeast Asian economies as agents or enterprises within the states or indeed in dominant parties become key players in the domestic economies.

Indonesia provides a neat illustration of the development of this nomenklatura capitalism. During Indonesia's oil boom phase (1973-1982), state intervention in the economy was widespread. It was reflected in the rapid growth of state enterprises in areas such as steel, fertilizer, cement and paper; the rapid increase in state intervention was accompanied by a range of highly interventionist policies in areas such as trade and banking. For example, the foreign investment laws introduced after 1974 required all foreign investors to take on local equity partners. In the trade area, a system of import monopolies for private and public firms was introduced thereby providing a lucrative system of rent for well-connected state enterprises. ${ }^{38}$

However, by the mid-1980s, these systems had become much more tenuous. Internationally, there was great pressure to deregulate the 
economy, particularly in the wake of the collapse in oil prices, but there were also significant domestic pressures because significant beneficiaries of the previously regulated economy began to chafe at state restrictions. Many of the cartels that were dependent on political connections were locked out of lucrative state monopolies and were intent on getting a slice of the action. In the light of these twin pressures, the Indonesian government in the mid-1980s began to pursue a more market-oriented approach to the economy.

While these reforms were much lauded by the international community, it is important to note that they occurred within the context of the emergence of a powerful group of nomenklatura capitalists. These economic reforms shifted power away from state enterprises towards this group of nomenklatura capitalists. Indeed, it may well be argued that

deregulation created the opportunity for sudden and extensive growth in the private sector and for the economic dominance of large predominantly Chineseowned conglomerates as well as business groups owned by powerful political families, notably the Suharto family. ${ }^{39}$

In short, far from the emergence of liberal markets, deregulation served to entrench domestic cartels (in the non-tradeable sector) whose defining attributes remained their connections to the dominant apparatus of political power - in the Indonesian situation, this meant the political and social coalitions surrounding the Suharto family. In essence, the market reforms that were at the heart of the kind of open economic strategies pursued by Indonesia served to entrench a dualistic economy composed of a foreign-owned tradeable sector and domestic-owned nontradeable sector composed of politically connected cartels.

In Malaysia, as with Indonesia, a dual economy is clearly apparent: a tradeable sector largely owned by foreign capital, and a domestic sector composed of enterprises with strong linkages to the ruling UMNO party. Of course, central to understanding the Malaysian political economy is the adoption in the 1970s of the New Economic Policy (NEP) designed to promote greater Malay entrepreneurship in the domestic economy, which was largely in the hands of Chinese capital. It is beyond the scope of this chapter to document the working of the NEP, ${ }^{40}$ but two significant effects need to be noted. First, the NEP created strong incentives for powerful Chinese capitalists to enter into alliances and relationships with Malay politicians. This nexus, which has become increasingly important over the last decade, has blurred the distinction between Chinese and Malay capital and formed the basis for a broad-based dominant coalition. ${ }^{41}$ Second, the NEP initially rested on an ambitious state-driven industrialization policy led by large state enterprises. These enterprises 
were controlled by powerful bureaucrats with close ties to the dominant political apparatus.

However, after the economic recession of the late 1980s, Malaysia embarked on an extensive programme of privatization and deregulation. This resulted in a shift of ownership from the public to the private sector, but control over the newly privatized assets was still dependent on linkages to the dominant political party, UMNO. Therefore, in Malaysia, ownership of key strategic enterprises shifted from state to party. As Alasdair Bowie points out, these developments have led to the

erection of a corporate empire blessed with unrestricted access to state-issued licences and Malay preferences that is under the direct control of the governing party, UMNO, and is used to raise funds for constituent and electoral purposes. ${ }^{42}$

In other words, Malaysia created its own brand of nomenklatura capitalists who are key components of the dominant coalition.

While the crisis has severely undermined the viability of these enterprises, it is clear that the linkages between UMNO and key sectors of the domestic economy are so strong that any attempt to introduce marketoriented reforms will be strongly resisted. The development of nomenklatura capitalism allows very little political space for the emergence of an alternative reform-oriented coalition. Nonetheless, it needs to be pointed out that there are significant pockets of domestic capital that may well form the basis of a future reform coalition. The recent electoral setbacks for the ruling party suggest that this may well be a plausible scenario.

More strikingly, Malaysian economic policies have a strongly nationalist orientation. However:

it aspires to find its fulfilment in an equally committed Malaysian nationalist goal of competing equally with the advanced nations of the world. Mahathir himself has alluded to all this before. ${ }^{43}$

Elements of this pervasive dualistic economy - though with a much higher degree of economic efficiency - are also evident in Singapore's political economy, which, like Malaysia, has two distinct elements: a tradeable sector largely controlled by foreign capital, and a powerful domestic sector composed of government-linked companies (GLCs) that have a strong presence in the domestic economy. The effective political and policy segmentation of the economy between the external and the domestic sectors reduces (though it does not eliminate) potential conflicts between the two sectors. However, the powerful GLCs and domestic enterprises are core components of Singapore's dominant coalition. Therefore, any analysis of policy reform in Singapore over the last decade or so needs to take into account the critical economic and political role of 
GLCs. Indeed, even as privatization and deregulation have proceeded apace, the government used key holding companies - Temasek Holdings, Singapore Technologies and the Health Corporation Holdings - to retain control over some of the biggest corporate entities in Singapore. ${ }^{44}$ In fact, as Garry Rodan ${ }^{45}$ points out, one of the distinctive features of the Singaporean political economy over the last decade and a half has been the gradual movement of state enterprises into the private sector without a concomitant shift in control of these enterprises.

These examples illustrate that, contrary to much of the prevailing economic orthodoxy, trade liberalization or open economic policies served to consolidate a particular economic and political bargain between a politically connected non-tradeable sector and an open oriented export sector. From the late 1980s state-led developmental projects gave way to a system of nomenklatura capitalism: powerful domestic cartels connected to the ruling apparatus of political power. To be sure, the precise nature of these connections (as well as the degree of economic efficiency) was dependent on the distinctive institutional configuration in each country, such as the "presidential cronyism" in Indonesia or party-led companies in Malaysia. Relevant for our argument here is the manner in which this model of nomenklatura capitalism and the domestic coalitions that sustained it were imbricated with a particular set of internationalist strategies.

\section{Nomenklatura capitalism and open regionalism}

The strategy of open regionalism that has defined APEC's multilateralism has reinforced this system of nomenklatura capitalism. Open regionalism is basically a strategy of unilateral trade liberalization with an extension of the benefits of this trade liberalization to non-APEC member countries on the basis of the GATT principle of most favoured nation (MFN) status, i.e. concessions offered by one country to any other GATT member should be offered to all. The rationale behind open regionalism is that freer trade within a trade area will increasingly produce positive trade liberalizing effects on other trade blocks and countries through the operation of the GATT's MFN principle. It is argued that this has the virtuous effect of avoiding trade diversion - a standard effect of a customs union (a trade area with common external restrictions). Open regionalism, therefore, extends the benefits of free trade to a greater proportion of the international economic system than to just the member countries of APEC. In short, it is a trade liberalizing strategy, the aim of which is to create lower trade barriers across the international economic system. 
The competing notion of "block regionalism" is based on the assumption that unilateral trade liberalization is not likely to be effective. NonAPEC members would have a "free-ride" on trade liberalization while holding back on their own domestic trade liberalization agendas. From this perspective, for APEC to be an instrument for effective economic cooperation it is necessary that there should be reciprocal trade concessions from non-APEC members. APEC's huge and rapidly developing market would provide a further carrot for non-members. This vision for APEC is premised on the more political GATT principle of reciprocity (essentially the Bergsten position, which preferred that APEC trade concessions be limited to countries willing to make similar concessions, as distinct from the unilateral trade liberalization favoured by proponents of open regionalism). A stronger version of block regionalism would suggest that APEC develop a well-regulated customs union along the lines of the European Union. This version of block regionalism is economically and politically untenable: economically, because of the vast differences in levels of economic development and the fact that most East Asian trade (if the United States is excluded) is inter-regional rather than intra-regional; politically, because, given the problems that North American Free Trade Agreement (NAFTA) faced, it would be next to impossible to gain political acceptance for a such a position in the United States, and more importantly, it would require the successful resolution of US-Japanese trade issues.

The key political point about open regionalism is that it is not just an economic description of a set of economic strategies but a reflection of the make-up of certain politically constituted sets of relationships between market sectors. Open regionalism is not about regional marketmaking but about maintaining export markets, and this helps to cement the dominant coalition between the domestic cartels in the non-tradeable sector and the tradeable sector.

In East Asia, where the position of the ruling elite is closely bound with the existing economic structure, the possible formation of markets beyond the state's influence as a self-regulating and autonomous sphere will strike at the heart of the dual economies that we have seen there. Indeed such a transformation represents a direct threat to extant patterns of political and economic power. Open regionalism is the preferred international strategy of embedded mercantilism and nomenklatura capitalism that are the hallmarks of the Southeast Asian political economy.

More generally, the point that needs to be made is that multilateral strategies are deeply intertwined with domestic economic and political projects. During the boom years, the APEC strategy of trade liberalization within the ambit of open regionalism fitted well with the political projects of nomenklatura capitalism. Nevertheless, during the Asian eco- 
nomic crisis, the domestic structures and coalitions that underpinned open regionalism were under severe pressure, and hence the APEC response to Southeast Asia's economic problems has been a conspicuous failure. Open regionalism is the preferred international strategy of the embedded mercantilism that defined the Southeast Asian political economy.

Open regionalism is paralleled by an equally distinctive approach to security questions that we can call, following Eric Heginbotham and Richard Samuels, "mercantile realism". ${ }^{46}$ Mercantile realism encompasses military security as an essential component. According to $\mathrm{He}$ ginbotham and Samuels, three broad ideas sustain mercantile realism:

(1) the possibility that the efficacy of appeals to arms has, for a variety of reasons, declined dramatically during the course of the twentieth century; (2) national economic power can be used to constrain the sovereignty and independence of states; (3) national economic power can be enhanced through industrial and trade policies designed to create comparative advantage in high-technology sectors. ${ }^{47}$

In brief the strategy of mercantile realism amounts to a potential tradeoff between military security and enhanced economic power. It is a security strategy that is closely tied to the dominant system of nomenklatura capitalism in Southeast Asia.

\section{Globalization and the crisis of embedded mercantilism}

The political economy of embedded mercantilism became increasingly vulnerable to the rapid and structural changes in the global economy, which have come to be identified as "globalization". Globalization has made it much more difficult to sustain the continuance of the compensating mechanisms of embedded mercantilism. In particular, over the long run, the rapid inflows of short-term capital proved a catalyst in unravelling the economic foundations of the politically connected domestic cartels, notwithstanding that initially such inflows served to reinforce the system of nomenklatura capitalism.

It might be useful to examine the analysis by Robert Wade and F. Veneroso of the causes of the financial crisis in East Asia. In a recent article, they have vigorously counter-attacked on behalf of institutionalist models. ${ }^{48}$ This exposition, if not at least winning any points from the International Monetary Fund (IMF), manages to keep the developmental state theorists in the bout after what appeared to be a knockout blow from neoclassical economists. In essence, the Wade and Veneroso argu- 
ment is that the crony capitalism explanation of the crisis misses the fact that there is a "financial rationale for cooperative, long-term, reciprocal relations between firms, banks and government in a system that intermediates high savings into high corporate debt/equity ratios". 49

Pivotal to the Wade and Veneroso argument is that East Asian capitalism has been characterized by high debt equity ratios. No doubt, this is also central to the moral hazard type of argument, but Wade and Veneroso argue that this structure is the outcome of two key institutional features of the East Asian political economy. First, savings are much higher than in other regions. In most East Asian nations, domestic savings are about one-third of the gross domestic product, ${ }^{50}$ and as most savings are held in bank deposits, it follows that bank lending is geared towards borrowing by firms. Second, in order to compete in large export markets local firms need to expend considerable resources, which can only be facilitated by extensive borrowing. In brief, the only means of financing the export industrialization of the kind experienced by Japan, Korea, and Taiwan over the last three decades is through the mobilization of the large reserves of domestic savings by local corporations.

However, such a system requires a high degree of collaboration among firms, banks, and the state; in other words, the high debt-to-equity ratios of East Asian capitalism need to be underpinned by a complex institutional infrastructure of regulations. Admittedly, the system is highly vulnerable to systemic shocks that depress the flow of capital, and for this reason the system must be safeguarded against such shocks in addition to having a system of constant state monitoring of private firms and banks. Indeed, the whole system depends on the effective monitoring of the corporate debt by the state. Furthermore, restrictions "on the freedom of firms and banks to borrow abroad, and coordination of foreign borrowing by government, are a necessary part of this system". ${ }^{51}$

Contrary to the neoclassical explanation of the crisis, Wade and Veneroso suggest there is a virtuous cycle between high savings, high levels of debt-to-equity ratios and close and collaborative links with state, banks and firms, which in turn leads to high investment, high levels of export performance and growth rates. This virtuous cycle is dependent upon a high level of restrictions of financial regulation of external borrowing because, among other things, this will lead to lower levels of monitoring by the state. Given the absence of credit safety nets to stabilize the system, the high wire act of East Asian capitalism requires a greater level of governmental capacity and monitoring. To put this in $\mathbf{J}$. Kornai's terms, ${ }^{52}$ governmental monitoring of private firm and bank behaviour is by means of a system of non-price signalling vital for the stability of economic coordination in East Asia. Nevertheless, the ability of 
the state to keep financial restrictions in place proved to be the chink in the armour of the developmental state. The crisis is explained by the fact that financial deregulation undertaken by East Asian governments:

removed or loosened controls on companies' foreign borrowing, abandoned coordination of borrowings and investments, and failed to strengthen bank supervision. By doing so, they violated one of the stability conditions of the Asian high debt model, helping to set the crisis in train. ${ }^{53}$

In short, the virtuous cycle of the East Asian political economy became in fairly short order a particularly vicious cycle, plunging these economies into deep crisis. For Wade and Veneroso ${ }^{54}$ opening up financial markets is akin to allowing, indeed encouraging, unlimited access to the cookie jar.

The core of this argument can be usefully applied to our understanding of Southeast Asian political economies. Certainly one of the main effects of globalization is the decline of the monitoring capacity of the state. This is not necessarily due to policy errors on the part of the technocracy but rather is the effect of the growing entrenchment of nomenklatura capitalism in Southeast Asia.

In Thailand, long the "teacher's pet" of the World Bank for its conservative macroeconomic and monetary policy, there has been a continual shift in political power away from central state agencies to business groups and politicians. ${ }^{55}$ Here, the close relationship between politicians and business groups was at the expense of central economic agencies, such as the Ministry of Finance. In this context, Anek Laothamatas maintains that:

with electoral politics in full gear in the later 1980s and early 1990s corrupt dealings between government and business have again picked up. In a country where vote-buying is often needed to win an election and funding for party activities and election campaigning comes mostly from covert donations (rather than legitimate government sources or publicly acknowledged donations), corruption becomes a crucial means for politicians to draw money from businesses. ${ }^{56}$

The point that needs to be recognized here is that the deregulation of the financial sector in the context of the dual economies provided a stage for the inevitable collision between global economic forces and the dominant coalitions solidly entrenched in the nomenklatura capitalism arrangements of Southeast Asia. From this perspective, while the depth of the economic crisis was no doubt a contributing factor, the mainsprings of the crisis lay in structures of the Southeast Asian political economy. Economic liberalization within a system of nomenklatura capitalism inevit- 
ably weakened the capacity of policy makers to respond to the crisis. Indonesia provides a clear illustration of our argument. First, deregulation in Indonesia led to the consolidation of powerful politically connected conglomerates. ${ }^{57}$ Second, successive rounds of liberalization left technocrats with very few instruments through which to control the economy. As Jonathan Pincus and Rizal Ramli point out:

Paradoxically, although successive rounds of liberalization failed to achieve their stated objective of reducing the level of rents in the system, they had the unintended effect of limiting the technocrats' capacity to intervene in a meaningful way to adjust to external shocks. ${ }^{58}$

Globalization served over the short term to reduce the capacity of the technocrats to regulate the economy. More seriously, regulatory institutions (such as the Indonesian central bank) were captured by domestic cartels, and this combined with the fact that strategies of liberalization further entrenched the power of nomenklatura capitalists. But, over the long term, an economic crisis of the magnitude of the shock of 1997-1998 was inevitable because the hitherto carefully regulated balance between the tradeable and the non-tradeable sectors was firmly tilted in favour of the non-tradeable sector.

\section{Post-crisis Southeast Asia: coalitions and policy outcomes}

Clearly, the crisis has unsettled the dominant coalitions within the region, and it has been very difficult to sustain the embedded mercantilism of the boom years. Yet, this does not necessarily mean the dismantling of the systems of nomenklatura capitalism in Southeast Asia. Indeed, the clear evidence of the post-crisis period suggests that the most arresting feature of developments in Southeast Asia has been the diversity of responses to the crisis. If in the pre-crisis boom period there was a fundamental commonality underpinning both economic strategies and the domestic coalitions, this was no longer the case in post-crisis Southeast Asia. What is most evident is the extent to which some states have embarked on reform, while others have resisted it, and yet others remain mired in a kind of stalemate. It is this diversity that will significantly alter the shape and form of multilateralism in Southeast Asia.

What determines the nature of policy reform in times of crisis? Crucial to our argument it is that the policy response of domestic coalitions to external economic crisis depends not just on the extent of their dominance within the domestic political economy but also on the severity of external shocks. In the case of a dominant reform coalition facing severe 
economic pressure and an alternative reform coalition with strong political support, the outcome is a programme of fundamental economic restructuring conditioned by institutional and ideological forces. In Southeast Asia, the only country that approximates to such a strategy is Thailand. ${ }^{59}$

More problematic are cases where status quo coalitions are dominant and no putative reform coalition is evident. In these circumstances, two different kinds of responses are possible: defensive or offensive policies of adjustment. Defensive adjustment, in this context, refers to the institution of highly protectionist and regulatory measures. Where there is strong structural pressure (reflected in the state of the external balance and fiscal capacity of the state), a politically dominant status quo coalition is likely to engage in a policy of defensive adjustment. The Malaysian response to the Asian crisis has been characterized by this kind of defensive adjustment.

In contrast a status quo coalition that faces moderate structural pressure is likely to engage in a policy of offensive adjustment. Offensive adjustment refers to an attempt to modify existing policies to make the economy much more competitive without a significant change in the structure and ownership of the domestic economy. Singapore's policy of gradual liberalization falls into this category of offensive adjustment.

In broad terms, then, the policy response to economic crisis is determined by the interaction between domestic coalitions and external pressures. In short, external pressures are refracted through the constellation of interests entrenched in the domestic political economy.

Figure 2.1 indicates the nature of the interaction between coalition types, structural pressure and domestic policy response.

In summary there are four possible coalition types in Southeast Asia:

1. A dominant reform coalition that attempts a radical restructuring of existing policy regimes.

2. A strong status quo coalition that responds to structural pressure by modifying aspects of the existing regime but without directly threatening its entrenched interests (offensive adjustment).

3. A strong status quo coalition that attempts not just to stave off economic restructuring but seeks to actively implement a nationalist agenda (defensive adjustment).

4. A stalemate where a very weak entrenched coalition faces an equally emasculated reform coalition.

However, this is only a partial outline of reform trajectories; a fuller picture needs to incorporate the impact of institutional capacity and ideological influences on economic decision-making. The point that needs to be underlined is how the crisis has produced a diversity of coalition arrangements and economic strategies in Southeast Asia. 


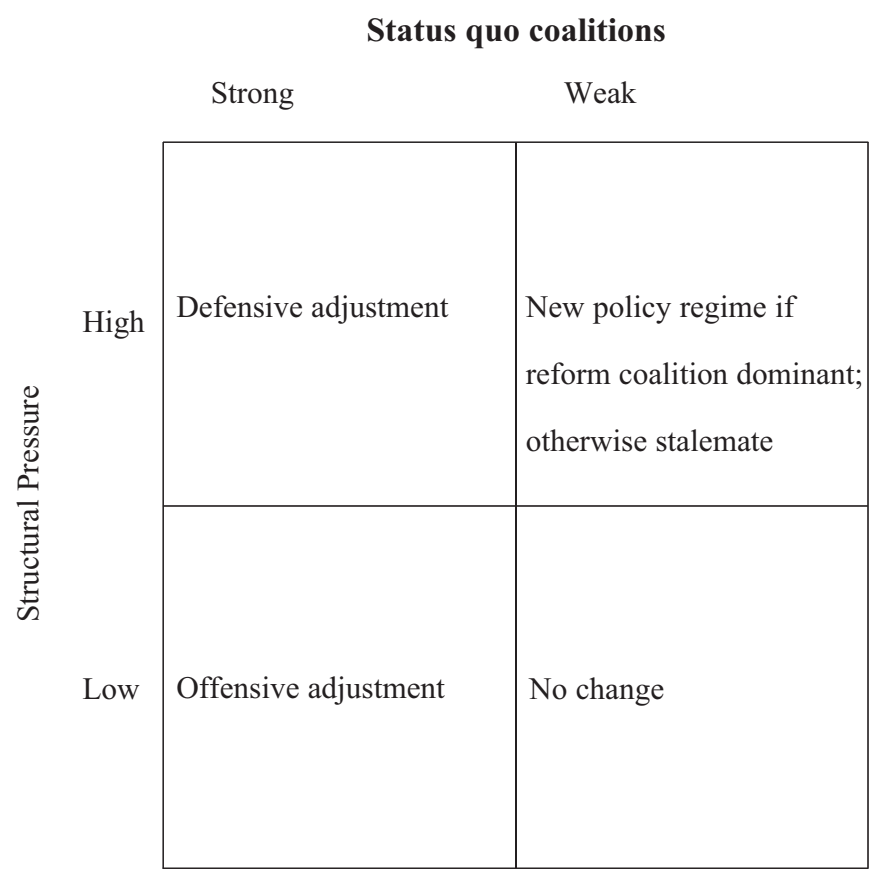

Figure 2.1 A structural model of coalitions, crisis, and policy outcomes

\section{Conclusion}

The overriding conclusion to emerge from this analysis is the extent to which the economic reform process is enmeshed in the political process. To be successful, any reform needs to have the political support of a significant group of actors. Reform strikes at the heart of deeply entrenched political and economic interests; therefore, to be successful an economic reform programme must galvanize its own political support. From this perspective, economic reform is not merely a technical exercise to implement the "right" policies, but a political project undertaken by the putative winners of economic reform. For this reason, economic reform is likely to be a deeply contested and prolonged process. The analysis presented here serves to underline the fact that markets are not neutral or abstract entities; they are deeply embedded in constellations of power and interests.

In this respect, our analysis differs from orthodox accounts that regard reform as a mere exercise in getting the policies right. Of course, many studies of economic reform in the post-crisis period have placed great 
emphasis on issues of institutional failure in explaining the widespread failure to pursue active programmes of economic reform. ${ }^{60}$ However, in these accounts, politics is conceived as external to the market, and hence the failure is often attributed to rent-seeking or irrational politics. By contrast, the alternative understanding would suggest that politics is not extrinsic but constitutive of both domestic and international economic strategies.

The overview of economic reform in Southeast Asia also suggests that the post-crisis period is marked by a significant diversity of reform trajectories. In the boom years of growth in the 1990s, there was a remarkable similarity of economic strategies and policies. However, it is precisely the convergence of domestic coalitions around a system of nomenklatura capitalism that enabled the kind of strategy of open regionalism associated with APEC. From this vantage point open regionalism was a strategy of internationalization that meshed with the internal configuration of power and interests embedded in Southeast Asia's domestic political economies. The economic crisis has undermined the domestic foundations of open regionalism and therefore has important implications for regional organizations such as APEC because consensus over issues such as trade liberalization will be much more difficult to achieve.

In a similar manner, we can rule out efforts at building a region-wide economic area. Though there have been recent moves through the ASEAN Plus Three process to formalize a version of the East Asia Economic Caucus (EAEC) originally proposed by Malaysia, any significant move towards building an East Asian economic region will face considerable obstacles. Among other considerations, one major difficulty lies in the fact that any political project of economic region-building presupposes a convergence of domestic coalitions around a particular economic programme. As we observed, far from such a convergence of domestic coalitions, post-crisis East Asia has witnessed considerable diversity in both coalitions and economic strategies. In short, none of the domestic conditions for successful regional integration can be identified in Southeast Asia.

The more likely scenario for East Asia is an increasing emphasis on coalition formation at the international level. Like-minded countries with similar domestic structures are likely to form coalitions. These coalitions will complement rather than replace existing regional organizations and institutions, such as APEC and the ASEAN Free Trade Agreement (AFTA). For example, AFTA and APEC are likely to provide an umbrella under which coalitions will form. AFTA already provides avenues for liberalization to occur at different speeds. Similarly, APEC provides "opt in/out" arrangements for areas such as telecommunications. Multi- 
ple timetables, opting arrangements, etc. enable international coalition formation within existing regional organizations.

In a similar manner, we are likely to witness greater bilateral agreement on free trade. The recent discussion between New Zealand and Singapore on a free trade treaty is likely to be a forerunner of a number of other similar trade agreements. Again, this provides an avenue for coalitions to form around specific trade issues. In short, the diversity of domestic coalition structures will portend a more fractious, messy and complex set of international coalitions. To be sure, it will not supplant existing regional organizations but will function alongside and within regional institutions.

\section{Notes}

1. The term "nomenklatura" was used in the Soviet context to refer to a list of important posts and of the people who are candidates for them. Generally, the term has been used to refer to the managerial cadre of the state. More recently, the term "nomenklatura privatization" has been used to describe how private enterprise in the ex-Soviet Union and Eastern Europe came to be controlled by the former nomenklatura. We use the term analogously in the Southeast Asian context to refer to the intertwined relationship between state and private business.

2. For a good survey of these issues see Richard Higgott (1993) "Competing Theoretical Approaches to International Cooperation: Implications for the Asia Pacific", in R. Higgott, R. Leaver, and J. Ravenhill, eds., Pacific Economic Relations in The 1990s: Cooperation or Conflict?, Sydney: Allen and Unwin, pp. 290-293.

3. Mark Beeson, and Kanishka Jayasuriya (1998) "Competing Political Rationalities of Regionalisms: APEC and the EU in Comparative Perspective", Pacific Review 11(3): 311-336.

4. The work of Zysman provides a good illustration of these arguments. See J. Zysman (1996) “The Myth of 'Global Economy': Enduring National Foundations and Emerging Regional Realities", New Political Economy 1(2): 67-184.

5. Ibid., p. 177.

6. This argument is particularly well developed in Mark Beeson and Richard Robison (2000) "Introduction: Interpreting the Crisis", in R. Robison, M. Beeson, K. Jayasuriya, and Hyuk-Rae Kim, eds., Politics and Markets in the Wake of the Asian Crisis, London: Routledge, pp. 19-24.

7. For some landmark work in this vein, see Peter Gourevitch (1978) "The Second Image Reversed: the International Sources of Domestic Politics", International Organisation 38(1): 881-912. Also Peter Gourevitch (1986) Politics in Hard Times Comparative Responses to International Economic Crises Ithaca: Cornell University Press.

8. Barrington Moore (1966) The Social Origins of Dictatorship and Democracy, Boston: Beacon Press.

9. A. Gerschenkron (1962) Economic Backwardness in Historical Perspective, Cambridge: Harvard University Press.

10. Etel Solingen (1998) Regional Orders at Century's Dawn, Princeton: Princeton University Press.

11. Ibid., p. 22. 
12. T.J. Pempel (1997) "Regime Shift: Japanese Politics in a Changing World Economy", Journal of Japanese Studies 23(2): 333-361. For an extended elaboration of this argument, see T.J. Pempel (1998) Regime Shift: Comparative Dynamics of the Japanese Political Economy, Ithaca and London: Cornell University Press.

13. Pempel, Regime Shift, p. 20

14. Ibid., p. 60.

15. Bruce Cumings (1987) "The Origins and Development of the Northeast Asian Political Economy", in Frederic Deyo, ed., The Political Economy of the New Asian Industrialism, Ithaca: Cornell University Press.

16. J. Ruggie (1983) "International Regimes, Transactions, and Change: Embedded Liberalism in the Postwar Economic Order", in Stephen Krasner, ed., International Regimes, Ithaca: Cornell University Press.

17. For an introduction to the concept of international regime, see Krasner, passim.

18. Ruggie argues that hegemonic stability theorists, such as R. Gilpin (1987) The Political Economy of International Relations, Princeton: Princeton University Press, focus on the stability of international regimes but are unable to account for the content of these regimes.

19. Ibid.

20. Ibid., p. 209.

21. Ibid., p. 231.

22. See Stephen Bell (1997) "Globalisation, Neo-liberalism and the Transformation of the Australian State", Australian Journal of Political Science 32(3): 345-367.

23. Philip G. Cerny (1990) The Changing Architecture of Politics, London: Sage.

24. See Kent Calder (1988) Crisis and Compensation: Public Policy and Political Stability in Japan 1949-1986, Princeton: Princeton University Press, and T. J. Pempel, Regime Shift.

25. B. Woodall (1996) Japan under Construction: Corruption, Politics, and Public Works, Los Angeles: University of California Press.

26. Ibid., pp. $9-10$.

27. See M. Moore (1987) "From Statism to Pluralism: Government and Agriculture in Taiwan and South Korea", in G. White, ed., Developmental States in East Asia, London: Macmillan.

28. See Alasdair Bowie (1991) Closing the Industrial Divide, New York: Columbia University Press, and Alasdair Bowie (1994) "The Dynamics of Business-Government Relations in Industrialising Malaysia", in A. Macintyre, ed., Business and Government in Industrialising Asia, Sydney: Allen and Unwin, pp. 167-194.

29. Ruggie, op. cit.

30. Richard Stubbs (1994) "The Political Economy of the Asia-Pacific Region", in R. Stubbs, and G. Underhill, eds., The Political Economy of the Changing Global Order, London: Macmillan.

31. K.S. Jomo, with Chen Yun Chung, Brian C. Folk, et al. (1997) Southeast Asia's Misunderstood Miracle: Industrial Policy and Economic Development in Thailand, Malaysia and Indonesia, Boulder: Westview Press.

32. Stubbs, passim.

33. Ibid., pp. $372-373$.

34. K.S. Jomo, ed. (1998) Tigers in Trouble: Financial Governance, Liberalisation and Crises in East Asia, London: Zed Books.

35. Khoo Boo Teik (2000) "Economic Nationalism and its Discontents: Malaysian Political Economy after July 1997', in R. Robison, M. Beeson, K. Jayasuriya, and Hyuk-Rae Kim, eds., Politics and Markets in the Wake of the Asian Crisis, London: Routledge, pp. 212-238.

36. K.S. Jomo, passim. 
37. J.A. Frieden (1991) "Invested Interests: The Politics of National Economic Policies in a World of Global Finance", International Organisation 45(4, Autumn): 425-451.

38. Richard Robison, and Andrew Rosser (1998) "Contesting Reform: Indonesia's New Order and the IMF", World Development 26(8): 1593-1596.

39. Ibid., pp. 1598.

40. K.S. Jomo (1986) A Question of Class: Capital, the State, and Uneven Development in Malaya, Singapore: Oxford University Press.

41. E.T. Gomez, and K.S. Jomo (1997) Malaysia's Political Economy: Politics, Patronage and Profits, Cambridge: Cambridge University Press.

42. Bowie, pp. 182.

43. Khoo Boo Teik (1995) Paradoxes of Mahathirism, Oxford: Oxford University Press, pp. 329.

44. Garry Rodan (1997) "Singapore: Economic Diversification and Social Divisions", in Garry Rodan et al., eds., The Political Economy of Southeast Asia, Sydney: Oxford University Press; see also W. Vennewald (1994) "Technocrats in the State Enterprise System in Singapore", Working Paper No. 32, Perth: Murdoch University, Asia Research Centre.

45. Rodan, passim.

46. Eric Heginbotham, and Richard J. Samuels (1998) "Mercantile Realism and Japanese Foreign Policy”, International Security 22(2): 171-203.

47. Ibid., p. 190.

48. Robert Wade, and F. Veneroso (1998) "The Asian Crisis: The High Debt Model Versus the Wall Street-Treasury-IMF Complex", New Left Review, March/April, pp. 1-24. Robert Wade is a prominent exponent of the "government intervention does matter" school.

49. Ibid., p. 10.

50. World Bank (1993) The East Asian Miracle, Washington, DC: World Bank.

51. Wade and Veneroso, p. 7.

52. J. Kornai (1992) The Socialist System: The Political Economy of Communism, Princeton: Princeton University Press.

53. Wade and Veneroso, p. 9.

54. Ibid.

55. See Anek Laothamatas (1992) Business Associations and the New Political Economy of Thailand, Boulder: Westview Press.

56. Ibid., p. 209.

57. See Robison and Rosser, pp. 1593-1609; and Jonathan Pincus, and Rizal Ramli (1998) "Indonesia: From Showcase to Basket Case", Cambridge Journal of Economics 22: 723-734.

58. Pincus and Ramli, p. 724.

59. Kevin Hewison (2000) "Thailand's Capitalism before and after the Crisis", in R. Robison, M. Beeson, K. Jayasuriya, and Hyuk-Rae Kim, eds., Politics and Markets in the Wake of the Asian Crisis, London: Routledge, pp. 192-211.

60. Stephen Haggard, and Andrew Macintyre (1998) "The Political Economy of the Asian Economic Crisis", Review of International Political Economy V.5(3): 381-392. 


\title{
Poverty and non-traditional
} security: Experiences of China's partnership with multilateral donor institutions on poverty alleviation

\author{
Qingxin K. Wang and Melissa G. Curley
}

Poverty is a multi-faceted and complex issue. As Amartya Sen has noted, we live in a world of unprecedented opulence where people live far longer and in which the human rights and political liberties, enshrined in democratic and participatory government, have become the dominant model of political organization. Yet we also live in a world of "remarkable deprivation, destitution and oppression". ${ }^{1}$ This chapter is primarily focused on illustrating why poverty is a security issue in international relations, both as a human security issue, within in a non-traditional security framework, and how major players of international politics at the global, domestic, and local levels have interacted with one another to cope with poverty.

In the first section we briefly consider how poverty has been dealt with in the field of international relations. Poverty, we assert, imposes a complex social and political relationship on the human security question. It can, however, also be related to traditional security concerns by threatening and undermining regime legitimacy and stability, and thus threatening to international peace. The consequences of poverty upon and within populations can escalate to the international level to cause crossborder and interstate tensions. We then look at two existing conceptual models of studying the interaction between international and domestic actors on poverty alleviation, which have downplayed the role of the state in poverty alleviation. Realizing the limits of these two models, we postulate an alternative conceptual model of how to study the interaction 
between different actors in poverty alleviation by emphasizing the importance of forming partnerships between state actors and international actors.

To support our hypothesis, we provide a case study of China's cooperation with international organizations (IOs) on poverty alleviation (PA) programmes in the second section. The state remains central in the quest to reduce poverty in China. Alongside its well-documented policies of economic reform, cooperation between China and international government organizations (IGOs) has been a key component of China's strategies for poverty alleviation over the last two decades. The third section evaluates the success and implications of this cooperation in human security terms, and the way in which IGO involvement has had an important influence on China's approach to poverty alleviation, and its capacity to tackle poverty in a planned and systematic manner over the last two decades. The case study shows that institutional cooperation between the state, IOs and international non-governmental organizations (INGOs) has provided an effective solution to tackling poverty in China, and of improving the human security of millions of China's poor.

\section{Poverty in the study of international relations}

Poverty has long been a concern in the study of international relations, far before it was linked to human security. The idea that poverty is related to traditional international relations concerns is not new. The idea that poverty was the breeding ground of communism was one of the central tenets behind the Truman Doctrine and the Marshall Plan in the aftermath of World War Two. In Truman's inaugural address for his second presidential term in 1949, the idea that poverty was a threat both to poor people themselves, and to the richer nations, was explicit. Truman announced the idea of a "fair deal" for all the world's people. An essential part of this was his appeal to the United States and to the international community to solve the problems of "underdeveloped areas". ${ }^{2}$

The Truman Doctrine dovetailed with the "Bretton Woods" institutions - such as the World Bank - and United Nations in undertaking a mission to replicate the conditions that were considered necessary for transforming underdeveloped areas to advanced societies. International governmental organizations (IGOs) provided an institutional framework to help develop third world countries by increasing prosperity and thereby reducing poverty. IGOs have since played an important role in making "development" and "poverty alleviation" recognizable global norms. 
The assumption underlying this process was that through democratic government, capitalism, and the application of modern science and technology, serious poverty could be alleviated, if not eradicated. It could be addressed through greater production, which was, in turn, the key to prosperity and peace. US foreign policy towards aid, development, and poverty alleviation, and Washington's participation in IGOs during the post-war period, reflected these aims. Poverty became linked to the ideological battles of Cold War politics. Yet IGO cooperation with recipient states on poverty alleviation gradually assumed a dimension of its own. Aspects of cooperation and conditionality mechanisms were an important arena of interaction between policy makers in the first world and elites in the third world.

Poverty was also an implicit part of the discipline's engagement with development theory. This was particularly the case with Wallerstein's World System's theory from the 1960s onwards in debates on dependency, structuralism, and then in various forms of neo-Marxian analysis. These debates, however, were concerned primarily with analysis of dependent international economic relations and the nature of development. Poverty as a material condition and potential threat to internal stability of regimes was only an indirect concern of international relations through the traditional framework of balance of power politics, or as the consequence of unequal dependent economic relations in structuralist and neoMarxian perspectives.

In the post-Cold War era, the field of international relations has incorporated the issue of poverty in non-traditional ways in an attempt to understand the relationship between security, poverty, and development in the global political economy. ${ }^{3}$ Within the discipline, the emergence of "non-traditional security issues" represent an intellectual shift from the hegemonic cold war understanding of security. This shift can be partly attributed to the belief that the traditional security framework could not adequately incorporate problems such as economic dislocation, migration, human trafficking, political violence, refugees, environmental degradation, and the possibility of sustainable livelihoods into its analysis. ${ }^{4}$ This shift is also a reflection of the entry of normative, ethical, and moral discourses in the disciplines of international relations and security studies.

The end of the Cold War and dismantling of the former Soviet Union, combined with the inclusion of post-structural, postmodern, feminist, third world and critical perspectives into the studies of international relations have broadened not only the referent object of security, but introduced social relations, gender, and equality as legitimate topics for analysis. As William T. Tow and Russell Trood argue, the passing of the Cold War period as a historical benchmark "served as the backdrop for a more comprehensive exploration of ideas ... which was noteworthy less 
for the clarity of structural or systemic change, than for precipitating debate over an unprecedented array of complex issues previously subordinated by ideological competition". ${ }^{5}$ The field of international relations has responded to this challenge in a number of ways.

Efforts to broaden the remit of security included discussion of how to include economic security, environmental security, societal insecurities, drugs, and human rights (amongst others) into the wider security umbrella. ${ }^{6}$ The shift from state security to focus on societal security ${ }^{7}$ has been another trend which attempts to analyse how internal societal factors (migration, population, and identity) enrich our understanding of the complexity of security factors within the modern state without moving fundamentally from a state-centric framework. ${ }^{8}$

\section{Poverty and human security}

It is generally accepted that "development" issues such as poverty form an important part of the human security agenda. Poverty as a human condition, and the analysis of it, has been inextricably linked over the last fifty years to the study of "development". Different understandings of poverty developed alongside development theory and development economics. To unravel the various definitions of poverty, one can usually resort to paradigmatic assumptions. Definitions of poverty have often been connected to economic indicators and low-income levels; however alternative human-centred development approaches that emerged to counter these downplayed purely economic factors, instead stressed basic human needs and internal indicators. There has been an acknowledgement within the development studies community in recent years that poverty has many different dimensions embedded in the economic, social, and political structure that affect people's lives at the micro and macro levels.

Recent World Bank research, conducted in 1999, interviewed over 22,000 "poor" people in 23 different countries. The "Perspectives of the Poor" study illustrated that poverty means many different things to different people. It defined poverty as nine interrelated aspects of powerlessness and ill-being - namely: livelihoods and assets; places of the poor; the body; gender relations; social relations; security; institutions; organizations of the poor; and capabilities. Understanding how poverty is linked to social, economic, and political structures of a society and their connections with the global economy is increasingly complex.

The term "human security" became popularized with the publication of the United Nations Development Programme's (UNDP) 1994 Human Development Report. The UNDP report was an attempt to put the individual at the centre of development thinking and policy and argued that 
human security had four essential characteristics: that it was universal; that its component parts are interdependent; that human security is best assured through prevention; and that it is people-centred. Threats to human security were divided into seven main categories: economic, food, health, environmental, personal, community and political. ${ }^{9}$ The 1994 UNDP report was significant in that it represented the organization's intention to use human security as an organizing concept for it policies in the area of development economics, public health, and poverty alleviation. It was thus a major institutional acknowledgement of the intersection between concern of security and development.

The operationalization of the human security agenda in contemporary international politics, however, is under considerable debate. King and Murray, for example, found many problems when interviewing politicians and officials involved with foreign policy in countries who base their policy in part on human security ideals. Many officials expressed concerned "that there existed no widely accepted or coherent definition of human security and that there were considerable conceptual problems in relating human security, human development, and the development focus on poverty together with the articulation of their foreign policy". ${ }^{10}$ A major concern is that by including developmental aspects, including poverty, into the concept of human security, its analytical and policy utility are considerably weakened. ${ }^{11}$ Thus it is argued that a more narrow definition of human security, one which refers to certain types of threats or security problems, can provide more analytical and policy value. Furthermore, Mack argues against having one correct definition of human security on the grounds that the definition may be appropriate in one context, and inappropriate in others. ${ }^{12}$

Proponents of a broader definition of human security, on the other hand, argue that its scope to incorporate multi-faceted threats and risks to the individual represent the concept's strength. Furthermore, where the definition of human security is taken to mean the right to basic human needs, human dignity, and the right to participate meaningfully in the life of the community, the concept takes on another dimension, suggesting that the everyday (in)security of individuals is embedded within global social and economic structures, where the state is often the cause of human insecurity. ${ }^{13}$ The debate about how to reconcile these tensions is an ongoing one in the contemporary study of human security. ${ }^{14}$

We believe the non-traditional security framework opens up the further possibility of treating poverty as a security issue because the nontraditional security framework broadens the referent objects of security to include both the state and the non-state actors such as social groups and individual human beings. Under this framework, poverty is a security issue because poverty poses threats to individual economic, social, and 
physical well-being. The referent object of security becomes individual human beings. To put it differently, poverty is a human security issue. The inclusion of poverty as a human security issue at the individual level may allow international relations scholars to explore human security concerns, in relation to the state and the international system, in more sophisticated ways and to find solutions to address the issues of poverty.

\section{Models for understanding international collaboration on poverty alleviation}

Poverty may be a domestic condition, but it can have important international repercussion for three reasons. First of all, it has been documented that poverty, together with other mitigating factors, can breed social instability and conflict, which may be transported across borders. ${ }^{15}$ Second, as the 11 September terrorist attacks demonstrate, growing economic inequality within states and across borders may breed international instability. ${ }^{16}$ Third, from the humanitarian and moral perspective, the international community has the obligation to improve the social and economic well-being of the poor, and to narrow the income gap between the poor countries and the rich countries, even if poverty does not bring international instability. That poverty is an international issue demands an international solution to the problem. ${ }^{17}$ Thus, how different players at the global, domestic, and local levels interact with one another to tackle the problem of poverty has been an important subject of study in recent years.

There have been two models to study international collaboration in response to the issue of poverty. The first one focuses on international multilateral donor institutions as the centre of international collaboration to tackle poverty. The IGOs play the central role in poverty alleviation because of the overwhelming amount of resources and expertise that they possess. We refer to this as the IGO-centric model. The second approach focuses on the growing importance of civil society and NGOs as the driving force of international collaboration for poverty alleviation. We refer to it as the civil-society-driven model. The civil-society-driven model implicitly acknowledges the dominant role of the IGOs because of their superior financial strengths, but it stresses the essential role that the civil society plays in poverty-alleviation. This is because NGOs' approach to poverty alleviation is more effective because of their stress on the direct participation and empowerment of the recipients of economic assistance. Furthermore, civil society plays an indispensable role in poverty alleviation through international NGOs' pressure on major multilateral donors to divert more resources to poverty alleviation and to influence the approaches and methods IGOs adopt in poverty-alleviation projects. ${ }^{18}$ 
The two models share an important drawback which is that they often ignore the role of the state in poverty alleviation. The IGOs-centric model considers the state as either being co-opted by the IGOs or as being too weak to resist the power and programs of IGOs. They believe that the state's role in poverty alleviation is diminishing. Some even argue that the state is being influenced and coerced by neo-liberal economic imperatives in the global political economy. Instead of the state being the main vehicle for poverty alleviation, they see the state as becoming merely the political structure for the effective operation of capitalism. ${ }^{19}$ The civil-society-driven model rejects the role of the state in poverty alleviation because the state usually formulates economic policies that are informed by neoclassical economic theories, which are not only ineffective in tackling poverty, but may be responsible for worsening poverty.

While there is no question that IGOs and NGOs are playing an increasingly important role in poverty alleviation in the era of globalization, the state has not retreated into the background of world politics. Neo-realism's stress on world politics as state-centric may have ignored the impact of globalization. But as neo-liberalism and constructivism argue, the state has remained a major, if not dominant, player in world politics. IGOs such as the World Bank may have dominated small developing countries in the implementation of its structural adjustment programmes, but it may be more difficult for IGOs to dominate large developing countries like India and China in the implementation of poverty-alleviation projects. Nonetheless, it is also difficult for big developing countries to dominate IGOs because of the resources and power that IGOs control.

Therefore we postulate that IGOs and large developing countries may form some kind of partnership in tackling the poverty issues. Partnership is understood as a relationship between two or more independent players, with mutual influence on one another. We use the case study of China's collaboration with IGOs on poverty alleviation to illustrate how partnership between IGOs and the state can work effectively in povertyalleviation programmes. Our main argument is that China has formed close and effective partnerships with multilateral donor institutions such as the World Bank and the UNDP in the course of fighting poverty.

\section{China's partnership with IGOs on poverty alleviation}

The successful reform of China's economic system since the late 1970s has lifted a large number of people out of poverty. While China's economic modernization has entered a new phase of rapid economic devel- 
opment, poverty eradication has remained a major issue for China. In 1978, it was estimated that some 250 million rural people throughout the country still lived in poverty. By 1985, the number had decreased to 125 million as a result of rapid economic growth in rural China. Since the mid-1980s, the Chinese government has focused on poverty alleviation as an important part of national economic policy and provided an extensive range of financial support to rural areas to fight poverty. By the early 1990 s, this section of the population had dropped to 100 million, representing less than 10 per cent of the total rural population. This population has been concentrated in remote mountains, desert, and semi-arid lands in Southwest and Northwest China. These areas share some common features such as geographic isolation, difficulty of access, ecological degradation, low levels of education, lack of suitable drinking water, and unfavourable production and living conditions.

There are many different ways of measuring poverty. The most common, which is being used by the World Bank, is to compare actual per capita consumption of commodities and services against a standard of living chosen to represent the absolute poverty line. The World Bank calculated the monetary value of the absolute poverty line based on two components. The first component is the monetary value of a $2,150 \mathrm{kcal} /$ day food consumption basket considered essential to supply adequate nutrients for normal human functioning. The food basket usually comprises fixed quantities of grain, vegetable oil, vegetables, pork, and eggs. The second component of the poverty line is a sum of expenditures on food commodities and services based on the average expenditure pattern of the poor. ${ }^{20}$ While there have been different views about the measurements of poverty inside China, the Chinese official poverty line is derived from the World Bank's estimates. The Chinese measurement focuses on food intake supplemented by the adjustment of living costs. But the official poverty line also reflects compromises between the Chinese central government and local administrations. ${ }^{21}$ This is because different provinces in China propose to draw a different poverty line due to the differences in the level of economic development across the country. In 1978, the poverty line in rural China was set at 98 yuan/per capita. In 1985, the line was changed to 190 yuan per capita and to 275 yuan per capita in 1990, reflecting the upward movement of inflation. It was then set at an income of 500 yuan in rural China (about one-quarter of the national average rural income) in $1994 .^{22}$

Until the early 1990s, China had relied mostly on domestic resources to implement these poverty-alleviation policies. While China's encounter with multilateral donor institutions began in 1980 when China became a member of the World Bank, most of the World Bank's lending to China in the 1980s consisted of loans for building infrastructure such as high- 
ways and ports. This was partly because of the World Bank's lack of interest in supporting poverty-alleviation projects. The World Bank in the 1970s under the leadership of President Robert McNamara had focused on poverty alleviation as the main focus of its lending policy to promote economic development. Beginning in the early 1980s, partly due to the onset of the debt crisis in the Third World and partly due to the resurgence of neoclassical economic policies championed by Margaret Thatcher and Ronald Reagan, there emerged the so-called "Washington consensus" formulated by the Bretton Woods Institutions (the World Bank and IMF), which defined development narrowly as good economic performance. Good economic performance was in turn equated with liberalization, deregulation, and privatization. This consensus assigned markets a central role in promoting economic growth and allocating resources while relegating the state to the role of providing a marketfriendly policy framework. Based on this neoclassical liberal philosophy, much of the World Bank's lending to the third world in the 1980s took the form of adjustment loans (or policy-based loans) that were geared toward fostering free market economies and promoting private enterprises. ${ }^{23}$ Moreover, China was not open to foreign economic assistance focusing on poverty alleviation for political reasons.

There are two reasons to account for China's emerging partnership with IGOs in poverty alleviation. The first reason was the global IGOs' increasing attention to poverty alleviation. The second reason was China's changing policy toward foreign economic assistance for poverty alleviation. The following two sections discuss these two reasons in more detail.

\section{Global IGOs' increasing concern about poverty}

The World Bank's market-centric approach to development suffered from major shortcomings. As critics charged, while Bank lendings may have promoted economic growth, they also contributed to a growing income gap, social inequality, and environmental degradation in recipient countries. As discussed above, the fruits of economic growth in many cases did not trickle down to the underprivileged segments of societies as predicted by neoclassical economics.

Consequently, the market-centric approach to development has gradually given way to a more human-centred approach to development pioneered by the UNDP since early 1990s. In its first Human Development Report published in 1990, UNDP called the world's attention to the importance of human development, which was understood as enlarging the range of all people's choices and making development more equitable, democratic, and participatory. The eradication of poverty was an impor- 
tant component of this new approach. The 1994 UNDP report's focus on human security built on these ideas.

In 1994, UNDP developed the term "sustainable human development" of which eradicating poverty was a key component. The UNDP defined the term as

development that not only generates economic growth but also distributes its benefits equitably, that regenerates the environment rather than destroying it, that empowers people rather than marginalizing them. It gives priority to the poor, enlarging their choices and opportunities, and provides for their participation in decision affecting them. It is development that is pro-poor, pro-nature, pro-jobs, pro-women, and pro-children. ${ }^{24}$

Thus, to promote poverty alleviation, UNDP has linked the allocation of its resources with a recipient country's efforts to reduce poverty. UNDP funds are distributed to all countries under a formula that takes into account population size and per capita income, the quality of sustainable human development assistance to be provided, and the ability of the recipient country to utilize the assistance efficiently and effectively.

UNDP's drive for promoting human development has had a significant impact on the World Bank's approach to development. Starting in the early 1990s, the World Bank began to reintroduce poverty alleviation as a major part of its broad-based development strategy. The 1990 World Development Report on poverty issued by the World Bank committed the Bank to focus on eradicating human poverty. The Bank then linked the volume of its lending to a country with that country's efforts to reduce poverty. The 1992 World Development Report committed the Bank to promoting environmental protection and sustainability. Thus, the UNDP's concept of sustainable human development has come to be accepted by the World Bank as a major basis of its lending policy as it no longer sees economic growth, poverty alleviation, and environmental protection as mutually conflicting objectives. ${ }^{25}$

The increasing international attention to human poverty led to the holding of the World Summit on Social Development (WSSD) in Copenhagen, Denmark, in March 1995, with 117 heads of state and government and the representatives of 196 countries attending the conference. In that conference, poverty eradication was identified "as an ethical, social, political and economic imperative of human kind". ${ }^{26}$ Since the World Summit of 1995, UNDP has focused its efforts on helping to implement the objectives of the summit centring around the alleviation of absolute poverty. In 1995, UNDP's executive board made poverty eradication the organization's "overriding priority".

The World Summit on Social Development provided new momentum 
to national and international action for poverty eradication. By 1997 , more than 70 countries either had national poverty plans or had incorporated poverty eradication into broader plans for national development. Governments were also making new commitments at the international level. In 1996, the members of the OECD's Development Assistance Committee (DAC) adopted the ambitious goal of halving the world's people living in extreme poverty by $2015 .{ }^{27}$ The increasing international attention to sustainable human development is in stark contrast to the "Washington consensus" developed in the 1980s.

\section{China's receptiveness to international assistance for poverty alleviation}

The increasing attention paid by global IGOs to poverty alleviation coincided with China's changing policy toward foreign assistance for poverty alleviation. In 1994, China launched a far-reaching poverty reduction strategy named the 8-7 Plan. The objective of the plan is to eliminate extreme poverty among 80 million poor within seven years by raising per capita income to RMB 500 (in constant 1990 prices). The plan designated 592 counties located in inaccessible mountainous and semi-arid areas in the central and western parts of China to receive priority support. To achieve this goal, the government called for close cooperation between the central government, local governments, and communities to create suitable conditions for agricultural development. The government promoted investments in off-farm income-generating activities to improve rural infrastructure including roads, village electrification, and rural water supply; it also invested in basic social services, including education and health, with a view to reaching universal coverage by the year 2000 . To achieve this goal of the 8-7 plan, the government would allocate the annual funding of RMB 15 billion to the 8-7 plan, with obligatory local counterpart funds equivalent to between 30 and 50 per cent of the Poverty Fund allocation. The combined central and local government funds for poverty reduction amount to over RMB20 billion (equivalent to US $\$ 2.4$ billion) annually. ${ }^{28}$

In March 1995, Chinese Premier Li Peng attended the World Summit on Social Development and signed the Copenhagen Declaration and Program of Action, which indicated China's commitment to engage the international community in its endeavor for poverty alleviation. To prepare for the World Summit on Social Development in October 1994, China's State Planning Commission (SPC), together with UNDP and the UN Social Development Summit Preparatory Committee, sponsored the Beijing International Workshop on Social Development which conducted extensive bilateral dialogue on social development and poverty eradication. In the subsequent three years the Chinese government has held a number of important conferences on poverty alleviation, employment, 
education, and health. In particular, the Ninth Five-Year Plan for National Economic and Social Development and Outline of Long-Term Goals Through 2010, adopted at the National People's Congress session held in March 1996, set forth the overall goals for future social development, and discussed in detail the development orientation and policy measures regarding poverty eradication, labour employment, social security, education, and health. In February 1998, China's SPC and UNDP again co-sponsored an international workshop in Beijing on China's Social Development during the period of Economic Transition, which once again focused on poverty eradication.

During the 1980s only a small number of international organizations, mainly NGOs, were involved in working with poor farmers, typically supporting the provision of health and education services at the grassroot level. Some assistance by inter-governmental organizations (IGOs) was allowed to target the less affluent inland provinces, but usually the needs of the most disadvantaged parts of the population were not addressed. In the early 1990s, and especially after the announcement of the 8-7 plan, the Chinese government began to encourage international donors to work in the poorest counties with the opening-up of areas previously inaccessible to foreign visitors. ${ }^{29}$

Close cooperation on poverty alleviation is mutually beneficial for China and IGOs. On the one hand, IGOs such as the World Bank and UNDP have genuine institutional interests to get involved in poverty alleviation in China. These institutions see their operation in China as critical to maintaining their legitimacy as global institutions focusing on economic development in developing countries. As China is the largest developing country and accounts for one-fifth of humanity, the absence of the World Bank and UNDP in China would undermine these institutions' legitimacy and prestige as global institutions devoted to promoting economic development in developing countries. ${ }^{30}$

On the other hand, it is in China's national interest to engage IGOs in its endeavor to fight poverty. China needs the support of IGOs if it is to completely eradicate poverty in the near future. Understandably, IGOs provide indispensable resources and services to China. The importance of IGOs for China can be seen in two respects. First, IGOs provide important financial resources for poverty alleviation in China. In this regard, the World Bank has become the most important international organization involved in China's poverty alleviation. Since China rejoined the World Bank in May 1980, its relationship with the World Bank Group has expanded into a mature and significant partnership for development. By June 2000, the World Bank had committed to China more than US $\$ 34$ billion in loans for a total of 226 projects, making China's portfolio by far the largest in the Bank. World Bank-supported projects 
can be found in all the major sectors of the economy and in most of the provinces, municipalities, and autonomous regions across China. More than half of the total portfolio has gone to infrastructure building (transport, energy, industry, urban development). Agriculture, social sectors (health, education, social protection), environment, water supply and sanitation account for the remainder. All these projects have a direct or indirect impact on poverty alleviation. China is also one of the Bank's best performing member countries in terms of project implementation.

The World Bank has provided a number of major projects specifically geared towards poverty reduction in the poor, upland provinces in China. Moreover, the Bank has also provided China with projects to improve education and health care in these provinces. During the fiscal years 1991-1998, the bank lent about US\$2.1 billion (almost all of them IDA credits) for poverty reduction in agriculture, rural health, education, and rural water supply in the Northwest and Southwest regions of the country. In the 1998 fiscal year alone, the Bank provided about US\$885 million for rural development and health care programmes. ${ }^{31}$

For example, the Western Poverty Reduction Project (WPRP), which started in 1999, is designed to alleviate chronic poverty for the absolute poor living in remote and inaccessible villages of Gansu and Qinghai Provinces and Inner Mongolia Autonomous Region. For this project, the World Bank agreed to lend US $\$ 160$ million (including US $\$ 100$ million IDA credits), with a matching fund of US $\$ 174$ million provided by the Chinese government. The project would enable poor households in the target areas to raise their incomes through increasing grain and livestock production sufficient to meet their basic food and clothing needs, and, in many cases, generate marketable surplus to improve their living standards. Simultaneously, the project would also improve the poor households' access to health and education services. To achieve this objective, the project would provide financial support for environmentally sustainable cropping and livestock development, irrigation development, rural infrastructure including rural roads, rural water supply and village electrification, small-scale rural enterprises, voluntary resettlement (Qinghai), labour mobility, and maintaining basic education and health. ${ }^{32}$

Second, IGOs provide important policy and technical advice for China's poverty alleviation because IGOs have long been involved in poverty alleviation on a global scale and have accumulated significant experience that is directly relevant to China. An important form of international technical support to China is to provide alternative modalities of poverty alleviation. The growing popularity of micro-finance is a case in point. The growing international technical assistance in China has given IGOs a degree of influence on China's policy making with regard to poverty alleviation. 
UNDP's technical assistance to China through grants exemplifies the growing involvement of IGOs in China's poverty alleviation. Since 1981, UNDP has given technical assistance to China in four country programmes. Country programmes are frameworks of cooperation between UNDP and the Chinese government. Each country programme contains a number of sustainable human development projects jointly approved by UNDP and the Chinese government. The first country programme was implemented between 1981 and 1985. The second country programme was implemented between 1986 and 1990. The third country programme was during the period 1991 to 1995 . The fourth and the latest country programme covers the period between 1996 and 2000. UNDP's technical assistance to China has totalled some US\$700 million between 1981 and 2000. The fourth country programme, also called UNDP-China Country Cooperation Framework (CCF1), provides core resources of approximately US $\$ 100$ million, with supplementary cost sharing of about US $\$ 121$ million for a total of US\$221 million. ${ }^{33}$

The country programmes have been geared towards promoting sustainable human development in three broad areas: poverty eradication, environmental protection, and economic reform. The fourth programme is especially concentrated on poverty elimination in western provinces through enhancing food security, increasing income for poor families, introducing cleaner industrial and energy sector technologies and practices, and improving rural basic education for girls. The implementation of the fourth country programme has resulted in the establishment of a total of 14 community-based poverty-alleviation projects scattered around 48 counties in 4 autonomous regions and 11 provinces in China. These projects provide support for capacity building and training both at institutional and individual household levels to fight poverty. ${ }^{34}$

Likewise, in addition to financial assistance, the World Bank also provides non-financial services in the form of technical assistance, policy advice, and workshops and training to China. The current World Bank assistance programmes in China have given priority to improving public infrastructure, strengthening public sector management in terms of fiscal and monetary policies, and helping to develop the legal, institutional, and regulatory framework in the process of China's transition to the socialist market system, and promoting rural social and economic development. ${ }^{35}$

\section{How China has cooperated with IGOs}

Chinese law requires that IGOs' poverty projects are administered by a Chinese counterpart agency. Furthermore, most of IGOs' povertyalleviation projects include a significant proportion of Chinese cofunding, which can include the provision of construction materials or 
production inputs. Large projects may require counterpart funding at various levels down to the individual households, which may be asked to contribute labour or small amounts of cash. When local governments in poor areas have difficulty meeting such requirements, they occasionally resort to unconventional solutions, such as matching up contributions from different international donors.

IGOs have launched a variety of initiatives to reach the poor in inland China. Five distinct but sometimes overlapping types of approaches can be identified:

- Working directly with the poor to alleviate poverty by providing loans and credits to improve income-generating opportunities in the underdeveloped areas. A typical example is the use of micro-finance projects. This method offers small amount of credits with poor households to enable farmers to engage in sustainable agricultural or non-agricultural production or business activities. Many major donor agencies, including the World Bank and UNDP, and a large number of NGOs, have launched projects of this type in China.

- Promoting overall social and economic development in the poor areas by funding projects that may strengthen overall agricultural productivity or to rehabilitate or protect the environment in a community. The World Food Programme's work in China, combining agricultural improvements with food aid (Food for Work), illustrates this approach.

- Improving Social Services in Poor Provinces and Counties. For example, World Bank projects in health and education are targeted to the poorest provinces in Western China. UNICEF has been supporting the provision of basic services in hundreds of designated poor counties. Likewise, UNDP has sponsored a US\$6 million rural education programme for girls in North-western China.

- Providing small-scale direct grant assistance. This type of programme usually focuses on improving living standards in poor areas in one specific aspect, for example, poor people's access to clean drinking water, unsafe school buildings, and lack of income-generating skills. The Canada Fund and similar grant schemes administered by the Embassies of Australia, Japan, New Zealand and the United Kingdom, among others, are of this type.

- Supporting Research and Experimentation. International donors sometimes offer financial support for poverty-alleviation research and experimentation carried out by Chinese policy makers and researchers in government, academic institutions, and fledgling NGO-type groups, which may complement other approaches outlined above. ${ }^{36}$

The remaining section examines in more detail China's cooperation with two major intergovernmental organizations, UNDP and the World Bank, on poverty alleviation. 


\section{United Nations Development Programme (UNDP)}

The UNDP has worked closely with the Chinese governments at different levels throughout the implementation of the four country programmes. The Chinese Ministry for Foreign Trade and Economic Co-operation (MOFTEC) plays the role of the overall counterpart for the UNDP. MOFTEC's China International Centre for Economic and Technical Exchanges (CICETE) served as the window of contact for UNDP. UNDP enters an agreement with MOFTEC under which MOFTEC disburses grants and loans to the ministries, provincial governments, or other organizations involved in project implementation. Small direct assistance funds may be disbursed directly to local governments and non-profit organizations.

Given the lack of autonomous farmers' organizations at the grassroots levels, UNDP's poverty-alleviation projects need to co-operate with local governments. To facilitate the direct participation of the beneficiaries in the target areas, project offices may create, with government endorsement, community organizations such as rural development associations, agricultural producers' associations and semi-formal financial organizations.

To ensure the effective implementation of UNDP poverty-alleviation projects, UNDP often enters into partnership with foreign governments. In many cases, foreign governments may provide a matching fund to support UNDP's poverty-alleviation projects in China. For example, UNDP has sponsored an innovative project addressing urban poverty through self-employment of laid-off women workers in Tianjin City with a cost-sharing contribution from AusAID (Australian Agency for International Development). Likewise, UNDP sponsored a handicraft development for poverty alleviation in Qomolongma Nature Preserve in 1996. The budget for the project was estimated to be US\$520,000 including US $\$ 360,000$ cost sharing from the Finnish government. ${ }^{37}$

INGOs have also played an important role in the implementation of UNDP programmes in China. There are two ways by which INGOs participate in UNDP projects. The first type of involvement is to provide technical support for UNDP poverty-alleviation projects in China. For example, the Development International Desjardins (DID), a Canadianbased international non-profit organization was selected by the UNDP as the international technical service provider for a UNDP project. DID carried out a mission to review the current status of UNDP programmes in China and developed a comprehensive work plan to address the needs of county project offices for project management, particularly that of the micro-finance operation, and to provide policy recommendation papers on micro-finance in China. ${ }^{38}$ 
The second type of involvement by NGOs is to play an advisory role in the implementation of UNDP projects. INGOs may exert some influence on the advisory board specifically created to implement UNDP projects. For example, under a UNDP project entitled "Support to the UNDP Poverty Alleviation Programme in China", which was geared to improve the implementation of the ongoing UNDP-assisted poverty-alleviation projects in China and to promote the replication of UNDP povertyalleviation projects approach elsewhere in the country, an advisory board was created with the participation of various key national and international organizations for poverty alleviation (such as the State Council's poverty-alleviation office, the Agricultural Bank of China, People's Bank of China, the MOFTEC, the World Bank, and the Asian Development Bank), to promote dialogue and information exchange at the policy level for the advancement of poverty alleviation in China. The Ford Foundation was among the NGOs that were members of the advisory board. One of the key issues often discussed by the board was the promotion of cooperation between NGOs and national and international donor agencies. ${ }^{39}$

\section{The World Bank}

The World Bank has formed partnerships with the Chinese government at various administrative levels in the preparation and implementation of World Bank projects in China. In the preparatory stage, the World Bank deals with its counterpart in China, which is the International Department of the Ministry of Finance. The International Department identifies projects that are in line with national poverty-alleviation strategies, prepares operational strategies for projects in accordance with World Bank guidelines, negotiates loans and credits for specific projects with the World Bank, and finally signs the agreements with the World Bank for the support of projects.

In the implementation stages, the World Bank has worked closely with its Chinese partners at different levels to ensure the effective implementation of its projects. At the national level, the State Council's Leading Group for Poverty Reduction (LGPR) and its Secretariat, the Foreign Capital Management Centre (FCPMC), are the highest bodies in charge of coordinating the Chinese government's 8-7 Plan. The FCPMC has been involved in the preparation of World Bank projects and has been in charge of the overall supervision and quality control of World Bank projects. At the provincial level, there is a Provincial Poverty Leading Group (PPLG) in every province which is in charge of supervising all poverty-alleviation projects in its province. A provincial deputy governor usually heads the group. The PPLG comprises provincial functional de- 
partments and agencies, including the economic planning commission, the finance bureau, the industrial bureau, the agricultural bureau, and other relevant bureaus, and it approves annual work plans and resource allocations to nationally designated poor counties and ensures the coordination of line agencies. Each PPLG has a Poverty Alleviation and Development Office (PADO) serving as its Secretariat. With assistance from line agencies, PADOs are responsible for the execution of targeted provincial poverty reduction operations, and they liaise with the LGPR. When World Bank lending is involved, the PADO usually establishes a World Bank Project Management Office (PMO) with technical staff recruited from the functional departments to oversee directly the operation and coordination of World Bank projects in its own province. PMOs sign service agreements with the line agencies for specific project-related tasks and maintain consolidated county project accounts for annual audits. At the county level, County Poverty Leading Groups (CPLG), comprising line agencies and chaired by a county magistrate, are established to oversee the poverty-reduction programme. The CPLG delegates the authority to administer and coordinate World Bank projects in the county to the County Project Management Office (CPMO), which is usually responsible for implementing World Bank projects, coordinating the activities of the functional agencies, providing technical support to township work stations and village committees, monitoring physical and financial progress, and reporting to PADOs. The CPMOs authorize local contracts for the execution of projects with township governments and villages. When World Bank projects involve resettlement, the World Bank works with the county government to establish a Resettlement Office to carry out resettlement plans and to select and transfer the settlers. At the village level, World Bank project beneficiaries are usually organized by Village Implementation Units (VIUs) to participate in all aspects of the projects. The VIUs, with technical support on new agricultural practices and technologies from Township Work Stations (TWS), are responsible for project implementation at the village level. The VIUs usually prepare a set of eligible investments to the villagers to choose from for funding. The VIUs also arrange the delivery and distribution of agricultural input packages to the project villagers. Depending on the nature of projects, villagers may be mobilized for infrastructure works.

The partnership modality between the World Bank and the Chinese government at various levels differs starkly from the existing Chinese organizational modality, which centres around the Bank of Agriculture and the Finance Bureau at various levels, for approving work projects and contributing the bulk of loans and credits. The existing Chinese modality undercuts the power and authority of the PPLG and CPLG and under- 
mines the coordination between relevant functional bureaux and lending institutions. In contrast, the partnership modality between the World Bank reduces the power of Chinese banks by centralizing the approval and supervision process of poverty projects under the PPLG and CPLG and thus enhances the coordination and effectiveness of poverty projects. ${ }^{40}$

Increasingly, the World Bank has also worked with Chinese NGOs in implementing projects in the country. Until recently, NGOs have played very little role in the implementation of World Bank projects. In response to the criticisms of NGOs, the Bank has made an effort to interact closely with civil society groups on a variety of levels. NGOs are involved in a broad range of the Bank's economic and sector work activities, through input into poverty assessments, national environmental action plans, and other key analytical tools. NGO involvement is also rising in national-level debates in borrowing countries on policy issues such as gender, the environment, and economic development. ${ }^{41}$ Moreover, NGOs are often the indirect recipients of proceeds from World Bank loans and credits that a borrowing government then channels to them as either grants or loans. Indeed, an increasing portion of the Bank's investment lending is channelled in this way. According to a 1999 survey of World Bank-assisted projects in seven countries, nearly US\$900 million was approved to support activities involving NGOs and communitybased organizations between the fiscal years 1985 and 1997; the projects reported on accounted for 13 per cent of all World Bank-supported projects with provision for NGO involvement approved during that same time-frame.

Chinese NGOs are involved in the World Bank projects at the operational level. For example, in the Shanxi Poverty Reduction Project, an IDA credit is funding the programmes managed by the local women's federations to support rural women in income-generating enterprises and activities such as skill training in handicrafts, rabbit, poultry and pig production and a range of sideline activities. In three large irrigation investment projects covering eight provinces, the Bank has supported development of pilot Self-Financing Irrigation and Drainage Districts (SIDDs) to encourage the participation of Chinese civil society. SIDDs comprise Water Users Associations (WUAs) established by farmers to operate and maintain the lower levels of the irrigation systems, and Water Supply Corporations (WSCs) which operate and maintain the main canal systems and diversion works and sell water to WUAs on a volumetric basis. The SIDD reforms increase the role and responsibility of farmers in managing their irrigation affairs, while reducing the burden and role of government in irrigation management and financing. The Bank also invites Chinese and international NGOs to consultation meetings on its projects. 


\section{Evaluating China's partnership with IGOs}

Despite China's potential loss of control on poverty projects supported by IGOs, the cooperation between China and IGOs in poverty alleviation has proved very successful by any standard. The success of China's cooperation with IGOs can be seen in two respects. First, IGOs' involvement in China's poverty alleviation has had an important influence on China's approach to poverty alleviation. Until the mid-1980s, the Chinese government mainly relied on social welfare programmes for the poor households to tackle poverty in rural areas such as "fiveGuarantee" households programmes (guaranteeing in rural areas food, clothing, housing, medical care for the aged, sick, and disabled, and burial for the poor) and other income maintenance programmes (such as providing direct payments in form of grain, cash and work points). Other assistance programmes are also used, such as subsidized loans and grants to promote rural collective enterprises under the condition that a certain number of poor people are employed. ${ }^{42}$

Since the mid-1980s, the Chinese government has begun to tackle poverty and development in a planned and systematic manner. ${ }^{43}$ Instead of relying on the previous approaches of delivering relief goods and funds through the social welfare system and of increasing investment in townships and village enterprises and infrastructure building, the government has come to stress the strengthening of farmers' personal empowerment and capacity building in poverty alleviation and economic development through making loans and credits and training techniques directly available to the poor for enhancing agricultural productivity, improving livestock breeding, and building small-scale processing industries. The 8-7 plan adopted in 1994 established the rural poor household as the focal point for designing poverty-reduction interventions, and set goals for moving households out of poverty. ${ }^{44}$ China's increasing emphasis on households coincides with the international trend towards capacity building and individual empowerment in poverty alleviation. This new Chinese approach can be partly attributed to increasing Chinese official contacts with IGOs and INGOs and the latter's influence on the Chinese government's policy making on poverty alleviation.

The adoption of micro-finance as a poverty-alleviation technique on an experimental basis after 1996 exemplified the positive contribution that international organizations have made to China's poverty alleviation. Micro-finance was first introduced into China as a novel model for poverty alleviation on an experimental basis by Chinese researchers at the Chinese Academy of Social Sciences (CASS) in 1994. Due to its initial success, many IGOs and NGOs have introduced a variety of microfinance models into China. Moreover, many provincial governments have 
also turned to micro-finance as a basis to design poverty-alleviation projects. With the blessing of the National Office of the Leading Group for Economic Development in Poor Areas, micro-finance has reached an increasing number of rural villages. China has become the first country in the world where the government itself has sponsored a large-scale microfinance programme. ${ }^{45}$

Second, the involvement of IGOs in China's poverty alleviation has enhanced the overall performance of China's efforts to fight poverty. The implementation of internationally supported poverty projects in China has strengthened its capacity to fight poverty, enabled it to learn about successful international experience of poverty reduction, and helped it to lift a large number of people out of poverty. The overall performance of the 8-7 Plan has been monumental. As a result of the Plan, the number of the poor has fallen from 80 million in 1994 to about 58 million in 1997. The contribution made by international organizations in this impressive endeavour cannot be ignored. Two major World Bank projects alone, the South-West and Qin-Ba projects, which were designed in accordance with China's 8-7 plan, have promised to lift out of poverty some 10 million poor people in the nine provinces concerned. Another case in point is the Training Programme for Cadres in Poor Areas initiated by the United Nations Development Programme (UNDP) in co-operation with the State Council Poverty Alleviation Office, which has trained several thousand government staff and enterprise managers in poor counties, and initiated a training network dedicated to poverty alleviation. This network has been playing a significant part in the implementation of the National 8-7 Poverty Reduction Plan.

\section{Conclusion}

Development partnerships between the state and IGOs represent the ongoing importance of the Chinese government in the development agenda at the macro level, and in implementing poverty-alleviation programmes with various actors at the grassroots level. Poverty alleviation programmes implemented through partnership with such actors are an important intersection between the goals of human security and human development. How human security and poverty alleviation can be effectively articulated and negotiated in the foreign policy of states, and within the domestic development agenda of states, is a significant challenge. We believe that the inclusion of poverty as a human security issue at the individual level does allow international relations scholars to explore human security concerns, in relation to the state and the international system, in more sophisticated ways. 
We have argued that effective collaboration between the state and multilateral donor organizations (IGOs) is central in the global war against poverty, and have tried to illustrate this argument by examining the partnership between the Chinese government and global IGOs in poverty-alleviation programmes in China. We are not suggesting that NGOs are not important in poverty alleviation. It is fair to say that a growing number of social organizations and Chinese NGOs are asserting themselves within the parameters of the law, and their existence serves to impact on government thinking and policy towards the relationship with IOs, INGOs, and the third sector in general. But NGOs in China are not playing the central role in poverty alleviation because civil society as understood in Western terms is not yet well developed in China.

In future research, more attention needs to be paid to developing a greater consensus on the definition and utility of human security, and developing theoretical models and empirical data on the points of connection between traditional and non-traditional security, such that useful policy prescriptions may emerge.

\section{Notes}

1. Amartya Sen (1999) Development as Freedom, New York: Anchor Books.

2. Harry Truman, inaugural address as President of the United States, 20 January 1949 quoted in Arturo Escobar (1995) Encountering Development. The Making and Unmaking of the Third World, Princeton, New Jersey: Princeton University Press, p. 3.

3. Julian Saurin (1996) "Globalisation, Poverty and the Promises of Modernity", Millennium: Journal of International Studies 25(3): 657-680; Craig N. Murphy and Roger Tooze( 1996) "The Epistemology of Poverty and the Poverty of Epistemology in IPE: Mystery, Blindness, and Invisibility", Millennium: Journal of International Studies 25(3): 681-707; Mary Durfee and James N. Rosenau (1996) "Playing Catch-Up: International Relations Theory and Poverty", Millennium: Journal of International Studies 25(3): 521-545; Andrew Hurrell and Ngaire Woods (1995) "Globalisation and Inequality", Millennium: Journal of International Studies 24(3): 447-470.

4. Simon Dalby (1997) "Contesting an Essential Concept: Reading the Dilemmas in Contemporary Security Discourse", in Keith Krause and Michael C. Williams, eds., Critical Security Studies, London: Macmillan, p. 5.

5. William T. Tow and Russell Trood (2000) "Linkages between traditional security and human security", in William Tow, Ramesh Thakur, and In-Taek Hyun, eds., Asia's Emerging Regional Order. Reconciling Traditional and Human Security. Tokyo: United Nations University Press.

6. Dalby, op. cit., p. 6. Examples in this group of literature include, Daniel Deudney (1990) "The Case Against Linking Environmental Degradation and National Security", Millennium: Journal of International Studies 19(3): 461-476; Dalby, Simon (1991) "Ecopolitical Discourse: Security After the Cold War?", paper presented at the International Geographical Union Commission on the World Political Map Meeting, Prague, August 1991; T. Homer-Dixon (1994) "Environmental scarcities and violent conflict: evidence from cases", International Security 19(1): 5-40. 
7. Ole Waever, Pierre Lemaitre, and Elzbieta Tromer, eds. (1990) European Polyphony: Perspectives beyond East West Confrontation, London: Macmillan; Ole Waever, Barry Buzan, Morten Kelstrup, and Pierre Lemaitre (1993) Identity, Migration and the New Security Agenda in Europe, London: Pinter; Barry Buzan, Morten Kelstrup, Pierre Lemaitre, Elzbieta Tromer, and Ole Waever (1990) The European Security Order Recast: Scenarios for the Post-Cold War Era, London: Pinter; Barry Buzan, Ole Waever, and Jaap de Wilde (1998) Security. A New Framework for Analysis, Lynne Rienner: Boulder Co. and London.

8. Bill McSweeney (1996) "Identity and Security: Buzan and the Copenhagen School", Review of International Studies 22: 81-93.

9. United Nations Development Program (UNDP) (1994) Human Development Report 1994. New York: Oxford University Press.

10. Gary King and Christopher Murray (2001) "Rethinking Human Security", Political Science Quarterly 116(4): 585-610 (591-592).

11. See, for example, the argument forwarded by Nicholas Thomas and William T. Tow (2002) "The Utility of Human Security: Sovereignty and Humanitarian Intervention", Security Dialogue 33(2): 177-192.

12. Andrew Mack (2002) "Report on the Feasibility of Creating an Annual Human Security Report", Program on Humanitarian Policy and Conflict Research, Harvard University, February 2002. http://www.hsph.Harvard.edu/hpcr/FeasibilityReport.pdf

13. See, for example, Caroline Thomas and Peter Wilkin, eds. (1999) Globalisation, Human Security and the African Experience, London: Lynne Rienner.

14. See, for example, Thomas and Tow, op. cit., and the related rejoinder and reply, Alex J. Bellamy and Matt McDonald (2002) "The Utility of Human Security: Which Humans? What Security? A Reply to Thomas and Tow”, Security Dialogue 33(3): 373-377; Thomas and Tow (2002) "Gaining Security by Trashing the State? A reply to Bellamy and McDonald”, Security Dialogue 33(3): 379-382.

15. For recent literature on the connection between poverty and conflict, see L. Sigelman and M. Simpson (1977) "A Cross-National test of the Linkage between Economic Inequality and Political Violence", Journal of Conflict Resolution 21: 105-128; M.I. Lichbach (1989) "An Evaluation of 'Does Economic Inequality Breed Political Conflict?' Studies", World Politics 41(July): 431-470; G.H. Peiris (1999) "Poverty, Development and Conflict in South Asia", paper presented at the Global Development Conference, Bonn, Germany, 5-8 December 1999; Ibrhim A. Elbadawi (2001) "The Economics of Civil Wars and Post-Conflict Recovery", paper presented at the DECRG/University of California, Irvine Conference on "Civil Wars and Post-Conflict Transitions", 1819 May 2001; Paul Collier and Anke Hoeffler (2001) "Greed and Grievance in Civil War", World Bank Program on the Economics of Civil War, Crime and Violence. http:// www.worldbank.org/research/conflict/papers

16. Not long after the terror attacks on the US, World Bank President, James D. Wolfensohn noted in a speech that "poverty ... does not itself necessarily lead to violence, but can provide a breeding ground for the ideas and actions of those who promote conflict and terror". Speech to Woodrow Wilson International Centre, 6 March 2002. http://wwics.si.edu/NEWS/speeches/wolfensohn.htm

17. Amartya Sen (1981) Poverty and Famines: An Essay on Entitlement and Deprivation, New York: Oxford University Press; Dharam Ghai (2001) "Human Solidarity and World Poverty", Global Governance 7(3) July-September; Jeffrey Sachs (1999) "Helping the World's Poorest", Economist, 14 August, p. 17; Laura D. Tyson (2001) "It's Time to Step Up the Global War on Poverty", Business Week, 3 December, p. 26.

18. For the IGOs-centric model, see Paul J. Nelson (1996) "Internationalising Economic and Environment Policy: Transnational NGO Networks and the World Bank's Expanding Influence", Millennium: Journal of International Studies 25(3): 605-633. For 
the civil society-driven model, see Kendall W. Stiles (1998) "Civil Society Empowerment and Multilateral Donors: International Institutions and New International Norms", Global Governance 4: 199-216.

19. A good example of this argument is Mustapha Kamal Pasha (1996) "Globalisation and Poverty in South Asia", Millennium: Journal of International Studies 25(3): 635-656.

20. World Bank (1992) China: Strategies for Reducing Poverty in the 1990s, World Bank: Washington, D.C., pp. 21-24.

21. UNDP (1997) The China Human Development Report, New York: Oxford University Press, pp. 88-89.

22. World Bank (1992) China: Strategies for Reducing Poverty in the 1990s, World Bank: Washington, D.C., p. ix.

23. Marc Williams (1994) International Economic Organizations and the Third World, New York: Harvester Wheatsheaf, pp. 118-119.

24. UNDP (1998) Overcoming Human Poverty: UNDP Poverty Report 1998, New York: UNDP, p. 18.

25. K. Sarar Lateef (1996) “The World Bank: Its First Half Century”, in C. Roe Goddard, John T. Passe-Smith, and John G. Conklin, eds., International Political Economy: StateMarket Relations in the Changing Global Order, Boulder: Lynn Rienner Publishers, p. 299; Williams, International Economic Organizations and the Third World, p. 119.

26. UNDP Poverty Report 1997.

27. UNDP Poverty Report 1998, pp. 14, 18.

28. Ruo Gang, ed. (2000) Zhong Guo Cai Zheng Fu Ping Wen Ti Yang Jiu (The Study of China's Financial Policy in Poverty-Alleviation), Beijing: Zhong Guo Cai Zheng Jin Ji Chu Ban She, chap. 3; Wang Lian and Chui Jian, eds. (1996) Zhong Guo de Fu Pin Zheng Ce Yu Zou Shi (The Trends in China's Policy Toward Poverty-Alleviation), Guangzhou: Ji Nan Da Xue Chu Ban She, chapters 1 and 2.

29. David Zweig (2000) “The Open Door and Foreign Donors: Can China Keep Control?", paper presented at the Fifty-second Annual Meeting of the Association for Asian Studies, San Diego, CA, 9 March.

30. Ibid. Zweig makes the argument that multilateral agencies like the World Bank and UN agencies could not argue they were global organizations if they did not have a presence in China. He points out that "being involved with China offered donors a "China strategy' for advancing organizational or individual prestige, influence and resources . . . and increased budgets and consulting opportunities".

31. http://www.worldbank.org.cn/English/Projects/hrdvpt.shtm.

32. http://www.worldbank.org.cn/english/services/pid/western.htm

33. See http://www.unchina/org/undp/ccp/html/cp1.html, and http://www.unchina.org/undp/ $\mathrm{ccp} / \mathrm{html} / \mathrm{cp} 4 . \mathrm{html}$.

34. http://www.unchina.org/undp/poverty/cpr96201.htm.

35. Http://www.worldbank.org.cn/English/IBRD/IBRDOverview.shtm.

36. Http://www.unchina.org/undp/press/html/support.html.

37. http://www/unchina.org/undp/poverty/cpr96221.htm.

38. http://www.unchina.org/undp/poverty/cpr96201.htm.

39. For a more detailed discussion on the role of NGOs and other "social organizations" in China, see Tony Saich (2000) "Negotiating the State: The Development of Social Organisations in China", The China Quarterly 161(March): 124-141.

40. He Ping (1997) "Xian Ji Fu Ping Gong Jian Xian Mu Zhong Ti Gui Hua de Zhu Zhi yu Shi Si" (The Implementation and Organization of the Poverty Alleviation Policy Planning at the County Level) in Gao Hong Bing, ed., Fu Ping Zheng Ce Yu Gui Hua (Policy and Planning for Poverty Alleviation), Beijing: Jin Ji Ke Xue Chu Ban She, pp. 146-168.

41. For a further discussion on the ability of NGOs to influence the policies of the World 
Bank, see Jane G. Covey (1998) "Is Critical Cooperation Possible? Influencing the World Bank through Operational Collaboration and Policy Dialogue", in Jonathan A. Fox and L. David Brown, eds., The Struggle for Accountability, Cambridge, Massachusetts: MIT Press.

42. World Bank (1992) China: Strategies for Reducing Poverty in the 1990s, Washington, D.C., World Bank, pp. 109-113.

43. For a recent analysis of the role of public spending in China's economic growth and poverty alleviation policies from 1978 to 1997, see Shenggen Fan, Linxiu Zhang and Xiobo Zhang (2000) "How does public spending affect growth and poverty? The experience of China", paper submitted to Second Annual Global Development Network Conference, Tokyo, Japan, 11-13 December.

44. Ruo, Zhong Guo Cai Zheng Fu Ping Wen Ti Yang Jiu, chapter 3; Wang and Chui, Zhong Guo de Fu Pin Zheng Ce Yu Zou Shi, chapter 2.

45. Wang Jia Ju (1997) “Guo Nei Xiao Er Xin Dai Fu Pin Xiang Mu Jin Yen An Li (The Cases of China's Microfinance in Poverty Alleviation)," in Gao Hong Bing, ed., Fu Ping Zheng Ce Yu Gui Hua (Policy and Planning for Poverty Alleviation), Beijing: Jin Ji Ke Xue Chu Ban She, pp.146-168; Albert Park, and Changqing Ren (2001 "Microfinance with Chinese Characteristics," World Development 29(1): 39-62. 
Part II

Governance 



\section{4}

Security and governance in
South Asia: Their linkages

P.R. Chari

South Asia is noteworthy for examples of poor governance. Scarce resources are inefficiently deployed or frittered away, government administrations are becoming increasingly divided on ethnic and sectarian lines, law enforcement is arbitrary and political leadership is inadequate. This situation derives largely from the lack of participatory government accompanied by a rapid erosion of government effectiveness. Greater transparency, access to information and oversight mechanisms to regulate the functioning of the state's machinery is fundamental to reversing this desperate situation. In their absence a "we-they" syndrome will become increasingly entrenched between the governing elite and the governed masses with the bureaucracy becoming the masters rather than the servants of the people. This chapter will describe the linkages between human security and governance in South Asia, in particular focusing on the negative impacts of bad governance. It argues that radical reform in governance across the region is essential but there is a major obstacle: how can the state reform itself if the state is a party to its misgovernance and has a vested interest in perpetuating misgovernance? The conclusion is that reform would only be possible if the people assert themselves and demand transparency, representation, and accountability. 


\section{Linking security and governance}

There is little policy coherence in South Asia in terms of recognizing an overall conception of national security and in relating national security to human security. There is barely even a debate about the place of good governance in managing the state in South Asia. Not surprisingly, there is little progress in reconciling the sometimes opposing needs of national and human security. Ultimately, hard political decisions need to be taken from a budgetary perspective, appreciating the scarcity of resources, the political issues embedded in their allocation and the difficulties of additional revenue mobilization, and the regional security sensitivities that exist.

The pursuit of dharma - one's duty in life as a virtuous person - provides an especially indigenous perspective to this issue. Ethical and moral principles in statecraft and in life lay the foundations of dharma. "The aim is social welfare, not the welfare of a particular group only but of the whole world, for 'the entire world of mortals is a self-dependent organism." " Yet dharma itself is relative and depends on the times and the conditions prevailing, apart from some basic principles, such as adherence to truth and non-violence. It would overstate the case to suggest that a unique theory of governance applies to South Asia as opposed to Western concepts. The essential question is "whether a body of universally applicable principles could be found to assess the governance function, and whether such a body of principles could be assembled with enough 'conceptual integrity' and 'clarity' to be accurately called a model or paradigm." 2

In truth, a regional perspective is not visible in any of the South Asian countries since the linkage between security and good governance has rarely been recognized. Neither has it been appreciated that security policy goes beyond the military, paramilitary forces, police, and intelligence agencies. National security management must include the judiciary, media, civil society, and business interests. An important duty has also to be performed by oversight mechanisms, whether established by parliamentary or constitutional authority, to ensure that the rule of law is not infringed: this is essential for the credibility and integrity of the governance processes and the management of national security.

The nexus between security and governance in South Asia is critical to the region. Nevertheless, a caveat needs mentioning here: overstretching the concept of security could eviscerate it of all meaning. As perceptively noted: "Once anything that generates anxiety or threatens the quality of life in some respect becomes labeled a 'security problem,' the field risks losing all focus. Such an agenda is conceivably rich, and is certainly inclusive, but can also be off-puttingly vague." ${ }^{3}$ This problem becomes 
acute if a central place is accorded to ensuring human security, apart from state security, and assessing the adequacy of the governance processes to ensure its provision. One way out of this difficulty is to review the direct and indirect threats to human security and classify them according to their visibility and immediacy. ${ }^{4}$ An element of discretion and uncertainty would always persist, but this methodology is useful to differentiate between the threats to human security that are remediable by the state and those that could yield to societal action. Thus a reconceptualization of the very concept of national security in South Asia is required by restricting the ambit of security to what threatens the state and human lives: this would include, apart from the military, non-military, and nontraditional threats identifiable, human security, and others like states failing or becoming totalitarian.

A similar conceptual overstretch would occur by extending the meaning of governance to embrace all aspects of societal activity. Clearly, there are some aspects of humane governance (like women's empowerment) that require social engineering: this lies partly in the sphere of state action, and partly in the area of social reform. Expectations in regard to governance must, therefore, be tempered with a pragmatic understanding of what is remediable by the state, and what lies in the domain of civil society. The state cannot be wished away in matters relating to humane governance. Although the nation-state concept is believed to be the source of many of its problems like the integration of minorities, there is no solution possible to the quandary as to how it might be disinvented. Moreover, many issues relating to humane governance like promoting literacy and providing basic health cannot be left entirely to private effort and requires the intercession of the state.

\section{The crisis of governance}

The inadequacy of governance processes constitutes a major threat to the security of the states and people of South Asia. The common causes underlying this crisis of governance are the decay of political parties and democratic institutions; the indifference of the ruling elite to common welfare needs; resistance to devolution and decentralization of powers to the people; difficulties with minority populations; irregularities of electoral processes; and the nexus between criminals and corrupt bureaucrats, politicians, and businessmen. The crisis of governance in South Asia exists in all its countries: the difference is only one of scale, the problems of the administrative system underlies state and human insecurity in the region. The ruling elites are largely responsible for this parlous state of affairs, as they are impelled by no higher motive for seeking 
power than personal aggrandizement; hence, the imperative need for greater democratization of the polity. The paradox is that whilst all the countries of South Asia with the present exception of Pakistan have democratic governments, their governance is not truly democratic. Except for India and Sri Lanka, democracy has not set down strong roots in the region. No doubt, elections are relatively free and fair; participatory politics and support to those elected also exists. But if the South Asian countries were judged by their adherence to the standards of liberal democracy "marked not only by free and fair elections, but also by the rule of law, a separation of powers, and the protection of basic liberties of speech, assembly, religion, and property", ${ }^{5}$ they could only qualify as indifferently practising democracies.

The crisis of governance is manifested by pervasive nepotism and corruption; misappropriation of state funds for personal or familial or sectarian purposes; absence of transparency and accountability in public administration; lack of respect for the rule of law and ethical behaviour in public life; and a reluctance to delegate administrative or financial powers to grass-roots organizations. This situation exists in all the South Asian countries, which is likely to deteriorate when burgeoning globalization spreads its tentacles into the region; its rentier classes will ensure greater public malfeasance taking place with a consequent diminution of security in its several dimensions. The continuing feudal character of South Asian society lies at the heart of this problem: the trappings of modernization have occurred over the last half century, but the core values and mental attitudes of its leadership remain firmly embedded in the past. For example, the manner in which the Indian middle class, expected to provide leadership to the country, acquiesced in the emergency imposed by Indira Gandhi in the mid-1970s exposed its pusillanimity at one level, but also underlined its inherent authoritarian impulses. Consequently, to expect the favoured upper and middle classes to be altruistic and usher in true modernization is unrealistic. To put it bluntly, the Indian middle class has no desire to alter the pre-modern attitude that exists in India when it comes to relations between people. In fact, they have a lot to lose and nothing substantial to gain should modernity come about. ${ }^{6}$

This is equally applicable to other South Asian nations. Feudal mores inform the region's ruling classes, which explains why the military aspects of security find greater resonance in them. It also predisposes them to view concepts like human security and humane governance with deep scepticism. The inadequacy, however, of a military approach to national security in South Asia is becoming clearer for at least four reasons that derive from the seminal changes that have occurred in international security regimes.

First, the locus of conflict has shifted from the external to the internal 
sphere, with non-military and non-traditional threats to security acquiring greater salience. They include such threats to national security as cross-border movements of population; ethno-political, socio-economic, and communal-religious politics; terrorism, with its linkages to moneylaundering operations and drugs/arms smuggling; environmental degradation; chaotic urbanization; and so on. ${ }^{7}$

These non-military and non-traditional sources of insecurity could spark off widespread social conflict, but have not received much academic or official attention. The shift in emphasis from the military to the non-military paradigm of security is important, since the focus changes from security through armaments to security through human development and from territorial security to food, employment and environmental security. The fundamental components of human security - the security of people against threats to life, health, livelihood, personal safety, and human dignity - can be put at risk by external aggression, but also by factors within a country. ${ }^{8}$

Second, a new relevance has been acquired by transnational sources of conflict in South Asia; they transcend national boundaries and constitute major threats to national security. They include, apart from non-military and non-traditional threats, cross-border threats to security like the proliferation of light weapons, explosives, and mines that are closely linked to the global trade in arms and drugs, international terrorism, and money laundering. The Cold War witnessed arms and drugs smuggling, besides support to religious terrorism, becoming instruments of state policy; this virus has spread quickly through the region. National governments have a limited capacity to deal with this range of security threats, highlighting the need for regional and international cooperation to mitigate them.

Third, a new conceptualization of national security has occurred. Human security or the security of the individual is gaining increasing recognition, with the focus shifting from "the protection of territorial integrity and political sovereignty from external aggression ... to include people's security". ${ }^{9}$ Poverty and deprivation exacerbate the problem of human security in South Asia. The dismal statistics relating to infant mortality, illiteracy, population growth, and gender discrimination are too well known to bear reiteration. They reveal the limited access of the people to food security, basic health, and educational facilities. Unfortunately, the military security fixation of the regional elite swallows scarce resources for military, not human, security. It would become increasingly difficult, however, for the regional governments to ignore the rising expectations of their people for a better quality of life with the passage of time. The electronic media and the revolution in information technology will ensure that their aspirations will strengthen, generate frustration, and incite violence. 
Fourth, Cold War dynamics had also informed the national security decision-making elite in South Asia, with the competing East-West blocs using arms transfers to equip their client states against external and internal threats. Their ruling elite developed a vested interest in reinforcing the centrality of the state and appropriating its powers. Wisdom dictates that plural societies in a democratic framework be governed by decentralizing and circumscribing the powers of the state. The grant of a larger measure of autonomy to minority and ethnic populations would protect them from the tyranny of the majority and knit together the state more firmly than by deploying military force. However, the natural inclination of governments in South Asia is to use force against signs of dissent in the body politic rather than introspect on its causes and the failures of governance that they portend.

Thus, difficult choices confront the state in mediating between military and non-military security and providing for human security when resources are scarce and need apportionment between competing demands. National security should obviously be assured from external and internal threats, but so must human security by strengthening the social and economic sectors of the economy. Instead of confronting these hard choices, the tendency of South Asian governments has been to deflect attention from their inadequacies by externalizing security threats and exaggerating the malevolence of their neighbours in exacerbating them. In practice, however, the relative weights to be accorded to the external and internal components of national security would vary from country to country. The external, including nuclear, aspects of military security are important for India and Pakistan, although the internal aspects of security have acquired greater attention in the last decade. For Sri Lanka, internal security is of primary significance, although its Sinhala-Tamil ethnic conflict may finally be showing some signs of abatement. Internal rather than external security threats are of greater relevance to Nepal, Bangladesh, Bhutan, and the Maldives. Human security issues are of obvious relevance to all the South Asian countries.

\section{The nature of the crisis}

The crisis of governance in the region largely arises from the inability of its states to govern, as differentiated from rule, which enfeebles their ability to ensure human security but strengthens inhumane governance in the region. There are several facets of this phenomenon.

First, the inability to govern has led these states to view citizen's protests against misrule as challenges to their authority that need to be suppressed. This paranoia is reflected in large accretions to police and 
paramilitary forces in terms of numbers, equipment, and budgetary allocations. The intelligence agencies have also grown and are widely being used to sustain the ruling parties in power. The politicization of the administrative services, police, paramilitary forces, and intelligence services over the years has greatly eroded their credibility, and they are generally perceived as the political instruments of the party in power. This impression is reinforced by wholesale changes in the upper administrative echelons, corresponding to a spoils system, occurring whenever a regime change takes place.

Second, there are identifiable enclaves in South Asia - Karachi, Northeast India, Bihar, eastern Uttar Pradesh, the Chittagong Hill Tracts, eastern Nepal, and the Jaffna peninsula - where the writ of the central authority is uncertain. This listing comprises insurgency areas, but also others where the administrative system has ceased to exist. A variety of militant groups, criminal mafias and local warlords have replaced the state here; their intimate links with the ruling elite aggravates this vacuum in the governance of the country.

Third, sometimes the security forces are not the solution but the main challenge to human security in South Asia. It is well known, for instance, that the Punjab police in India "might have managed to break the back of the terrorist movement in the state [in the eighties] but, in the process, has become a terrorist outfit itself". ${ }^{10}$ This could also be said of Kashmir, where the surrendered militants were formed into a vigilante force permitting the "co-optation of anti-social elements into the governance processes as the price for ceasing their resistance to the state", ${ }^{11}$ and are much feared by the local population. The crisis of governance in South Asia encapsulates these other dimensions of security threat to the state and its individuals. The erosion of the governance processes enfeebles the capacity of the state to administer and deliver social services. A tour d'horizon of the region reveals that its crisis of governance has a common aetiology. Three major symptoms of this malaise that have serious implications for national security are discussed below.

\section{Crumbling of democratic institutions}

It has been perceptively noted that: "the current restoration of representative regimes [in South Asia] has ... to be viewed in a longer perspective in order to emphasize both the fragility of the process and to caution us against over-optimism". ${ }^{12}$ Coalition governments seem most likely to achieve power in India and Nepal in the foreseeable future; they have proved too weak and indecisive to provide the leadership needed for adequately ensuring human security. Being vulnerable to arbitrary 
demands made by their coalition partners and by their own parties makes it difficult for them to reach consensus or make the sacrifices needed to adequately provide military and human security. Further, the opposition parties in the region are notorious for indulging in irresponsible politics; often, they have opposed the very policies they had promoted in power only to embarrass the government of the day. A different set of problems obtains in Pakistan and Bangladesh. Both countries were under long periods of military rule, in Pakistan since October 1999 until very recently. Indeed, the transfer of power from a military to a civilian government or vice versa has rarely occurred in these countries by constitutional means. Hence their civilian governments are inherently fragile, with the military occupying an overweening presence in the background. Ironically, the population welcomed the military government when it re-established itself in Pakistan, which is a revealing indictment of the preceding venal civilian governments.

The role of the military is critical in the governance of Sri Lanka since its civilian governments have proved unable thus far to bridge the country's ethnic divide, requiring their dependence on the armed and police forces to ensure the stability of the government. These forces often function outside civilian control, which is a reality that is accepted. A similar situation obtains in Nepal, with the armed forces owing primary allegiance to the monarch and the civilian government hesitating to exercise control over them. Witness the difficulty of the elected governments to deploy the armed forces against the Maoist movement in the country.

This militarization of South Asian states weakens the democratic forces in their polity. This process could accelerate with the political parties decaying and their grass-roots organizations withering away. Power is now being acquired by politicians, not from the people, but from power brokers and sectional elite who deliver votes during the elections and exact a price if their candidate succeeds in gaining public office. The limited purpose of this new political class is to derive legitimacy through the ballot box: once elected, their hold over power is blatantly misused to seek personal and familial advantage by garnering the resources of the state. The politics of manipulation has replaced the politics of mass appeal, enfeebling its democratic and representative character.

This flawed manner of choosing the people's representatives is reflected in the farcical manner in which legislatures function in South Asia. Devoid of sanctity, they are a mockery of "democracy" and legislators are the object of ridicule rather than respect. Hardly a session passes without its quota of walkouts, deadlocks, suspension of proceedings, forced adjournments, and sometimes violence. Attendance by legislators is minimal, and maintaining the quorum is difficult: indeed, proceedings 
are often known to continue without a quorum and without any objections being raised. Legislators use their time during the sessions to do everything except legislate. The passage of laws and budgets without debate, and issue of ordinances during inter-session periods, reveals the pathetic state of legislative functioning in South Asia.

An offshoot of the politics of manipulation replacing the politics of mass appeal is the co-optation of the civil services into working this system. The district magistrate was the backbone of the colonial administration, owing allegiance to the British Indian regime and enjoying its complete trust. This extended to control over the district administrative machinery and unfettered use of discretionary powers to exercise that authority. This patriarchal administrative system did not survive the postIndependence reality that power had to be exercised through political authority and its representatives. The tragedy is that no effort was made to undertake systemic reforms in South Asia; the reports of committees for this purpose were either ignored or met with token action. The monumental Administrative Reforms Commission Report drawn up in India during the late 1960s is an object lesson in cynicism - it remains shelved. The ad hoc policies pursued thereafter to refashion the administrative machinery have led to dissatisfaction all around, whilst the fall in efficiency and probity continues. Instead, the politicization of the administration continues, with the civil services becoming the tools of the political parties. Phrased differently, the colonial paradigm of a merit-based civil service was founded on the twin pillars of an impartial and politically neutral administration. This model was destined to crumble when democratic elections based on adult franchise legitimized a self-serving political class interested in using the civil services for party and personal ends. The problem now arising is: "How to include politics in the system of administration so that there is popular participation in government, and yet, exclude politics so that it does not use the administration for its narrow ends?" ${ }^{33}$ There is no answer to this fundamental question: consequently, a loss of organizational coherence has occurred. "District police chiefs lose effective control over their station officers who look to their local legislator for protection in return for favours rendered and are disinclined to follow priorities established at the apex level of the organization. In course of time this pattern is repeated all the way up to the top levels, resulting in erasure of the professional expertise, which is the raison d'être of the bureaucratic organization." 14

The rapid deterioration in public and civic administration presages the state's incapacity to grapple with increasingly difficult challenges to national security. Instead, an easy propensity exists to strengthen the forces of repression - intelligence, police, paramilitary, and armed forces rather than wrestle with the hard questions involved in providing effec- 
tive governance, like improving the quality and responsiveness of the administration, eradicating corruption, reducing redundancy in the bureaucracy, and disciplining unruly civil servants.

\section{Alienation of minority populations}

All South Asian countries face the common problem of accommodating the aspirations of minorities in their political framework, and dealing with conflicts arising from ethnicity related issues. Defining "ethnicity" is not easy, but a holistic approach recognizes its five components: "(a) a subjective belief in real or assumed historical antecedents; (b) a symbolic or real geographical centre; (c) shared cultural emblems, such as race, language, religion, dress and diet (d) self-ascribed awareness of distinctiveness and belonging to the group; and (e) recognition by others of the group differentiation." 15 Ethnic affinities are stronger than national identities; ethnicity, therefore, can be easily channelled into dissent and insurrection against the state or violence against other ethnic groups. For instance, the various ethnic movements in north-east India

have all to do with identity. Some have been fought for outright independence, the outstanding case being the Naga movement. A second lot has something to do with minority communities or sub-nationalities seeking separation not from India but from Assam or Bengal or autonomy within them in order to safeguard their identity (ethnic, linguistic, tribal). The third kind has been struggling to forestall or fight against a demographic transformation as a result of in-migration of foreigners or outsiders. ${ }^{16}$

Ethnic conflict within northeast India has its parallels elsewhere in South Asia. For instance, the secessionist option informs the LTTEsponsored Eelam movement in Sri Lanka and some militant groups in Kashmir. A greater autonomy demand inspired the Chakma movement in Bangladesh, and the Mizo and Gorkhaland agitations in India that led to the creation of Mizoram and the Darjeeling Hill Council. Similarly, the fear of demographic submersion due to population movements has triggered sporadic violence throughout South Asia, for example, against Nepali migration into Sikkim, Bhutan, and northeast India, or Bangladeshi migration into India of people searching for a better quality of life. The recent carving out of the new states of Uttaranchal, Jharkand, and Chattisgarh from Uttar Pradesh, Bihar, and Madhya Pradesh connotes the Indian union government's acceptance of the logic that discrete geopolitical units sharing an identity based on civilization and linguistic congruence need recognition.

The generic reason for ethnic and sectarian resentments is the sense of deprivation and discrimination informing minority groups against the 
state's political and economic capital being appropriated by the majority community or dominant ethnic group. These convictions have inspired movements in South Asia coming within the three categories listed above. Left unaddressed, these grievances fester and could generate conflicts between adversary ethnic groups, or between them and the state. These social conflicts are exacerbated by the state's inability to govern with any clarity of purpose, which has implications for national security. Special mention should be made of a new consciousness of injustice and discrimination informing the rural poor, who had been ruthlessly exploited in the past by feudal elements. The failure to carry out meaningful land reforms in South Asia due to the vested interests in their ruling elite has heightened this sense of deprivation, leading to socially disadvantaged groups organizing themselves to wrest a fair deal. This has led to caste-based violence in backward regions like eastern Uttar Pradesh, Bihar, and eastern Nepal, which could spread across South Asia. Private armies (Senas) have sprung up in Bihar to support the exploiting classes. They fall into two categories: first, and the most common, are the armies of the landlords. They employ musclemen to keep the peasants and tenants in their place, and ensure that taxes and rents are paid regularly. Second, is the dominant caste Senas or private caste militias or armies, which have become a part of the agrarian struggle in Central Bihar. They were mainly constituted to suppress the militant peasant organizations. ${ }^{17}$

They are opposed by several leftist extremist organizations that have arisen in India and Nepal, which has imbued this social conflict with a Marxist orientation. Ironically, the state, which is charged with maintaining public order, has become a helpless spectator, unable to prevent the open violence in the countryside, or take ameliorative measures to address the underlying agrarian unrest. The failure of security and governance is therefore manifest. The inability of the state to maintain law and order through its coercive organs has led to an anarchic situation developing. Many parts of the state are under the control of these combating groups; a form of warlordism also exists, with the state abdicating its authority here. This aspect of the crisis of governance undermines both state and human security.

The polarization of political forces on caste and sectarian lines is growing apace in South Asia and weakening its civilizational ethos premised on tolerance and moderation. This polarization is fissiparous in its effects and militates against the inclusive culture of the region. The dangers emanating from the growth of fundamentalist forces in South Asia - Muslim, Hindu, Sikh, and Buddhist - are reflective, perhaps, of a global phenomenon, namely, religious revivalism in the international system. A thoughtful view holds that: 
Two things unite their [religious groups] outlook and purpose. First, the movement is a reaction against the alienation of the leaders from the masses and the development of a two-tiered society: a privileged, westernised and self-seeking urban elite ... and the vast majority who live below the poverty line .... And, second, while committed to the ideal of democratic governance and popular accountability, they [religious groups] are convinced that the terms of constitutional discourse are alien and incomprehensible to the great majority of the people and must therefore be made to reflect indigenous social and religious experience. ${ }^{18}$

These assertions are undeniable, and it is unlikely that these developments will abate in South Asia. Our concern is with the sectarian violence distinguishing this phenomenon, which is often encouraged by the state. It is easy for the ruling elite to imbue an ethnic movement with a communal dimension to besmirch both as being unpatriotic: this informs majoritarian sentiments against the minorities to strengthen their support base. Examples of this phenomenon abound in South Asia: Sunnis in Pakistan stigmatizing Shias, Hindus in India branding Muslims and Sikhs as anti-national, and so on. The backlash against these developments has resulted in the mobilization of the minority communities (Sikhs, Jaffna Tamils, tribals and backward/Scheduled Castes), which aggravates social conflicts. Secularism may not be on the retreat in South Asia, but its weakening is clearly visible. The patronage of religious terrorists by Pakistan (Harkat-ul-Ansar and Lashkar-e-Toiba) has led to a predictable reaction in India and the encouragement of the Shiv Sena and other Sangh "Parivar" ("family") organizations like the Vishwa Hindu Parishad and the Bajrang Dal. Sikh extremist demands for a separate state (Khalistan) have abated, but the association of Sinhala extremism with the Buddhist clergy continues in Sri Lanka. These ideological predilections have become politicized due to bloc voting by different communities for candidates belonging to their religious persuasion, thereby widening cleavages and heralding greater sectarian strife in future in South Asia.

The distressing aspect of sectarian and communal strife is the partisan role being adopted by the state. Such a policy is clearly short-sighted and designed for marginal political gains is apparent. In the context of India and Hindu fundamentalism, it has been noted that "The greater harm that can befall India from the pursuit of a narrowly defined nationalistic vision lies with the Hindu society itself. The divides within the Hindu faith, on account of castes and languages, are many. And each one of them is a potential faultline along which confrontations can be launched." ${ }^{19}$ Hence, religious fundamentalism carries the seeds of its own aggravation and destruction, and divisiveness within the state cannot leave its integrity unaffected. 


\section{Nexus between corrupt elements in the governing apparatus}

The accumulated black money (unaccounted income) in South Asia now constitutes a parallel economy. The inability of the state to unravel this economy and proceed against tax-evaders exemplifies the bonding between corrupt politicians, officials, and businessmen to defraud the exchequer. Their linkage in the matter of defence purchases and contracts is common knowledge in the region; the national-interest plea has conveniently been taken by governments to maintain opacity in these cases. Looking into the future, enormous sums of money would be involved in divestment of the public sector, deregulation of industry, and undertaking large-scale infrastructural and developmental schemes as the liberalization and globalization of the South Asian economies proceed further. Past experience informs that the scale of malfeasance would also be enormous. One judgment holds that "all the agencies dealing with corruption, tax evasion, smuggling and other economic offences have been so politicised over the decades that prompt and proper action against the politicians is the exception rather than the rule". ${ }^{20}$

This judgment, expressed in regard to India, is applicable to the entire region, although a few salutary exceptions have occurred with the conviction and sentencing of three past prime ministers, one past president, ${ }^{21}$ and some other notables. It would be fair to concede, however, that these cases were the exception rather than the rule in South Asia. The rule, illustrated in innumerable other cases, has been for these worthies to avoid investigation into their misdeeds, delay their progress by the investigating authorities if they are initiated, then delay cases if they reach the courts by various judicial devices, and, finally, occasion more delays by appealing to higher judicial authorities should the judgment be adverse. The tardiness of the judicial process greatly assists these machinations. The resulting politicization of crime exacerbates both the crisis of governance in South Asia and its security problematique in at least two ways.

The first way is by accentuating the virtual immobility of the state in dealing with the growing challenges to national security, especially internal and human security. Indeed, the state organs have often become part of the problem rather than the solution. For instance, the police services are widely perceived as part of the state's machinery to oppress the poor, not protect them from exploitation. "In such circumstances the police are feared as much as the criminals ... [T] o the extent that the police may connive with and protect criminals and be used by the ruling political party and by men of property to promote their interests, the forces of law and order are seen to be part of the problem of the criminalisation of society rather than its solution." 22 
But the police and paramilitary forces continue to appropriate increasing budgetary outlays despite their patent inadequacies leading to the breakdown of law and order in large parts of the region. Disconcertingly, the paltry additions to social sector outlays and its poor management illustrate the low priority accorded to human security by the regional governments.

The second way, the criminalization of politics and its linked phenomenon, the politicization of crime, have permeated South Asia: this greatly reduces the state's capacity to ensure national security. The entry of criminal elements into the legislative chambers and cabinets at the federal and provincial levels should raise deep concern. This largely explains the incapacity of the state to maintain law and order and assure the physical security of its citizens, which is the most basic function of the state. The inability of the state to arrest and prosecute criminals with political connections or politicians with criminal antecedents delineates this problem. The celebrated Vohra Committee Report informed that

there has been a rapid spread and growth of criminal gangs, armed "senas" (armies), drug Mafias, smuggling gangs, drug peddlers and economic lobbies in the country which have, over the years, developed an extensive network of contacts with the bureaucrats/Government functionaries at the local levels, politicians, media persons and strategically located individuals in the non-state sector ... DIB (Director Intelligence Bureau) has stated that the network of the Mafia is virtually running a parallel government, pushing the state apparatus into irrelevance. ${ }^{23}$

The report concludes that "The various crime Syndicates/Mafia organisations have developed significant muscle and money power and established linkages with governmental functionaries, political leaders and others to be able to operate with impunity." This indictment of the Indian political system has not bestirred any systemic reform by the Indian Government; recurrent exposures of links between criminals, bureaucrats, businessmen and politicians only confirm the growing expansion of this criminalization process.

A study of narco-politics in Pakistan is also instructive; ${ }^{24}$ it points out that no consensus was possible in the government on taking steps against drug trafficking. Frequent transfers of honest officials in the Pakistan Narcotics Control Board (PNCB) and the Anti-Narcotics Force eroded the legitimacy of political parties and people's faith in the democratic process. Another investigative report ${ }^{25}$ informed that the drugs-army nexus was fuelled by an identity of mutual interests; the army's need for narco-money to pursue its strategic interests in Afghanistan found congruence with the mafia's interests in ensuring the safe transport of its drugs. Apparently, "Vehicles of the army-controlled National Logistics 
Cell and those used to supply arms to Mujahideen have also been used as drug carriers. The PCNB and other agencies do not have the authority to check these vehicles and so they were the safest means for drug transportation." 26

The situation pertaining to criminalization of politics in Nepal, Bangladesh, and Sri Lanka may differ in scale, but is little different in character, establishing that the inner processes of governance in South Asia have been infiltrated. This should be a matter of concern as it could affect their national security by providing opportunities for foreign elements to influence their decision-making processes. In other words, the entry of criminals, national and international, into governing structures can provide transnational forces entry into the governing structures in South Asia, which could prejudice their national security in a direct fashion.

The question now becomes germane of why people elect criminals to the legislatures, thus enabling them to enter cabinets and the inner processes of governance. It would be naive to believe that the voters are unaware of the candidates' dubious character and antecedents; this would assume that the voters are collectively gullible and ignorant about the general reputation of the candidates. A counsel of despair would suggest that the lack of suitable alternative candidates is responsible for this state of affairs. Or is it possible that voters are intimidated? Or that their judgment is swayed by caste, class, and communal loyalties? It is arguable, however, that South Asian citizens are not averse to electing criminals if they can "deliver the goods" and exercise patronage to benefit the elector. It has been realistically, if cynically, urged that

we, in India, do not elect representatives but patrons. Both the rich and the avaricious, as well as the poor and the stricken, vote on this principle ... [E]fficiency, diligence and adherence to norms and procedures are of little significance in the Indian context. They are all right if you are an underachiever with negligible ambitions, but not otherwise. It is fine if one wishes to lead one's life incognito, but to make a mark it is essential to seek out a patron. ${ }^{27}$

This leads to the conclusion that reversing the increasing criminalization of politics in the coming years is difficult, if not futile. The implications of this assessment are profound for governance and security in South Asia. The criminalization of politics affects the processes of governance by immobilizing the state. The entry of criminals into the legislatures and cabinets hollows out the state from within, strengthening the nexus between the pillars of government and anti-social elements. Left unattended this is a prescription for "failing" or "failed" states emerging. The nexus between the military, jihadist groups and organized crime in 
Pakistan foretells a serious crisis brewing in that country. Interpol has informed the US Congress that:

Structural links between political terrorism and traditional criminal activity, such as drugs trafficking, armed robbery or extortion have come increasingly to the attention of law enforcement authorities, security agencies and political decision makers. There is a fairly accepted view in the international community that in recent years, direct state sponsorship has declined, therefore terrorists increasingly have to resort to other means of financing, including criminal activities, in order to raise funds. ${ }^{28}$

The lesson here for the South Asian countries is that encouragement of terrorism in their neighbours is sowing the seeds that will ultimately cause their own instability. The cancerous growth engendered within the system would become difficult to reverse, but the consequent erosion of the governance processes would only aggravate state and human security.

\section{A final word}

The dangers to governance and security from the criminalization of politics and the politicization of crime in South Asia need greater recognition. The transnational aspect of this threat underlines the need for greater regional and international cooperation to combat its menace. This is necessary because national, regional, and international criminal groups and terrorists are increasingly forging links for mutual profit. Law enforcement, consequently, has to function in an undefined national/ international zone, which is difficult and costly. Money laundering, for instance, underpins the illegal activities associated with drugs and arms smuggling; trafficking in human beings and similar nefarious activities have profound implications for governance and security. But they cannot be effectively tackled unless countries cooperate with each other to collectively devise an integrated strategy that addresses their economic, social, and legal dimensions. Recognition by SAARC of the fuller contours of this crisis of governance in the region and its serious implications for national security is important. This could, hopefully, inform the regional countries to collectively devise national and regional measures to mitigate the problem.

A greater recognition is also required that the crisis of governance in South Asia also derives from inadequate understanding of the region's inherent tolerance for multiculturalism; adequate space was always available in the region for plural societies and diverse communities to live together in amity and peace. The post-independence political compulsions seem to have dictated, however, the evolution of divisive societies 
that are fragile and degenerate into social conflict and violence derived or premised on caste, class, and communal particularities. If multiculturalism in the plural societies of South Asia is to be preserved, its governance processes must consciously create space for its practice. A new context is provided, therefore, for greater devolution and decentralization of administrative, political, and economic powers to minority groups on the peripheries of the state. In short, enlarging local autonomy and accommodating the sectional interests in the state must be recognized as the sine qua non for good governance and security in South Asia.

All this may seem hopelessly idealistic, but the alternative of creating new political entities like states, union territories, autonomous regions, autonomous districts, and so on, to defuse movements for greater sovereignty, as is being attempted in India, offers no viable long-term solution to the issue. In truth, the underlying problem of enlarging local autonomy and accommodating sectional interests would only be transferred to another level, ignoring the basic issue of strengthening multiculturalism. Indeed, the new political entities created would be less equipped to handle the problems of devolution and decentralization due to their more acute lack of resources. The essential question remains whether the governments in South Asia have the political will to reverse the downward trend in their polities. The symptoms, as elaborated above, include the crumbling of democratic institutions, alienation of minorities, and the nexus between corrupt elements in their governing elite. The answer is a resounding "No", but it also needs appreciation that this answer will remain in the negative unless a radical restructuring of their polities occurs. How this will happen is a question whose answer remains in the void.

It is generally believed that the root cause of the crisis of governance and security in South Asia lies embedded in the electoral process. This process has been subverted by illicitly acquired money power, which can also buy muscle power. Hence, this dispensation serves the interests of the rich and feudal, apart from organized communal and caste, elements. As trenchantly observed, "The root cause of corruption is the role of black money in politics. Elections have become extremely expensive and all political parties spend huge sums in every election. The need to incur colossal expenditure during elections is often put forward as a justification for making illegal collections. That is, of course, a lame excuse." 29 Besides, in an era of coalition politics, money is also required to ensure that legislators support the government and not defect to the opposition by yielding to temptation in times of legislative stress. The politician's career is also likely to be short-lived, hence, their need to put by funds for the future outside office. The guiding principle for the South Asian politician - with several honourable exceptions, of course - is to earn as 
much out of a short career in public office as feasible, in the quickest possible time. The expense incurred in the elections is treated, therefore, as an investment to be recouped whenever the opportunity presents itself. The electoral laws, especially those concerned with the observance of limits on election expenditure, are, therefore, more usually than not, observed in the breach.

It is generally agreed that the requirement for large funds to fight elections has befouled the electoral process in South Asia, but efforts to curb this pernicious tradition have floundered in the past. State funding of elections is unlikely to provide an acceptable solution due to valid suspicions that such funds would be spent in addition to the expenditure incurred by political parties and candidates out of their own resources. The more practicable remedy is an upward revision of the limits to electoral expenditure and a strict observance of these limits by a system of detailed declarations and audit of expenses. Infractions of the electoral laws relating to election expenditure should be prosecuted without exception; currently, they have not proceeded very far due to judicial delays and the availability of appellate courts to indefinitely delay a final decision. Hence, there is a pressing need to devise a system of administrative tribunals charged with delivering a judgment within specified time-frames.

Still, the basic dilemma remains: how can the state reform its governance processes if the state is a party to its misgovernance, and has a vested interest in perpetuating misgovernance? The conclusion is unavoidable that reform would only be possible if the people assert themselves and demand that the country be governed and not ruled, and that the issue of misgovernance is seriously addressed. There is an obvious need for transparency in the government, lack of which is chiefly responsible for the pervasive corruption in the governance processes. Public campaigns to secure the right to information are making a dent in several states of India, which is snowballing into a mass movement. This could spearhead a radical corrective process to reduce corruption and ensure a better standard of public service, which could enhance human security in the region.

What this example suggests is that the inadequacies in the governance processes, which are prejudicial to both state and human security, require a greater assertiveness by the people to ensure its rectification. It is the "demos" (people) in democratic societies who are the ultimate repositories of power; hence, greater people's activism and a people's movement to cleanse the governance processes is imperative. Before that can occur, more voices must be raised in South Asia to highlight the dangers of the current drift into political and administrative anarchy, with the attendant bonding between misgovernance and insecurity. A con- 
spiracy of silence would only encourage the perpetrators of the deteriorating governance processes, which is presently exacerbating the problem of security in the region.

\section{Notes}

1. Jawaharlal Nehru (1986) The Discovery of India, New Delhi: Oxford University Press,), fifth impression, p. 107.

2. M.J. Vinod (2000) "Conceptualising Good Governance: Questions of Democracy and Development”, Mainstream XXXVIII (45): 16.

3. Lawrence Freedman (1998) "International Security: Changing Targets", Foreign Policy (Spring): 53.

4. Kanti Bajpai (2000) "Human Security: Concept and Measurement", Occasional Paper No. 19, Joan B. Kroc Institute for International Peace Studies, University of Notre Dame, Indiana, pp. 22-27.

5. Fareed Zakaria (1997) “The Rise of Illiberal Democracy”, Foreign Affairs, November/ December, p. 22.

6. Ibid., p. 10. What the author notes regarding India has relevance for the entire South Asian region in view of its common ethos and traditions.

7. P.R. Chari (1998) Newer Sources of Insecurity: The Crisis of Governance in India, RCSS Policy Studies 3, Colombo: Regional Centre for Strategic Studies, January 1998, p. 2.

8. Ramesh Thakur (2000) Security in the New Millennium, keynote address, eighth Summer Workshop on Defence, Technology and Cooperative Security in South Asia, Lalitpur, Nepal, 10-20 September, p. 5.

9. Security Sector Reform and Development Co-operation: A Conceptual Framework for Enhancing Policy Coherence, Informal DAC Task Force on Conflict, Peace and Development Co-operation, Organisation for Economic Co-operation and Development, DCD (2000) 4/REVI, p. 3.

10. Ashis Nandy (1994) "Violence in our Times: In Search of Total Control", Times of India, 29 October.

11. Chari, op. cit., N. 9, p. 15.

12. Gowher Rizvi (1994) "Democracy, Governance and Civil Society in South Asia", Pakistan Development Review 33(4): 595.

13. S.K. Das (2001) Public Office, Private Interest: Bureaucracy and Corruption in India, New Delhi: Oxford University Press, p. 223.

14. G.K. Arora (1998) "Bureaucracy in India: A Time of Troubles", in P.R. Chari, ed., India: Towards Millennium, New Delhi: Manohar, p. 79.

15. Urmila Phadnis (1990) Ethnicity and Nation-Building in South Asia, New Delhi: Sage Publications, p. 14.

16. B.G. Verghese (1996) India's Northeast Resurgent, New Delhi: Konark Publishers, p. 285.

17. Alok Kumar Gupta (2000) "Senas (Caste Armies) of Bihar", www.ipcs.org/nmt/ milgroups/sena-india.html (20 October).

18. Rizvi, op. cit., n. 14, p. 623.

19. Verghese Koithara (1999) Society, State \& Security: The Indian Experience, New Delhi: Sage, p. 235.

20. S. Swaminathan (1996) "Economic Offences and the New Class", The Hindu, 29 August.

21. They are former Prime Ministers Zulfikar Ali Bhutto and Nawaz Sharif in Pakistan, 
former Prime Minister Narasimha Rao in India, and past President Ershad in Bangladesh.

22. Rehman Sobhan (2000) "Problems of Governance in South Asia: An Overview", in V.A. Pai Panandiker, ed., Problems of Governance in South Asia, New Delhi: Konark, p. 16.

23. Government of India, Ministry of Home Affairs (1993) Vohra Committee Report, mimeographed copy dated 5 October 1993.

24. Aabha Dixit (1991) "Narco Power: Threatening the Very Roots of Pakistan", Strategic Analysis XN (May).

25. Zahid Hussain (1989) "Narco Power: Pakistan's Parallel Government", Newsline (Karachi) December 1989, reproduced in Strategic Digest, New Delhi, June 1990.

26. Op. cit. Strategic Digest, p. 2495.

27. Gupta, op. cit., n. 7, pp. 144-145.

28. Written testimony presented by Ralf Mutschke to the House Subcommittee on Crime on 12 December 2000, "The Threat Posed by the Convergence of Organised Crime, Drugs Trafficking and Terrorism", http://www.house.gov/judiciary/3.htm.

29. P.S. Appu (2000) "Need for Thoroughgoing Reforms", The Hindu, 26 December. 
5

\title{
Governance in plural societies: Sri Lanka
}

\author{
Paikiasothy Saravanamuttu
}

\section{Introduction}

At the outset, it must be stressed that any discussion of governance, and especially one of governance in plural societies, is by definition an ideological one. Certain key assumptions are invariably read into the discussion and condition the diagnosis of the problem as well as the proposed solutions. The discussion is inherently political in that the subject-matter is political. It is about the structure of power and authority in society and the relationships between groups based upon it. Therefore, a clarification of the ideological perspective of this chapter is in order.

This chapter is written from a liberal democratic perspective, imbued with the values of individual liberty, democratic pluralism and faith in the belief that diversity in society must be cherished as a source of strength rather than weakness. Whilst fully acknowledging the pivotal role of the state in society, it argues that this role must be seen in terms of a facilitating framework for welfare and well-being for the pursuit and enjoyment of the good life by all. Furthermore, the notion of governance that informs this chapter is both about the processes of mediating societal needs and tension, as well as, most importantly, the substantive content of that mediation and the values that underpin it. It is fundamentally about what should be done and why, as well as how it is to be done. Governance is not in this conception a matter of technique and techni- 
cality alone, it is first and foremost a way of looking at society stemming from a vision of the organization of society.

Accordingly, the problem of governance in Sri Lanka stems in large measure from the failure to acknowledge the pluralism inherent in society through constitutional guarantees and through the propagation of this value in the political culture. Consequently, it gives rise to and sustains a crisis of legitimacy of the state. This is underpinned by defensive selfperceptions of the State and societal perceptions of it that range from the authoritarian and discriminatory to the corrupt and inefficient. These perceptions are mutually reinforcing and societal insecurity is thereby compounded.

What follows is an attempt to identify the sources of this problem. Sri Lanka is in the throes of a prolonged and seemingly intractable nation/ state building process. Within this, armed conflict and constitutional reform for conflict resolution have been identified as key elements, and the question of an overarching political culture facilitating political pluralism assumes particular significance in respect of governance. It is allied to the question of whether "nation-state" or "state-nation" is the better characterization of the highest unit of collective political organization in Sri Lanka. Accordingly, this problématique needs a general statement as central to the challenge of governance in a plural Sri Lanka.

\section{The nation-state/state-nation problem ${ }^{1}$}

In Sri Lanka and South Asia in general, governmental structures still bear the hallmarks of the colonial legacy, and social relations that of precolonial influences. Consequently, although the dominant Eurocentric paradigm for collective political organization and economic development is the nation-state and modern capitalism, in Sri Lanka the political formation is better characterized as the state-centric nation in which economic development has been uneven. Unlike the European experience of the symbiotic development of state, nation, and market, here the state, essentially the colonial state, preceded nation, and has become the principal institutional agency in the creation of the nation through strategies of assimilation, integration and coercion. Development of the market has lagged behind both.

These centralizing tendencies of the state have bedevilled the objectives of developing socio-political harmony and an overarching national consciousness. Rather, the inability and/or unwillingness of the state to accommodate social diversity and provide democratic "space" to a variety of groups, has in turn nurtured and intensified centrifugal tendencies. Moreover, the compulsions of the State to forge a nation in its thrall in- 
variably involves the pre-eminence of coercive strategies and the gradual erosion of democratic rights and freedoms. The institutionalization of hegemony through the insistence on linguistic conformity, with its repercussions on educational and employment opportunities, and, to a lesser extent, the elevation of the majority religion to "foremost" position, have struck at the fundamental tenets of minority identity in a representative secular democracy and have gone far in entrenching perceptions of discrimination.

There is another related factor contributing to this as well. It pertains to the political-civil society relationship, on the one hand, and to economic development on the other. It also accounts for the rise of populism and the consequent erosion of the early parliamentary democratic ethos that accompanied the initial transfer of power in 1948.

Populism rises in proportion to the widening disjunction between the pretensions and performance of the State as seen in its ability to deliver the goods to its people. And, as the State expands its role and reveals its incompetence, it becomes more authoritarian and feeds the crisis of its legitimacy. The failure of the State to deliver on its promises with regard to the good life of its citizens and its tendency to camouflage its limited capabilities with coercion and authoritarianism invariably give rise to anti-establishment/anti-systemic forces, not all of which seek to define identity in ethnic terms. They view the system of governance as corrupt, exclusive, and bankrupt: thus economic development is denied democratic legitimacy.

In a context in which all power and authority is jealously guarded at the centre and concentrated in a class, a community, a party, and then in a single individual, in Sri Lanka those who believe that the system is not working for them seek to capture the system itself through armed insurrection. This is a course of action which serves only to replicate the problem as it is, by its very nature, a thoroughly statist response.

The development of a strong liberal rights consciousness, which can temper the costs and consequences of populism, has been mitigated by the overwhelming politicization of society imposed by the nation and state-building imperative. When power, authority and opportunity stem from ethnic identity and partisan affiliation, the development of flourishing institutions of civil society that would serve as independent guardians of democratic rights is stymied. Secular, democratic civil society is not seen as the measure of the democratic health of society, but as a potential threat to the "state-nation" bent on becoming the "nation-state".

As independence is seen to be the regaining of sovereignty by the "imagined community" of the nation, therefore, rights are initially conceived and later canvassed with an external orientation vis-à vis the international system. The multiplicity of threats that constituted the Cold 
War compounded this. Within the political unit, corresponding duties of citizens are stressed along with the assertion of the rights of the majority. At the international level, notions of justice have priority; at the domestic level they are superseded by arguments positing order as the higher goal. In both instances, rights and duties are collective and selective. They are not an end in themselves, but a means toward the end of forging a viable and secure collective entity the nation state in the image of the majority community.

The suppressing of civil society and the emphasis on allegiance from citizens to an overarching authority, uphold a particular version of collective good which is further buttressed by the model of economic development. The traditional notion of the state as the primary - if not exclusive - provider of the welfare and well-being of the collectivity has been enthusiastically pursued. Again, the dominant ideology was collective and selective. The State enters the economy to control it. Consequently, the modernizing effects of economic development, especially as far as social mobility is concerned, is limited by the preponderant role of the State in controlling and distributing economic largesse under its political patronage and according to discriminatory criteria. Like civil society, private enterprise is not encouraged and is, therefore, unable to play its role in opening up alternative routes to social mobility, and, most importantly, the related function of facilitating the articulation of individual rights. The stultifying role of the State with regard to social mobility has also had the effect of allowing, by default, the persistence of feudal, caste, and class considerations.

In this situation, minorities are doubly disadvantaged, as citizens and as persons. They have responded in various ways and with mixed results, depending on their particular circumstances. Some who have acquired material prosperity and social advancement have done so on the tenuous basis of political patronage or a particular power configuration, rather than on or through solid institutional foundations. Individuals have succeeded by virtue of social class. As a group, though, minorities are disproportionately vulnerable to the vicissitudes of politics.

It is important to stress that the ultimate political expression of minority demands - national liberation/self-determination - is in effect a reaffirmation of the majoritarian principle and illustrative of the political culture. Other anti-systemic political forces whose leitmotif can be best described as the "hijacking" of the State also share this anti-liberaldemocratic feature. In this sense, post-Independence politics has entrenched the monolithic nation state bias of collective political organization without fostering the mediating attractions of meaningful constitutional and political experimentation to accommodate social diversity. The em- 
phasis on "meaningful" is apposite because such experimentation, as there has been, has maintained the state-centric bias, and, at most, has been perceived by the minorities and the anti-systemic forces as tactical manoeuvre the marginal tinkering with form as a smokescreen for the denial of substantive change.

The consistent denial of meaningful redress through political accommodation by the State only reinforces the belief that the system only works for some and is not intended to work for others. Therefore, it has to be abandoned, captured, destroyed, or replaced. At the margins, the belief that underpins political action is that the State so designed cannot reform itself. It will always oscillate between provider and predator, and never partner. Is there a way out in Sri Lanka to create and sustain a political culture of partnership in the basic social contract between the government and the governed?

Whilst there have been changes in Sri Lanka from the description provided in the general statement made above, it should be stressed that these changes have yet to produce a durable political culture and institutions for democratic governance and conflict resolution in the future. My contention is that we are into a state of "becoming", as opposed to a state of "being", with regard to the question of nation and state and the answer to it in terms of democratic governance.

The horrors of the Janata Vimukthi Peramuna (JVP), or "People's Liberation Front" insurrections (1971 and 1987-1989) and ethnic conflict (in its armed manifestation since 1983), the temerity of the 17 years of the United National Party (UNP) rule (1977-1994), and the upheaval and cultural challenge of the open economy and structural adjustment conditionality have highlighted the need for a redefinition of the status quo. There are many interests and sections of society which stubbornly and, at times, even viciously cling to the immediate past and beyond. As their insurance policy against alienation and anomie in a situation of change, they have fallen back on certainties culled from the situation that is being transformed. Fear of the future leads them to a position of going back to it.

These differences in response to change, of acceptance and accommodation or outright denial and rejection, define the political dilemma of contemporary Sri Lanka. Governance becomes a balancing act, a series of ad hoc, quid pro quos for quick fixes. The current process of constitutional reform for conflict resolution is illustrative of this, and highlights the element of good political governance identified in the 1999 Report on Human Development in South Asia as a constitution not easily amendable by any of the branches of government. It should be read together with an analysis of the ethnic conflict. ${ }^{2}$ 


\section{Ethnic conflict: democratic governance and conflict resolution}

The ethnic conflict in Sri Lanka stems from Tamil minority perceptions of discrimination dating back to the colonial era, and augmented since independence. In the latter period in particular, discrimination was institutionalized through the Official Language policy (1956) which struck at the heart of minority aspirations regarding education and employment. State colonization of predominantly Tamil-populated areas, seen by them as areas of their historic habitation, was also inflammatory.

The accumulated sense of grievance and discrimination was exacerbated by the inability or unwillingness of successive governments to address this, and especially by their determined pursuit of majoritarianism. As attempts to seek political compromise through the established channels of elite democratic politics proved futile, extra-parliamentary militancy was nurtured and grew to the point of armed insurgency against the State. Political demands traversed the spectrum from federalism to secession, as championed by the Liberation Tigers of Tamil Eelam (LTTE).

In 1983 a number of militant groups took up arms against the Sri Lankan State. Indian intervention in the form of a peacekeeping force and the Indo-Sri Lanka Accord of 1987 paved the way for the Thirteenth Amendment to the Sri Lankan Constitution that provided for a measure of autonomy through provincial councils. All the militant groups entered mainstream establishment politics except the LTTE, which held out for secession, at best, and far-reaching autonomy for the north and east of Sri Lanka, at the least. Since 1990, barring intervals in which talks between them and the Sri Lankan State have taken place, the LTTE and the Sri Lankan State have been at war with each other. The LTTE fought the Indian Peace Keeping Force as well (1987-1990). ${ }^{3}$

The ethnic conflict is reported to have cost some 60,000 lives so far, with over a million people both internally displaced and made refugees abroad. It is a conflict which has been marked by widespread terrorism and atrocity, including high-level political assassinations, suicide bombings, the continued recruitment of child soldiers, traumatization and brutalization of the population, and other human rights abuses. Included in this is the increase in violent crime and the deterioration in law and order attributable to army deserters. According to the figures provided by the Human Development Centre in its 1999 report on the Crisis of Governance in South Asia, the rates of murder and armed robbery are higher in Sri Lanka than in its immediate neighbours. In economic terms, the defence budget stands at 6 per cent of GDP, soaring considerably with the rearmament necessitated by LTTE successes in April/May 2000. Consequent to this, the country was put on a "war footing" and there 
continue to be frequent increases in the prices of essential items - also partly attributable to increases in world oil prices. ${ }^{4}$ A study by the Institute of Policy Studies values the cost of the conflict in the period 19841996 alone at nearly 170 per cent of Sri Lanka's total GDP for 1996. The Central Bank in its 1999 Annual Report estimates that the conflict has reduced growth by $2-3$ per cent points annually. ${ }^{5}$

Whilst the conduct of the Sri Lankan security forces is commonly believed to have improved considerably with regard to human rights abuses, allegations still persist and thereby feed perceptions of discrimination and the ethnic conflict. These extend from the massacre of Tamil inmates in the Bindunuwewa rehabilitation camp to the use and abuse of emergency regulations which have been in force for most of the last three decades, and, in particular, the recourse to the draconian Prevention of Terrorism Act (PTA), which has been in existence since 1979. ${ }^{6}$ Large parts of the north and east of Sri Lanka, for the duration of the conflict, have been effectively governed by either the security forces or the LTTE, raising grave concerns for the observance of democratic rights and norms and the rule of law. The LTTE, on the other hand, has been internationally proscribed as a terrorist organization, and, whilst it has earned a reputation for military and political prowess, this has been overshadowed in popular perception by its fascist organization, ruthlessness and brutality in practice. ${ }^{7}$

The repeated failure since 1983 of either side to win an outright military victory quickly or cheaply has focused attention on a political solution, its substantive provisions and modalities. Constitutional reform has been identified as a key component for this, and is accordingly framed by the need to restructure the State and define the nation to meet the twin demands of democratic conflict resolution and governance.

Resolution of the ethnic conflict hinges upon the existence of an attractive enough alternative for the Tamil people to the LTTE goal of a separate state of Tamil Eelam. Attempts at crafting proposals for the devolution of power will have to recognize this basic political point; they will have to contain viable, effective guarantees against discrimination, and convince the Tamil polity that they can seek the good life within a united Sri Lanka. Devolution and power sharing are now on the agenda because the Tamil minority took up arms against the Sri Lankan government, after various attempts at political accommodation had failed. The LTTE, which seeks to establish totalitarian control and hegemony over the Tamils in the north and east of the country, is an outgrowth of the Tamil problem, and the political success of this essentially fascist organization has been its ability to acquire the rhetoric of Tamil nationalism in the absence of government attempts to effectively address Tamil grievances. 
President Kumaratunga appeared to acknowledge most (if not all) of the foregoing at the outset of her first term in office (1994). However, naivety and arrogance characterized her attempt at direct negotiations with the LTTE, who, in any event, found a context of hostilities more conducive to the advancement of their totalitarian political project. With the LTTE leader Prabhakaran's unilateral decision to resume hostilities on 19 April 1995, the government too allowed itself to fall back upon its primary reliance on military force for conflict resolution.

The use of force, however, is not politically neutral, and, as all the classic texts on its use point out, it releases its own dynamics. War was waged for peace, and terrorism had to be destroyed so that the Tamil problem could be addressed. However, for the majority the Tigers have become synonymous with the Tamil problem in the Sinhala psyche, and the use of military force and the apparent success it met with in Jaffna in 1995 restricted the space for devolution and meaningful power sharing to resolve the Tamil problem.

The Peoples Alliance (PA) government released an unprecedented devolution package as the nucleus of a political solution of the ethnic conflict in August 1995. It was the first time any Sri Lankan government had ever come up with a set of proposals that entailed movement away from the unitary state. However, by the time it was presented to the Parliamentary Select Committee on Constitutional Reform as the government's proposals on devolution in January 1996, the balance of power was clearly restored in favour of the central government to allay the doubts and apprehensions voiced. The point to be noted is that the restoration of the military balance in favour of the government as a result of the intervening Riviresa military offensive was not interpreted as strengthening the government's hand in the pursuit of more meaningful devolution.

The extent of the reform of the political structures for peace and reconciliation, and, accordingly, the shift in the political culture, was best exemplified by explanation of the Minister of Justice and Constitutional Affairs regarding the amendment to Article 2 of the present Constitution enshrining the unitary state. The proposed amendment described the state structure of Sri Lanka as an "indissoluble Union of Regions", and, according to the minister, in his published commentary on the proposed constitutional reforms, this is a necessary "redefinition" of the unitary state as opposed to a wholesale jettisoning of the concept. ${ }^{8}$ There was, in this document (and in subsequent versions including the Constitution Bill eventually presented to Parliament), a marked reluctance to make an explicit statement on the federal characteristics of the State that were being introduced.

My concern here is to understand how much is popularly understood 
by "ethnic conflict", and to locate that understanding in the context of democratic governance in a plural society. The constitutional settlement is surely intended to take the ethnic conflict into account and provide future insurance against it, rather than deny its significance. Perhaps the lesson about the political culture to be discerned from the devolution debate is that, however inadequate, there are proposals along these lines, and, however distorted, there is a debate and not a riot.

The proposed new Constitution incorporating the devolution proposals was presented to Parliament on 3 August 2000 by the President, and then withdrawn when the necessary two-thirds majority of the legislators was not forthcoming for its passage. Whilst the latter was the direct reason for its withdrawal, protests and demonstrations from right-wing groups and significant sections of the Sangha (or Buddhist clergy), including a fast unto death by a monk, also influenced legislators, though they were by no means the only ones. It has been reported that various attempts to induce legislators to defect to the government, euphemistically labelled the "handsome rewards scheme", were checkmated by the UNP opposition. Sections of moderate Tamil opinion, too, including the oldest Tamil political party, the Tamil United Liberation Front (TULF), and the only one in Parliament not to have resorted to arms were going to vote against the Constitution on the grounds of the inadequacy of its devolution provisions. ${ }^{9}$

The devolution package has been through many incarnations since it was first presented as the government's basic thinking on the resolution of the ethnic conflict in August 1995. Presented as the government's proposals on devolution in January 1996, and then as the Legal draft of the Constitution in October 1997, it was not brought to Parliament till 3 August 2000, three weeks before the term of Parliament expired.

The reason cited for this delay was the unwillingness of the opposition United National Party (UNP) to engage constructively in the process of constitutional reform and lend support to the government's efforts. The UNP at the outset positioned itself as a champion of the unitary state. The absence of a bipartisan consensus between the two main political parties has been a key factor in the past that had obstructed a solution of the ethnic conflict. The UNP, for its part, has argued that the government is not really interested in a consensus and is more concerned with the consolidation of power, in the pursuit of which the government constantly alludes to the corruption, fear and terror that characterized the 17 years of UNP rule (1977-1994).

Whilst the search for consensus has been stuck in partisan invective and parochialism, events on the ground have served as the catalyst for changing perspectives on the substance and modalities of a political solution to the ethnic conflict. 
The government's key military offensive Jayasikuru ("Victory Assured"), in what it termed a "War for Peace", was aimed at opening the main supply route from Colombo to Jaffna in the north. The rationale for this campaign was that it would facilitate the return of normalcy to the Jaffna peninsula and pave the way for the passage and implementation of the devolution package, which the LTTE had rejected outright. The government hoped that this could be accomplished by April 1998. They calculated on a referendum on devolution on the heels of the successful completion of the offensive, local government elections in the peninsula in January 1998, and the fiftieth anniversary celebrations of independence in February 1998.

Local government elections were held and hailed as a success, in that they demonstrated the desire of the population for returning to normalcy. However, the unwillingness of the government to release the necessary funds for local government, and the series of political assassinations carried out by the LTTE destroyed the potential for the democratization portended by the elections. The LTTE also launched a bomb attack on 25 January 1998 against the Dalada Maligawa or "Temple of the Tooth", the premier Buddhist symbol of religious and temporal power in Sri Lanka, and thereby decisively altered calculations regarding a referendum on devolution. The independence celebrations were to be held at the site of the temple in Kandy.

Launched in May 1997, the Jayasikuru military offensive was aborted in October 1998 after the LTTE overran the military camp at Killinochchi killing over a thousand Sri Lankan troops. The focus of attention then shifted to a series of provincial elections, culminating at the end of 1999 with a presidential election called over a year ahead of schedule. A mandate for the political resolution of the ethnic conflict was the stated purpose for this decision.

\section{Recent political and military developments}

In November 1999, after the presidential election was announced, the LTTE scored another military victory by capturing chunks of territory in the Wanni region of the northern province, which the security forces were reported to have taken two years to capture. Consequently, the presidential election was fought under conditions of censorship of military news. Whilst intense partisan politicking dominated the contest, including allegations of a UNP LTTE conspiracy at the heart of the military defeat in the Wanni, one issue came to the fore with regard to a resolution of the ethnic conflict and was the subject of considerable controversy. 
Ranil Wickremesinghe, the UNP candidate and leader of the Opposition, proposed that an interim council for the north-east be set up with LTTE participation for a period of two years to prepare the ground for a lasting political settlement. He had earlier proposed that there be deescalation of the conflict and asymmetrical devolution for the north-east. Part of the UNP strategy vis-à-vis the government's devolution proposals was to label them as irrelevant, in the face of LTTE rejection, and to argue that talks with the LTTE had to be initiated. The government, on the other hand, whilst not averse to resuming talks with the LTTE, always hoped to be able to do so from a position of military advantage. Wickremesinghe's interim council proposal was roundly castigated for being tantamount to handing the north-east to the LTTE, indefinitely. ${ }^{10}$ It brought out the entrenched fear and loathing of the LTTE, and raised questions about popular willingness to entertain a political settlement with them.

Indeed, the dilemma of conflict resolution in Sri Lanka continues to be the choice between the peace that can be sought with the LTTE and the peace that can be had without them. The former will entail incorporation of the Thimpu Principles (a statement of the principles of self-determination agreed to by all Tamil political representation in talks with the Sri Lankan Government at Thimpu in 1985) and asymmetrical devolution based on them in a constitutional settlement. ${ }^{11}$ The latter will involve either the military and political marginalization and/or defeat of the LTTE, and the emergence and effectiveness of credible, alternative Tamil political representation to implement the devolution proposals. None of this has been forthcoming as yet.

Whilst Wickremesinghe won the bulk of the Tamil vote in the presidential election, the incumbent president Chandrika Bandaranaike Kumaratunga won the election and a second term with 51.12 per cent of the popular vote. The LTTE intervention to influence the outcome of the election extended to a suicide bomb assassination attempt on the life of the President as she was leaving her last election rally on 18 December. The unsuccessful attempt blinded her in one eye.

The configuration of circumstances following the election raised hopes that there could be a national government and that negotiations with the LTTE would be commenced in earnest. Conciliatory statements by the President, including an invitation to the leader of the Opposition to join her in the search for a settlement, were largely responsible. She revealed that she had attempted to open talks with the LTTE through the good offices of the Commonwealth Secretary General and the government of Norway, and that she had been rebuffed in both instances. ${ }^{12}$ This had been earlier confirmed by LTTE leader Prabhakaran in his annual Heroes Day speech (26 November 1999) in which he referred to the Kumaratunga government as a "curse on the Tamil people". ${ }^{13}$ 
In January 2000 it was officially announced that Norway had been identified as the third party to assist in talks between the government and the LTTE, and by February the UNP leader of the Opposition, breaking the past pattern of bipartisan relations, announced his party's willingness to support the government's 1997 draft Constitution were it to be brought to Parliament. What followed the UNP leader's announcement was a reopening of discussions on the $1997 \mathrm{draft}$, first within the ruling PA coalition, then with the UNP and the Tamil parties. It was assumed that the consensus that emerged from these talks would be presented to the LTTE.

The PA-UNP talks stretched over a period of five months and resulted in the whittling down of the devolution proposals. Whilst the unitary state clause of the 1978 Constitution was dropped, so was the concept of a "Union of Regions". Tamil parties tried to restore the 1997 devolution provisions as a minimum position for incorporation in the proposed new Constitution. They succeeded to some extent, and hoped to present further amendments to the document once it was presented to Parliament in August.

The LTTE, in the meantime, scored a spectacular military success in late April 2000. They overran the Elephant Pass military complex at the entrance to the Jaffna peninsula and positioned themselves to take Jaffna town and the air and naval bases at Palaly and Kankesanthurai, respectively. They were also in a position to capture or destroy the core of the Sri Lankan Army, some 30,000 troops, who were isolated as a consequence of the Elephant Pass debacle.

In May, expectations were rife that the LTTE would take control of the peninsula - a sine qua non, it was believed, for their engaging in any talks. The Sri Lankan government sought military assistance from India, and the very forces that had opposed Indian intervention in 1987 appealed to India for help. The Indian response was to offer "humanitarian assistance" if requested. Weaponry was hurriedly acquired from Pakistan, Iran, and the Czech Republic, and diplomatic relations were re-established with Israel to obtain Kfir fighter aircraft and military material. Consequently, there has been a lull in the fighting, and whilst the LTTE has not advanced, it has not been ousted either.

The presentation of the new Constitution to Parliament in its dying days, plus an amendment to the current Constitution, which sought to amend the electoral system, was to be debated, amended, and passed: all within a space of three weeks at the most. The Constitution bill was presented to the Supreme Court for determination as a "bill urgent in the national interest", and likewise the Seventeenth Amendment to the current Constitution, which sought to change the electoral system. In both cases, the court determined in a space of 24 hours, as it was constitutionally mandated to, that the government could go ahead. The government 
had informed the court that it intended to pass the new Constitution by a two-thirds majority in Parliament, and thereafter subject it to an islandwide referendum, as required by the current Constitution. The court did not address the question whether the referendum could be held in the lifetime of a parliament other than the one which passed the Constitution.

In the case of the Seventeenth Amendment, the court determined that the government could go ahead with a two-thirds majority and without the requirement of a referendum. In both cases, there were a host of petitions to the court submitted by political parties, religious and civilsociety organizations, citing lapses and lacunae in the process of constitution-making. In the case of the proposed change to the electoral system, petitioners argued that it fundamentally affected the franchise, and therefore required a referendum. None of the petitions on either score were successful. ${ }^{14}$

The questions of process on which most of the petitions challenging the method of passage of both the new Constitution and the proposed change of the electoral system were based go to the core of the problem of democratic governance and the acknowledgement of pluralism in its institutions and processes.

The government has argued that since 1995 there has been sufficient consultation and advocacy of the devolution proposals, and therefore the arguments about a "secret" process and the lack of public participation in the constitution-making, on the lines of South Africa or Thailand, for example, do not hold. It charges the UNP with reneging on the understanding reached during the talks with them to support the Constitution. It also points out that a number of UNP proposals have been incorporated in the new Constitution, including the interim council concept.

Whilst it is correct that the government and civil society groups did engage in public information campaigns and advocacy on behalf of the devolution proposals over the last five years, it is also the case that there was no time provided to the public to acquaint itself with the final composite document presented to Parliament. The question also arises as to whether the limited time provided was sufficient for parliamentary debate on crucial issues, such as the Constitution and the electoral system. Furthermore, there has been no record presented to the public of the various deliberations, ranging from the parliamentary select committee to the PA-UNP talks. Moreover, the Constitution is about more than devolution, it is also about the supremacy of the Constitution, fundamental rights, the independence of the judiciary and judicial review of legislation, all vital safeguards in a pluralist democracy.

The proposed new Constitution is also about the abolition of the Executive Presidency and the return to fully-fledged parliamentary democracy. It contains transitional provisions in this regard. These have been 
the source of considerable controversy in that they provide for the current President to retain her office and enjoy the executive powers of prime minister under the proposed new Constitution for a period of six years. The transitional provisions were cited by some as the basis for their opposition to the new Constitution. The President has promised to abolish the Executive Presidency - an office seen by the PA as the source of authoritarianism by July 1995.

The new Constitution and the proposed change in the electoral system were complementary exercises, and whilst there has been public discussion on devolution, there was none on the change to the electoral system. In fact, right up to the dissolution of Parliament, the government assured the people that the impending general election would be fought on the existing electoral system.

The government's strategy seems predicated on profound distrust of the UNP and the conviction that it would vote against the Constitution at the last moment. The UNP defence has been that provisions not agreed upon were included therein, and that there was an understanding that the document would be presented to the LTTE and the Buddhist clergy (or "Sangha") before it was introduced in Parliament.

With regard to the Seventeenth Amendment, it is clear that the government wanted to adopt a system that would give it a two-thirds majority in Parliament. This, in turn, could have been used for, amongst other things, amendment of the new Constitution in the future, including, perhaps, agreement with the LTTE on a political solution, were that possible. The proposed Seventeenth Amendment provided for a parliament of 298 members, of which 168 were to be elected on a "first-past-the-post" basis, another 100 on district-based proportional representation, and 30 from a national list nominated by political parties and based on their share of the popular vote. ${ }^{15}$

The danger inherent with this process of constitution-making is that it has allowed the opponents of devolution to present themselves as the champions of the democratic process and transparency by derailing constitutional reform for the moment. Moreover, the problems of process and their impact on both democratic governance and conflict resolution could arise if the government sought to promulgate the new Constitution after the general elections on the basis of a mandate secured in that election. Given the current proportional representation system of election, it is virtually preordained that no party can obtain a two-thirds majority in the legislature.

Were a new constitution to be promulgated on the basis of a mandate underpinned by a simple plurality of the legislature, this would clearly be unconstitutional under the terms of the present Constitution as well as the Supreme Court determination regarding two-thirds majority and countrywide referendum. Importantly, it should be pointed out that any 
constitution so promulgated could be abrogated by the same procedure. Accordingly, the guarantees to minorities and the devolution provisions will always be vulnerable to the vicissitudes, whims, and fancies of partisan politics. Every party that has come into power since 1970 has changed the Constitution to suit its needs. There is a distinct possibility that this bad practice would be perpetuated.

The "mandate theory" procedure for promulgating a new Constitution was compounded by the results of the general election, which made the government heavily dependent on the support of the smaller and minority community parties, and also the manner in which the elections were conducted. Serious allegations of electoral violence and malpractice implicating the ruling party were made during the elections, and grave doubts persist about the freeness and fairness of any electoral contest. The very forces that agitated against the Constitution, particularly because it was quasi-federal and departed from the unitary state, will be able to present themselves as the champions of the democratic process if the results of the referendum on the Constitution are seen to be manufactured by electoral violence and malpractice.

From the perspective of pluralist governance, process is important, because it is through process that the legitimacy crucial to the durability and effectiveness of the Constitution can be obtained. Any "ends-justifythe-means" logic with regard to constitution-making will imperil governance in the long term. The dilemma, nevertheless, remains as to how a constitution that lays the foundations for a pluralist democracy can be promulgated in the face of entrenched institutional and cultural bias against it. The same forces that were galvanized against the Constitution because it espoused the devolution of power launched a successful challenge to the government's attempts to introduce equal opportunity legislation in September 1999. The legislation had to be withdrawn. ${ }^{16}$

Partisan politics defined by a zero-sum political culture militating against a political solution to the ethnic conflict has been alluded to above. It has frustrated attempts to accommodate minority grievances throughout the post-Independence period and thereby given rise to armed ethnic conflict. Despite the optimism afforded by the PA/UNP talks in early 2000, it has resurfaced in the aftermath of the general election. There are other factors worthy of comment, which relate directly to the insecurities entangled in the ethnic conflict and governance.

\section{The Sangha and the media}

The role of the Sangha is of especial significance and is linked to the perceptions of insecurity on the part of the majority Sinhala community. ${ }^{17}$ The conflict in Sri Lanka has been described as "one between two 
minorities", or one in which the majority has a minority complex and vice versa.

The extent to which the majority community too has a perception of grievance and insecurity is attested to by the establishment of a nongovernmental Sinhala Commission in 1998 ostensibly to inquire into the grievances of the majority community, 50 years after Independence and 15 years after the armed ethnic conflict started. Its real target was the government's devolution proposals, and many associated with this group have joined with other groups such as the National Movement Against Terrorism (NMAT) to found a new political party named "Sinhala Urumaya" (Sinhala Heritage). The depth of this majority-community feeling of grievance and discrimination must be measured against entrenched constitutional provisions since 1972 relating to the unitary state and granting "foremost-place" status to Buddhism, the religion of the majority and, until the 1987 Indo-Sri Lanka Accord, the institutionalization of the Sinhala language as the official language of the country since 1956.

This majority-community perception, with its espousal of the trinity of the land, the race, and the faith, arises from perceptions of discrimination under colonial rule and the fear of being dwarfed in a region in which there are some 60 million Tamils in the South Indian state of Tamil Nadu and more in Southeast Asia. From this perspective, the Tamils have other options and other places to go to: the Sinhalese have only Sri Lanka. Therefore, the Tamils and other minorities must accommodate the Sinhalese.

Members of the Sangha have been amongst the most forceful proponents of this perspective. Their stance is augmented by defining the ethnic conflict as a problem of "terrorism", and therefore one that should be resolved through military victory, not political negotiation. Historically, the Sangha has been at the forefront of the development of the Sinhala language and culture, and, in the era of mass democratization, has been drawn into politics as a legitimizing force. Whilst their influence may not be as widespread now as it has been in the past, and although, in political terms, they cannot be said to constitute a homogeneous monolith of chauvinist opinion, they do retain a powerful hold on popular opinion as figures of authority and as community leaders.

Another factor that bears mention is the media, which, in Sri Lanka, is divided into the state-owned and privately-owned organs. The former are at the service of the government of the day and operate largely as the propaganda tools of the party in power. As far as a resolution of the ethnic conflict is concerned, the state media have been fully utilized to support the devolution package.

The attitude of the private media to the current government ranges 
from the uneasy to the adversarial, and this invariably affects their position on the ethnic conflict. That they may criticise the government's management of the conflict should not obscure the stereotype and bias it (and the state media) subscribe to in the coverage of the conflict and the attempts to resolve it.

Popular prejudices about terrorism and ethnic grievance, as well as ethnic stereotypes, abound. Coverage falls within the confines of the prevailing dominant paradigm and little attempt is made to pursue stories not incorporated in official accounts. There is a discernible willingness to cover the conflict from Colombo, and to accept the version of events handed down by the publicity organs of the principal protagonists. Independent accounts are rare. Indeed, as a result of the availability of international networks, the average Sri Lankan has a better idea of what war has done to Bosnia and Rwanda, for example, than of what it has done to the Jaffna peninsula. The failure of the media in this respect is, in turn, a key factor in the absence of a critical mass of opinion that could be mobilized as an effective peace constituency.

In defence of the media, and from the perspective of governance, the relationship that has evolved between the state and the media must be mentioned. In the 17 years of UNP rule, in which many human rights abuses took place, and in which the crisis of democratic governance was brought to a head, the alternative media acted as sources of criticism of the regime. As a consequence, there was harassment of media institutions, and journalists were abducted and murdered. The possibility of a return to this climate of fear and repression is sometimes cited as a sobering factor, inhibiting the media from violating censorship regulations covering war reporting, and adopting self-censorship in the absence of regulations. Whilst these fears cannot be discounted, they do not hold equally for all media organizations, and the extent to which the media are the repository of public prejudice and stereotyping, as far as the ethnic conflict is concerned, should not be underestimated.

\section{Democratic governance: the media, civil society and the electoral process}

\section{The media}

The role of the media as essential institutions of democratic governance bears further elaboration. Government-media relations have undergone severe strain over the last six years, and have plummeted from the level of cordiality and optimism that obtained in 1994. As a consequence, acrimony, charge and counter-charge, confrontation and fear characterize 
the relationship between the government and the private media. The government maintains that the private media are partisan in favour of the UNP opposition. This is a reason cited for its retention of the statecontrolled media. It argues that the private media will always be used in the service of the Opposition to frustrate radical change and the realization of its progressive agenda, including the devolution of power as the basis for a solution to the ethnic conflict. The reasons for the deterioration in relations, however, go deeper and can be traced to the situation that obtained in the PA's ascent to office. Whilst this is especially true of the private alternative media, it also reflects a situation that obtains in respect of some civil society organizations working for democratization and human rights.

Alternative media organizations and civil society groups in this area were closely associated with the PA, and worked for the defeat of the UNP in 1994 on the grounds that such an outcome was essential for the survival of democracy in Sri Lanka. Once in office, the PA government set up a series of committees to advance media freedom, including the reform of media laws. The reports of these committees were never published, but there have been attempts by the government to introduce legislation to control the media, like the proposed Independent Broadcasting Act of 1997. As a consequence of a campaign against it and the Supreme Court declaring it unconstitutional, the Act was withdrawn. In the wake of this, the government set up a parliamentary select committee to look into media reform. The committee has yet to release its findings.

The private media allege further instances of the government's bad faith, such as the frequent recourse to the law of criminal defamation against journalists. More recently, media organizations alleged that the Presidential Security Division was responsible for an attack on journalists covering an opposition rally (July 1999), for violent attacks on journalists critical of the government, and for the murder of a newspaper editor (September 1999) as clear evidence of authoritarianism. In early January 2000 , the state electronic media alleged that two editors of private newspapers were involved with the UNP and LTTE in a conspiracy to overthrow the government. The President herself, in an island-wide television broadcast (3 January 2000), publicly castigated two editors by name as agents of the Opposition. ${ }^{18}$

The private media's response to the government argument that they are flagrantly abusing the unprecedented climate of media freedom ushered in by the PA Government is the counter-argument that media freedom is not the gift of the PA, and that sections of the media played key contributory roles in the PA's ascent to power. They insist that it is their right and duty to expose lapses and lacunae in the government. Investigative reporting and exposes of continued corruption in government by 
certain media organs, whilst labelled as partisan by the ruling party, have raised public awareness about the impediments to governance in Sri Lanka.

An improvement in the government-media relationship and its elevation to that of a constructive interaction is necessary for governance. Unfortunately, there are no indications of an improvement in the relationship, rather a worsening of the situation following the general elections. There is no gainsaying the government argument about media bias and corresponding shortcomings in professional standards. On this score at least, there is some hope held out in the recognition by media organizations of the need for voluntary self-regulation and maintenance of professional standards, codes of ethics and conduct. This was initially flagged in the media organization's Colombo Declaration of Media Freedom and Social Responsibility issued in April 1998, which lays the foundation for a self-regulatory organization. This is expected to be convened in the near future.

\section{Civil society}

As mentioned, whilst this applies to civil society organizations working in the field of democratization and human rights as well, there are other dimensions to the relationship between these organizations and the government. ${ }^{19}$

The concern here is with the risk of partisan politicization of organizations whose raison d'être is the checks and balances of governmental power in the interests of democratic governance. Were such organizations to find themselves in either a situation of indefinite confrontation with the government, or alternatively one of co-option and subservience, democratic governance will be affected adversely. This is an issue that arises, in particular, with regard to the resolution of the ethnic conflict and the propagation of devolution and meaningful power-sharing as indispensable to its resolution. Whilst on the one hand there are organizations openly hostile to this, on the other, there are those which, in their association with the government in this campaign, have laid themselves open to the charge that they are acting as its agents, as opposed to independent actors which are supportive of the government on this issue. For instance, conviction in the indispensability of devolution to conflict resolution is not synonymous with exclusive support of the government's devolution package. There is a danger here that on governance and human rights issues, these organizations could take on the role of "service providers" on behalf of the government in these areas - a situation which occurred in the area of poverty alleviation in the late 1980s and early 1990s. 
The argument for an issue-based democratic, secular, civil society agenda may be difficult to realize in practice when the issues are hotly contested in political life and define party positions. Moreover, the relationship between the government and civil society organizations is invariably an asymmetrical one in favour of the former. The current government, like its predecessors, has attempted to pass legislation to control non-governmental organizations effectively on the grounds that it is the government's responsibility to ensure financial probity in this sector. The effect of such legislation would be to obliterate the distinction between the governmental and non-governmental sectors and thereby weaken the prospects for democratic governance. Yet the carving out of a separate and distinct space for civil society organizations in the face of such challenge is indispensable for the vital contribution they make to plural and democratic governance.

\section{The electoral process}

Regular, free, and fair elections with multi-party democracy have been identified in the Human Development Report in South Asia 1999 as one of the basics of good political governance. In Sri Lanka, the issue of free and fair elections has become a cause for grave concern in the last three decades, since threats to the integrity of the electoral process as the basic mechanism of choice and change in a functioning democracy cumulatively destroys public confidence in democracy itself. It should be noted that Sri Lankans have enjoyed universal adult franchise since 1931.

The issue of election violence and malpractice is inextricably linked to the zero-sum political culture cultivated and perpetuated by the main political parties. This includes the extensive use of patronage in all walks of life, as well as across-the-board partisan politicization of the institutions of civil society. Consequently, each election (even those at the level of cooperative societies in which manslaughter and murder are not uncommon, or even that of the Cricket Board) is seen as a matter of life and death in which physical safety, security, and well-being are at stake.

The lack of intra-party discipline and democracy is at the core of this problem. This is reinforced by institutional and procedural decay which make extra-parliamentary and extra-judicial methods of problem-solving and dispute settlement attractive in comparison, thus enabling those who are the least respectful of democratic norms to get elected, and ensuring their re-election as well. And once elected, they demonstrate that the requirements of winning an election are not only quite different to those of governance, but in direct violation of it as well.

Whilst party leaders make rhetorical commitments to non-violence and exercise party discipline on members identified as perpetrators of vio- 
lence and malpractice, encouragement and promotion of such individuals by the very same party leaders is a common occurrence. The latest example is the reappointment of General Ratwatte to the post of Deputy Minister of Defence, despite complaints against him by cabinet colleagues alleging major campaign and election day violence and malpractice. ${ }^{20}$ This is corroborated by the reports of both international and local monitors on the October 2000 general election. ${ }^{21}$ General Ratwatte's appointment to this ministry and to the cabinet is not the only such example. There are others, in a total of over 40 , who have been appointed despite allegations of electoral violence and malpractice against them. During the election campaign, the President gave an assurance that such appointments would not be made. ${ }^{22}$

The cynicism and sense of powerlessness on the part of the voter is also compounded by the partisan politicization and undermining of the institutions charged with the conduct of elections - namely, the Election Commission, the police, and the public service. Whilst reform of the law will embolden them in the performance of their duties, the pervasive culture of patronage, violence, and retribution could persist and undermine progress, as it does at present with regard to the observance and exercise of existing laws and regulations.

Civil society groups monitoring elections have highlighted the pervasive use of violence in elections. ${ }^{23}$ They have, in turn, been subject to vilification and attack as agents of the Opposition. This was the case in the provincial council elections throughout 1999, with that in the northwestern province being widely acknowledged as an egregious example of violence and malpractice, as well as in the presidential election at the end of the year and the general elections in October 2000. The 17 years of UNP rule were no exception, and the ruling PA frequently makes the point that the excesses that occurred during its tenure in office do not match those that occurred under the UNP.

Whilst it is true that no party has a monopoly of electoral violence and malpractice, it is a sad reflection on the state of governance that bad practices are sought to be justified by reference to worse ones.

\section{Some aspects of economic and civic governance}

This chapter has paid primary attention to the political and constitutional aspects of governance in Sri Lanka. This is not intended to suggest that the areas of economic and civic governance identified in the Human Development Report are problem-free or without challenge. The situation obtaining in the fields of poverty alleviation and local governance are cases in point, and by no means the only ones, which clearly indicates 
that there is a crisis of governance that can be identified, and which is not directly or exclusively related to the ethnic conflict. It is, however, a product of the partisan politicization of all spheres, impeding and distorting service delivery, and the fair and efficient utilization of resources.

These were the issues of poverty alleviation and governance in general, along with relief, rehabilitation, and reconciliation relating to the conflict and tertiary education, that constituted the agenda of the 18 December 2000 Paris Development Forum on Sri Lanka. ${ }^{24}$ Earlier known as the "Aid Consortium" meeting, the annual Paris discussion has been renamed to reflect Sri Lanka's middle-income status. The meeting in December 2000 was the first to be held after two years (elections had been the principal cause for postponement). The December 2000 meeting was not meant to result in pledges of assistance from donors, but billed as a listening and learning exercise between them and the government of Sri Lanka. However, the political and public perception of the meeting was largely adjudged in terms of the government's ability to attract more donor assistance. The real issue here was not the pledging of further assistance, but the gross under-utilization of funds already pledged and the deep, systemic problems in programme implementation and democratic governance, which donors specifically focused on at the Paris meeting.

The situation currently obtaining in the poverty alleviation field is that in the "Samurdhi" ("Prosperity"), as the government programme is called, animators are employed for party activities, and benefits are distributed according to party allegiance. In the course of the 1999 presidential election, with the assistance of the Centre for Policy Alternatives, a petition was filed by some voters in the Supreme Court requesting it to ensure that Samurdhi workers were not used for electioneering. ${ }^{25}$

The World Bank, in its report discussed at the Paris meeting, entitled "Sri Lanka: Recapturing Missed Opportunities", notes that "it is widely acknowledged that successive poverty alleviation programmes in Sri Lanka have been designed and implemented more as vehicles for political leverage/patronage at the grass-roots level than as mechanisms to create opportunities for the poor ... the political bias in the implementation of poverty programmes makes the poor highly vulnerable to changes in the political climate". ${ }^{26}$ It also states that programme officials charged with the identification of beneficiaries are political appointees, and cites documented research and surveys to show that party affiliation and voting patterns determine the allocation of income transfers to beneficiaries. The report also notes that the "central government's control over the delivery of poverty programmes and social services devolved to the provinces has inhibited the development of local institutions better able to represent the needs of the poor" (emphasis in original). ${ }^{27}$

That the centralizing mindset of the bureaucracy and its political masters has severely affected the emergence of true local governance is a 
central theme of the 1999 research study done by Shelton Wanasinghe entitled, "Effective Local Governance: The Foundation for a Functioning Democracy in Sri Lanka". Wanasinghe too identifies the politicization of the bureaucracy and the consequent alienation of the people from the institutions of local governance resulting in corruption and a lack of commitment to public good and services. He notes that "local government has not escaped the insidious intrusion of patronage networks that have come to characterize all levels of the Sri Lankan polity and to affect the functioning both of the electoral system as well as of the political and bureaucratic institutions at these different levels. These patronage networks have been major contributors to the pervasive corruption that characterizes the Sri Lankan polity and influences its bureaucracy." 28 Local government, in short, is devoid of local governance, and is a mere extension and creature of the power relationships at the centre. Likewise, the bureaucracy.

\section{Conclusion}

The current political debate centres around the prospect of negotiations with the LTTE with Norwegian facilitation and against the backdrop of a month-long unilateral ceasefire by LTTE leader Prabhakaran, which has now been extended twice, each time for a further month. In contrast, the government insists that the two sides can talk and fight at the same time. The government is determined to ensure that it will not be inveigled into talks which will be broken off by the LTTE once it is ready and able to resume hostilities. Hard-line opinion, citing the improved performance of the army as the better mechanism for conflict resolution, and the UK ban on the Tigers are contributory factors. Another key element in the current political configuration is the rising cost of living, with dire prognostications of worse to come. The debate also centres on opposition and civil society demands for independent commissions to deal with the public service, elections, the judiciary and the police.

The degree of international interest and pressure is such that both sides may have to commence talks or risk a debilitating war of attrition in the future. Both protagonists as well as the UNP opposition favour talks, but the modalities are yet to be worked out. No doubt, political, economic, and military exigencies will determine this. It is clear, though, that the need of the hour is to commence a process of negotiation. It is also clear that negotiations are not a panacea, but they do hold out the promise of a process culminating in peace, laying the foundations for democratic, pluralist governance. There will be pitfalls and challenges on the way, including public acceptance and support for the final constitutional settlement and the method of its enactment. ${ }^{29}$ 
On all fronts, the attitude towards governance has to undergo a paradigm shift. The establishment of independent commissions, for example, will not in itself ensure governance. The Commission on Bribery and Corruption established by the current government is a case in point of an institution established with great fanfare and paralysed from the outset. The Human Rights Commission, also established by the government, has yet to reach anywhere near its potential, and the office of the Ombudsman (whose powers were augmented through government legislation), was resource-starved and is now vacant. Moreover, there is the persistent problem of appointment to commissions. Were it to be done by politicians, the pernicious influence of political patronage could undermine them.

The partisan politicization of all aspects of governance needs to be combated. With its zero-sum culture, inherent fear and suspicion of pluralism and diversity, it is central to the crisis of legitimacy of both institutions and processes of government, and hence of governance in Sri Lanka. This will entail internal party democracy and the strengthening of those institutions meant to serve as checks and balances on the exercise of executive power and authority. It will also entail an espousal of meaningful devolution and power-sharing as a sine qua non of peace and prosperity. An end to the conflict is a necessary condition for democratic governance in Sri Lanka. However, it is by no means sufficient. Yet, with it, the crucial paradigm shift in the political culture will have space to expand and be consolidated.

As Wanasinghe observes, "Fifty years after Independence, a democratic way of life in Sri Lanka has yet to be institutionalized as a viable system of governance." He goes on to contend that:

the experience of the first half of the century of independence has, thus, underscored the need for a strategy for the enforcement, by the citizens, of continued vigilance and accountability over the political institutions at the different levels as well as over their administrative apparatus. This is a prerequisite for the Sri Lankan polity to cease being a parody of democracy and to begin to evolve as a functioning democracy. ${ }^{30}$

Ultimately, it is a matter of the polity reconciling the governance it desires with what it believes it deserves.

\section{Notes}

1. See also Paikiasothy Saravanamuttu (2000) "Sri Lanka: The Intractability of Ethnic Conflict", in John Darby and Roger MacGinty, eds., The Management of Peace Processes, London: Macmillan Press, pp. 195-227. 
2. A valuable collection of essays on all aspects of constitutional reform in Sri Lanka is Chanaka Amaratunga, ed. (1989) Ideas for Constitutional Reform, Council for Liberal Democracy, Sri Lanka, and Friedrich Naumann Stiftung.

3. For analyses of the events leading up to the 1987 Indo-Sri Lanka Accord and the attempts at negotiations, see Ketheshwaran Loganathan (1996) Sri Lanka: Lost Opportunities, Colombo: Centre for Policy Research and Analysis, University of Colombo; Kumar Rupesinghe, ed. (1998) Negotiating Peace in Sri Lanka: Efforts, Failures \& Lessons, International Alert of London, February; Robert I. Rotberg, ed. (1999) Creating Peace in Sri Lanka: Civil War and Reconciliation, Washington: Brookings Institution Press; and Paikiasothy Saravanamuttu (1990) "Instability in Sri Lanka", Survival XXXII(5), September/October, London: Brassey's International Institute for Strategic Studies.

4. "Government has no intention of Suppressing People through Emergency Regulations President", Daily News, 4 May 2000, "War footing" effective from 3 May 2000. The price of diesel went up by 25 per cent, kerosene by 48 per cent, LP gas by Rs. 30 per cylinder and bus fares by 15 per cent in February (Island, 8, 9 February 2000). Following the 5 per cent devaluation of the rupee, prices of consumer items went up by 10 per cent in June (Island, 20 June 2000). A 20 per cent increase in the price of industrial gas followed in November and the price of diesel and kerosene was increased by a further Rs 2 $(15,16,19$ November 2000). See the Budget Speech for details on defence expenditure (Daily News, 9 March 2001).

5. "Sri Lanka Lagging Behind Asian Economies Because of War", Daily News, 4 May 2000.

6. "25 Killed in Mob Attack on Detention Camp", Daily News, 26 October 2000. "Twenty Years of the Prevention of Terrorism Act", monograph of the seminar held on 11 December 1999 by the Centre for Policy Alternatives.

7. "Britain Bans the LTTE", Island, 1 March 2001. The list of 21 "terrorist" organizations was announced on 28 February. "The Need for a British ban on the LTTE", Daily News, 1 March 2001. The United States proscribed the LTTE on 8 October 1997; India banned the LTTE in May 1992, and thereafter extended the ban every two years, as required.

8. Ministry of Justice and Constitutional Affairs (1996) Draft Provisions of the Constitution Containing the Proposals of the Government of Sri Lanka Relating to Devolution of Power, Including a Commentary on the Draft Constitutional Provisions, 38978-50, 000(96/01), p. 28.

9. "TULF Under Pressure", Daily Mirror, 7 August 2000. The TULF adopted a resolution to oppose the bill due to its inadequacies regarding three key factors the structure of the state, the unit of devolution, and the question of land.

10. "Ranil Proposes Interim Council for North and East", Daily News, 19 November 1999. See also, Daily News, 1, 7, 8, 15, 20 December 1999. Also Paikiasothy Saravanamuttu (2000) "Sri Lanka in 1999", Asian Survey XL(1, January/February): 219-225.

11. See Rohan Edrisinha (1999) "Constitutionalism, Pluralism and Ethnic Conflict", in Rotberg, ed., op. cit., pp. 169-189; and Rohan Edrisinha (2000) "Federalism and the Case for Radical Constitutional Reform in Sri Lanka", in K.M. de Silva and G.H. Peiris, Pursuit of Peace in Sri Lanka: Past Failures and Future Prospects, International Centre for Ethnic Studies, Colombo, Sri Lanka, pp. 163-183.

12. "Prabhakaran Should Give Up his Politics of Terror and Come to the Negotiating Table President", Daily News, 31 December 1999.

13. "Prabhakaran Offers Talks at 'Heroes Day' Speech", Island, 28 November 1999.

14. See Daily Mirror, 5 August 2000, and Island, 6 August 2000.

15. "Ministers Rebel over Reforms", Sunday Leader, 6 August 2000; "Electoral Reforms Bill Withdrawn", Island, 9 August 2000. 
16. "Equal Opportunities Bill will Not be Tabled in Parliament, AG assures court", Island, 19 October 1999. See also Daily News, of 19 October 1999 and Sunday Observer, 10 and 17 October 1999.

17. H.L Seneviratne (1999) The Work of Kings: The New Buddhism in Sri Lanka, Chicago: University of Chicago Press.

18. "President Kumaratunga Bares her Heart out to the People", Daily News, 5 January 2000.

19. Paikiasothy Saravanamuttu (1998) "Sri Lanka: Civil Society, the Nation and State Building Challenge", in Alison Van Rooy, ed., Civil Society and the Aid Industry, London: Earthscan Publications, pp. 104-133.

20. "D.M. Fires Bombshell at Two Ministers", Daily Mirror, 6 October 2000; "Hakeem Condemns Mass Scale Rigging, Violence", Island, 11 October 2000; "Verdict Not Free and Fair", Sunday Leader, 15 October 2000.

21. "Commission of Inquiry into Kandy Election Violence", Daily News, 30 October 2000; "Was it Free and Fair", editorial, Island, 12 October 2000; "Most Serious Election Violence Reported from Central Province", Daily Mirror, 13 October 2000; "Prompt Action on Alleged Election Offences in Kandy", Daily News, 11 October 2000. See the EU Electoral Observation Mission to Sri Lanka, Final Report, Parliamentary Election, 10 October 2000.

22. "Join Hands for New Political Culture Devoid of Violence and Terror", Daily News, 30 September 2000.

23. "Vote Against Violence, say Religious Leaders", Island, 5 October 2000. "Election Related Violence on the Increase" Centre for Monitoring Election Violence (CMEV), Island, 18 September 2000; the CMEV is made up of the Centre for Policy Alternatives (CPA), the Free Media Movement (FMM) and the Coalition Against Political Violence. All its election monitoring reports can be accessed on http://www.cpalanka.org. Since it called for the annulment of the January 1999 North-Western Provincial Council election, CMEV has been accused of being partisan by the ruling PA and regularly attacked by the PA in the state-controlled media. The CMEV was threatened with criminal defamation in the aftermath of this provincial council election: "Two Senior Ministers to Sue Centre for Monitoring Election Violence for Criminal Defamation", Daily News, 28 January 1999. Also see "Party Leader Must Insist on Non-Violence Peoples Action for Free and Fair Elections (PAFFREL)”, Island, 27 August 2000. The PAFFREL monitors elections with the Movement for Free and Fair Elections (MFFE).

24. "Paris Forum Focuses on Four Development Areas", Daily News, 15 December 2000.

25. "Misuse of State Resources by the Government for Election Purposes", C.A. No. 1215/ 99 filed on 9 December, 1999; 'Samurdhi Niyamakas Cannot be Used for Elections', Weekend Express, 18 December 1999: court order issued on 17 December 1999.

26. World Bank (2000) "Sri Lanka: Recapturing Missed Opportunities", Report No. 20430CE, 16 June, p. 36.

27. Ibid., p. 37.

28. Shelton Wanasinghe (1999) "Effective Local Governance: The Foundation for a Functioning Democracy in Sri Lanka", Research Studies: Governance Series No. 5, Institute of Policy Studies, May, p. 5.

29. Centre for Policy Alternatives (2001), A Commentary-Seminar Series on Structure and Processes of Negotiations: Some Lessons \& Reflections, January; and PA-UNP Consensus on the Constitution, Centre for Policy Alternatives, forthcoming. See also, Jayadeva Uyangoda (1999) “A Political Culture of Conflict", in Rotberg op. cit. (n. 3 above), pp. 157-168; and Liz Philipson (1999) "Breaking Recurring Themes in the Cycles of War and Peace in Sri Lanka", Research Paper 3, London: Centre for the Study of Global Governance, London School of Economics and Political Science.

30. Wanasinghe (1999) op. cit. (n. 28 above), pp. 2 and 3. 


\section{Part III \\ Environment}



6

\section{Sustainable development and human security: Lessons from South Asia}

Adil Najam

Like all concepts that are fundamental to the definition of their disciplines, the term "security" has remained a subject of constant enquiry, debate and evolution. Although the extent of exactly what is being "secured", for whom, by whom, and how have long been in some contention, the interest in what is now called "non-traditional" security gained considerable momentum in the wake of the end of the Cold War.

During the last half century the term "security" was primarily a matter of states and their military alliances, principally applied to the "security" of borders and institutions from outside threats. ${ }^{1}$ The bipolar nature of world dynamics that prevailed during the period intensified the emphasis on external threats. Such a definition, although considered minimalist by some, is accepted by many because military threats to security are easily identifiable and carry clear and often extreme consequences. In contrast, non-military threats within nations, such as poverty, social vulnerability, or ecological resiliency are generally not perceived as concrete and tangible. A key conceptual difference between the two approaches is that the traditional definition of security presupposes that threats arising from outside the state are more dangerous to the state than threats that arise within it.

Recent debates on whether and how the concept of security might be expanded beyond issues of geo-polity, international power balance, military strategy and statecraft have been both intense and rich. ${ }^{2}$ One strand of this debate on non-traditional security issues relates to the increase in 
attention paid to the connection between the natural environment and security. Scholarly discourse in this area has been prolific. ${ }^{3}$ Environmental issues require new ways of thinking about policy, including security policy, because the environmental problematique is distinct by its very nature and must be kept separate from many other "traditional" issues. ${ }^{4}$ The means of international environmental policy-making tend to be more consensual and cooperative than in other arenas, ${ }^{5}$ and these issues involve a very different set of actors, notably nongovernmental organizations. $^{6}$

This chapter presents the key lessons that emerge from a South Asiawide study that explores environment and security links in the context of South Asia. While it is not the explicit goal of this chapter to posit and defend a new and better framework for studying questions of environment and security, it is our hope that we will be able to contribute to such a framework. South Asia (and the nations within it) has already been the subject of earlier research on environment and security. ${ }^{7}$ Here, our principal concern is not on the specific experience of particular South Asian countries or the region as a whole. Our focus is on what this South Asian experience can contribute to the larger conceptual literature on environment and security - or, to be more precise, on sustainable development and human security. We do so in the context of the conclusions of the aforementioned study. ${ }^{8}$ We begin with a quick review of the literature on environment and security, which leads us to develop a framework for organizing this discussion.

\section{Environment and security: are the links real?}

It has been argued that the environment is among the earliest and most pervasive sources of human conflict - and therefore of security concerns. Water, for example, has been - and remains - one of the most persistent sources of conflict at every level: international, national, community, and even individual. Energy is similarly one of the most potent motifs of environmental as well as security issues at every relevant level, from supranational to individual. Looking at environment and security links from a different perspective highlights the deep relationship between the deterioration of environmental quality - whether it is in the form of urban pollution, water contamination, soil degradation, deforestation, or biodiversity loss - and human well-being. Ultimately, a threat to human well-being can be seen as a threat to human security. Indeed, one could argue that the wrong end of a smoke stack can be as much of a security concern to humans as the barrel of a gun.

For many, the linkage is patently obvious and beyond debate. As Mark Halle points out in his foreword to a literature review on the subject, 
"the relationship between environment and security feels right. It seems intuitively correct to assume a direct correlation between environmental degradation on the one hand and social disruption and conflict on the other". ${ }^{9}$ While this intuitive feeling is widely shared, it is not universally accepted. On the one hand, there is now a sizeable literature that seeks to broaden the definition of the word "security" in order to position environmental concerns as a central issue on the security agenda. Table $6.1^{10}$ presents a sampling of views from those who consider the connection between environment and security to be overwhelming and obvious. On the other hand, however, many are not entirely convinced by the passion or the conviction with which such views are articulated. At the

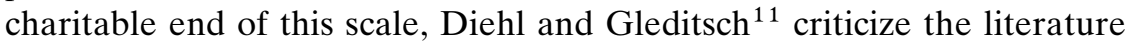
on environment and security for offering "insights without evidence"; at the less sympathetic end, Daniel Deudney considers the zeal to establish a connection between environment and security an example of "muddled thinking". ${ }^{12}$

Table 6.1 Environment and security: an "obvious" connection?

- World Commission on Environment and Development: "Nations have often fought to assert or resist control over war materials, energy supplies, land, river basins, sea passages and other key environmental resources". ${ }^{13}$

- Colinvaux: "History has been a long progression of changing ways of life and changing population ... [with] wars, trade and empire [the results]". ${ }^{14}$

- McMichael: "The end-stage of unequal power relations and economic exploitation in the world will be tension and struggle over life-sustaining resources. Fossil fuels, freshwater, farming and fish have already become the foci of armed struggles". ${ }^{15}$

- Renner, et al.: "Throughout human history, but particularly since the system of sovereign states, struggles over access to and control over natural resources ... have been a root cause of tension and conflict". ${ }^{16}$

- Myers: "National security is no longer about fighting forces and weaponry alone. It relates increasingly to watersheds, croplands, forests, genetic resources, climate, and other factors ... that taken together deserve to be viewed as equally crucial to a nation's security as military prowess. The situation is epitomized by the leader who proclaims he will not permit one square meter of national territory to be ceded to a foreign invader, while allowing hundreds of square miles of topsoil to be eroded each year". ${ }^{17}$

- Lodgaard: "Where there is environmental degradation, or acute scarcity of vital resources, war may follow". ${ }^{18}$ 
- Hassan: "Environmental deterioration leads to political deterioration, which engenders national and international insecurity". ${ }^{19}$

- Brock: "Control over natural resources has always been important in enabling a country to wage war". ${ }^{20}$

- Ehrlich and Ehrlich: "Population-related problems seem to be increasing the probability of triggering a thermonuclear Armageddon". ${ }^{21}$

- Opschoor: "Ecological stress and the consequences thereof may exacerbate tension within and between countries". ${ }^{22}$

- Galtung: "Wars are often over resources [and] destruction of the environment may lead to more wars over resources ... environmental effects make a country more offensive because it is more vulnerable to attack and because it may wish to make up for the deficit by extending the ecocycles abroad, diluting and hiding the pollution, getting access to new resources". ${ }^{23}$

- UN Security Council: "The absence of war and military conflicts amongst States does not itself ensure international peace and security. The non-military sources of instability in the economic, social, humanitarian and ecological fields have become threats to peace and security". 24

In his review of the subject, Marvin Soroos identifies four arguments that are commonly put forth by those who envision a strong link between environment and security:

- The conceptual argument that "security implies freedom or protection from serious threats to human well-being ... [therefore] whatever poses such a threat, be it in military, economic, resource, food, or environmental realms, becomes a security problem". ${ }^{25}$ The works of Ullman, Mathews and Myers, for example, tilt heavily towards such arguments. ${ }^{26}$

- The theoretical argument focuses principally on "empirical cause-andeffect relationships, in particular the potential of major environmental changes to generate and intensify [violent] conflict between and within states". This argument most identifies with the work of Thomas Homer-Dixon and his colleagues ${ }^{27}$ but also with the research of Arthur Westing (1988), Peter Gleick (1991) and others. ${ }^{28}$

- The political argument for linking environment and security seeks to "advance the environmental cause by taking advantage of the potency of the term security ... [and] bestow the [environmental] problematique with a greater sense of urgency that elevates it to the realm of "high politics". Overtones of such a rationale are apparent in the writings of many who write on the subject from an environment-centric perspective. 
- Finally, the normative case "presumes the primacy of environmental values and the threat that modern civilization poses to them" and seeks to place "societal values in a more appropriate hierarchy". One might cite authors such as Ehrlich and Ehrlich, Brock and McMichael as exemplars of this argument. ${ }^{29}$

While this characterization of the key facets of the argument remains quite valid, the discourse on environment and security has matured quite rapidly in recent years. Marc Levy ${ }^{30}$ labelled the first wave of research on environment and security as being preoccupied with rewriting the security agenda. Characteristic of this wave of research was Ullman's attempt to redefine security as follows:

A threat to national security is an action or sequence of events that: 1) threatens drastically and over a relatively brief period of time to degrade the quality of life for the inhabitants of a state, or 2) threatens significantly to narrow the range of policy choices available to the government of a state or to private, non-governmental entities (persons, groups, corporations) within the state. ${ }^{31}$

Others, such as Marvin Soroos, have also tended to define "security" very broadly, as "the assurance people have that they will continue to enjoy those things that are most important to their survival and wellbeing". ${ }^{32}$ The attempts to "play" with the definition of security so as to insert environmental concerns were resented by a number of scholars of international affairs. They therefore found it necessary to call attention to the ambiguous nature of the link between environment and security. ${ }^{33}$

The more recent literature on the subject, what Levy ${ }^{34}$ calls the "second wave", has shifted away from this thrust in two important ways. The first is to move away from the notion of security and towards the term "conflict". This has a number of important implications, including a) bypassing the conceptual debates about the definition of "security", b) getting a relatively more easily testable variable for analysis, and c) moving from an interstate to an intra-state focus. The second conscious shift made by the literature is toward more empirical research based on case studies in order to understand exactly how environment and conflict are linked. While there are multiple concentrations on this type of research in Europe and America, the most prominent work in this direction comes from the Peace and Conflict Studies Program at the University of Toronto. Eight key findings of this stream of research were highlighted in the program's 1998 book Ecoviolence: ${ }^{35}$

- Under certain circumstances, scarcities of renewable resources produce civil violence and instability. The role of this environmental scarcity is often obscure, although it generates intermediate social effects that analysts often interpret as immediate causes of conflict.

- Environmental scarcity is caused by the degradation and depletion of 
renewable resources in addition to the increased demand for these resources and/or their unequal distribution. These causes often reinforce and interact with one another.

- Environmental scarcity often encourages powerful groups to capture valuable resources and prompts marginal groups to migrate to areas that are already ecologically sensitive.

- If social and economic adaptation is unsuccessful, environmental scarcity constrains economic development and contributes to migrations.

- In the absence of adaptation, environmental scarcity sharpens existing distinctions among social groups.

- In the absence of adaptation, environmental scarcity weakens governmental institutions and states.

- The above intermediate social effects of environmental scarcity can, in turn, cause ethnic conflicts, insurgencies, and coups d'état.

- Conflict generated in part by environmental scarcity can have significant indirect effects on the international community.

Such conclusions are characteristic of the second wave of research on "environment and conflict". While these results exemplify the ways in which this research has distanced itself from traditional "security" debates, it has not been without its own problems. On the one hand, by shunning the language of security (except in the restricted terms of violent conflict) it stands open to the charge of retreating from the strong conceptual arguments an earlier generation of scholarship had made on why security should be redefined. On the other hand, many still fault it for lessening the importance of the issues due to an imprecise methodology and an ambiguous conceptualization.

In a particularly piercing review of this scholarship, Nils Petter Gleditsch identifies nine persistent problems with this new wave of research on environment and security. ${ }^{36}$ These include tendencies toward a) confusing resource scarcity with environmental degradation; b) polemically exaggerating the security aspect; c) overlooking important political, economic and cultural variables; d) devising complex and untestable models; e) using a biased selection of cases; f) reversing causality by inordinately focusing on environmental stress as a cause of conflict, g) using the future, rather than the past, as evidence; $h$ ) inappropriately generalizing between civil and interstate war; and i) muddling up different levels of analysis. In essence, such criticism constitutes a conceptual as well as a methodological challenge. In their response, Schwartz et al. ${ }^{37}$ contend that Gleditsch seeks to impose a "methodological straightjacket" of "conventional, quasi-experimental methodology" which is inappropriate for research in this area because of its inherent complexity; they defend both their methodology and their conceptual framework and stress that 
"methodological pluralism" is necessary to make sense of a subject as complex as this, as opposed to the traditional, unilateral approach that Gleditsch would have them take.

This debate is presented here to illustrate the vitality and the passion of the conceptual as well as methodological discourse in this area. Indeed, the fault lines are far more complex than a binary opposition between those who see a strong link between environment and security and those who do not. For example, Gleditsch points out that, "HomerDixon ${ }^{38}$ criticized earlier writing [on environment and security] as 'anecdotal' and has lambasted the work of a well-known environmentalist ${ }^{39}$ as being 'marked by an almost complete absence of empirical rigor and theoretical structure ${ }^{40} "{ }^{41}$ Ironically, Homer-Dixon's own case studies have been criticized by Marc Levy for offering "more anecdotes, but not more understanding". ${ }^{42}$

The point to be made, however, is that this area of research is still evolving; more importantly, it is an area characterized by rich and lively debate. There is certainly merit to the conceptual and methodological arguments of the critics. ${ }^{43}$ Even as the debate continues to rage, however, there is nonetheless an emerging unison of interest between those coming from the security side of the question and those arriving from the environmental side. Indeed, the debate has now begun to also capture popular attention via the works of authors like Robert Kaplan. ${ }^{44}$

Moreover, the debate has now earned both scholarly and policy salience. From the scholarly perspective, there is (at the very least) the acknowledgement that this is an area worth studying in order to understand and explicate the extent of the linkage (implying that it does exist and the debate is on its strength rather than its validity). From the policy perspective, the language of environment and security has begun to seep not only into the documents of international organizations such as the United Nations and the North Atlantic Treaty Organization (NATO) but also into military establishments; indeed, the US Department of Defense has had a permanent position for a "Deputy Under Secretary for Defense (Environmental Security)".

To summarize by way of responding to the question in the title of this section, there is now a growing consensus that the link between environment and security actually does exist. However, even though we have an improving understanding of the nature and extent of this link, it remains contested on both conceptual and methodological grounds. Moving forward from this, there is much interesting work being done both in terms of advancing the frameworks and ideas discussed above and in exploring related but new directions. Of particular interest to us is the currently emerging interest in looking at the issue from the perspective of human 
security and embedding it within the concept of sustainable development. The following section will outline key elements of this new development and propose a framework for organizing the various arguments.

\section{Broadening the base: focusing on human security}

The literature on environment and security has evolved over the years from its early focus on trying to expand the definition of "security", to the incorporation of environmental and related concerns, and its more recent preoccupation with understanding how environmental change can be a cause or amplifier of violent conflict. An emerging trend within this evolution has been a move towards greater emphasis on the concept of human security. ${ }^{45}$

This broadening of the base is not in opposition to the earlier trends of redefining security or of mapping the environmental roots of violent conflict. In fact, it is an outgrowth of these trends. Indeed, many of the early attempts to broaden the definition of "security" used very similar language to those who debate on "human security" today. For example, consider the following definition from Norman Myers' Ultimate Security:

security applies most at the level of the individual citizen. It amounts to human well-being: not only protection from harm and injury but access to water, food, shelter, health, employment, and other basic requisites that are the due of every person on Earth. It is the collectivity of these citizen needs - overall safety and quality of life - that should figure prominently in the nation's view of security. ${ }^{46}$

By a similar token, those who have focused on explicating the environmental causes of violent conflict have also brought the debate closer to the notion of human security, most noticeably by focusing on intra-state, and often local, insecurities. In sum, they have each pushed the debate towards "the concept of 'human security' [which] offers a third perspective that allows us to move beyond conventional security thinking, appreciates both the local and global dimensions of the many insecurities experienced by real individuals and groups, and identifies useful ways of linking security and development policies." 47

While the concept of human security has earlier roots, its recent prominence comes from the 1994 Human Development Report of the United Nations Development Programme (UNDP). ${ }^{48}$ Suhrke points out that "while offering an imprecise and controversial definition, the starting point for the UNDP was poverty rather than war - but 'security' suggested an escape from both". ${ }^{49}$ The currency of the concept was further 
advanced by the importance given to it in the report of the Commission on Global Governance. ${ }^{50}$ Both reports tried to shift the direction of the security discussion by focusing on issues of "human life and human dignity" rather than on weapons and territory.

Lorraine Elliott points out two dimensions of the human security paradigm that are of particular relevance:

The first is that the concept of "human security" provides an antidote to the more conventional focus on states, borders and territorial integrity. The answer to the question, "security for whom" is not the state but the individual and communities, which suggests that even when a state is secure from external threats or internal instabilities, security for its people is not guaranteed. Protecting individuals and communities from the consequences of environmental decline (in this case) is therefore a security issue. The second dimension is that human insecurity (which includes equity, gender, human rights and identity concerns) is a central factor in social tensions and political instabilities and conflicts that can ... become a feature of state insecurity ... If peoples and communities are insecure (economically, socially, politically, environmentally), state security can be fragile or uncertain.

Environmental scarcity becomes a distributive equity problem rather than one simply of market failure, externalities or zero-sum calculations about access to resources and environmental services. ${ }^{51}$

Indeed, as Elliott recognizes, the human security paradigm "turns the conventional security aphorism - secure states means secure people - on its head". ${ }^{52}$ Dabelko, Lonergan, and Matthew add that the concept also "helps understand the complex interactions that determine the relative distribution of security and insecurity". ${ }^{53}$ They point out that "under certain conditions, such as war, the distribution and composition of force may be the most important determinant of security and insecurity". However, "in many other situations, security and insecurity will be most closely related to poverty or resource scarcity or social discrimination". Importantly, this leads to the conclusion that "in these cases, traditional security institutions may have only a minor contribution to make, or none at all".

While Dabelko, Lonergan, and Matthew also point out the similarity between the goals of enhancing human security and sustainable development, they would agree with Astri Suhrke that a key relationship exists between the concepts of "human security" and "human development". 54 For the Human Development Report itself, "human development is a broader concept, defined as a process of widening the range of people's choices. Human security means that people can exercise these choices safely and freely". ${ }^{55}$ Suhrke also argues that this relationship is more important to understanding the concept of human security: 
There are two possible starting points for exploring the substantive core of "human security". One is in relation to the security of states, the other in relation to human development ... The major contribution of the 1994 UNDP report was its attempt to define human security and human development, and sort out their relationship. The result, however, was confusingly circular. "Human security" was presented both as an end-state of affairs - "safety from such chronic threats as hunger, disease and repression" - and a process in the sense of "protection from sudden and hurtful disruptions in the patterns of daily life" ... Human security was seen as essential for human development; without minimal stability and security in daily life, there could be no development - human or otherwise. But the obverse was true as well. Long-term development that improves social and economic life would produce human security, the UNDP report concluded. In this reasoning, there is no difference between development and human security, or between process and end-state. ${ }^{56}$

In trying to place this emerging interest in human security within the context of the evolution of the environment and security debate, one might propose a simple heuristic. In simplifying, for the purpose of exposition, figure 6.1 conceives of an environment and security "space" that is defined on one axis by the focus of analysis (ranging from statecentred to society-centred analysis) and on the other by sources of insecurity (ranging from violent conflict to social disruptions).

As we have already discussed, the early literature on the subject was concerned predominantly with state-centred discussions. While it did flirt with expanding the discussion of insecurity beyond traditional confines to also include social disruptions, it was mostly focused on interstate conflict (since the audience of this literature was mostly restricted to the "traditional security community"). Hence, the emphasis of the environ-

\section{Sources of insecurity}

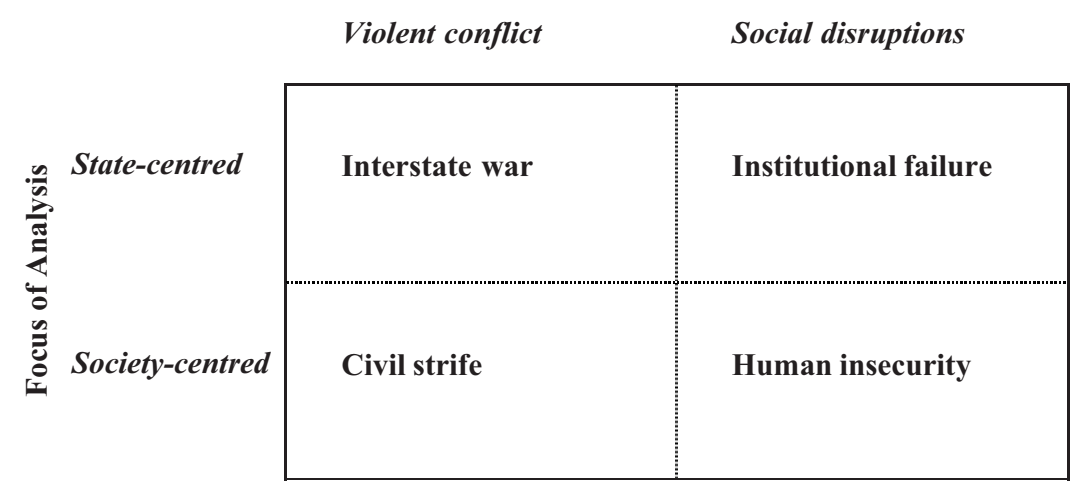

Figure 6.1 Organizing the environment and security discussion 
ment and security analysis very often turned to discussions of whether or not interstate war was a likely outcome. The "second wave" of the literature honed in on the emphasis on violent conflict but made the focus of analysis more society-centred. The emphasis of the discussion, therefore, moved to whether and to what extent environmental change was a trigger for civil strife. The new focus on human insecurity is also society-centred, but is more concerned with social disruptions (rather than violent conflict) as the principal source of insecurity. One of the key benefits of using such a heuristic is that it begins to point us towards other formalizations of the problematique that are not yet dominant in the available literature. In this case, figure 6.1 points out the insecurity that emerges from social disruptions at the level of the state rather than the level of society. It is proposed that such insecurity is most likely to manifest itself as institutional failure and be best understood through a focus on the mechanisms of societal governance.

Although this heuristic is tentative and in need of empirical validation, it provides us with one way to organize and understand the discussion. Interestingly, but not surprisingly, the conclusions emerging from country-focused as well as issue-focused studies from South Asia ${ }^{57}$ lie very much in the right-hand half of figure 6.1, and predominantly in the bottom-right quarter. The emphasis is very much on environment-related insecurities as manifest in social disruption rather than in outright conflict. In order to begin understanding how, and why, issues of institutional failure and human insecurity are more immediate to the concerns of South Asians let us quickly review what this region looks like.

\section{South Asia in context: Poverty as the key link between environment and security}

Home to nearly a quarter of all humanity, the South Asian subcontinent is a region where histories, geographies, and politics are truly intertwined. Although we define the region by membership in the South Asian Association for Regional Cooperation (SAARC) - which was formed in 1987 and includes Bangladesh, Bhutan, India, Maldives, Nepal, Pakistan, and Sri Lanka - the roots of the region's distinct identity predate the histories of any of the countries that now constitute it. The region has been home to great empires of its own as well as prey to the lust of others. It is a region that has been familiar with insecurities of all kinds throughout its rich and tortured history; this still holds true today. The 1997 Human Development in South Asia Report described South Asia as "the most deprived region" in the world. ${ }^{58}$ Certain elements of the rather depressing picture of the region that the report painted are worth repeating here: 
- South Asia is the world's poorest region with a per capita GNP below even that of sub-Saharan Africa, which is home to 40 per cent of the world's poor and to over 500 million people below the absolute poverty line.

- South Asia is the world's most illiterate region and home to nearly half of all the illiterates in the world; there are more children out of school in this region than in the rest of the world combined; two-thirds of this wasted generation are female.

- South Asia is the region with the highest human deprivation: 260 million people lack access to basic health facilities, 337 million are without safe drinking water, 830 million are without rudimentary sanitation, and 400 million people go hungry every day.

South Asia may also be among the most militarized regions in the world. India and Pakistan have both declared themselves nuclear powers. They have fought three full-scale wars with one another and continue to have near-constant skirmishes on their borders, especially over the disputed region of Kashmir. Neither India nor Pakistan can afford their massive military expenditures: US $\$ 15$ billion and US $\$ 3.5$ billion, respectively. Indeed, as the Human Development in South Asia Report pointed out

India was ranked by the World Bank at 142 in terms of real per capita income (PPP dollars) between 1988 and 1992, yet it ranks first in the world in total arms imports. Pakistan's position is marginally better, at 119 in per capita income and tenth in arms imports. When most basic social services are missing in both India and Pakistan ... the rising defense burdens in these countries continue to impose prohibitive social and economic costs on their people. ${ }^{59}$

The other countries of the region, while nowhere near as committed to large militaries, are also burdened by military expenditures greater than they can afford, often because of internal threats.

Table 6.2 presents a brief profile of the five largest countries of the region. It is clear from the table that on all the variables presented, South Asian countries are not only significantly behind the world as a whole, but also well behind developing countries as a group (measured here as the average of all low and medium income countries). These are the roots of human insecurity in the region and end up having significant implications for the environment.

Table 6.2 also highlights the fact that, although there are important differences within the region (for example, in terms of education), there is a certain uniformity in the development profiles of the region. In essence, the table helps us make three important points about South Asia. First, this is very much a region that can be studied as a region, not only in terms of its historical legacy, but also in terms of its current devel- 
opmental predicament. Second, this is a region that should be studied; the region's acute developmental deprivations point towards the potential for equally acute, even violent, human insecurity in the future. Third, given this context, it is not surprising that the predominant South Asian concerns about environment and security are really about "sustainable development" and "human security", and tend to lie in the right-hand half of the heuristic presented in figure 6.1 and predominantly in its bottom-right corner. This becomes clearer by reviewing the key conclusions from various country and issue results in the aforementioned study: ${ }^{60}$

- Environmental stress can and does translate to human insecurity, but it does not necessarily take the form of violent conflict.

- The absence of sustainable human development can lead to environmental degradation, thereby triggering social inequity and injustice.

- Poverty is, and is likely to remain, the most important source of environmental vulnerability and insecurity in many South Asian countries.

- An atmosphere of insecurity can be created when environmental stresses interact with societal vulnerability, disruptive development, and perverse markets; it is this volatile mix, rather than the environmental stress alone, that can become a trigger for insecurity or violence.

- The environment-security nexus is integrally tied to the cultural and institutional robustness of societies.

- Structures of governance and policy - rather than natural endowments alone - are the key to enhanced energy security.

- Institutional design is the most critical determinant of land-related environmental insecurity, particularly in terms of food security.

- There is little likelihood of interstate conflict in South Asia on issues related to water and much room for improved regional cooperation in this area.

Contrary to the thrust of the mainstream literature which struggles, often unconvincingly, to express the environmental problematique in the language of state-centric "national" security, ${ }^{61}$ the research summarized here makes it clear that in the context of South Asia (and arguably of most developing countries) it is the language of people-centric "human" security that dominates the discussion of what might be considered simple environmental concerns elsewhere. More than that, poverty - rather than simple environmental stress or violent conflict alone - emerges as the defining link between environment and security.

Importantly, the research from South Asia validates two key findings from the larger literature. The first relates to the models proposed by Thomas Homer-Dixon and his colleagues. ${ }^{62}$ An abridged version of the argument of this body of literature is presented in the introduction to the book Ecoviolence: 
Table 6.2 South Asia's many roots of insecurity

\begin{tabular}{|c|c|c|c|c|c|c|c|}
\hline & Bangladesh & India & Nepal & Pakistan & $\begin{array}{l}\text { Sri } \\
\text { Lanka }\end{array}$ & $\begin{array}{l}\text { Developing } \\
\text { countries }\end{array}$ & World \\
\hline Area in 1,000 square kilometres (1999) & 144 & 3,288 & 147 & 796 & 66 & 101,487 & 133,572 \\
\hline Population in millions (1999) & 128 & 998 & 23 & 135 & 19 & 5,084 & 5.975 \\
\hline $\begin{array}{l}\text { Population growth rate (annual) } \\
\quad(1990-1999)\end{array}$ & 1.6 & 1.8 & 2.4 & 2.5 & 1.2 & 1.9 & 1.7 \\
\hline GNP per capita (in US\$) (1999) & 370 & 450 & 220 & 470 & 820 & 1,240 & 4,890 \\
\hline GNP per capita (in PPP \$) (1999) & 1,475 & 2,144 & 1,219 & 1,757 & 3,056 & 3,410 & 6,490 \\
\hline Under-5 mortality (per 1,000) (1998) & 96 & 83 & 107 & 120 & 18 & 79 & 75 \\
\hline Life expectancy $(\mathrm{M} / \mathrm{F})(1998)$ & $58 / 59$ & $62 / 64$ & $58 / 58$ & $61 / 63$ & $71 / 76$ & $63 / 67$ & $65 / 69$ \\
\hline $\begin{array}{l}\text { Adult illiteracy (\% population } 15 \text { and } \\
\text { above, M/F) (1998) }\end{array}$ & 49/71 & $33 / 57$ & $43 / 78$ & $42 / 71$ & $6 / 12$ & $18 / 33$ & $18 / 32$ \\
\hline $\begin{array}{l}\text { Urban Sanitation (\% with access, } \\
\text { 1990-1996) }\end{array}$ & 77 & 46 & 34 & 53 & 33 & - & - \\
\hline $\begin{array}{l}\text { Children } 10-14 \text { in labour force ( } \% \text { of } \\
\text { age group) (1999) }\end{array}$ & 29 & 13 & 43 & 16 & 2 & 13 & 12 \\
\hline Gini Index (1995-97) & 33.6 & 37.8 & 36.7 & 31.2 & 34.4 & - & - \\
\hline $\begin{array}{l}\text { Public spending on education (\% of } \\
\text { GNP) (1997) }\end{array}$ & 2.2 & 3.2 & 3.2 & 2.7 & 3.4 & 4.1 & 4.8 \\
\hline $\begin{array}{l}\text { Public spending on health (\% of } \\
\text { GDP) (1990-1998) }\end{array}$ & 1.6 & 0.6 & 1.3 & 0.9 & 1.4 & 1.9 & 2.5 \\
\hline External debt (\% of GNP) (1998) & 22 & 20 & 31 & 41 & 41 & - & - \\
\hline
\end{tabular}

Source: World Bank (2000) 
severe environmental scarcities often contribute to major civil violence. Poor countries are more vulnerable to this violence, because large fractions of their populations depend for their day-to-day livelihoods on local renewable resources ... Moreover, poor countries are often unable to adapt effectively to environmental scarcity because their states are weak, markets inefficient and corrupt, and human capital inadequate. ${ }^{63}$

Related to the above is one of the key findings that Geoffrey Dabelko, Steve Lonergan, and Richard Matthew come to in their major literature review of the subject: "research on environment and security often strengthens the conclusion that poverty is a key factor in causing tension, unrest and, eventually, conflict". ${ }^{64}$ This finding is borne out quite strikingly. All across South Asia, poverty emerges as the key variable, both in terms of defining environmental degradation and outlining human insecurity. Importantly, poverty is both the causal motivator of environmental stress as well as the most important manifestation of human insecurity. Not only is poverty one of the key elements that exacerbate the causal chain that can lead from environmental degradation to violence and insecurity, research from South Asia suggests that it may well play a more central role in this chain of causality than much of the literature seems to acknowledge.

Linking these two arguments, one might argue that it is chronic and structural impoverishment, more than anything else, which forges the connection between environmental degradation and violent conflict. Such a conception leads itself to a focus on social disruptions at the level of the society (rather than the state). As posited above, this lends itself to conceptualizations related to human insecurity. It should be noted that others who have looked at the myriad security threats faced by South Asians have come to similar conclusions. Most notably, in launching the Human Development in South Asia reports, Dr. Mahbub ul Haq identified the shift:

Security is increasingly interpreted as: security of people, not just of territory; security of individuals, not just of nations; security through development, not through arms; security of all people everywhere - in their homes, on their jobs, in their streets, in their communities, and in the environment. ${ }^{65}$

In short, it is not simply that environmental degradation is more likely to lead to violent conflict in poor countries, but it is that poverty - in terms of economic, social, or political disenfranchisement and vulnerability may be a required condition for this connection to be made. This is an area that requires more empirical research and may, in fact, have the potential to untie many of convoluted knots that the debate on the subject tends to find itself in. 


\section{Five key lessons}

Beyond the potential contribution to our conceptual understanding of the links between environment and security, the research from South Asia also highlights a handful of broad lessons that are more specific to the region and its constituent countries. The following five broad lessons are of particular importance because they have the potential to add to the learning on environment and security. These, of course, are to be understood within the context of the overarching conclusion already laid out above: a need to focus on poverty as a primary, but not sole, motor of human insecurity.

\section{Lesson 1}

For South Asia in particular, and developing countries in general, environment and security are best conceptualized within the context of sustainable development. Not only does it make sense to broaden the notion of "security" into one of "human security", it makes sense to understand the human security framework within a sustainable development context. Indeed, human security can be viewed as a fundamental requirement for the achievement of sustainable development. This is not entirely a surprise since the World Commission on Environment and Development had itself made that connection explicit. ${ }^{66}$ However, it is noteworthy because so much of the literature on environment and security tends not to highlight this connection.

Placing the environment and human security problematique within the sustainable development complex has at least two important implications. First, such a conceptualization allows for articulating issues related to environment and security at the level of, and in the language of, policy and practice. Second, it contributes towards a better understanding of what sustainable development means in practice. Such a conceptual focus broadens the scope of the enquiry from whether and how environmental degradation might lead to societal and state insecurities, to also include how human insecurities influence, or are influenced by, accelerated environmental degradation. Imperfect as it might be, sustainable development policy becomes a potential means of addressing the twin challenges of environmental degradation and human insecurity.

Research from India, Pakistan, and Bangladesh are most explicit on drawing out the links between the environmental dimensions of human security and the broader policy goal of sustainable development. A key point to be made is that the notion of security is intricately related to the issue of livelihood and, therefore, cannot be de-linked from concerns about the content and context of the development experiment. Taken 
together, it should be pointed out that debates regarding human and environmental security are, in themselves, attempts to better understand and operationalize the concept of sustainable development.

On a related note, it is noteworthy that the South Asian research being reported on has tended to ignore, if not resist and reject, debates about whether environmental degradation should or should not be an element of "traditional" military- and state-related security concerns. ${ }^{67}$ This is a departure from the norm of the broader literature. Clearly, and for rather compelling reasons given South Asia's (lack of) development predicament, the region's scholars seem more comfortable defining environmental security as one more component of sustainable development, than as a dimension of "traditional" national security.

\section{Lesson 2}

The challenge of environment and security in South Asia is principally a challenge at the domestic, even local, level; but it is a challenge common to the region.

One of the conclusions reached by Dabelko, Lonergan, and Matthew in their review of the literature on the subject is that "the most severe challenges for individual well-being in many parts of the world may not be external (to the country of residence), but internal; although internal problem are likely to be affected in some way by external forces". ${ }^{68}$ This lesson is echoed and amplified by the experience from South Asia. Indeed, there is a distinct tendency to bring the problem "down" to the ground level rather than raise it "up" to national, let alone regional, levels. This is not to suggest that the regional dimensions are unimportant; however, it is to underscore the view that the local challenges are more numerous, as well as more profound.

This, of course, is a surprise given the intensity of regional tensions in South Asia. Paradoxically, it is that very intensity which makes it unlikely that environmental issues will become significant international security concerns in the region. The argument is that the countries in the region have so many other and more pressing disputes to keep them busy that environmental issues slip down the list of potential flare-up points. At the same time, one must recognize the possibility that such issues can easily become embroiled in existing and unrelated disputes with in the region. (I will expand on this later).

In addition to the points already made, taking a regional perspective is also valid for another reason. The local environmental and human security stresses that afflict the various countries of the region are so pressing in each case and so similar to each other that the countries of the region can learn much from each other because there are so many similarities in 
the challenges they face. The lesson to be highlighted here, however, is not just the importance of the regional perspective, but that a local perspective is of even greater importance.

\section{Lesson 3:}

The challenge of environment and security in South Asia is, at its core, not just a problem of resource endowments or geography but, quite distinctly, a problem of institutions and governance, if only because it is the latter rather than the former that we have the ability to change.

Possibly our most significant lesson relates to the centrality of institutions and governance to our understanding of how environment and security are linked in the South Asian context. At one level, the conclusions are not particularly surprising; after all, it is quite well known that environmental crises in many developing regions, including South Asia, are not just crises of resource scarcity or environmental degradation but are fundamentally tied to fragile institutions for environmental governance. This is an important insight since so much of the literature on environment and security tends to underplay, if not ignore, the governance dimensions.

Thus, while the literature is apt to concentrate on resource scarcity and environmental degradation as the key defining variables, the research from South Asia tends to highlight weaknesses in institutions and governance as the key causal determinant. In many cases, a lack of appropriate institutions and governance can help explain not only the levels of human insecurity but also the scarcity and degradation of environmental resources. Institutional and governance weaknesses can lead to significant human insecurity even in the absence of severe environmental scarcity or degradation. The latter condition only worsens the former.

The implication of this critical point is that the solutions to issues of environment and security will not come from techno-fixes and mega projects that might somehow "overrule" the forces of geography and nature, the solutions are more likely to come from institutional and governance reform. This implies that democracy counts, transparency counts, culture counts, decentralization counts, and, most importantly, participation counts.

In broadening the focus beyond resource scarcity and degradation we raise some conceptual issues for the literature on environment and security. An earlier generation of scholars had been preoccupied with the effects of security issues (particularly war and preparation for war) on the environment, or more precisely on natural resources. ${ }^{69}$ The current phase of interest in the subject has moved in the opposite direction and tends to focus on how environmental degradation can lead to insecurity and violence. ${ }^{70}$ Both arguments have environmental conservation, rather 
than human security, as their core interest. In focusing on sustainable development as the metric of analysis and placing human security more centrally in the discussion, we highlight the importance of looking at both linkages together - how does insecurity, at any level, impact the environment and how does environmental scarcity and degradation impact insecurity, at any level?

Such a formulation also allows us to move away from the more restrictive notion of "acute violence" to the more encompassing concept of insecurity, particularly human insecurity. The finding from across South Asia is that even where environmental variables do not directly cause conflict, they can increase insecurity by accentuating the variables that can precipitate conflict. ${ }^{71}$ Importantly, other forms of insecurity can accentuate the conditions conducive to environmental degradation, thereby increasing eventual environmental insecurity. The implication, of course, is that the key to understanding the link between environment and security in any given context may not lie in variables directly related to either (such as scarcity or war). It may lie, instead, in issues that impact but are not directly related to either, such as failure of institutions and governance.

\section{Lesson 4}

The prospects of interstate violence in South Asia over environmental issues is slim; however, given the region's history of distrust and dispute, environmental differences can add to existing tensions and apprehensions and perpetuate the general sense of insecurity that pervades interstate relations in the region.

Unlike others who have studied environment and security in South Asia and who tend to consider the region as a prime "action theatre" for environmental conflicts, ${ }^{72}$ this current set of studies from all over South Asia ${ }^{73}$ are far more careful about painting doom scenarios. In fact, there is unanimity amongst researchers on the belief that the prospects of outright war in South Asia over these issues are not high.

Indeed, there is also a tone of caution that suggests that, given existing regional security tensions and apprehensions, the broader sense of insecurity that defines the region's interstate relations can be exacerbated by environmental concerns. Arguably, there are far more immediate causes of interstate tension in the region. Environmental issues, even though they are important, are likely to be overwhelmed by these other more "traditional" security concerns. Moreover, despite fractious relations, even India and Pakistan have demonstrated a remarkable degree of cooperation (and even occasional goodwill) in the shared management of a precious resource such as water. The Indus Water Treaty remains one of the few areas of sustained cooperation between the two countries (this 
cooperation has been severely tested in recent months but, fragile as it is and despite much sabre-rattling, it remains intact).

This should not negate the importance of environmental degradation as a factor in regional security. Given the deep and strong security fault lines in the region, it is not at all inconceivable that cross-boundary environmental problems could add to an already volatile situation and exacerbate existing apprehensions and distrust. In his study of environment and security in South Asia, Norman Myers posits a fundamental question: "How can we realistically suppose that environmental problems will not exert a substantial and adverse influence over the prospects for the region's security throughout the foreseeable future?"74 It is also quite clear that the ultimate effect of human insecurity and environmental degradation tends to be political instability. As Shaukat Hassan puts it, "in South Asia environmental deterioration has a very direct and immediate impact on the economy of the states, which in turn affects social relations in ways detrimental to political stability". ${ }^{75}$

Environmental deterioration, then, can be sources of additional stress that are likely to deepen existing lines of conflict (rather than create new ones). Although the main challenge is domestic, the regional context cannot be ignored; largely because regional environmental disputes, even when they may be relatively minor in and of themselves, can flare into larger conflicts because they are played out in a context of general distrust and dispute.

Lesson 5

There is the potential - albeit small - for a new generation of security relations in the region emerging around the nexus of environment and security that is based on the principles of mutual trust, harmony and cooperation rather than on legacies of distrust and dispute.

Even though security (in the international context) is generally seen as an adversarial concept, the environment demands a politics of consensus and cooperation. This points towards the potential for a new approach to security - one that stresses the need for cooperative management of shared environments rather than the adversarial contest over scarce resources. However, a cautionary note needs to be sounded about the potential for moving to a new generation of security relations that start from the necessity of cooperation rather than from a history of confrontations. Given the "traditional" security profile of the region, it is unlikely that such cooperation would emerge on its own in the natural evolution of things. Indeed, even where the need for such cooperation is self-evident, the hurdles to its establishment are profound. One must note with some concern that the South Asian Association for Regional Cooperation (SAARC) has made little to no effort for fostering regional 
environmental cooperation. Given the persistent regional tensions in South Asia, establishing meaningful cooperation on the environment will be an uphill challenge and requires more than declaratory intent.

Yet, some initial steps could begin creating an atmosphere of cooperation. An important first step could be the institutionalization of some level of region-wide information sharing and joint planning for common concerns such as water, climate change, and biodiversity. The sharing of best practices, particularly in the areas of technological and institutional innovations for environmental enhancement, is another obvious step. A third step relates to the need to strengthen and deepen expert dialogue and communication at the regional level. Finally, the increasing prominence of global environmental politics and the North-South dimension within it is one more reason for the developing countries as a whole, and regions such as South Asia within it, to think in terms of coalitional rather than individual politics related to the international environment. ${ }^{76}$ The SAARC is, indeed, well placed to take such steps and should be urged to continue its efforts in this direction.

To end on a positive note, one might suggest that the environment has the potential to become an "entry point" for wider regional cooperation. On the one hand, the very nature of the environmental problematique points towards the urgency of adopting a cooperative mindset. On the other hand, the language of human security at least allows for the potential of focusing on regional security without necessarily regurgitating stylized debates about traditional hurdles to cooperation. This, of course, is the most optimistic of our conclusions. But when one is dealing with the future of a billion and a half people, including the poorest and most vulnerable populations in the world, one simply cannot afford to give up on optimism.

Meaningful regional cooperation for improved environmental and human security in South Asia may well be too much to hope for. But hope we must.

\section{Notes}

1. S. Dalby (1992) "Security, Modernity, Ecology: The Dilemmas of Post-Cold War Security Discourse", Alternatives 17: 95-134.

2. J. Galtung (1982) Environment, Development and Military Activity: Towards Alternative Security Doctrines, New York: Columbia University Press; R.H. Ullman (1982) "Redefining Security", International Security 8(1): 129-153; J.T. Mathews (1989) "Redefining Security", Foreign Affairs 68(2): 162-177; S.M. Walt (1991) "The Renaissance of Security Studies", International Studies Quarterly 35(2): 211-239; S. Dalby (1992) "Security, Modernity, Ecology: The Dilemmas of Post-Cold War Security Discourse", Alternatives 17: 95-134; B. Buzan (1991) People, States and Fear: An Agenda for Inter- 
national Security Studies in the Post-Cold War Era (second edition), Boulder: Lynne Reinner; R.W. Jones (1995) "Message in a Bottle? Theory and Praxis in Critical Security Studies", Security Policy 16(3): 309.

3. A.H. Westing (1988) Global Norms, War and the Environment, Oxford: Oxford University Press; P. Gleick (1991) "Environment and Security: The Clear Connections", Bulletin of the Atomic Scientists, April, pp. 17-21; S. Libiszewski (1992) "What is an Environmental Conflict?", Environment and Conflict Project (ENCOP) Occasional Paper No. 6. Zurich: Center for Security Studies and Conflict Research; N. Myers (1993) Ultimate Security: The Environmental Basis of Political Stability, New York: W.W. Norton; T.F. Homer-Dixon (1999) Environment, Scarcity, and Violence, Princeton, NJ: Princeton University Press; D.H. Deudney, and R.A. Matthew, eds. (1999) Contested Grounds: Security and Conflict in the New Environmental Politics, Albany: State University of New York Press; G. Dabelko, S. Lonergan, and R. Matthew (2000) "Stateof-the-Art Review on Environment, Security and Development Co-operation", prepared for the Working Party on Development Co-operation and Environment, OECD Development Assistance Committee, Paris; P.F. Diehl, and N.P. Gleditsch, eds. (2001) Environmental Conflict, Boulder: Westview Press.

4. C. Thomas (1992) The Environment in International Relations, London: Royal Institute of International Affairs; Alker, H.R., Jr., and P.M. Haas (1993) "The Rise of Global Ecopolitics", in N. Choucri, Global Accord: Environmental Challenges and International Responses, Cambridge, Mass.: MIT Press; L. Elliott (1998) The Global Politics of the Environment, New York: New York University Press; A. Najam (1995) "An Environmental Negotiation Strategy for the South”, International Environmental Affairs 7(3): 249-287.

5. C.D. Stone (1993) The Gnat is Older than Man: Global Environment and Human Agenda, Princeton, NJ: Princeton University Press; L.E. Susskind (1994) Environmental Diplomacy: Negotiating More Effective Global Agreements, New York: Oxford University Press; G. Porter, J.W. Brown, and P.S. Chasek, eds. (2000) Global Environmental Politics (third edition), Boulder: Westview Press; A. Najam (2000) "The Case for a Law of the Atmosphere", Atmospheric Environment 34(23): 4047-4049.

6. T. Princen, M. Finger, and J. Manno (1995) "Nongovernmental Organizations in World Environmental Politics", International Environmental Affairs 7(1): 42-58; A. Najam (1996) "Understanding the Third Sector: Revisiting the Prince, the Merchant and the Prince", Nonprofit Management and Leadership 7(2) 203-219; A. Najam (1999) "Citizen Organizations as Policy Entrepreneurs", in David Lewis, International Perspectives on Voluntary Action: Reshaping the Third World, London: Earthscan; A. Najam (2000) "The Four C's of Third Sector-Government Relations: Cooperation, Confrontation, Complementarity, and Co-optation", Nonprofit Management and Leadership 10(4): 375-396; J.T. Mathews (1997) "Power Shift", Foreign Affairs 76(1): 50-66; J. Fisher (1998) Nongovernments, Hartford, CT: Kumarian Press.

7. N. Myers (1989) "Environmental Security: The Case of South Asia", International Environmental Affair 1(2): 138-54; N. Myers (1993) Ultimate Security: The Environmental Basis of Political Stability, New York: W.W. Norton; S. Hassan (1991) "Environmental Issues and Security in South Asia", Adelphi Papers, 262, London: International Institute for Security Studies; S. Hassan, "Environmental Sources of Conflict in the South Asian Subcontinent", Disarmament 15(1): 79-95; N. Islam (1994) "Environment and Security in South Asia: A Regional Overview", in Iftikharruzzaman, South Asia's Security Primacy of Internal Dimension, Dhaka: Academic Publishers; P. Gizewski, and T. HomerDixon (1998) "The Case of Pakistan", in: T.F. Homer-Dixon and J. Blitt, eds., Ecoviolence: Links Among Environment, Population, and Security, Lanham, MD: Rowman and Littlefield. 
8. A. Najam (2002) Environmental Dimensions of Human Security: Perspectives from South Asia, Lanham, MD: University Press of America.

9. M. Halle (2000) "Foreword", in G. Dabelko, S. Lonergan, R. Matthew, "State-of-theArt Review on Environment, Security and Development Co-operation", prepared for the Working Party on Development Co-operation and Environment, OECD Development Assistance Committee, Paris.

10. This is based primarily on citations quoted in P.F. Diehl, and N.P. Gleditsch (2001) "Controversies and Questions", in P.F. Diehl and N.P. Gleditsch, eds., Environmental Conflict, Boulder: Westview Press.

11. P.F. Diehl, N.P. Gleditsch (2001) "Controversies and Questions", in P.F. Diehl and N.P. Gleditsch, eds., Environmental Conflict, Boulder: Westview Press.

12. D.H. Deudney (1991) "Environment and Security: Muddled Thinking", Bulletin of Atomic Scientists 47(3): 22-28.

13. WCED (1987) Our Common Future: The Report of the World Commission on Environment and Development, Oxford: Oxford University Press, p. 290.

14. P.A. Colinvaux (1980) The Fates of Nations: A Biological Theory of History, New York: Simon and Schuster, p. 10.

15. A.J. McMichael (1993) Planetary Overload, Cambridge: Cambridge University Press, p. 321.

16. M. Renner, M. Pianta, and C. Franchi (1991) "International Conflict and Environmental Degradation", in R. Vayryned, New Directions in Conflict Theory: Conflict Resolution and Conflict Transformation, London: Sage Publishers.

17. N. Myers (1993) Ultimate Security: The Environmental Basis of Political Stability, New York: W.W. Norton, p. 21.

18. S. Lodgaard (1992) "Environmental Security, World Order and Environmental Conflict Resolution", in N.P. Gleditsch, ed., "Conversion and the Environment", Proceedings of a Seminar in Perm Russia, 24-27 November 1991, PRIO Report Number 2, Oslo, Peace Research Institute, p. 119.

19. S. Hassan (1991) "Environmental Issues and Security in South Asia", Adelphi Papers, 262, London: International Institute for Security Studies, p. 64.

20. L. Brock (1991) "Peace Through Parks: The Environment on the Peace Research Agenda", Journal of Peace Research 28(4): 409.

21. P.R. Ehrlich, and A.H. Ehrlich (1970) Population, Resources, Environment: Issues in Human Ecology, San Francisco: Freeman, p. 425.

22. J.B. Opschoor, "North-South Trade, Resource Degradation and Economic Security", Bulletin on Peace Proposals 20(2): 137.

23. J. Galtung (1982) Environment, Development and Military Activity: Towards Alternative Security Doctrines, New York: Columbia University Press, p. 99.

24. UN Security Council (1992) "Note by the President of the United Nations Security Council", UN document s/23500, New York: United Nations.

25. M.S. Soroos (1994) "Global Change, Environmental Security, and the Prisoner's Dilemma", Journal of Peace Research 31(3): 318-319.

26. R.H. Ullman (1983) "Redefining Security", International Security 8(1): 129-153, J.T. Mathews (1989) "Redefining Security", Foreign Affairs 68, No.2): 162-177; N. Myers (1993) Ultimate Security: The Environmental Basis of Political Stability, New York: W.W. Norton.

27. T.F. Homer-Dixon (1994) "Environmental Scarcities and Violent Conflict: Evidence from Cases", International Security 16(2): 76-116; T.F. Homer-Dixon (1999) Environment, Scarcity, and Violence, Princeton, NJ: Princeton University Press; T.F. HomerDixon, and J. Blitt, eds. (1998) Ecoviolence: Links Among Environment, Population, and Security, Rowman and Littlefield: Lanham, MD. 
28. A.H. Westing (1988) Global Norms, War and the Environment, Oxford: Oxford University Press; P. Gleick (1991) "Environment and Security: The Clear Connections", Bulletin of the Atomic Scientists, April, pp. 17-21

29. P.R. Ehrlich, and A.H. Ehrlich (1970) Population, Resources, Environment: Issues in Human Ecology, San Francisco: Freeman; L. Brock (1991) "Peace Through Parks: The Environment on the Peace Research Agenda", Journal of Peace Research 28(4): 407423; A.J. McMichael, Planetary Overload, Cambridge: Cambridge University Press, 1993.

30. M. Levy (1995) "Is Environment a National Security Issue?", International Security 20(2): 35-62.

31. R.H. Ullman (1983) "Redefining Security", International Security 8(1): 133.

32. M.S. Soroos, (1997) The Endangered Atmosphere: Preserving a Global Commons, Columbia, SC: University of South Carolina Press, p. 236.

33. D.H. Deudney (1990) "The Case Against Linking Environmental Degradation and National Security", Millennium 19(3): 461-476; M. Levy (1995) "Is Environment a National Security Issue?", International Security 20(2): 35-62; N.P. Gleditsch (2001) "Armed Conflict and the Environment", in P.F. Diehl and N.P. Gleditsch, eds., Environmental Conflict, Boulder: Westview Press.

34. M. Levy (1995) "Is Environment a National Security Issue?", International Security 20(2): 35-62

35. T.F. Homer-Dixon, and J. Blitt, eds. (1998) Ecoviolence: Links Among Environment, Population, and Security, Rowman and Littlefield: Lanham, MD): 223-228.

36. N.P. Gleditsch (2001) "Armed Conflict and the Environment", in P.F. Diehl and N.P. Gleditsch, eds., Environmental Conflict, Boulder: Westview Press.

37. D.M. Schwartz, T. Deligiannis, and T. Homer-Dixon (2001) "The Environment and Violent Conflict", in P.F. Diehl and N.P. Gleditsch, Environmental Conflict, Boulder: Westview Press, pp. 273, 274, 291.

38. T.F. Homer-Dixon (1991) "On the Threshold: Environmental Changes as Causes of Acute Conflict", International Security 16(2): 83.

39. N. Myers (1993) Ultimate Security: The Environmental Basis of Political Stability, New York: W.W. Norton.

40. T.F. Homer-Dixon (1999) Environment, Scarcity, and Violence, Princeton, NJ: Princeton University Press, p. 184.

41. N.P. Gleditsch (2001) "Armed Conflict and the Environment", in P.F. Diehl and N.P. Gleditsch, eds., Environmental Conflict, Boulder: Westview Press, p. 263.

42. M. Levy (1995) "Is Environment a National Security Issue?", International Security 20(2): 56.

43. D.H. Deudney (1990) "The Case Against Linking Environmental Degradation and National Security", Millennium 19(3): 461-476; D.H. Deudney (1991) "Environment and Security: Muddled Thinking”, Bulletin of Atomic Scientists 47(3): 22-28; M. Levy (1995) "Is Environment a National Security Issue?", International Security 20(2); N.P. Gleditsch (2001) "Armed Conflict and the Environment", in P.F. Diehl and N.P. Gleditsch, eds., Environmental Conflict, Boulder: Westview Press.

44. R. Kaplan (1994) "The Coming Anarchy", Atlantic Monthly, February, pp. 45-76.

45. G. Dabelko, S. Lonergan, and R. Matthew (2000) "State-of-the-Art Review on Environment, Security and Development Co-operation", prepared for the Working Party on Development Co-operation and Environment, OECD Development Assistance Committee, Paris; L. Elliott (2001) "Regional Environmental Security: Pursuing a NonTraditional Approach", in A.T.H. Tan, and J.D.K. Boutin, eds., Non-Traditional Security Issues in Southeast Asia, Singapore: Select Publishing.

46. N. Myers (1993) Ultimate Security: The Environmental Basis of Political Stability, New York: W.W. Norton, p. 31. 
47. G. Dabelko, S. Lonergan, and R. Matthew (2000) "State-of-the-Art Review on Environment, Security and Development Co-operation", prepared for the Working Party on Development Co-operation and Environment, OECD Development Assistance Committee, Paris, p. 48.

48. UNDP (1994) Human Development Report 1994, New York: Oxford University Press.

49. A. Suhrke (1999) "Human Security and the Interest of States", Security Dialogue 30, No. 3, p. 269.

50. CGG (1995) Our Common Neighborhood: Report of the Commission on Global Governance, Oxford: Oxford University Press.

51. L. Elliott (2001) "Regional Environmental Security: Pursuing a Non-Traditional Approach", in A.T.H. Tan, and J.D.K. Boutin, eds., Non-Traditional Security Issues in Southeast Asia, Singapore: Select Publishing, p. 449.

52. Idem.

53. G. Dabelko, S. Lonergan, and R. Matthew (2000) "State-of-the-Art Review on Environment, Security and Development Co-operation", prepared for the Working Party on Development Co-operation and Environment, OECD Development Assistance Committee, Paris, pp. 48-49.

54. G. Dabelko, S. Lonergan, and R. Matthew (2000) "State-of-the-Art Review on Environment, Security and Development Co-operation", prepared for the Working Party on Development Co-operation and Environment, OECD Development Assistance Committee, Paris; A. Suhrke (1999) "Human Security and the Interest of States", Security Dialogue 30, No.3): 265-276.

55. UNDP (1994) Human Development Report 1994, New York: Oxford University Press.

56. A. Suhrke (1999) "Human Security and the Interest of States", Security Dialogue 30, No.3): 270-271.

57. A. Najam (2002) Environmental Dimensions of Human Security: Perspectives from South Asia, Lanham, MD: University Press of America.

58. Mahbub ul Haq (1997) Human Development in South Asia, Karachi: Oxford University Press and the Human Development Center.

59. Ibid., p. 80.

60. A. Najam (2002) Environmental Dimensions of Human Security: Perspectives from South Asia, Lanham, MD: University Press of America.

61. For example: J.T. Mathews (1989) "Redefining Security", Foreign Affairs 68, No.2): 162-177; D.H. Deudney (1990) "The Case Against Linking Environmental Degradation and National Security", Millennium 19(3): 461-476; T.F. Homer-Dixon (1991) "On the Threshold: Environmental Changes as Causes of Acute Conflict", International Security 16(2): 76-116; N. Myers (1993) Ultimate Security: The Environmental Basis of Political Stability, New York: W.W. Norton; K. Conca (2001) "Environmental Cooperation and International Peace", in P.F. Diehl and N.P. Gleditsch, eds., Environmental Conflict, Boulder: Westview Press; N.P. Gleditsch (2001) "Armed Conflict and the Environment", in P.F. Diehl and N.P. Gleditsch, eds., Environmental Conflict, Boulder: Westview Press.

62. T.F. Homer-Dixon (1991) "On the Threshold: Environmental Changes as Causes of Acute Conflict", International Security 16(2): 76-116; T.F. Homer-Dixon (1999) Environment, Scarcity, and Violence, Princeton, NJ: Princeton University Press; T.F. HomerDixon, J.H. Boutwell, and G.W. Rathjens (1993) "Environmental Change and Violent Conflict", Scientific American 268(2): 38-45; T.F. Homer-Dixon, and J. Blitt, eds. (1998) Ecoviolence: Links Among Environment, Population, and Security, Rowman and Littlefield: Lanham, MD.

63. T.F. Homer-Dixon, and J. Blitt, eds. (1998) Ecoviolence: Links Among Environment, Population, and Security, Rowman and Littlefield: Lanham, MD, p. 15. 
64. G. Dabelko, S. Lonergan, and R. Matthew (2000) "State-of-the-Art Review on Environment, Security and Development Co-operation", prepared for the Working Party on Development Co-operation and Environment, OECD Development Assistance Committee, Paris, p. 56.

65. Mahbub ul Haq (1997) Human Development in South Asia, Karachi: Oxford University Press and the Human Development Center, p. 84.

66. WCED (1987) Our Common Future: The Report of the World Commission on Environment and Development, Oxford: Oxford University Press.

67. See, for example, J.T. Mathews (1989) "Redefining Security”, Foreign Affairs 68, No.2): 162-177; T.F. Homer-Dixon (1991) "On the Threshold: Environmental Changes as Causes of Acute Conflict", International Security 16(2): 76-116; N. Myers (1993) Ultimate Security: The Environmental Basis of Political Stability, New York: W.W. Norton; M. Levy (1995) "Is Environment a National Security Issue?", International Security 20(2): 35-62; D.H. Deudney, and R.A. Matthew, eds. (1999) Contested Grounds: Security and Conflict in the New Environmental Politics, Albany: State University of New York Press.

68. G. Dabelko, S. Lonergan, and R. Matthew (2000) "State-of-the-Art Review on Environment, Security and Development Co-operation", prepared for the Working Party on Development Co-operation and Environment, OECD Development Assistance Committee, Paris, p. 56

69. J. Galtung (1982) Environment, Development and Military Activity: Towards Alternative Security Doctrines, New York: Columbia University Press; A.H. Westing (1984) Environmental Warfare, London: Taylor and Francis; A.H. Westing (1988) Global Norms, War and the Environment, Oxford: Oxford University Press; M. Renner (1991) "Assessing the Military's War on the Environment" (1989), in L. Brown, State of the World, New York: W.W. Norton.

70. D.H. Deudney, and R.A. Matthew, eds. (1999) Contested Grounds: Security and Conflict in the New Environmental Politics, Albany: State University of New York Press; T.F. Homer-Dixon (1999) Environment, Scarcity, and Violence, Princeton, NJ: Princeton University Press; P.F. Diehl, and N.P. Gleditsch, eds. (2001)Environmental Conflict, Boulder: Westview Press.

71. T.R. Gurr (1993) Minorities at Risk: A Global View of Ethnopolitical Conflicts, Washington, DC: United States Institute of Peace; S. Libiszewski (1992) "What is an Environmental Conflict?", Environment and Conflict Project (ENCOP) Occasional Paper No. 6, Zurich: Center for Security Studies and Conflict Research; G. Dabelko, S. Lonergan, and R. Matthew (2000) "State-of-the-Art Review on Environment, Security and Development Co-operation", prepared for the Working Party on Development Cooperation and Environment, OECD Development Assistance Committee, Paris.

72. N. Myers (1989) "Environmental Security: The Case of South Asia", International Environmental Affair 1(2): 138-54; N. Myers (1993) Ultimate Security: The Environmental Basis of Political Stability, New York: W.W. Norton; S. Hassan (1991) "Environmental Issues and Security in South Asia", Adelphi Papers, 262, London: International Institute for Security Studies; S. Hassan (1992) "Environmental Sources of Conflict in the South Asian Subcontinent", Disarmament 15(1): 79-95.

73. A. Najam (2002) Environmental Dimensions of Human Security: Perspectives from South Asia, Lanham, MD: University Press of America.

74. N. Myers (1993) Ultimate Security: The Environmental Basis of Political Stability, New York: W.W. Norton, p. 117.

75. S. Hassan (1991) "Environmental Issues and Security in South Asia", Adelphi Papers, 262, London: International Institute for Security Studies, p. 65. 
76. A. Najam (1995) “An Environmental Negotiation Strategy for the South”, International Environmental Affairs 7(3): 249-287; A. Najam (2000) "Trade and Environment After Seattle: A Negotiating Agenda for the South", Journal of Environment and Development 9(4): 405-25; A. Najam, and A. Sagar (1998) "Avoiding a COP-out: Moving Towards Systematic Decision-Making Under the Climate Convention", Climatic Change 39(4); A. Agarwal, S. Narain, and A. Sharma (1999) Green Politics: Global Environmental Negotiations-1, New Delhi: Centre for Science and Environment. 


\title{
How critical is "environmental security" as a non-traditional security issue in Northeast Asia?
}

\author{
M. Shamsul Haque
}

\section{Introduction}

The state-centric and militaristic perspective of security has lost practical relevance and intellectual credibility due to a range of processes and events. These include the end of the Cold War, global integration of national economies, erosion of national identities and cultures, shift in priority from military rivalry to economic competition, and the diminishing role of the state as the dominant actor in international politics. On the other hand, there have emerged diverse new issues - ranging from poverty to refugee crisis, information privacy to cyber terrorism, environmental crisis to natural disaster - which require non-state and nonmilitary policies and strategies. ${ }^{1}$ These newly emerging security concerns have been characterized as non-traditional and are now considered a major component of comprehensive security. It is within this context that the environmental question has gained worldwide significance as a security issue. In fact, among all the non-traditional security issues mentioned above, environmental security stands out to be the most widely debated, especially due to its all-pervasive nature, cross-national scope, and intergenerational implication. ${ }^{2}$

The growing significance of environmental security is reflected in major international conferences. The primary examples include the UN Conference on the Human Environment (1972), Ottawa Conference on Conservation and Development (1986), United Nations Conference on 
Environment and Development or the Earth Summit (1992), World Summit for Social Development (1995), UN Symposium on the Global Environment in the Twenty-first Century (1997), the World Summit on Sustainable Development (2002), and so on. These conferences and symposia eventually resulted in various international conventions and protocols for environmental protection or security, such as the Vienna Convention for the Protection of the Ozone Layer, the Montreal Protocol on Substances that Deplete the Ozone Layer, the Convention on Biological Diversity, the Framework Convention on Climate Change, the Convention to Combat Desertification, and the Kyoto Protocol. ${ }^{3}$ On the other hand, in order to enforce these conventions and protocols, there emerged the United Nations Environment Programme, the United Nations Commission on Sustainable Development, the Secretariat of the Convention on Biological Diversity, the Secretariat of the Convention to Combat Desertification, the Climate Change Secretariat, and the International Centre for Trade and Sustainable Development. ${ }^{4}$ The increasing significance of environmental security is also evident in the expansion of environment-related programs by international agencies such as the World Bank and the International Monetary Fund (IMF); in the creation of ministries, agencies or commissions for the environment by national governments; and the proliferation of environmental NGOs at the national and international levels.

Most Northeast Asian countries, like countries in other regions of the world, suffer from various forms of environmental disorders and are influenced by the international conventions and institutions mentioned above. However, in order to decipher how serious the various forms of environmental insecurity are, and what factors contribute such insecurity, it is necessary to provide more specific explanations based on certain concrete empirical evidence. In this regard, this chapter presents some of the basic indicators of environmental disorder in Northeast Asia, explores major factors causing or worsening these disorders, analyses the interstate tensions emerging from such environmental problems in the region, evaluates existing initiatives and institutions adopted by governments to address such non-traditional security matters, and finally makes some recommendations.

\section{Environmental disorder in Northeast Asia: Major indicators and causal factors}

Lester Brown, in his classic paper titled Redefining Security, identifies some of the major forms of environmental insecurity, including climate change, threats to biological systems, energy scarcity, food insecurity, and 
so on. ${ }^{5}$ In the case of Northeast Asia, the main forms of environmental disorder - which represent a threat to environmental security and often lead to trans-border tension - include the emission of hazardous gases causing the greenhouse problem and acid rain, pollution of water harming marine resources, and extensive deforestation worsening land degradation and biodiversity loss. On the other hand, there are certain major factors, including excessive economic growth, industrial and urban expansion, and population pressure, which are largely responsible for such environmental disorders. This section of the chapter deals with these two components - indicators and causal factors - related to environmental problems in Northeast Asia.

\section{Indicators of environmental disorder}

First, among the regions responsible for emitting greenhouse gases (especially carbon dioxide) that cause global warming, Northeast Asia shares a significant part of global responsibility for this emission of hazardous gases. More specifically, due to the highly industrialized and urbanized nature of countries such as Japan, Taiwan, and South Korea, the region has been emitting greenhouse gases for many decades. The rapid industrial growth of these countries during the post-war period has been achieved at the expense of heavy carbon dioxide emission. However, a more alarming rate of such emission is being caused now by China. In the process of realizing its ambitious industrialization agenda through coal-fired power plants, China has become a major source of greenhouse gases. During the period 1990-1996, there was an increase in carbon dioxide emission from 241 million to 408 million tonnes in South Korea, 1.0 billion to 1.2 billion tonnes in Japan, 244 million to 254 million tonnes in North Korea, and 2.4 billion to 3.3 billion tonnes in China. ${ }^{6}$

Second, Northeast Asian countries are also responsible for emitting a considerable amount of chlorofluorocarbons (CFCs) that contribute to the depletion of the ozone layer. This is more critical today due to a massive increase in the consumption of luxurious electronic goods such as refrigerators and air conditioners that emit CFCs in the process producing and using them. In fact, Japan, Taiwan, and South Korea have been well known for producing these electronic goods and exporting to countries all over the world. More recently, China has become a major producer and consumer of these ozone-depleting products. Another environmentally disastrous gas challenging the region is sulphur dioxide, which often causes acid rain. Once again, it is China's coal-burning factories and power plants that account for the major share of sulphur dioxide emission (700,000 tonnes per year) - the acid rain caused by this 
sulphur emission affects not only China but also Japan, South Korea, and North Korea. ${ }^{7}$

Third, there are various sources of marine pollution in Northeast Asia - including industrial waste, oil spills, radioactive waste, agricultural chemicals, and heavy metals - which have severely affected the Sea of Japan, the Yellow Sea, the South China Sea, and the East China Sea. ${ }^{8}$ The level of oil pollution has worsened in the Sea of Japan, and the volume of marine oil spills has nearly tripled along the coast of South Korea. ${ }^{9}$ Another environmental danger is caused by the disposal of radioactive materials and potential nuclear accidents resulting from nuclear power plants in Japan, South Korea, North Korea, China, and Taiwan. Today, in South Korea, more than 30 per cent energy demand is met by nuclear power generated by 14 nuclear reactors; Japan produces about 33 per cent of its electricity from nuclear energy; and China is also increasingly engaged in developing nuclear energy. ${ }^{10}$

Fourth, countries in Northeast Asia have been infamous for causing deforestation, which is considered a major cause of environmental and ecological threats such as soil erosion, land desertification, and biodiversity loss. The rate of deforestation has increased in the region, especially due to the increasing demand for forest timbers in Japan and South Korea, and more recently in China. ${ }^{11}$ It has been observed that during a five-year period between 1990 and 1995, the total area of deforestation was $130 \mathrm{sq} \mathrm{km}$ in South Korea, $132 \mathrm{sq} \mathrm{km}$ in Japan, and $866 \mathrm{sq} \mathrm{km}$ in China. ${ }^{12}$ A high rate of deforestation can be found along the Pacific coast and the Chinese and Mongolian borders. In fact, China is seriously affected by deforestation in terms of land desertification, siltation of rivers, and severe floods. For instance, in June 1998, the flooding of the Chang (Yangtze) River led to 2,500 deaths and 56 million people homeless. ${ }^{13}$ Finally, there is a problem of diminishing biodiversity in Northeast Asia, which is often caused by environmental problems, such as air pollution, acid rain, marine pollution, and deforestation. It was found in 1997 that the total number of lost or endangered plant and animal species

was 91 in South Korea, 30 in North Korea, 769 in Japan, and 477 in China. ${ }^{14}$ Such losses in biodiversity imply a greater danger to the ecological balance in the region.

\section{Factors worsening environmental disorder}

First, it is widely recognized that one of the most critical dangers to environment security has been the industrial civilization governed by the fetish for economic accumulation. Despite the adverse implications of industrial expansion for environmental problems such as air and water 
pollution, carbon emission and global warming, toxic waste, and resource depletion, Northeast Asian countries, especially Japan, South Korea, and Taiwan, have pursued massive industrialization since the 1950s and 1960s. In particular, these countries have used environmentally hazardous coal, oil, and nuclear energy in this process of industrialization, which worsened these various forms of environmental disorder. Thus, industrialization has been a major factor behind environmental degradation in these advanced industrial countries. ${ }^{15}$ Lately, China has been aggressively pursuing rapid energy-intensive industrialization, which is more catastrophic because of the colossal scope of such industrialization given the vast demographic and territorial size of the country. In the process of such industrialization, there has been a considerable increase in China's electricity production from hazardous coal. In fact, China is now the second largest electricity producer in the world, and nearly 66 per cent of its total power generation capacity comes from coal. ${ }^{16}$ With regard to this upsurge of industrial growth in China, Hernandez, Tigno, and Torres mention that such a fast rate of growth is likely to make this country "the world's largest emitter of greenhouse gases by 2013". ${ }^{17}$

Associated with this industrialization is the rapid pace of urbanization in Northeast Asian countries, especially Japan, South Korea, and Taiwan, which is also detrimental to the environment, because it intensifies pressure on wetland, forest, and coastal habitat, and worsens the problems of pollution and non-biodegradable toxic waste. In the process of urban development, nearly 40 per cent of natural coastline has been modified and the area of beaches and lagoons has declined in Japan; and 65 per cent of coastal wetlands has been lost due to planned reclamation in South Korea. ${ }^{18}$ While the excessive urbanization process in these advanced industrialized countries has already created heavy pressure on environmental resources in the region, recently more critical challenges to the environment have emerged due to nationwide urban expansion in China. It is projected that the size of urban population in China may increase from the current 425.7 million to 556 million in 2010 to 715.2 million in $2020 .{ }^{19}$ The increasing number of mega-cities in China represents a serious threat to the environment in terms of problems such as energy consumption, urban pollution, and waste disposal.

Second, during the period since the 1950s, the advanced market economies in Northeast Asia such as Japan, Taiwan, and South Korea have aggressively pursued the agenda of economic growth and consumerism often at the expense of environmental security. The average rate of economic growth was 9.8 per cent in Japan during 1956-1973; 8.95 per cent in South Korea during 1963-1991; and 9.7 per cent in China during $1979-1999 .^{20}$ The high rates of economic growth based on industrial expansion, according to the World Bank, may have been achieved in 
Northeast Asia without due consideration of environmental concerns. ${ }^{21}$ It is because, in most cases, economic growth leads to resource depletion, energy consumption, carbon emission, industrial pollution, toxic chemical waste, excessive irrigation, and over-cultivation. The policy measures associated with economic growth in Northeast Asia - including free trade and foreign investment - are also considered environmentally hazardous. ${ }^{22}$ Unfortunately, all these issues and policies have been the main features of widely known "economic miracles" in Northeast Asia, especially in Japan, South Korea, and Taiwan. More recently, the economic growth fetish has also become a primary feature of the giant Chinese economy, which may rapidly deteriorate environmental disorders in the region. It is found by $\mathrm{Li}$ from the data of recent two decades that there is a significant positive correlation between the GDP growth rate and the growth rate of environmentally harmful energy (electricity) consumption in China. ${ }^{23}$ With regard to the relationship between economic growth and environmental problems, Hernandez, Tigno, and Torres mention that Northeast Asian countries have pursued unprecedented economic growth "with attendant environmental destruction". ${ }^{24}$

Although economic growth is largely a matter of production, it is inseparable from consumption and consumerism, which is equally detrimental to environmental security. Coinciding with their high rates of economic growth, Northeast Asian countries have increasingly been transformed into consumerist societies, especially in terms of their consumption of hazardous industrial goods such as automobiles, air-conditioners, aerosols, and so on. In particular, the number of cars, which constitute one of the main sources of air pollution and carbon emissions, has considerably increased in the region. Between 1990 and 1996, the number of cars per 1,000 people increased from 283 to 373 in Japan, 48 to 151 in South Korea, 5 to 12 in Mongolia, and 1 to 3 in China; and between 1987 and 1997, the consumption of motor fuel per person increased from 20 to 35 litres in China, 39 to 245 litres in South Korea, and 308 to 422 litres in Japan. ${ }^{25}$ One can imagine what may happen to the environment if the per capita car ownership in China becomes equivalent to that in Japan or the US.

Third, one most commonly cited threat to environmental security is population pressure on the earth's biological systems such as forests, fisheries, grasslands, and croplands. ${ }^{26}$ This population pressure is a serious concern in Northeast Asian countries, especially in China where the amount of arable land is insufficient for its massive peasant population. ${ }^{27}$ Such increased population pressure endangers the environment in terms depleting natural resources, degrading land through over-cultivation, destroying forests for fuel and cultivable lands, multiplying slums, and polluting air and water. ${ }^{28}$ Despite this challenge of population to envi- 
ronmental security, it has increased in Northeast Asia. During the period 1996-1998 alone, the population size increased from 125.86 million to 126.49 million in Japan, from 45.55 million to 46.43 million in South Korea, and from 21.68 million to 22.08 million in North Korea. ${ }^{29}$ In China, the population increase was 1.25 billion in 1998 to nearly 1.28 billion in 2000, and it is estimated to reach almost 1.48 billion by year $2020 .^{30}$ This increasing demographic pressure on the environment certainly represents a major cause of environmental insecurity in the region.

Finally, the adverse impact of population pressure on the environment becomes even more damaging when there is serious poverty and inequality within the population. While the rich tend to maintain a luxurious lifestyle based on hazardous goods such as cars and electronic products, the poor (especially landless farmers) have no alternative but to depend on natural resources such as virgin forests for their livelihood. ${ }^{31}$ In Northeast Asia, in 1996, the percentage of people earning less than one dollar a day was 18.5 per cent in China and 13.9 per cent in Mongolia. ${ }^{32}$ The conditions of such environmentally harmful poverty, in fact, has worsened in most countries in the region (except China) due to the recent economic crisis. ${ }^{33}$ There is also a considerable degree of economic inequality, which further shows the severity of poverty beyond the national average in each country of the region. More specifically, the shares of income for the poorest 10 per cent and the richest 10 per cent are respectively 4.8 and 21.7 per cent in Japan, 2.9 and 24.3 per cent in South Korea, 2.8 and 24.5 per cent in Mongolia, and 2.4 and 30.4 per cent in China. ${ }^{34}$ Although inequality in Japan is relatively less critical, it is quite serious in China, Mongolia, and South Korea. According to Zarsky and Tay, the post-crisis problem of worsening poverty and unemployment in Northeast Asia may have increased pressure on agricultural land, and intensified resource scarcity and depletion of natural resources in the region. ${ }^{35}$

\section{Environment-led tensions and remedial policies in Northeast Asia}

From the above discussion, it is clear that there are serious environmental disorders in Northeast Asia. These environmental problems represent inherent security threats at a number of levels: individual, national, and regional. Environmental disorders, such as resource scarcity created by excessive resource depletion, acid rain caused by sulphur emission, marine pollution worsened by toxic waste disposal, biodiversity loss and land degradation exacerbated by deforestation, are challenges at all or some of these levels. Environmental disorders created within an individ- 
ual country pose a security challenge not only to that country's own citizens, but, where these environmental problems cross national borders, they also affect the peoples in neighbouring countries, and can thus create cross-national or intra-regional tensions. ${ }^{36}$ Although some national and regional policies do exist to remedy these cross-border security problems, they are usually quite inadequate. In this section, some examples of such environment-led regional tensions are discussed, and the existing remedial measures in this regard are pointed out.

\section{Examples of environment-led tensions}

First, one of the major environment-related factors leading to tension or conflict between nations is "resource scarcity". ${ }^{37}$ More specifically, environmental degradation such as soil erosion, land desertification, drought, and flood may create such a severe resource scarcity in a country that its government demands assistance from other countries, and its people are forced into cross-border migration, which eventually results in interstate tension. Among Northeast Asian countries, China and North Korea are considered especially vulnerable to resource scarcity. In the case of North Korea, environmental degradation and resource scarcity (together with the political atmosphere) have increased cross-border migration and refugee flow from North Korea to China. ${ }^{38}$ On the other hand, in China itself, resource scarcity is a serious problem due to its huge population size (nearly 1.3 billion) and its considerable degree of poverty. It is estimated that in China, about 100 to 130 million people are always on the move in search of resources (land, water, and fuel wood) endangered by soil erosion, over-cultivation, and deforestation. ${ }^{39}$ In the case of North Korea and China, the problems of migration, refugee, and cross-border mobility caused by environment-related resource scarcity are often a source of apprehension or tension among other countries in Northeast Asia. In fact, some of the existing tensions among Northeast Asian countries are related to their desires to expand control over land and water resources. Examples include the continuing disputes over fishing in the regional seas resulting from each country's intention to increase its share of the fishery stocks. ${ }^{40}$ Similar motivation of increasing the national share of resources lies behind the existing disputes over islands, territorial claims, and maritime boundaries among these countries. ${ }^{41}$

Second, interstate tension is also caused by the "spill-over effect" of one country's environmental disorders onto other countries. In general, problems such as transboundary pollution, acid rain, greenhouse effect, and sea-level rise do not remain confined to any specific nation - they adversely affect the neighbouring countries, and thus often lead to conflict between states. ${ }^{42}$ Hernandez, Tigno, and Torres make a similar ob- 
servation in the case of Northeast Asia that although the environmental problems "may originate from particular countries, their impacts are beyond national boundaries, and thus, have the potential to complicate interstate relations." 43 Examples of such environment-led tensions in Northeast Asia include the pollution of coastlines shared by Northeast Asian countries. More specifically, the coastlines of the Yellow Sea shared by China and Korea, and the Sea of Japan shared by Korea and Japan, are polluted by industrial and radioactive wastes and oil spills. ${ }^{44}$ In fact, the radioactive waste and potential nuclear accidents from nuclear power plants in one country represent an environmental threat to other countries in the region. It has been found that there have been 350 nuclear power accidents in South Korea since the nuclear programme began, that such nuclear accidents are not often disclosed in Japan, that storing radioactive waste is a serious problem in Japan and Taiwan, and that the policy to transfer radioactive waste from Taiwan to North Korea may contaminate the Korean Peninsula. ${ }^{45}$

On the other hand, the emissions of carbon dioxide and sulphur dioxide from China's coal-fuelled power plants affect other countries in the region in terms of greenhouse effect and acid rain. ${ }^{46}$ According to the 1998 figures, of the total energy consumption in China, coal accounts for 71.6 per cent, oil 19.8 per cent, natural gas 2.1 per cent, and hydro-power 6.5 per cent. ${ }^{47}$ In particular, acid precipitation from this coal-fuelled energy of China often crosses the Yellow Sea and the Sea of Japan and affects certain parts of South Korea and Japan. ${ }^{48}$ Although China is frequently singled out as the major cause of environmental degradation in Northeast Asia due to its recent energy-intensive industrialization, one should not forget the fact that the early industrialized economies like Japan, South Korea, and Taiwan have damaged the region's environment for many decades. Beyond this controversy over which countries are responsible for environmental degradation, the most central issue here is that, due to the common natural habitat shared by Northeast Asian countries, any environmental damage done by one country adversely affects others and thus causes tension between them.

\section{Existing policy measures}

In response to the above environment-related and environment-led security problems in Northeast Asia, there have emerged various preventive and remedial measures at the international, regional, and national levels. At the international level, it is already pointed out that there are major environmental conventions and protocols that are enforced by institutions such as United Nations Environment Programme, United Na- 
tions Commission on Sustainable Development, Secretariat of the Convention on Biological Diversity, Secretariat of the Convention to Combat Desertification, and so on. Although these conventions and institutions are applicable to most countries, including those in Northeast Asia, they are not often effective in persuading national governments to comply with the standards of environmental protection, and forcing them to address environmental disorders such as air and water pollution, ozone depletion, waste disposal, and biodiversity loss.

At the regional level, the so-called Tumen River Area Development Programme, which involves China, North Korea, South Korea, Mongolia, and Russia, attempts to pursue environmental protection in Northeast Asia through joint projects on environmental awareness and management. On the other hand, one of the main tasks of the Northeast Asia Environment Programme is to organize conferences attended by foreign ministry officials in order to facilitate dialogue on environmental problems, conduct research and training, and monitor marine pollution and acid rain. Similarly, the Northeast Asian Conference on Environmental Cooperation (introduced in 1992) is also an annual conference attended by administrators and researchers working on environmental issues in Korea, China, Japan, Mongolia, and Russia. ${ }^{49}$ The purpose is to share information, identify remedial measures, and enhance cooperation in relation to environmental concerns in the region. On the other hand, Northeast Asian countries (with the exception of Mongolia) are members of the Northwest Pacific Action Plan that deals with the protection of coastal and marine resources in the Yellow Sea and the Sea of Japan. In addition, initiatives such as the South Pacific Regional Environment Programme and the Lower Mekong Basin Development Programme aim to facilitate environmental cooperation between Southeast Asia and Northeast Asia.

At the bilateral level, there is a series of interstate arrangements for environmental cooperation. For instance, Korea and China signed the Agreement on Environmental Cooperation (1993) and established the Korea-China Environmental Cooperation Joint Committee, which led to several meetings and joint projects dealing with cross-border air pollution and the Yellow Sea pollution. ${ }^{50}$ Korea and Japan adopted the Agreement on Cooperation in the Field of Environmental Protection (1993) and created the Korea-Japan Environmental Cooperation Joint Committee. ${ }^{51}$ Similarly, China and Japan introduced the Environmental Cooperation Treaty (1994) with the agenda of joint research on acid rain. ${ }^{52}$ At the national level, on the other hand, Northeast Asian countries have their respective ministries, agencies, commissions, think tanks, and/or nongovernment organizations to deal with internal environmental problems 
and external environmental threats. ${ }^{53}$ In addition, North Korea, South Korea, China, and Japan have adopted "exclusive economic zones" in order to protect marine resources within their entitled boundaries.

\section{The major limits and flaws of existing environmental policies}

It is clear from the above discussion that there are various sets of policies and institutions at the global, regional, bilateral, and national levels to strengthen environmental security. However, the preceding analysis of the indicators of continuing environmental disorders and environmentled tensions in Northeast Asia implies that these existing measures of environmental protection have not been entirely effective. Despite the prevailing conventions, agreements, treaties, dialogues, and networks related to environmental security, there are critical problems - such as land degradation, greenhouse gases, marine pollution, deforestation, radioactive waste, and acid rain - which often lead to interstate tensions. Why have the existing environmental initiatives and institutions failed to overcome these environmental threats?

First, the current environmental conventions and institutions at the international level often lack the authority and power of enforcement. Unlike international institutions related to traditional security issues such as defence and finance - including the UN Security Council, the World Trade Organization, and the International Monetary Fund - institutions for non-traditional security issues like the environment are relatively weak and unable to impose any sanction on countries violating international conventions. Institutions such as the United Nations Environment Programme and United Nations Commission on Sustainable Development do not have adequate supervisory controls and resources to ensure that all nations, including those in Northeast Asia, comply with international environmental standards. At the regional level, although there are certain plans and programmes for environmental cooperation among Northeast Asian countries, according to Hernandez, Tigno, and Torres, such measures of intra-regional cooperation remain "too rudimentary when compared to Europe and North America". ${ }^{54}$ In Northeast Asia, instead of adopting comprehensive multilateral initiatives for environmental security, there is a tendency to emphasize the aforementioned bilateral agreements, treaties, and meetings between various countries in the region. In addition, the existing regional and bilateral initiatives and institutions are mostly for joint projects related to research, training, information, and assessment; they rarely cover concrete environmental protection measures based on mutually binding legal provisions, obligations, and sanctions. 
Second, one major reason for the relative absence of comprehensive environmental security measures in Northeast Asia is the dominance of traditional security perception based on state-centric and militaristic assumptions. The overwhelming concern of each state in the region is for military security, which has dominated the security framework for many decades and still remains the primary focus, while less attention is paid to non-traditional security issues such as the environment despite its growing significance. This continuing dominance of traditional military security over environmental security is quite evident in the expansive defence expenditures in Northeast Asian countries. While China's annual defence spending since 1995 has constituted more than 8 per cent of the national budget, Japan's military expenditure at nearly $\$ 49$ billion is now the second highest in the world (after the US). ${ }^{55}$ China is specifically concerned about Japan's renewed defence posture and Taiwan's acquisition of advanced weapons - in both cases, with open support and assistance from the US. ${ }^{56}$ In the Korean Peninsula, the situation remains tense as the two Koreas continue to maintain a strong military presence along their borders and to develop missile programs. ${ }^{57}$ These are a few examples of how Northeast Asian countries are still preoccupied with traditional, rather than non-traditional, security concerns. This continuing antagonistic security structure based on military strength may constrain any substantive progress in regional cooperation for environmental security.

Third, there are various historical and contemporary factors reinforcing the primacy of traditional (military) security over non-traditional (environmental) security in Northeast Asia. The past legacies, such as the role of Japan during World War II, the memory of the Korean War, and the deep ideological division and rivalry during the Cold war, ${ }^{58}$ have not yet been overcome by these countries. The age-old interstate distrust among countries in the region tends to perpetuate their mutual suspicion and reinforce their belief in military security. Thus, effective environmental cooperation among these countries is difficult to attain when they still hold a traditional security perception based on the assumption of mutual military threats. Another factor prohibiting regional cooperation for environmental security is the tradition of a "dominant state" playing major roles in both domestic and foreign affairs in all Northeast Asian countries. During the pre-colonial and post-colonial periods, the state was always the main actor in China, Taiwan, Japan, South Korea, and North Korea. Even in realizing the recent economic achievements in these countries, the state has played a primary role while the non-state actors have been subservient to the state apparatus. ${ }^{59}$ This tradition of state-centrism in Northeast Asia, which is often reinforced by ultranationalism, is not conducive to the adoption and implementation of comprehensive or multilateral legal and institutional structures related to 
environmental security in the region. It is because the dominant state often considers such a binding multilateral security arrangement - which involves the participation of various non-state actors - a barrier to its assertion of sovereign power.

Fourth, a major external factor constraining interstate cooperation in both military and environmental security in Northeast Asia is the hegemonic military presence of the US in the region. The defence alliance of the US with Japan, Taiwan, and South Korea, which evolved under the Cold War atmosphere, has even been intensified after the Cold War, especially in terms of the continued US military presence in Japan and South Korea, the US decision to supply advanced weapons to Taiwan, and the US commitment to deploy a missile defence system in Japan, and perhaps Taiwan. ${ }^{60}$ The military tensions between the US and China and between the US and North Korea remain unresolved. In this context of the strategic alliance of the US with Japan, Taiwan, and South Korea, and its rivalry with China and North Korea, it is easy to see that such a US-led security structure represents a formidable barrier to cooperation between China and Taiwan, China and Japan, and South Korea and North Korea. In fact, while the strategic decisions of Japan, South Korea, and Taiwan are largely formulated under the auspices of US support and interest, the defence policies of China and Taiwan are always shaped by the dynamics of US alliances with its three strategic partners in Northeast Asia - Japan, Taiwan, and South Korea. Thus, as long as there is no basic change in US alliances and rivalries in the region, which is often endorsed by security experts under the façade of hegemonic stability, it is very unlikely that there will be any substantive bilateral and multilateral cooperation among Northeast Asian countries in the area of military security. And as long as there is no adequate regional cooperation in the sphere of military security, the hope for a genuine cooperation in environmental security remains rather bleak.

Finally, one major flaw of current environmental measures practised by Northeast Asian countries is their reductionist nature. More specifically, although these countries have shown concerns for various environmental disorders and adopted certain remedial policies and institutions in this regard, they simultaneously continue to pursue the policies of rapid economic growth, industrialization, and urbanization that are environmentally detrimental. In other words, while the governments in Northeast Asia attempt to rectify the environmental damage already done, they tend to ignore the actual "causes" of such environmental problems discussed above. Although this policy agenda includes reactive environmental policies focusing mainly on the manifest after-the-effect problems (pollution and acid rain), it excludes or overlooks the primary causes of such undesirable outcomes (economic growth and industrial expansion). 
Since the 1950s, Japan, South Korea, and Taiwan have undertaken all possible policies and projects to enhance economic growth, especially those related to energy, industry, and investment, without much concern for the environment. According to Lee, although these countries are now trying to use diplomatic pressure on China to prevent it from pursuing a similar policy agenda, the Chinese government apparently has no intention to compromise its plan to maximize economic growth. ${ }^{61}$ As discussed earlier, this fetish for economic growth based on industrial and urban expansion represents a major threat to environmental security in most Northeast Asian countries.

In addition, the agenda for industrial and urban expansion has not been sensitive to the worsening situation of poverty and inequality among various sections of the population in Northeast Asian countries, especially in South Korea, North Korea, and China. The current agenda of China to enhance market-led economic and industrial growth has, in fact, exacerbated the situation of rural poverty and unemployment. The poverty problem is also exacerbated by the colossal defence expenditure in Northeast Asia, which diverts scarce resources from anti-poverty programmes into military build-ups. Irrespective of the sources or causes of economic poverty and inequality, as discussed earlier, such adverse economic conditions remain major factors responsible for environmental degradation because, while the poor become dependent on environmental resources, the rich get accustomed to environmentally hazardous consumption patterns. Thus, the exclusion of poverty and inequality from the equation of environmental security represents another form of reductionist tendency in the current agenda of environmental protection in Northeast Asia. Without a comprehensive environmental approach dealing with both the forms and causes of environmental disorders, the prevalent reductionist policies are less likely to strengthen environmental security in Northeast Asia.

\section{Summary and conclusion}

This chapter has described how Northeast Asian countries suffer from various forms of environmental disorders - such as land degradation, marine pollution, acid rain, greenhouse effect, sea-level rise, radioactive waste, and biodiversity loss - which are often linked to population pressure, expansive economic growth, intensive industrialization, rapid urbanization, and rising consumerism. It is also discussed how these disorders, which themselves represent serious environmental insecurity, often lead to interstate tensions in Northeast Asia, including tensions generated by "resource scarcity" (cross-border migration, territorial claims, and mari- 
time disputes), and those created by "spill-over effect" (pollution of coastlines, dumping of radioactive waste, nuclear accidents, and acid rain). In relation to these environmental disorders and environment-led tensions, various environmental protection measures have been adopted at the national, regional, and international levels. The chapter then explained why these existing measures are inadequate to ensure a genuine environmental security in Northeast Asia. This last section attempts to outline some policy alternatives to achieve such an authentic environmental security. In this regard, the chapter takes an incremental but holistic approach that incorporates environmental concerns into economic and foreign policy issues. ${ }^{62}$

\section{Internal policy options}

First, Northeast Asian countries need to rethink their current agenda for expanding economic growth based on environmentally hazardous industrialization, which largely accounts for the emission of carbon dioxide (causing greenhouse effect) and sulphur dioxide (causing acid rain), use of nuclear energy (disposing radioactive waste), pollution of water sources (endangering marine species), and so on. The reckless industrialization behind high economic growth in Japan, South Korea, and Taiwan has caused considerable environmental damage during recent decades, although the economic performance of these countries is admired globally. Thus, it is crucial for the governments in Northeast Asia to reexamine the growth-oriented policies related to industry, trade, market, and consumerism in terms of their environmental costs. In fact, one major reason for excessive resource depletion and pollution in Northeast Asia is allegedly the under-pricing of natural resources and exclusion of negative environmental externalities. ${ }^{63}$ Thus, beyond the reorientation of Northeast Asian states in terms of a policy shift from growth-biased industrialization to environment-sensitive development, it is essential that these states carefully assess environmental costs and incorporate them into the costs and prices of industrial goods. In any case, there is a growing international debate on this strategy of internalizing environmental costs into the production and consumption of commodities. There is no doubt that such a policy of incorporating environmental costs may discourage foreign investors, who have often been motivated to make heavy investments in South Korea, Taiwan, and China by the relative absence of environmental regulations, but this option is essential to prevent producers and consumers from degrading the environment - thus enhancing environmental security in the region.

Second, the economically poorer countries in Northeast Asia, espe- 
cially China, Mongolia, and North Korea, must address another environmentally harmful factor, which is poverty and inequality in these countries. It is because the environmental protection initiatives at the national and regional levels may be rendered ineffective if the millions of rural poor become more dependent on environmental resources (virgin forests, marginal lands, marine resources) and the rich continue to expand the production and consumption of hazardous industrial goods that cause pollution, acid rain, greenhouse effect, and ozone depletion. Despite these adverse environmental implications of poverty, the situation of rural poverty and unemployment may have worsened in China and Mongolia due to their recent market-led and urban-centered state policies. In North Korea, the poverty situation is more severe due to famine and the scarcity of resources. Even in South Korea, the recent economic crisis has thrown many people into a much worse form of poverty and unemployment. Thus, there is an urgent need to address these problems, not only on human grounds but also in order to save the environment. In this regard, the governments in Northeast Asian countries should reevaluate their current neo-liberal policies of reducing welfare budgets, subsidized services, and social programmes that used to help low-income families, especially the rural poor. Initiatives should be undertaken by the state to generate employment and income for the poor, and guarantee the satisfaction of their basic needs such as food, education, health, housing, and transportation.

Lastly, another factor requiring immediate attention is the increasing population in Northeast Asia which, as discussed earlier, represents a primary cause of environmental degradation in the form of over-exploiting marine and forest resources in the region. The problem is more serious in China, with the largest population of the world. Although China has extensive policies and programmes to control population, it needs to go beyond the traditional top-down, and often coercive, policy agenda, and adopt more motivational programmes in terms of providing adequate health care and basic education, and ensuring access to information about family planning and birth control. In fact, anti-poverty policy and population control programmes should complement each other, because poverty is often caused by over-population, and population increase is often accentuated by poverty. For instance, an increase in population reduces the share of national wealth, per capita income, and access to resources. On the other hand, in order to ensure their own future economic security, poor parents are likely to have large families in order to offset the risks posed by high infant mortality. Thus, these two interrelated causes of environmental insecurity, population and poverty, should be addressed simultaneously. 


\section{External policy options}

Due to the cross-boundary nature of environmental issues, it is essential to build interstate cooperation in order to achieve environmental security, which in turn, requires states to overcome traditional conflicts and security perceptions. In the case of Northeast Asian countries, first, it is crucial to transcend the legacy of negative images and perceptions they hold about each other. It is often these images and perceptions based on mutual distrust rather than reality that shape the interstate relations among these countries. Subjective constructs such as the "China threat" and "Japan's military reassertion" are often used to rationalize a militaristic security perception in the region that needs to be questioned. In the process of re-examining or deconstructing such negative mutual perceptions, the governments in the region need to deploy serious confidence-building measures, information exchanges, with frequent informal meetings and dialogues. The purpose is to question existing perceptions, rebuild mutual trust, and discover areas of common interests. These are basic preconditions for any bilateral and multilateral cooperation in all spheres of regional security, including environmental security.

Second, negative perceptions among states in Northeast Asia have certain historical roots and contemporary causes, including the colonial experience, World War II, the Korean War, the Cold War, the Taiwan issue, and territorial disputes. However, these age-old sources of tension should not continue to determine the fate of the current and future generations of the Chinese, Japanese, and Koreans. These past experiences need to be put behind, and a mutually beneficial security structure has to be established among various states in the region. Once again, this venture requires intensive dialogue and negotiation based on mutual confidence and rational criteria. However, the potential of such a trustworthy interstate cooperation is often weakened by the aforementioned "US factor", implying the US military presence and interest in the region. In this regard, Japan, South Korea, and Taiwan need to reassess their defence alliances with the US: because the very reasons for which they seek US assistance (the Chinese and North Korean threats especially) may diminish, if not completely disappear, if the US military presence itself is substantially reduced.

In other words, since China's negative attitude toward Japan and Taiwan is largely shaped by those countries' military collaboration with the US, and since North Korea's hostility towards South Korea is often reinforced by the presence of US armed forces in the latter, it is quite likely that a serious reduction in US military personnel and weapon supplies in the region would lead to greater collaboration between South Korea and North Korea, Japan and China, and China and Taiwan. In addition, to a 
great extent, the current mutually negative perceptions and tensions between these countries is a product of the US Cold War doctrine, security framework, and defence interest in the region. Therefore, it is an immense task to transcend the past rivalries, sort out the current conflicts, demystify the US factor and thereby achieve genuine regional strategic security. As far as Northeast Asia is concerned, this regional collaboration in military security is almost a precondition for non-military, environmental security.

Third, after completing the above groundwork - examining negative perception, putting behind past rivalries, reassessing the US factor, and building mutual confidence - the stage may be set for Northeast Asian countries to get involved in adopting mutually binding conventions and treaties based on equality and transparency. In order to enforce such conventions and treaties, these countries must create adequate institutions with equal participation of member countries while bestowing sufficient authority and power upon these institutions to ensure that each member country complies with such agreed upon treaties and conventions. These legal and institutional measures of regional collective security in Northeast Asia must represent a comprehensive security framework encompassing all major domains of interstate relations, including the military, economic, and environmental sphere, and involve both state and non-state actors. Although the national initiatives and bilateral agreements are important, they should be articulated within this multilateral framework of regional cooperation and collective security. Multilateralism is particularly essential for a security issue such as the environment, which involves multiple sectors and stakeholders.

Finally, once these misconceptions are replaced by mutual trust and cooperation, and legal and institutional structures for collective regional security are created among the Northeast Asian countries, they can then reduce the scope and size of their defence sectors in terms of budgets, personnel, and weapons. In this venture, it is equally important to reach a consensus through engagement in dialogue and negotiation; in this respect, China - in view of it having the largest military arsenal in the region - could play a major role by setting examples and making compromises. In fact, if some of the preconditions mentioned above are accomplished - especially the rejection of an excessive US military presence by Japan, Taiwan, and South Korea - China may be willing to take the first major step by significantly reducing its defence sector and cutting military expenditure. As far as environmental security is concerned, this reduction in defence build-up and budget is very crucial: it would not only save the environment from hazards caused by arms production, especially by radioactive waste from nuclear arsenals or programmes (in China and North Korea), it would also release a considerable amount of 
resources from the defence sector, which could be used to expand social programmes and help mitigate environmentally harmful poverty.

In fact, Northeast Asia represents one of the most expensive regions of the world in terms of defence. If the colossal amount of military spending in Japan, China, South Korea, and North Korea can be reduced on the basis of the regional cooperation and collective security discussed above, the consequent peace dividends can easily eradicate poverty, reduce the need for excessive economic and industrial growth, and thus create a better prospect for environmental security in the region. Although one may consider the suggestions made as somewhat generic and unconventional, the fact remains that without such a deconstructive, multidimensional, and collective approach to regional security, the existing piecemeal measures are unlikely to achieve any form of long-lasting security, including environmental security, in such a complex region as Northeast Asia, which is characterized by conflicting historical legacies, political ideologies, and external alliances.

\section{Notes}

1. Rowland T. Maddock (1996) "Environmental Security", in M. Jane Davis, ed., Security Issues in the Post-Cold War World, Cheltenham, UK: Edward Elgar, pp. 160180.

2. Some of the major environmental disorders that may pose a challenge to security include: transborder pollution (air and water); resource scarcity (energy and food); resource degradation (land and forest); biodiversity loss (animal and plant species); and natural disasters (global warming and sea-level rise).

3. See M. Shamsul Haque (1999) "The Fate of Sustainable Development Under the Neoliberal Regimes in Developing Countries”, International Political Science Review 20(2): 199-222.

4. Ibid.

5. Lester Brown (1977) Redefining Security, Worldwatch Paper No. 14, Worldwatch Institute, Washington, D.C.

6. World Resources Institute (2000) World Resources 2000-2001, Washington, D.C.: World Resources Institute.

7. Peter Hayes and Lyuba Zarsky (1994) "Environmental Issues and Regimes in Northeast Asia", International Environmental Affairs 6(4, Fall); Shin-Wha Lee (2000) "Safeguarding the Environment: An Agenda for Regional Cooperation in South Korea, Northeast Asia, and Beyond", in Carolina G. Hernandez and Gill Wilkins eds., Population, Food, Energy, and the Environment: Challenges to Asia-Europe Cooperation, Tokyo: Council for Asia-Europe Cooperation, p. 188; and Carolina G. Hernandez, Jorge V. Tigno, and Crisline G. Torres (2000) "The Asian Overview: Population, Food, Energy, and the Environment", in Carolina G. Hernandez and Gill Wilkins, eds., Population, Food, Energy, and the Environment: Challenges to Asia-Europe Cooperation, Tokyo: Council for Asia-Europe Cooperation, p. 131.

8. Hernandez, Tigno, and Torres (note 7) pp. 130-132; NISSD (Nautilus Institute for Se- 
curity and Sustainable Development) (1999) Energy, Environment and Security in Northeast Asia: Defining a U.S.-Japan Partnership for Regional Comprehensive Security, (Berkeley, CA: NISSD, December) [http://www.nautilus.org/papers/energy/ESENAfinalreport. html]; Standing Committee on Foreign Affairs (SCFA) (1998) Crisis in Asia: Implications for the Region, Canada, and the World, report of the Standing Committee on Foreign Affairs, December, Canada.

9. Hayes and Zarsky (note 7); Lee (note 7) p. 188.

10. Lee (Note 7), p. 195.

11. Hayes and Zarsky (note 7).

12. World Bank (2001) World Development Report 2000/2001, New York: Oxford University Press, p. 291.

13. Matsushita Kazuo (2000) "Environment and Development in Asia", Japan Echo 27(3, June).

14. World Bank (2000) World Development Report 1999/2000, New York: Oxford University Press, p. 222.

15. Lee (note 7), p. 187.

16. NISSD (note 8); Li Kai (2000) "The Impact of Expanding Population and Economic Growth ... in the People's Republic of China", in Carolina G. Hernandez and Gill Wilkins, eds., Population, Food, Energy, and the Environment: Challenges to Asia-Europe Cooperation, Tokyo: Council for Asia-Europe Cooperation, p. 158.

17. Hernandez, Tigno, and Torres (note 7), p. 131.

18. Lyuba Zarsky (1995) "The Domain of Environmental Cooperation in Northeast Asia”, paper prepared for the Sixth Annual International Conference Korea and the Future of Northeast Asia: Conflict or Cooperation?, Portland State University, Portland, Oregon, 4-5 May 1995.

19. Li (note 16), p. 145.

20. Ibid., p. 141.

21. World Bank (1999) Environmental Implications of the Economic Crisis and Adjustment in East Asia, Washington, D.C.: World Bank, p. 2.

22. Hernandez, Tigno, and Torres (note 7) p. 130; Lyuba Zarsky and Simon Tay (2001) "Civil Society and the Future of Environmental", in D. Angel and M. Rock eds., Asia's Clean Revolution: Industry, Growth and the Environment, Sheffield, U.K.: Greenleaf Publishing; Gill Wilkins (2000) "The European Overview”, in Carolina G. Hernandez and Gill Wilkins, eds., Population, Food, Energy, and the Environment: Challenges to Asia-Europe Cooperation, Tokyo: Council for Asia-Europe Cooperation, pp. 9-10.

23. Li (note 16), p. 155.

24. Hernandez, Tigno, and Torres (note 7), p. 130.

25. World Resources Institute (note 6).

26. Brown (1977) (note 5); Jessica T. Mathews (1989) "Redefining Security", Foreign Affairs 68(Spring): pp. 162-177.

27. Jack A. Goldstone (1992) "Imminent Political Conflicts Arising from China's Environmental Crises", Occasional Paper of the Project on Environmental Change and Acute Conflict. University of Toronto, December.

28. Haque (note 3 ).

29. Tsuneo Akaha (2000) "Non-Conventional Security Cooperation in Northeast Asia", paper presented at the workshop of Inter- and Intra-Regional Cooperation and Institutions Research Group, University of Hong Kong, 11-12 December.

30. Li (Note 16), p. 143.

31. Haque (note 3 ).

32. World Bank (note 12) pp. 280-281. 
33. Between 1996 and 1998, the nominal per capita income declined from US\$36,543 to US $\$ 29,836$ in Japan, US\$11,422 to US\$6,908 in South Korea, US\$989 to US\$573 in North Korea, and US\$460 to US\$436 in Mongolia. Akaha (note 29).

34. World Bank (note 12) pp. 282-283.

35. Zarsky and Tay (note 22).

36. It has been pointed out, in general, that environmental degradation may result from armed conflict as well as leading to armed conflict. See Johan J. Holst (1989) "Security and the Environment: A Preliminary Exploration", Bulletin of Peace Proposals 20(2): $123-128$.

37. Ted Robert Gurr (1985) "On the Political Consequences of Scarcity and Economic Decline", International Studies Quarterly 29: 51-75.

38. It is estimated that about 100,000 to 400,000 North Koreans have fled to China with an intention to eventually settle down in South Korea. Lee (note 7), p. 202.

39. SCFA (note 8 ).

40. Zarsky (note 18).

41. Examples of such disputes include territorial disputes (mostly over islands) of Japan with China, South Korea, and Taiwan; and the maritime boundary dispute between China and Vietnam. SCFA (note 8); Deng Yong (1998) "The Asianization of East Asian Security and the United States' Role”, East Asia: An International Quarterly, Autumn.

42. Homer-Dixon, Thomas (1991) "On the Threshold: Environmental Changes as Causes of Acute Conflict", International Security 16(Fall): 76-116.

43. Hernandez, Tigno, and Torres (note 7), p. 131.

44. Lee (note 7), p. 188.

45. Ibid.

46. Zarsky (note 18); NISSD (note 8).

47. $\mathrm{Li}($ note 16$)$, p. 157.

48. Lee (note 7), p. 188.

49. Hernandez, Tigno, and Torres (note 7), p. 137.

50. Lee (note 7), pp. 190-191.

51. Ibid., p. 191.

52. Ibid.

53. For the examples of national-level initiatives in China and South Korea, see Yi-Chi Wang (2000) "Republic of China", in Asian Productivity Organization, Asian Approach to Resource Conservation and Environment Protection, Tokyo: Asian Productivity Organization, pp. 43-56; Kyung-Ho Maeng (2000) "Republic of Korea", in Asian Productivity Organization, ed., Asian Approach to Resource Conservation and Environment Protection, Tokyo: Asian Productivity Organization, pp. 142-146. For such initiatives in Japan, see Organization for Economic Co-operation and Development, (1994) OECD Environmental Performance Reviews: Japan, Paris: OECD.

54. Hernandez, Tigno, and Torres (note 7), p. 131.

55. Government of China (2000) China's National Defense in 2000, Beijing: Information Office of the State Council of the People's Republic of China, October.

56. Ibid.

57. Deng (note 41); Masashi Nishihara (1999) "Japan's New Search for Security”, Department of Foreign Affairs and International Trade, Canada.

58. Hernandez, Tigno, and Torres (note 7), p. 136.

59. Although the communist states in China and North Korea, the authoritarian regimes in Taiwan and South Korea, and the one-party-dominant system in Japan have recently been weakened by diverse factors such as market expansion, economic crisis, globalization process, and forces of democratization and civil society, the state still remains 
the dominant actor in these countries, especially in determining their interstate relations.

60. Government of China (note 55).

61. Lee (note 7), p. 208.

62. For the distinction between "incremental approach" and "quantum leap approach", see Jessica T. Mathews (1994) "Preserving the Global Environment", in Eugene R. Wittkopf, ed., The Future of American Foreign Policy, New York: St. Martin's Press.

63. World Bank (note 21), p. 3. 
8

\section{A cultural theory perspective on environment and security issues in Nepal}

Ajaya Dixit and Dipak Gyawali

On 9 May 2000, Gajendra Sahi, the Nepali Congress Chairman of the Dandeldhura District Development Committee, led a delegation from his district to meet Prime Minister Girija Prasad Koirala. The committee chairman handed over a protest note opposing the implementation of re-regulating the Poornagiri Dam, whose construction downstream of the Pancheswar Dam was proposed under the Integrated Treaty on the Mahakali River. Earlier, the District Committee of the Nepal Communist Party United Marxist-Leninists (UML) had passed a similar resolution opposing the Poornagiri Dam proposal, because the dam and the reservoir would submerge the highly productive valley there. The Poornagiri is a re-regulating dam which would be built downstream from the 315-metre high Pancheswar Multi-Purpose Dam. The Pancheswar Dam would also submerge a large land area of the Dandeldhura and Baitadi districts. According to preliminary estimates, about sixty thousand people would be displaced. For its part, the proposed Poornagiri Dam would submerge a substantial amount of cultivated land in the Dadeldhura District.

The story of water resources, as exemplified by these dams and the struggles associated with them, is a story of how conflicts over environmental issues become intrinsically intertwined with the battle for human security, particularly in developing countries such as Nepal. 


\section{The Mahakali Treaty: Unmet expectations}

The Mahakali Treaty between India and Nepal was ratified by the joint session of the Nepali Parliament on 20 September 1996 with a two-thirds majority that included the then-ruling Nepali Congress and the opposing UML. This treaty aimed to set the stage for the development of the Pancheswar Multi-Purpose Project. The Mahakali Treaty, which overrode the earlier Memorandum of Understanding on the Tanakpur barrage, stipulated specific provisions regarding the ways in which India and Nepal would share the water of the Mahakali River and the energy that the high dam would generate (see Figure 8.1). In order to derive as much benefit as possible from the project, the treaty laid out the following provisions:

- The Detailed Project Report (DPR) to be finalized by both countries within six months of the treaty's enaction. (Ratification by Nepali parliament; India's parliament does not have to ratify decisions made by the government).

- An agreement for the financing and implementation of the project, including the proposed establishment of the Pancheswar Development Authority, to be negotiated and finalized by both countries within one year of finalization of the DPR.

- The project to be completed within eight years of the date of the agreement for its implementation, subject to the provision of the DPR.

Today, five years after its high profile ratification, the treaty's basic provisions remain unimplemented. Even the DPR remains in limbo. Moreover, the likelihood of its ever being implemented in its original spirit is now in question. What went wrong? While ratifying the treaty, its proponents had argued that it would make Nepal and its people more secure by generating revenue and other benefits by storing large volumes of water: irrigation, power, recreation, navigation, fishery development, etc. However, on the insistence of the project's critics, four stricture clauses redefining the provisions of the treaty were also passed prior to ratification. These clauses related to water rights, the price of electricity, the status of the river and disagreements about the origin of the river at Kalapani. The disputes over these issues still remain unresolved. Because of these lingering differences and the problems of arriving at a mutually acceptable DPR, the opponents of the enterprise now consider it to be an illegitimate venture despite the two-thirds majority which originally ratified the treaty. From the side of the Nepali Congress, the former Minister of State for Water Resources and the current coordinator of the Nepali Congress's water resources policy has said that, until the issue of Kalapani and the source of Mahakali is settled, it is impossible to prepare the 


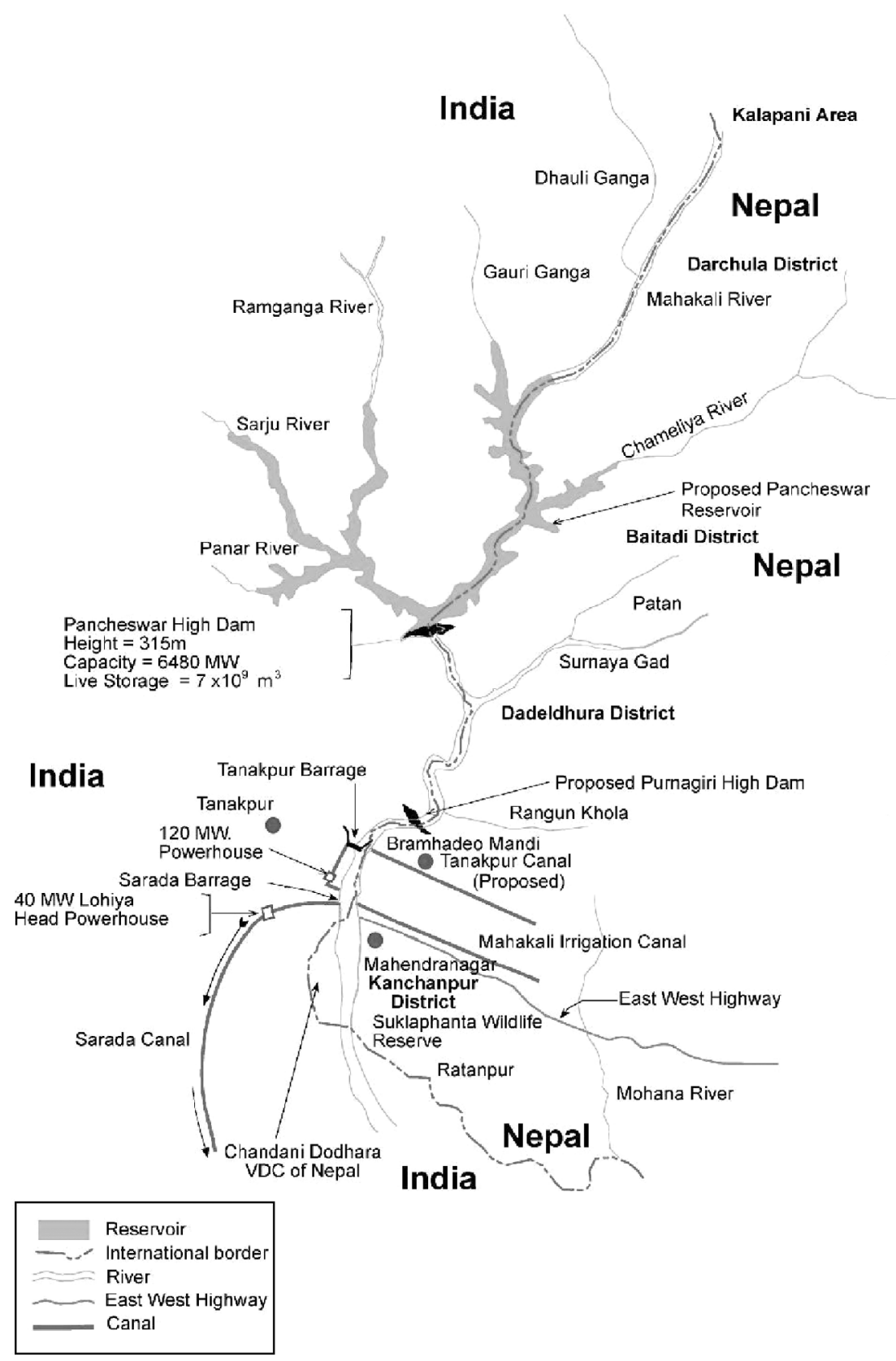

Figure 8.1 Map of the Mahakali River 
DPR (detailed project report) of Pancheswar. He goes on to point out that if India agrees to Nepal's position on Kalapani, the implementation of the Mahakali treaty may move forward, but even then it is doubtful if the DPR could solve the issue of water sharing in an agreeable manner. Indeed, this leaves the treaty frozen in a deadlock. ${ }^{1}$

The Mahakali Treaty is a classic example of a bureaucratic response that has filtered out the social and political questions from a resource pool dominated by the engineering mindset. The hierarchic solidarity in both Nepal and India concurs with this mindset, and the voices that have sought to highlight alternative points of view have been both marginalized and ignored. Criticism has come from social activists who have highlighted the social, economic, and political risks of the chosen path. Many of the problems, they insist, need political rather than engineering responses because they relate to the rights, obligations and issues of territory that an engineering document like the DPR simply cannot resolve.

Even if the differences are resolved, the implementation of a regional project of this scale will be rife with uncertainties and disputes. The example of the Tehri Dam in Garhwal (Uttar Pardesh, India), located 150 kilometres due west of Pancheswar, is a case in point. ${ }^{2}$ The Tehri project on the Bhagirathi, which was sanctioned in the late 1960s, still awaits completion. The three-decades-long debate on that project highlights the enormity of the sense of insecurity that can arise between parties by the loss of sustenance at the hands of large bureaucracies running megaprojects from afar. Not only have the existing arguments over the compensation and rehabilitation of displaced families not been resolved but the possibility - or rather probability - of future disputes becomes ever stronger. As they looked at the case of neighbouring Tehri, the reality of having to leave one's own home began to dawn on those Nepalese that could be affected by the construction of this dam. Their collective stress expressed itself in the form of a memorandum to the government from the district committees of the two main political parties of Dandeldhura District. What is ironic in this protest memorandum is that the committees represent at the grassroots level the parties whose central leadership overwhelmingly ratified the Mahakali Treaty at its inception. It shows that the perception of security can differ dramatically as the scale changes, even within a political party.

\section{Security and risk}

The point underscored by these disputes over large projects is that security is not simply the desire of the government to provide for its citizens. ${ }^{3}$ A proposal made by the state with the aim of providing energy or water 
security to some people is seen by others as a threat to their own livelihood security. People living in the paths of proposed reservoirs see an immediate security threat in the possibility of having their land drowned. Such threats, however, are often ignored in the hierarchic rationality of the engineering mindset. When those parties who feel threatened join forces to reject the implied rationality, the result is often an impasse.

The case of the Sardar Sarovar Project in Narmada (India) typifies the nature of opposing rationalities on a confrontational course. Supporters of the dam outline the benefits of the project while acknowledging the cost, which they argue is resolvable by procedures. They point out that the needs of the 40 million people who are expected to benefit from the project (those whose security will be enhanced because of the dam) dwarfs those of the 240,000 people who will be harmed by the project. ${ }^{4}$ The Narmada Bachao Andolan (NBA), the major civil society coalition of project stakeholders, rejects this notion of security and instead argues that the construction of the dam must be halted in order to avoid the insecurity that the displaced people would face. These examples of megaprojects highlight the dynamic notion of "securities in conflict", thereby providing a different lens through which to view the issues at stake.

The notion of "security" is intricately related to the issues of survival and livelihood. Therefore, access to water and energy become central in how these issues are articulated in the lives of the Nepali people. Ways in which they cope with insecurity are a function of how they perceive risks. It is useful, therefore, to understand how people perceive and deal with issues related to risks. An individual makes choices, forms alliances, and takes part in a community where his or her relationships are defined. Social scientists who study risk allow that individuals are active organizers of their own perceptions and how much they choose to fear, preconditioned by their need to support their own way of life. These ways of life have four basic groupings, or "cultural biases", in institutions that can be characterized as hierarchical, egalitarian, entrepreneurial, or fatalist. Each of these has a different institutional filter, through which risks are perceived and assessed. Risks are akin to a lens for sharpening the focus on the social organization itself. ${ }^{5}$

Hierarchies (and governmental departments) tend to risk minimization: they consistently make it clear to their members that they can best secure their interests through conformity. Those who see rewards in taking risks espouse an entrepreneurial (or individualistic) outlook. They gravitate towards an adversarial or heroic stance that challenges the real distribution of power, whether over scientific data and interpretation (as in the case of independent academics) or dissemination of information (in the case of investigative journalists). The entrepreneurial urge could manifest itself in challenging the official line as well as in manipulating 
the official machinery into a position from which it could benefit (in the case of consultants and CEOs). Much of the entrepreneurial urge is, however, expressed in trying to devise clever solutions and profiting from them. It is this inherent suspicion of conformity and individual profiteering that galvanizes volunteers with an egalitarian and high risk-averse outlook, "an association whose members are able to boast more of having kept together than of having achieved anything in particular". ${ }^{6}$ Fatalists, unlike the others, are passive about risk. They are so attached to the external order that the best they can do is to cope with, and at worst react in anger against, a situation in which they find themselves. These are the street people, the masses whose status is hard to change and who lack a clear sense of group cohesion. They fear uncertainty and look toward authority to provide predictability in their lives.

\section{Water-related livelihoods and security}

Using the conceptual constructs about the nature of security and risk introduced in the previous section, let us now apply these insights to the problematique of livelihoods and security in the water-related sectors. Human security is closely related to issues of livelihood, which in turn are dependent on specific activities like irrigation, food and drinking water supply, pollution, flood mitigation and energy. We will now turn our focus to these activities.

\section{Irrigation}

The modern irrigation system led to a political bureaucracy centred on the construction of new institutions to increase food production. This approach not only discounted areas irrigated by systems built and managed by farmers, but also assumed that if water were delivered to the canal, productivity would automatically be increased. However, the question of irrigation lies on the line between the private and the collective; its impacts are neither linear nor deterministic. Agricultural land is privately owned, and its management is based on the judgment of individual farmers and by their interaction with one another in the realm beyond their households and villages. Irrigation introduces collective values into individualistic patterns of organization because it contains a common resource pool - flowing water. Farmer-managed irrigation systems have evolved over time in order to best share the resource. Their systems include sanctions like fines and decrees that stipulate when groups must unite in order to clear the canal or rebuild the syauli (brushwood) dam after a monsoon flood washes it away. These systems have acquired a 
certain amount of social legitimacy in terms of their capacity to efficiently provide irrigation water to entire communities.

The situation, however, is not as encouraging in government-built systems where reliability of and access to water supplies are often unsatisfactory. Because these state-run systems are often unable to provide easy access to water, they are being handed over to groups of farmers for management. This approach uses lessons learned from farmer-managed irrigation systems while also taking advantage of collective management. The farmers are allowed limited access to the canal network while the governing agency maintains control of it. The imbalances in and poor reliability of water levels, coupled with the invention of a pump whose use is backed at the highest level by an incentive regime, has resulted in large-scale "dieselization" of irrigated agriculture. A pump is flexible and reliable, and it makes a farmer less dependent on other sources for irrigation. While the use of groundwater irrigation has contributed to an increase in food production, its negative impacts include groundwater depletion and equity problems faced by latecomers to the system. This practice has caused increased pollution in many cases by allowing saline water to intrude into fresh water aquifers in both coastal and arid zones.

\section{Degradation and pollution}

The rising population and urbanization levels are leading to increases in stress between the traditional and statutory water-management organizations. Even though this shift in population would require some reallocation of water from use in the rural agricultural sector to urban areas, this is a trend that is likely to continue because of economic liberalization policies. Industrialization has pollution as its by-product; it also affects the quantitative allocation and sharing of water in the dry season. In both types of systems, urbanization, pollution, and the common preference to opt out of a collectivist system often cause problems. While the farmerbased system may have some social legitimacy, it lacks the ability to react to new kinds of stress. Pollution upstream would render the available water unusable and externalize the cost of treatment, which can also create disputes between the upstream and downstream users who depend on the same water source for their very existence.

\section{Floods}

Flooding often occurs in the region. Unfortunately, the governmental response to disasters focuses principally on the natural or biological events 
which trigger them. ${ }^{7}$ Indeed, the phrases "natural hazard" and "natural disaster" are often used interchangeably. Policymakers, donors, and relief and development agencies treat disasters as isolated events that break the continuity of the "normal" way of life. This approach relies upon the assumption that these events are departures from "normal" social functioning and that recovery from disaster means a return to normal conditions. As a result, interventions to mitigate disasters are post hoc responses made under the assumption that an emergency support in the form of relief will change the situation of hardship; they do not solve the underlying problems.

Recent experience shows that disasters, and the environmental stress and human insecurity that accompany them, are the outcome not only of natural hazards, but also of socio-economic structures and political processes which actually make individuals and families more vulnerable to disasters. This perspective focuses on the ways in which these social systems conduct themselves. It begins with the belief that natural hazards are significant and normal characteristics of the regions where they occur most often, and goes on to recognize that vulnerability is equally important. Vulnerability is a characteristic of a person or a group that measures the capacity to anticipate, cope with, resist, and recover from the impact of a natural hazard. ${ }^{8}$ It can also be defined as social resilience in facing a hazard.

In Nepal the "normal" daily life of most of the population is vulnerable. Individuals and families in many communities find it hardest to reconstruct their livelihoods after a disaster strikes. These people do not live under vulnerable conditions out of ignorance. Instead, most have little freedom to choose where or how they live. Low-income families, for example, often have no other housing options except those in vulnerable locations, such as flood plains. They are forced to live there not because land-use planning is poor, but because the prevailing agrarian relations and the practice of social and economic exclusion in their society make them unable to own property in safer areas.

The focus on a broader political and economic outlook also needs to recognize the specific details of each disaster. Only a combined analysis of natural events, technology, and societal context can provide a realistic understanding of floods and their impact. Extreme natural events, like cloudbursts that can bring more than 500 millimetres of rain in 24 hours, are common here. Every perspective on natural events, technology and society is necessary, but none by itself is sufficient; we must separate them in analysis but integrate them in policy formulation. Through such distinctions, we begin to analyse natural events as well as processes that make individuals and families vulnerable. The impact of a disaster is felt at the individual, family, and community levels. In other words, we cap- 
ture the interactions among various sub-systems and locate the constraints among them in order to be able to design responses that are specifically tailored to a specific context. ${ }^{9}$ Instead of just focusing on technical solutions such as embankments or dams, the insurance schemes, primary health services, and education in Nepal should be far better prepared to face the impact of floods at the individual, family, and community levels. It is these "risk-resilience" approaches that are better suited to respond to the human security concerns posed by floods.

\section{Energy}

Among the most hotly-contested issues in Nepal is that of hydropower development, which had until recently operated under an unchallenged monopoly run by the government. This, of course, has left direct and profound impressions on livelihoods and human security. Hydropower came to Nepal in 1911, about two decades after Nikola Tesla patented the commercial production of the current alternating motor. Ninety years later, only 15 per cent of the population has access to the electricity supply from the national grid, and hydropower accounts for a scant 1 per cent of the nation's energy use. Moreover, Nepali consumers pay what is perhaps the highest price per unit of electricity in the world, a fact which was acknowledged by Deputy Prime Minister Ram Chandra Poudel at the beginning of the general meeting of the Langjung Electricity Development Company (LEDCO). ${ }^{10}$ The result is a stunted possibility of developing electricity as a means of production, thereby facilitating a transformation of the nation's agrarian economy into one based on industrial production. At the same time, due to the fact that local capacities to plan and implement projects are still in their nascent stages, the backward linkage of the investment made in developing hydropower projects remains weak. A preliminary analysis of the investment that has gone into the development of hydropower projects after 1995 indicates that less than five per cent returns to the local economy or results in the creation of jobs. ${ }^{11}$ The rest is used to purchase goods and services from outside the country.

When the new government took charge in 1991, one of the main issues it faced was the Arun III hydropower project. It was supposed to be at the end of a road 120 kilometres long, which had yet to be built. The size of the project was eventually downscaled, but the budget was estimated at more than one billion dollars. Questions were raised about reductions in local capabilities as well as the unbearable risks involved in the project. Not only did egalitarians critique the project, but in this case they also provided alternatives that were cheaper and would produce more 
power quicker. In 1995 the World Bank, which was the main investor in the project, withdrew its support. In an overt sense, the campaign that attacked Arun III in Nepal would be the first example of this in post-1990 Nepal, when social auditors were in action. The campaign against the Arun III brought academics and activists together to challenge a project the estimated cost of which was about four times greater than the private sector's figure, and also to present a set of alternatives that would be cheaper, more effective, and more efficient than the proposed project. After the cancellation of the Arun III, six projects quickly began construction. These are expected to produce a third more electricity than would the Arun III at approximately half the cost, as well as in half the time. $^{12}$

After the Arun III fiasco, two distinct paths have formed for hydropower development in Nepal. On the one hand, government-led initiatives continue. On the other hand, there has been a spurt of initiatives wherein individuals and district representatives have formed cooperatives to develop hydropower projects using local resources, investments, and skills. Notable among these are the Lamjung initiative and the Piluwa Khjola Hydropower Company, which have mobilized local investments and explored ways to minimize the costs involved in creating hydropower. This approach is also guided by concerns about extending services to areas that do not have hydropower available to them. Not only do these initiatives champion the self-help hydropower development mode, but they also question the large-scale projects proposed to export power to India. These two approaches - hierarchic government-led or egalitarian community-based - represent dramatically different biases. They also point towards a different approach to resolving the "securities in conflict" - one that involves different actors and arrives at different answers to that of the traditional hierarchical approach.

\section{Security and solidarity}

In Nepal, natural disasters interact with societal vulnerability, disruptive development interventions, and perverse market exchanges to create an atmosphere of insecurity. Water pollution, sedimentation in and shifting of river channels, land rights, tenancy conflicts, a lack of local maintenance capacity, high electricity costs, dependence on external sources for developmental needs, and many other issues add to this harsh reality and put further stress on the system. What does the future hold for human security, when it is related to water access for irrigation, drinking, and respite from flooding and pollution including energy needs? This is an important question in a milieu which is marked by a complex interaction 
of physical, social, cultural, and institutional factors. As in other nations, individuals, families, and communities in Nepal perceive security differently and respond differently to challenges. The idea of a single "Nepali perspective" on security would therefore be a misnomer. Instead, this chapter suggests three perspectives which result from the conceptual discussion of security and risk presented earlier:

- Hierarchies would seek additional security through procedural rationality; their technological and developmental choices are biased toward the large scale and therefore require additional expertise and control.

- Those in the individualistic mode would seek security through innovation and networking; their choices veer toward the path that provides the most substantive benefits. Egalitarians will seek social justice as the foundation of human security; they are suspicious of choices not easily controlled by the community.

Security enhancement must therefore occur within the constraints imposed by the region's climate, hydrogeology, and geotectonics, including financial macroeconomics. It must also match the diversity of its social base. Hydrogeology and geotectonics are the contexts within which possible solutions must be negotiated. These constraints are real and cannot be overcome. Because variability among natural, social, and institutional factors is high, the response must also be varied - several problems require several solutions. The most common practice in all water-related areas is to define the problem in a unitary mode and generally seek one solution within a hierarchic framework - a large dam, for example. Historically, however, security issues have been viewed through state-centric lenses without taking a single cue from the grassroots. With the emergence of new stress points within and between systems, the unitary approach has become a recipe for depletion of social resilience and, thus, has created an increase in human insecurity.

Institutional pluralism does not just mean organizational multiplicity, with ministries, departments, and parastatal organizations multiplying and cloning themselves at various levels. Security enhancement via access to water and energy supplies has to follow the mutually reinforcing homeostasis of state, market, and civil society. The market, by its very nature, would affect change, and the state would provide a regulatory framework to ensure a fair playing field. A cautionary civil society such as that of the social auditors, much like the third leg of a stool, would provide a countervailing check on the rapacity of the market and the powers of government. So far, there has existed uncontested terrain, ${ }^{13}$ where the state has been playing the role of both the market and civil society, essentially stunting the evolution of either a competitive market or a vibrant civil society. The result is a weak market and an uncommitted civil society juxtaposed with a rent-seeking state. 
The status quo must be challenged, even though to do so is an action uncomfortable to those accustomed to free rein of an uncontested terrain. Contestation and cautionary voices can sometimes lead to benefits, as was made obvious by the campaign against the Arun III. The cancellation of its funding by the World Bank led to the initiation of a more pluralistic path to hydropower development, though at this point in time less coordinated questions are being asked about the high cost of electricity and its links with the local economy. The same is also true of projects like the Pancheswar High Dam. Compromises made in achieving the Mahakali Treaty, which was ratified without either the necessary homework or a filter on questions about cost and risks, have had a severe backlash in Nepal. Political parties on both the left and the right have split, while the benefits promised appear to be further in the future than ever before; this has inflicted a deep sense of betrayal upon the population. Major political parties and the state structure in Nepal continue to get caught up in the ideology of unitary solutions, particularly in the form of building gigantic hydropower projects as a salvation for the country's social and economic woes. Yet it is not at all clear whether, when, and what these projects do for the human and environmental security of the Nepali people.

This mindset is reflected in a policy speech by Nepal's late King Birendra, given to the Nepali Parliament on 19 May 2000. In reaffirming the need to mobilize private and foreign investment in the development of water resources he said, "While proceeding with the Pancheswar Multi-Purpose project, the works relating to the preparation of the Detailed Project Report of projects such as the Sapta Koshi and Sun KoshiKamala Diversion shall be taken up". This fascination with the pursuit of technologically and organizationally inflexible options only serves to limit the scope for performing other necessary activities; in the process, the state ceases to become an institutional resource that helps its people enhance their security.

The key to meeting the future challenges of human security and their links to the environment lies in transcending the conventional way of looking at security itself. These securities can only be enhanced by resorting to institutional pluralism with an emphasis on the harmony between society and the environment and providing freer access to resources such as water and energy. The starting point for security enhancement is to build on the age-old resilience provided by families, neighbourhoods, hamlets, and communities as agents of security. Under such an approach the styles of management may vary at each level, and they are linked to practices of good governance at all levels, from the local to the national. This process consists of allowing space at all levels (from the village to state and regional levels) for a genuine market that is 
open and competitive, egalitarian social auditors with transparent voluntarism, and honest regulation that is not driven by hubris or rentseeking propensities on the part of the state.

In this process, the societal balance of power is key. As per the principle of balance of power, all three institutional sectors should be able to stand together in "social solidarity". In order for the sense of security to be enhanced, state, market, and social auditors must be provided to the system as well as ample space for creative experimentation in the management of water, energy, and risks. If the state-market-social auditor combination were actively engaged, a clumsy compromise could be found; it would be less than what each wanted but much more than what everyone would have if no compromise were reached. The way in which roles would be redefined would ensure that these institutional solidarities are in harmony and not in confrontation. They would depend also on ways in which far-sighted statesmanship could change the role of the state from a rent-seeker to a sagacious adjudicator. Such a "three-legged stool" would bring greater security, not just to Nepal, but possibly to all societies at every level. ${ }^{14}$

\section{Notes}

1. L. Ghimire (2000), Kantipur, 20 January.

2. M. Aryal (1995) "Dams: The Vocabulary of Protest", Himal 8(4).

3. M. Thompson (1997), Security and Solidarity: An Anti-Reductionist Framework for Thinking about Relationship Between Us and Rest of Nature, Norwegian Research Centre in Organisation and Management, Bergen.

4. S. Postel (1999) Pillar of Sand: Can The Irrigation Miracle Last?, New York: W.W. Norton.

5. M. Douglas (1985) Risk Acceptability According to the Social Sciences, London: Routledge and Keegan Paul.

6. Ibid.

7. Blakie, T. Cannon, I. Davis, and B. Wisner (1994) At Risk: Natural Hazards, People's Vulnerability, and Disasters, New York: Routledge.

8. Ibid.

9. Moench, E. Caspari, and A. Dixit, eds. (1999) Rethinking the Mosaic: Investigations into Local Water Management, Kathmandu: Nepal Water Conservation Foundation and Institute for Social and Environmental Transition, Kathmandu.

10. L. Ghimire (2000) Kantipur, 20 January.

11. B. Panday (1996) "Local Benefits from Hydro Development in Nepal", Studies in Nepali History and Society 1(2); A. Dixit (2000) "Water as an agent of Social and Economic change in Nepal", Water for Food and Rural Development Approaches and Initiatives in South Asia.

12. K. Panday (1998) "Hydropower Development in Nepal", Nepal Water 6(1), Conservation Foundation, Kathmandu.

13. M. Thompson (1997) Security and Solidarity: An Anti-Reductionist Framework for Thinking about Relationship Between Us and Rest of Nature, Bergen: Norwegian Research Centre in Organisation and Management.

14. D. Gyawali (2001) Water in Nepal, Kathmandu: Himal Books. 


\title{
The hydro-politics of the Mekong River Basin: Regional cooperation and environmental security
}

\author{
Evelyn Goh
}

\section{Introduction}

The English word "rival" is derived from the Latin term rivalis, meaning "using the same stream (rivus)". Shared water resources epitomize the rivalry surrounding common pool resources, whose use by one party may diminish the potential benefits to others. This is particularly the case with major rivers that traverse multiple nation states. One of the world's largest rivers, the Mekong, flows across the territories of six countries on the East Asian mainland - China, Myanmar, Laos, Thailand, Vietnam, and Cambodia. ${ }^{1}$ This chapter explores the relationship between the exploitation and management of the resources of this international river basin and the national and regional security of its riparian states.

\section{Conflicts over transboundary rivers}

The particular problems associated with sharing a transboundary river are the result of the interaction among three systems - political, hydrological, and ecological. The political system of a sovereign state places a premium on the autonomous right of action of the individual state. In hydrological terms, in contrast, the river basin is an integral unit, encompassing the waters of the river and its tributaries and distributaries, as well as the surrounding land making up the catchment area. At the 
broadest level, the ecological system incorporates both the human and natural systems, emphasizing their interrelations and interdependencies.

The incongruity between political and hydro-ecological boundaries may cause interstate tensions as a result of three corresponding levels of problems at the interface among these systems. The first and most common problem is upstream/downstream interstate allocation conflict: upper-stream abstraction, impoundment, or pollution reduces the quantity and quality of water available to downstream users. Second, ecological feedback effects arise from interlinkages in the hydrological system: land or water use in one part of the basin has unintended consequences on complex relationships, such as those between river discharge and silt loads, seasonal stream flow and fish stocks. These concerns expand the scope for interaction and conflict between upstream and downstream users. The third problem is socio-environmental conflict deriving from the direct and indirect impact of resource utilization and development. There are two key concerns here: sustainability, which is the ability of the ecological system to support indefinitely human development aims, ${ }^{2}$ and security, which refers to the relationship between the integrity of the environmental system and the integrity of human socio-political systems.

Riparian states in the Mekong River Basin face all three types of problems. More than 62 million people depend on the Mekong for basic needs, such as drinking water, irrigation water, fish, and transport. The river's greatest developmental potential, though, lies in hydropower generation and large-scale irrigation projects. These potential resources have been relatively undeveloped until recently because of internal and regional conflict in Vietnam, Laos, and Cambodia. However, the relative peace and economic liberalization programmes of the 1990s have boosted a regional economic development drive and spurred a range of national, bilateral, and multilateral water development plans. The troubled experiences in other transboundary rivers, such as the Nile, the Jordan, and the Tigris-Euphrates, suggest that these developmental projects will have significant impact on the environmental quality of, and relations among, the Mekong riparian states. ${ }^{3}$

\section{Hydro-politics and environmental security}

The term "hydro-politics" is not an exaggeration of the dynamics governing developments in the Mekong Basin: serious conflict over water is not confined to water-scarce areas, such as the Middle East. Water also means energy, food, and fertile land on which millions in this basin depend. In this sense, the security of its riparian states is intimately related to the hydrological integrity and environmental quality of the Mekong.

"Environmental security" is a much-debated concept within the 
broader controversy about extending the notion of security to cover nonmilitary issues. ${ }^{4}$ Proponents have tended to argue in terms of the environmental causes of military conflict between states, in which water is often cited as the most likely resource over which states would fight. To Barry Buzan, for instance, "it is not difficult to imagine the issue of allocations of water along rivers such as the Nile, the Mekong, and the Indus becoming causes for the use of military force". ${ }^{5}$ Yet, most writers who have studied specific cases agree that such "water wars" are unlikely, either because the costs of a state employing force to resolve conflicts over water far outweigh the benefits of potential victory or because water conflicts only serve to exacerbate other pre-existing political tensions between states. ${ }^{6}$

This chapter seeks to bridge the current conceptual gap between those who would redefine security only insofar as to include the environmental causes of national insecurity and ecologists and environmentalists who are concerned with the security of the environment per se. ${ }^{7}$ Environmental disruption and degradation can lead to a significant array of potential tensions and instabilities within and between states, short of violent conflict, and these may be argued to affect the stability and hence security of a region. On the other hand, the discourse of ecology and ethics does not hold much sway in this pragmatic, developmentalist region. Hence this chapter argues that in the Mekong Basin context, the key mediators of environment and security are asymmetrical geopolitical relationships, national development goals and regional economic interdependence, and human welfare. By exploring these interconnections, this analysis will help to strengthen the argument for why securing the integrity and sustainability of environmental resources is an important priority for states.

This chapter addresses three central questions: How has the recent development of large water projects on the Mekong River become a source of conflict in the region? How do these conflicts impinge on regional stability? What are the possible cooperative solutions to these conflicts, and in what frameworks are they best to be found?

The following analysis is divided into three sections. The first examines the competing and conflicting interests of the riparian states over Mekong resources in terms of asymmetries in physical distribution, demands, and dependencies. This provides a basis for identifying potential causes of interstate conflicts. The next section discusses three ways in which conflicts over resources and environmental issues in the Mekong have impinged on security: national resource security in the form of water allocation conflicts; economic security in the case of hydropower development in Laos and the implications for national development and bilateral relations with Thailand; and human security as hydropower development 
impacts on local communities and the implications for domestic political stability. The extent to which existing regional and international institutional frameworks can address these conflicts is also considered in each case. The final section considers implications for developing a useful concept of "environmental security" for the region and for building a greater institutional capacity for cooperative approaches to managing the environmental resources of the Mekong.

\section{Conflicts of interest: Geopolitical asymmetries and Mekong resources}

Fundamentally, conflicts of interests among riparian states in a transboundary river basin stem from differential access, demands, and vulnerabilities in relation to the river's resources. The resources of the Mekong River Basin have been utilized by disparate riparian communities for centuries, but the sharing of these resources is increasingly becoming a source of conflict because the scale, scope, and speed of recent developments have exacerbated underlying asymmetries and inequities.

It is useful to begin by sketching the basic geographical pattern of influence and vulnerability of each riparian state. China wields the greatest advantage as the most upstream state, while Myanmar, Laos, and Thailand are mid-stream states. Geographical control of the river basin can additionally be measured in terms of each state's proportion of river discharge, basin area, and basin population. As table 9.1 shows, Laos is geographically crucial, in that it contributes the largest amount of water flow and controls a larger basin area than any other riparian state. However, Thailand dominates in terms of basin population and has the second largest flow contribution and land area, which also puts it in a position of

Table 9.1 Geographical control of the Mekong River Basin

\begin{tabular}{lcccccc}
\hline Country/control & China & Myanmar & Laos & Thailand & Cambodia & Vietnam \\
\hline $\begin{array}{c}\text { Percentage of flow } \\
\quad 16\end{array}$ & 2 & 35 & 18 & 18 & 11 \\
$\begin{array}{c}\text { contribution } \\
\begin{array}{c}\text { land area } \\
\text { lantage of basin }\end{array}\end{array}$ & 12 & 2 & 26 & 23 & 20 & 8 \\
$\begin{array}{c}\text { Percentage of basin } \\
\text { population }\end{array}$ & 16 & 1 & 7 & 34 & 14 & 28 \\
\hline
\end{tabular}

Sources: Mekong River Commission Secretariat (MRCS) (1995) Mekong River Commission: Towards Sustainable Development: Annual Report 1995, Bangkok: MRCS, p. 1; MRCS (1997) Mekong River Basin Diagnostic Study, Bangkok: International Environment Management; Global Environmental Consultants, p. 4-2. 


\section{Proportion of land area and population of riparian countries within the MRB}

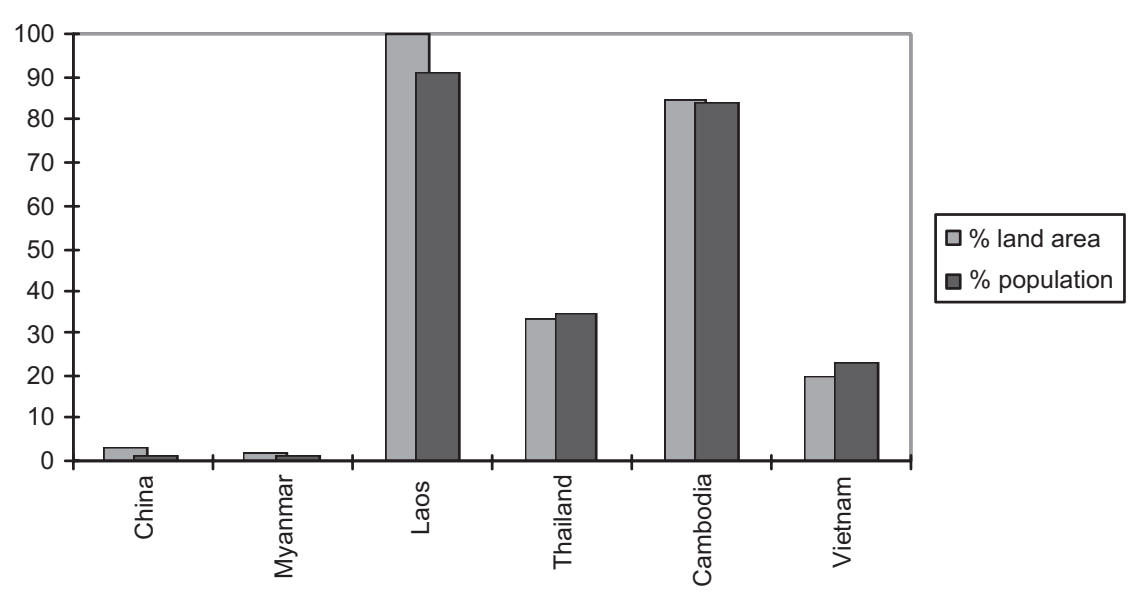

Figure 9.1 Geographical importance of the Mekong Basin to riparian states

strength in the lower Mekong Basin. Cambodia and Vietnam, on the other hand, make significant flow and population contributions but are fundamentally disadvantaged by their downstream position, which subjects them to floods, droughts, and the effects of upstream development.

At the same time, direct dependence on the river's resources, and thus vulnerability to environmental changes, can be measured with reference to the proportion of each state's land area and population that lie within the Mekong Basin and the socio-economic importance of these areas. Figure 9.1 illustrates the quantitative aspects of their relative dependency. The upper riparian states are least reliant on the Mekong, especially Myanmar, which is a very minor riparian. ${ }^{8}$ In contrast, Laos and Cambodia are both almost totally defined by the Mekong. Laos is landlocked and 70 per cent mountainous - its population depends on the river for fish and transportation and on its floodplains for settlement and agriculture. In Cambodia, the Tonlé Sap, or Great Lake, and Mekong floodplains cover the entire country, providing fishing, agriculture, and navigation. In addition, the unique hydrology of the Tonle Sap is crucial to the ecology of southern Cambodia and the Vietnam Delta, acting as a natural flood regulator and sustaining wetlands, which are crucial spawning grounds for the migratory fish stocks of the entire Mekong River. ${ }^{9}$

Although Vietnam appears to be relatively less dependent on the Mekong in quantitative terms, the Mekong Delta is one of two intensively 
cultivated alluvial plains in mountainous Vietnam on which its population is concentrated. ${ }^{10}$ The Mekong Delta is Vietnam's "rice bowl", producing up to 60 per cent of the country's agricultural and fisheries output. ${ }^{11}$ This dependence, coupled with the ecological and hydrological sensitivity of the deltaic system, renders Vietnam extremely vulnerable to the impact of developments in other parts of the river basin. Large parts of the delta are subject to seasonal saltwater intrusion, soil acidity, and waterlogging. Thus the delta must be guaranteed a minimum low flow to limit saltwater intrusion and soil acidification but it must also be protected from excessive flows, which may cause devastating floods. High quality water and silt loads that can maintain the delta are also necessary. ${ }^{12}$

The Mekong Basin is also quantitatively significant in Thailand, where it accounts for a third of the land area and population. However, Thailand's direct dependence on the Mekong is less marked than that of the other lower Mekong states: the key national river is the Chao Phraya, while the Thai portion of the Mekong Basin is located in the relatively remote north-eastern Isan region.

The importance of the Mekong to each riparian state depends also on the demands made by national development priorities and plans and each state's capacity to realize them. The Mekong riparian states, with the possible exception of Myanmar, are experiencing a period of rapid population growth and economic development (see table 9.2). In the wake of the Cold War and civil war, peace and economic liberalization in the socialist economies of China, Vietnam, Laos, and Cambodia have fostered aid and investment in the region as a whole. Large water development projects now play a prominent role in national and regional

Table 9.2 Selected socio-economic indicators for Mekong riparian states

\begin{tabular}{|c|c|c|c|c|c|c|}
\hline & Cambodia & Laos & Thailand & Vietnam & Myanmar & $\begin{array}{l}\text { Yunnan, } \\
\text { PRC }\end{array}$ \\
\hline $\begin{array}{l}\text { Population } \\
\text { (millions) }\end{array}$ & 10.6 & 4.7 & 60.1 & 75.6 & 45.5 & 40.5 \\
\hline $\begin{array}{l}\text { Population } \\
\text { growth (\%) }\end{array}$ & 3.4 & 2.2 & 1.2 & 2.2 & 1.9 & 1.6 \\
\hline GDP/capita (\$) & 295 & 390 & 3,100 & 320 & 250 & 400 \\
\hline $\begin{array}{l}\text { Real GDP } \\
\text { growth }(\%)\end{array}$ & 6.0 & 7.5 & 6.7 & 9.5 & 6.0 & 11.2 \\
\hline
\end{tabular}

Sources: Asian Development Bank (1997) Greater Mekong Subregion SocioEconomic Review, Manila: ADB, p. 2; United Nations (1997) Economic and Social Survey of Asia and the Pacific 1997, New York: UN, p. 23.

Note: Figures for 1997, and not a more recent date, are used here to avoid the distortions of the economic crisis that affected the region from late 1997. The most recent figures for 2000 were not available at the time of writing. 
economic development plans, which greatly increases each country's competitive stake in Mekong resources.

Thailand dominates the Mekong Basin economically - it is the most industrialized country with a per capita GDP 100 times higher than that of the other riparian states - and is putting great pressure on Mekong resources on three fronts. First, the central government plans to "green" the semi-arid Isan region through large-scale irrigation expansion by diverting water from the Mekong into Thai tributaries. Isan is the country's most economically backward region, and developing it is seen as a national security issue because of the border region's ethnic affinity with Laos and its history of communist insurgency. ${ }^{13}$ The Thai government has also planned a second project that will divert water from the Mekong into the central Chao Phraya Basin to supplement the demands of the Bangkok metropolis. ${ }^{14}$ Lastly, Thailand is looking towards its neighbours for new energy supplies. Economic growth has tripled Thai electricity demand over the last decade; hydropower supplies 20 per cent of national needs, and is an important source of future expansion, but Thai sources are exhausted. ${ }^{15}$ Thailand has made arrangements to purchase hydroelectricity from Laos, Cambodia, China, and Myanmar and is exploring joint development of a regional electric transmission grid. ${ }^{16}$ These energy linkages will render more complex the relations of interdependence in the basin.

Hydropower is a prominent preoccupation of the other lower Mekong states, all of which have only two main domestic supplies of electricity: hydropower and diesel generators. Hydropower is also an important driver of economic growth. For Laos, one of the poorest countries in the world, the most promising economic asset is its considerable hydropower potential. The former socialist republic began economic restructuring in 1986, focusing on infrastructure development, privatizing state enterprises, and attracting foreign investment. As its small and dispersed population constrains major industrial consumer-based development, foreign aid and investment have concentrated on Laos's abundant natural resource base and strategic links with its much larger developing neighbour economies. Hydropower exports to Thailand generated most of Laos's foreign exchange for many years, and 77 per cent of foreign investment is currently in this sector. ${ }^{17}$ Laos currently has about 50 hydropower projects in various stages of planning and construction. ${ }^{18}$ It has also negotiated agreements to sell hydroelectricity to Thailand, Vietnam, and Cambodia for the next 20 years. ${ }^{19}$ However, this concentration on hydropower development serves to render Laos more dependent on its neighbours and international donors and may overshadow the crucial importance of the Mekong to Lao livelihoods.

Cambodia needs Mekong water for an urgent overhaul of the failing 
Khmer Rouge-built irrigation system, to boost agricultural productivity and ensure food security for its population, which is 90 per cent rural. Like in Laos, the largest economic potential of the Mekong for Cambodia lies in hydropower, and irrigation tends to be considered only in conjunction with and as a side benefit of hydropower development. ${ }^{20}$ Seventeen dams have been planned for the country, foremost of which is the Sambor Dam, which may produce between 500 and 3,300 MW of electricity for export to Thailand and Vietnam. ${ }^{21}$ Much controversy surrounds these plans and their potential impact on the country's fisheries, fuelled by the lack of reliable and long-term hydrological and other data necessary for informed decisions.

Vietnam also has hydropower plans in the mid-stream section of the Mekong River within northern Vietnam, although notably, the government appears to place less public emphasis on these plans than its neighbours do. This probably reflects the upstream/downstream tensions faced by Vietnam, which is uniquely both a mid- and downstream state. ${ }^{22}$

In China, where the Mekong is known as the Lancang Jiang, the upper basin occupies a very small portion of the country. However, the river provides one of China's best hydropower sites - deeply incised valleys and a reliable snow-fed flow offer remarkable potential, which the Chinese have begun to tap as part of a large, ambitious plan in Yunnan Province, consisting of a cascade of seven dams. Thus China occupies a privileged resource position on the Mekong Basin, which combines a primary upstream location with relatively low dependence and vulnerability.

Table 9.3 summarizes the relative influence and vulnerabilities of each state, based on the broad criteria of geographical, economic, and political strength and autonomy discussed above. The overall picture is one of significant imbalance. Myanmar is very weak on all counts, except that it has no pressing national need for the Mekong's resources. China is autonomous enough and Thailand probably economically strong enough to unilaterally develop or dominate their sections of the basin. Their activities will compete with and adversely affect the interests of Laos, Cambodia, and Vietnam, who are most dependent on Mekong resources and most vulnerable in all criteria. The upstream/downstream conflict element is very strong, especially because of the good correlation between downstream positions and dependency on the common resource.

\section{Conflict and security in the Mekong Basin}

The nature of the environmental and hydrological problems and the asymmetries of influence and vulnerability specified above constitute the underlying reasons for potential conflict in the Mekong Basin. The like- 
Table 9.3 Summary of the relative geopolitical and resource positions of the Mekong states

\begin{tabular}{|c|c|c|c|c|c|c|}
\hline & Yunnan/PRC & Myanmar & Laos & Thailand & Cambodia & Vietnam \\
\hline \multicolumn{7}{|l|}{ Strength of position in MRB (rank) $)^{a}$} \\
\hline a) geographical position & 1 & 2 & 3 & 3 & 4 & 5 \\
\hline b) \% MRB area & 3 & 6 & 1 & 2 & 4 & 5 \\
\hline c) $\%$ flow contribution & 3 & 5 & 1 & 2 & 2 & 4 \\
\hline d) $\%$ MRB population & 3 & 6 & 5 & 1 & 4 & 2 \\
\hline \multicolumn{7}{|l|}{ National importance of MRB (rank) ${ }^{b}$} \\
\hline a) MRB as $\%$ country land area & 5 & 6 & 1 & 3 & 2 & 4 \\
\hline b) \% country population in MRB & 5 & 6 & 1 & 3 & 2 & 4 \\
\hline \multicolumn{7}{|l|}{$\begin{array}{l}\text { National dependence upon MRB resources } \\
\quad(\text { on a scale of } 1 \text { to } 6)^{c}\end{array}$} \\
\hline a) current & 2 & 1 & 6 & 2 & 6 & 6 \\
\hline b) planned & 6 & 2 & 6 & 4 & 6 & 6 \\
\hline $\begin{array}{l}\text { Extent to which exploitation of MRB } \\
\text { resources depends on neighbouring use } \\
\text { and activities (on a scale of } 1 \text { to } 6)^{d}\end{array}$ & 2 & 1 & 6 & 2 & 6 & 6 \\
\hline Political strength $(\text { rank })^{e}$ & 1 & 5 & 4 & 2 & 5 & 3 \\
\hline \multicolumn{7}{|l|}{ Economic strength $(\text { rank })^{f}$} \\
\hline a) population & 4 & 3 & 6 & 2 & 5 & 1 \\
\hline b) per capita GDP & 2 & 6 & 3 & 1 & 5 & 4 \\
\hline c) \% GDP growth & 1 & 5 & 3 & 4 & 5 & 2 \\
\hline
\end{tabular}

a. Based on data in Table 9.1.

b. Based on data in Figure 9.1.

c. Based on foregoing analysis about the country's current usage and planned development of the Mekong Basin.

$d$. Based on the countries' relative positions on the river and their market dependencies, as discussed above.

$\stackrel{\sim}{\exists} \quad$ e. Based on my understanding of each country's regional and international political clout. 
lihood of conflict, on the other hand, depends on the extent to which competing claims are reconcilable. This section discusses manifestations of political conflict at the multilateral, bilateral, and national levels arising from the key areas of asymmetry identified above, evaluating their impacts on national and regional security and the extent to which existing institutional frameworks deal with these problems.

\section{National security and water allocation conflicts}

For traditional security analysts, one of the firmest arguments for considering environmental security is the potential for states to engage in armed conflict to protect their perceived fair share of international waters. However, this extreme prospect is unlikely on the Mekong. Indeed, the classic upstream/downstream water distribution and allocation problem in the Mekong context have more to do with improving prospects for cooperation: formulating rules for water utilization and abstraction in the lower basin; and integrating development and management plans of the upper and lower basins. Both issues present urgent cause for political disagreement among riparian states. On the other hand, both are specific remits of the regional institution that seeks collective solutions to these problems, the Mekong River Commission (MRC).

The lower Mekong Basin is regularly cited as an example par excellence of cooperation in a shared river basin. ${ }^{23}$ Its first cooperative institution, the Committee for Coordination of Investigations of the Lower Mekong Basin (Mekong Committee), was set up in $1957 .{ }^{24}$ The initiative, led by the US Bureau of Reclamation and the UN Economic Commission for Asia and the Far East, ${ }^{25}$ was an offshoot of Cold War superpower politics. These "investigations" were aimed at the construction of a cascade of mainstream hydropower and irrigation projects which would help to "develop" the region as a bulwark against communism. However, the subsequent Indochina wars, the "fall" of Vietnam, Laos, and Cambodia to the communists in the 1970s, and Cambodia's withdrawal from the Mekong Committee in 1975 precluded the development of these dams. Yet the cooperative framework persisted, as the remaining members set up the Interim Mekong Committee (IMC) in 1978 to continue collecting data and planning. ${ }^{26}$ In 1992, as the political situation in Cambodia stabilized, the lower Mekong states began negotiating a new agreement. However, these negotiations occurred in the absence of a strong external driving force, and the riparian states had to reconcile the interests of neighbours facing very different developmental pressures from those of 20 or 40 years previously. It brought to the fore key allocation conflicts. 


\section{Rules for water utilization}

Recent disputes about water allocation in the lower basin have centred on Bangkok's plans to divert water from the Mekong mainstream into tributaries in northeast Thailand. The Mekong Committee did in fact formulate an unusually strict set of water utilization rules in a joint declaration in 1975, which required complete consensus among riparian states for any project involving the mainstream or any major tributary. ${ }^{27}$ However, because of Cambodia's withdrawal, the committee never formally adopted the declaration. Thus Thailand was able to proceed with the Kong-Chi-Mun project unilaterally during the 1980s.

The Kong-Chi-Mun project will divert up to 6,500 million cubic metres of water each year from the Mekong mainstream on the Laotian border into Isan and will reduce the annual runoff in the area of abstraction by over 10,000 million cubic metres. ${ }^{28}$ No downstream impact study has been conducted, and it is unclear how this will affect river flows further downstream, but environmentalists say crucial mainstream and tributary fish migrations will be blocked by the planned dams. In addition, Laos and Vietnam have expressed fears about the effects of lowered dryseason water levels on navigation, the Tonlé Sap and the delta. ${ }^{29}$

However, in 1992, the prospect of Cambodian readmission into the Mekong Committee promised the resurrection of the 1975 rules, which would give Thailand's neighbours the power of veto over such diversion projects. This led to the first open upstream/downstream dispute in the lower basin, as Bangkok tried to block Cambodian entry until new water utilization rules could be drawn up. The Thai deputy foreign minister called for new rules that would better reflect the new "economic and political realities" in the region, meaning the superior technological capability and economic development, and hence more urgent water shortages, of Thailand. He also defensively argued Thailand's sovereign right to use its share of Mekong waters, threatening that "if joining the committee means the loss of our sovereignty, we prefer to go it alone". ${ }^{30}$

This was a dispute in which geopolitical and economic rivalry between Thailand and Vietnam played an important role. Vietnam was particularly opposed to Thai diversion schemes, partly because of the suspicion that the latter was restricting Mekong water flows to combat rising Vietnamese competition in rice exports. ${ }^{31}$ Between 1992 and 1994, Thailand also tried to broaden the scope of the water allocation dispute to include the upper Mekong Basin. Bangkok first demanded that Cambodia's readmission to the Mekong Committee be tied to Chinese and Burmese membership, then it issued veiled threats that it would leave the committee for an Upper Mekong Forum. ${ }^{32}$ Although a restructuring of the 
committee to include the entire basin is sound in hydrological and environmental terms, Thailand's strategic concern was for China and Myanmar to increase its upstream bargaining power. Vietnam, because of strained relations with China, was especially riled by these Thai moves, which were seen as attempts to isolate a newly liberalizing Vietnam. It, in turn, tried to muster downstream opposition and threatened to leave the committee. ${ }^{33}$

The stand-off was eventually overcome by the intervention of the UN Development Programme (UNDP), which took over chairmanship of the committee, and a new Mekong Agreement was signed in April 1995. ${ }^{34}$ Drawn up by a UNDP legal adviser, its departures from the joint declaration can be summed up by a Thai foreign ministry statement that "we have finally compromised in such a way that it will not adversely affect [Thailand's] ongoing projects". ${ }^{35}$

The right of veto of members on any mainstream or major tributary project has been replaced with the requirement of "prior consultation" for all dry-season or inter-basin projects and "specific agreement" on dry-season and inter-basin projects. ${ }^{36}$ These general guidelines alone sum up the core principle of reasonable and equitable utilization, and the new MRC is left to define the details at a later date. ${ }^{37}$ Furthermore, the obligation to provide a detailed downstream ecological impact study for major projects has been removed; only "minimum flow levels" and the Tonlé Sap reverse flow must be maintained. ${ }^{38}$

Provision B.2.b) of Article 5 provides a final indication of how much the new principles were drawn up to suit Thailand's needs. It makes an exception for dry-season inter-basin projects that seek to utilize "a surplus quantity of water available in excess of the proposed uses of all parties", which will only require prior consultation instead of specific agreement. Thailand will be able to use this for the Kong-Chi-Mun project, which Thai authorities have claimed will divert only the surplus water released from China's upstream dam. ${ }^{39}$ In any case, the non-retroactive nature of the agreement excludes the project, which Bangkok claims was approved before April 1995. ${ }^{40}$ Vientiane and Phnom Penh were reportedly surprised when informed that Thailand's two water diversion projects were outside the jurisdiction of the agreement, and the dispute continues. ${ }^{41}$

Water allocation in the lower basin is very much an ongoing issue, subject to continuing negotiation within the regional institutional framework of the MRC. The commission is charged with determining the precise rights and obligations of lower Mekong riparian states in using their shared waters in a "reasonable and equitable" manner. Based on comprehensive data, it must establish the timeframe for the wet and dry seasons, the minimal flow requirements at specified hydrological stations, 
and criteria for determining surplus dry-season mainstream flows. In effect, though, the framework agreement has already significantly narrowed the meaning of "equitable" use: as they stand, any member state may divert any amount of water from tributaries or the mainstream at any time except the dry season. Thailand has even managed to put its second mainstream diversion project on the commission's work programme. ${ }^{42}$

Vietnam has fought back in the sphere of MRC negotiations on water utilization rules to defend its compromised interests. Citing the link between upstream diversion and delta salinization, Hanoi wants the monitoring of water quality to be included in the water utilization rules, but Bangkok maintains that the MRC mandate extends only to water quantity, and quality should be treated separately. ${ }^{43}$ This quarrel has hindered progress, but it has resulted in an agreement to prepare rules for both water quantity and quality. Both projects are still being discussed and seeking funds, but it is positive that specific quality guidelines are being drawn up, as the issue of transboundary water pollution is addressed very vaguely in the agreement. ${ }^{44}$

\section{Integrated basin planning}

While the MRC is still arguably a relatively young institution charged with a difficult task, its greatest setback was perhaps its failure to extend its reach into the upper Mekong Basin during the 1992-1995 renegotiations. The idea of integrated basin planning is the raison d'être of the MRC, but the failure to include the upper riparian states, particularly China, seriously limits its institutional effectiveness. China and Myanmar have been observers at all MRC meetings, but commission staff admit that they still have a long way to go towards membership. Beijing has bluntly stated that it will need to "study in depth the effect of the ... water usage rules on China's capacity to utilize upstream water", and its decision whether to join will be put off until the MRC produces the agreed water utilization rules. ${ }^{45}$ However, since China started large-scale exploitation of the Lancang's hydropower potential in 1993, its exclusion has threatened to undermine the MRC's avowedly "basin-wide" regime. It is the classic "free-ride" problem: as the uppermost riparian state, China, cannot be excluded from obtaining the benefits of the collective resource and has little incentive to contribute voluntarily to its protection. Furthermore, China is the most influential country in the basin, with heavy political clout and one of the fastest economic growth rates in the world, and has ambitious water development plans, which it has the expertise, capital, and gumption to carry out.

Beijing particularly wants to develop the relatively backward Lancang Basin, where ten million people, half from minority ethnic groups, are 
lagging behind within one of the already poorest provinces in China. ${ }^{46}$ The Lancang Basin has been designated one of 19 state-level areas for the central government's concentrated development efforts. Official Chinese plans for large-scale Lancang development date back to the 1970s, but it was only through exchanges between upper and lower riparian academics in the early 1990s that the latter obtained a clear picture of what was being planned upstream.

The Chinese have planned a seven-dam cascade on the Lancang Jiang, which will store over 23,000 million cubic metres of water and generate 15,500 MW of electricity. The first project, Manwan, was completed in 1993/4; construction of the second dam, Dachaoshan, began in 1996. The Chinese want to complete the first four projects, which include one intended primarily for power exports to Thailand and one of two "mega dams", by the year 2010. Altogether, the cascade will tap 60 per cent of the Lancang's total hydropower potential. ${ }^{47}$

Some argue that Chinese dams will have little impact on the lower basin because the Lancang only contributes 16 per cent of the Mekong's total discharge. However, the level of the upper Mekong has a determining influence on reaches immediately below China - it contributes 100 per cent of the flow at the Yunnan-Laos border and 60 per cent as far downstream as Vientiane. ${ }^{48}$ Vientiane began protesting the impact of the Manwan dam on water levels in 1993, and a year after it was completed, unusually low water levels impeded navigation in the Golden Triangle, with the lowest levels on record at some stations. ${ }^{49}$ China's failure to release enough water was certainly linked to reservoir impoundment, construction on one of the dam sites, or simply the summer closure of Manwan. ${ }^{50}$ This was despite Chinese reassurances about dryseason releases from the dams.

Indeed, the Chinese have even predicted a 40-per-cent increase in mean dry-season discharge at the Yunnan-Laos border with the completion of the first mega-dam and an eventual 171-per-cent increase when the second mega-dam is built. ${ }^{51}$ While Thailand views this extra flow as a bonus for its water diversion schemes, the Indochinese committee members are not convinced. ${ }^{52}$ The latter have expressed their worries repeatedly about a sharp increase in bank erosion, the unusually low flows, and changes in flood patterns after $1993 .{ }^{53}$ The direct costs of Chinese dam developments are obvious: the total wet-season discharge from the Lancang into the Mekong could be reduced by up to 25 per cent, posing yet uncertain effects on fish migrations and wet-season aquaculture in the Tonlé Sap. ${ }^{54}$ Decreased flows will also reduce the production potential of downstream hydropower projects.

The inadequacy of the Mekong Agreement is epitomized here: even if China does sign the agreement, lower riparian states have no right to 
demand impact studies or mitigation measures as China's projects are intra-basin, requiring only prior consultation but not specific agreement of all MRC members. The most the water utilization rules can do is require that "minimum" water levels be guaranteed through releases. ${ }^{55}$ Many fear that China has no intention of joining the MRC and is instead intent on pursuing bilateral negotiations, such as electricity deals with Thailand and navigation negotiations with Laos. ${ }^{56}$ China has never signed any international water agreements; it was one of three countries that voted against the 1997 UN Convention on the Law of the Non-Navigational Uses of International Watercourses, aimed at guiding states in the negotiation of such agreements. ${ }^{57}$

Upstream/downstream allocation conflicts undoubtedly reflect the operation of power politics on the Mekong, where there is a good correlation between relative political and economic strength and favourable geographical positions. Upstream Thailand and China are the drivers of regional development. Thailand is particularly important, with its explicit commitment to help turn Indochina "from a battlefield into a marketplace" through investment and economic expansion in the region. ${ }^{58}$ The Indochinese states, for their part, are not only acutely aware of their dependency on Thai economic partnerships but have also been driven in the 1990 s by a parallel need to establish their credentials as stable, aid-, loan- and credit-worthy, internationally acceptable legitimate states. The final reason is especially important for Laos and Cambodia. Vietnam, for its part, probably decided not to push too hard on the water rules issue because of the need to cultivate an image of willingness to engage in regional cooperation, so as to strengthen its bid to join the Association of Southeast Asian Nations (ASEAN). ASEAN membership was the main concern for Hanoi in 1995, as it was a necessary step towards clinching vital regional investment and would grant it significant political leverage against China. ${ }^{59}$

These clear power asymmetries indicate that resorting to force, and thus a directly threatening regional security, in disputes over Mekong resources is very unlikely. Such disputes over water allocation are more likely to have an indirect impact; for instance, they have exacerbated existing rivalries between Thailand and Vietnam and could provide yet another point of contention between China and its southern neighbours.

\section{Economic security and hydropower development in Laos}

In this rapidly developing region, we can also expect that power politics will be played out chiefly in the economic realm. Here, environmental security concerns may be conceived in relation to resource exploitation and its implications for economic relations and economic security. The 
case of Laos perhaps best illustrates the economic dimensions of environmental security in the Mekong context. It has experienced interstate tensions over economic dependency and domestic economic instability, both stemming from a heavy reliance on hydropower development.

Although still a relatively underdeveloped country, Laos has significant development potential deriving from its geography. It occupies a central geopolitical role in the Mekong Basin, sharing borders with the other five riparian states. It is also a mid-stream state, possessing an estimated $13,000 \mathrm{MW}$ of hydropower potential - over a third of the total lower Mekong potential and second only to China's potential. ${ }^{60}$ In other respects, Laos faces considerable developmental constraints - the country is landlocked, has a small domestic market, lack of skilled manpower and a majority sector of subsistence farmers, and faces high costs of developing its physical infrastructure, all of which render it inherently dependent on its neighbours. ${ }^{61}$

The Laos government therefore views "hydro-industrialization" as its best hope ${ }^{62}$ - it will not require Vientiane to build the infrastructure (the practice is for power importers to foot the bill) and promises vast foreign currency earnings. As it is, electricity sales currently contribute 14 per cent of export earnings by tapping just 2 per cent of the country's total hydropower potential. ${ }^{63}$ Convinced that hydropower exports represent the quickest and easiest way to economic liberalization and poverty eradication, Vientiane has ambitious plans to tap nearly all the potential of Laotian tributaries. It has identified 49 projects and aims to complete 23 by 2010 in partnership with foreign companies and investors. Thus Laos has high stakes in its national development in hydropower. However, its favourable natural resource position may be outweighed by its vulnerability in some key economic areas, which seriously dampen its bargaining power and environmental security prospects.

\section{Dependency on the Thai market}

Laos's hydropower export drive is based on its prime geographical location at the centre of the Mekong Basin; its leaders envisage landlocked Laos becoming "another Switzerland, crossed by roads and railways, a country of services and hydropower". ${ }^{64}$ In theory, such a location at the regional crossroads would afford Laos a more equal interdependent relationship with its neighbours. For instance, Thailand's diminishing resource base, which has made necessary a policy of "befriending its neighbours" in an on-going process of "resource diplomacy", may add to Lao bargaining power. ${ }^{65}$

For the foreseeable future, however, Laos is still in a weak position because Thailand currently provides the only demand for its key export. 
Until the region develops further, Lao hydropower exports are destined only for the Thai market, which currently consumes 70 per cent of the region's electricity output. ${ }^{66}$ This is a classic case of asymmetrical interdependence, in which increased economic interchange actually provides more points of potential conflict for the states involved. ${ }^{67}$ Laos has so far signed memoranda of understanding (MoUs) to provide the Electricity Generating Authority of Thailand (EGAT) with 3,000 MW of hydroelectric power by 2006. These are non-binding agreements, and Thailand's monopsonistic position contributes greatly to the high-risk nature of Lao hydropower development.

As a powerful state-owned monopoly, EGAT has considerable ability to manipulate supply, demand, and price to the disadvantage of producers. In 1980, when Laos attempted to raise the price for electricity from an earlier hydropower station, EGAT turned off the electricity grid, its deputy general manager commenting, "we have no problem if Laos doesn't want to sell ... its power accounts for 1 per cent of our demand". Vientiane agreed to accept the Thai price within a day. ${ }^{68}$

To date, EGAT has finalized power purchase agreements for two major hydropower projects in Laos, but the viability of four other multi-billiondollar projects awaits the outcome of negotiations over how much electricity EGAT will buy and the price it is willing to pay. The uncertainty of this situation was recently exacerbated by the regional financial crisis. During negotiations with Laos about tariffs in 1998, EGAT suddenly announced that Thailand would defer its entire power purchasing schedule for up to two years beyond the initial 2006 deadline, citing the currency crisis and a significant downward revision of domestic power demand projections as the reason. EGAT's move heightened doubts over Thailand's commitment to purchase power from Laos, which, together with doubts about the creditworthiness of some of the Thai partner firms, led to potential lender reluctance to provide financing for these projects. ${ }^{69}$

At the same time, estimates of Thai electricity demand may be inflated - by EGAT's own estimates, Thailand already has a glut of generating capacity, making about half of its planned generating capacity until 2006 unnecessary. Sources in the Thai energy sector estimate that EGAT will accept a maximum of only about $700 \mathrm{MW}$ from Laos by $2006 .{ }^{70}$ Thai demand for Lao hydropower is also subject to competition from other suppliers. EGAT has made it plain that it seeks neighbouring energy sources based on two core considerations: diversification and competitive prices. EGAT has negotiated MoUs with Cambodia, Myanmar, and China for hydropower, oil, and gas. At the same time, Thai energy officials have in recent years placed more emphasis on domestic independent power producers, who, with the recent privatization of the Thai electric- 
ity market, are competing to supply cheaper electricity generated from natural gas. ${ }^{71}$

This asymmetrical dependency relationship gives Thailand considerable influence over socio-economic development in Laos. In the longer term, this increases the scope for tension in a relationship that has historically been clouded by Lao resentment of its Thai "big brother". With its entry into the world economy, Laos has tried to establish a more equal footing in its relations with Thailand; at the same time, however, Lao officials clearly feel that Thailand has a degree of obligation to help Laos develop. This frustration was evident in the course of wrangles over the terms of bilateral electricity deals in the last two years, with Lao ministers pointedly asking Thailand to honour its previous agreements to demonstrate friendship and empathy for Laos. ${ }^{72}$ Thai non-governmental organizations (NGOs), in their campaign against large dam projects in Laos, have also warned that Thai demand for energy from economically non-viable and environmentally costly dams will ultimately harm bilateral relations because of the adverse impact on local communities in Laos. $^{73}$

Laos's vulnerability lies not only in that it is subject to external economic fluctuations, but also in that Thai decisions and promises significantly affect the overall cost-benefit assessments of controversial water development projects, with major environmental impacts in and beyond Laos. This is best seen in the instance of Nam Theun 2, a US $\$ 1.2$ billion project on the Mekong's fourth largest tributary, which plans to supply electricity to Thailand. Its projected revenue would double Laos's foreign exchange earnings and increase its GDP by 15 per cent. ${ }^{74}$ However, the project has been dogged by controversy because of its socio-environmental implications: the reservoir will displace about 5,000 people and flood part of a National Biodiversity Conservation Area designated by the Lao government in 1993. The area consists of 70 per cent primary forests and rich fisheries, as well as containing 17 threatened mammal species and 24 endangered bird species. ${ }^{75}$

Partly due to the scale of the project - it is Laos's largest foreign investment project to date - and the vocal opposition of environmental groups, Nam Theun 2 has faced protracted problems with financing. The delay in implementation led EGAT to cancel the power purchase deal in October 1996, after which there were real doubts about the viability of the project, given that there was no potential buyer. With the economic recovery this year, though, EGAT has renegotiated the deal, agreeing to buy 95 per cent of the projected energy output, but at a significantly lower price than initially agreed. ${ }^{76}$ This has effectively made the controversial project financially viable, although it will tie Laos to a development programme with considerable environmental problems and costs. 


\section{International financing and national debt}

Can existing institutional frameworks help mitigate the dependency and environmental security impacts of these projects? The MRC has little influence in big hydropower projects, which fall increasingly under the remit of international financing institutions, such as the Asian Development Bank (ADB) and World Bank. Such institutions, with their economic development and profit imperatives, in fact contribute to Laos's vulnerability. The financial arrangements for dam building implemented by the World Bank particularly would appear to impose additional financial risk and national debt burden on Laos.

For instance, Nam Theun 2 is one of new generation projects that will be built by a joint "build-operate-transfer" (BOT) venture with a private consortium. The Lao government will own 25 per cent of the project, with private firms owning 75 per cent. The private consortium is responsible for raising the bulk of the money for construction from commercial banks and export credit agencies. Once funding is secured, it will build, own, and operate the facilities for a set period of 25 years until an agreed profit target is reached, after which ownership of the project will be transferred to the Lao government "free of charge". So far, the developers promise that, for this investment, Laos will earn more than US $\$ 1$ billion over the 25 -year concession period and US\$400 million annually when the government takes over ownership.

Yet, Laos's returns from Nam Theun 2 are far from secure. Critics argue that the BOT deal means that private consortiums will in fact own and earn from the dams during their most profitable period. After 25 years of operation, the dams will need extensive maintenance and overhaul. ${ }^{77}$ It is at this costly and unprofitable point that the Lao government will gain ownership - and liability. ${ }^{78}$

As mentioned earlier, the Nam Theun 2 consortium has had problems raising the required funds because commercial lenders have been wary of the project. The project may yet be made viable by a new World Bank guarantee mechanism, designed to protect commercial lenders from risks incurred in making joint investments with governments of poor countries. The World Bank sometimes offers financial guarantees by which it agrees to answer for a country's debts if they default. In May 1997, the bank decided to extend the mechanism to high-risk, low-income countries such as Laos to create a more secure environment for private investments. This offers insurance to commercial lenders who would otherwise not lend to projects such as Nam Theun 2. The policy was reportedly designed with the Lao project in mind. ${ }^{79}$

The World Bank has not yet decided if it will extend this guarantee to Nam Theun 2, but it is a prerequisite for commercial lending and thus the 
viability of the project. Critics argue that this policy gives the World Bank even greater ability to intervene in Lao economic decisionmaking. For instance, if Laos decides some time in the future that it is not receiving what it expected from Nam Theun 2 in terms of revenue and tries to renegotiate, this could be interpreted by the developers as a "political risk" and therefore a reason to call in the guarantee. Laos would then have to pay the bank all its outstanding dues plus a fine, to afford which it would probably have to implement strict bank structural adjustment policies. ${ }^{80}$ For now, the bank appears to be using the issue as leverage to pressure Vientiane to commit itself to significant economic and political reforms. ${ }^{81}$

\section{Human security and environmental impacts of water development}

The viability of projects such as Nam Theun 2 does not depend only on financial costs and benefits. The emphasis on economic development and growth has often obscured the negative impact of dams on the environment and local communities, which are treated as "externalities" not factored into cost-benefit analyses. Yet such effects cannot be ignored, as they carry implications for social stability. This linkage has best been explored recently in the "human security" literature. The concept of human security reaches beyond the state-level focus of traditional security studies, emphasizing the primary importance of protecting individuals from both violent and non-violent threats to their safety, rights, and social systems - threats that include environmental degradation. ${ }^{82}$ The environmental conflict literature has drawn links between environmental degradation and national security in terms of the effects of social dislocation - especially migration and intercommunity tensions - on political stability. ${ }^{83}$ Yet such effects are not confined to cross-border phenomena; they occur within states as well, especially where dislocation causes politically embarrassing protest campaigns from affected communities. Once environmental problems are recognized as having clear implications for human security and social stability, the key underlying issues become the often local-scale insecurities associated with the erosion of individual and group welfare and resilience, and concerns about distribution, civil liberties, accountability, and participation. ${ }^{84}$

Increasing awareness of the adverse socio-environmental effects of dams in recent decades has generated sustained criticism of such projects from environmentalists and pressure groups, which have to some extent obliged developers to take these concerns into account. ${ }^{85}$ This section discusses some linkages between environmental degradation and human security in the Mekong, based on environmentalists' key critiques of ongoing hydropower projects. ${ }^{86}$ 
The first set of critiques alleges that existing structures and procedures to evaluate and mitigate the environmental impact of such projects are inadequate. Environmental impact assessments (EIAs) are currently the primary means by which environmental factors are incorporated into construction projects in general. Ideally, EIAs should collect baseline data covering key aspects of the existing environmental and socioeconomic systems; predict and evaluate the relative effects of alternative project sites and designs on these variables; and describe and evaluate the effectiveness of measures that may be employed to mitigate these impacts. ${ }^{87}$

Environmental groups have pointed out that EIAs for hydropower development projects in Laos are fundamentally limited by inadequate baseline data (this is especially the case for fisheries and downstream hydrological data). This means that there is no reliable basis for assessing subsequent impacts of the project. ${ }^{88}$ At the same time, procedural aspects of EIAs are also questioned: the responsibility for conducting EIAs currently lies with the prospective dam developer, while the consultants who prepare feasibility studies are often from branch operations of the private or state dam construction companies that are eventually offered the contracts to build approved dams. Given these vested interests, the objectivity and accuracy of the EIAs may be doubtful. ${ }^{89}$

Other vested interests may actively contribute to environmental degradation at project sites. Deforestation of upper watershed areas is a major problem in Laos, and dam projects may provide an excuse for uncontrolled logging. For instance, even though the Nam Theun 2 project has not been approved, a military-run logging company has already cleared one million cubic metres of forest since the signing of the MoU with EGAT in $1993 .{ }^{90}$ NGOs also claim that foreign logging companies are investing in dam projects to win timber concessions that will be granted for the area to be inundated by the reservoir. ${ }^{91}$

The second set of critiques asserts that there are inadequate procedures to evaluate and mitigate both the direct and indirect social impact of hydropower projects. The main direct social impact of dam building is the relocation of local communities whose land will be inundated. The human security implications are clear: in the absence of well-planned and well-executed resettlement programmes, such communities stand to lose their subsistence, livelihoods and way of life. There is great controversy about the process of implementing resettlement plans in hydropower projects in Laos, particularly in the case of Nam Theun 2, which is being held up by the World Bank as a model of public participation. At the end of a series of EIAs and public consultation meetings required by the World Bank, developers have promised to spend an impressive US $\$ 20,000$ to resettle each affected family..$^{92}$ However, critics question 
the lack of details in the plans for resettlement and alternative livelihoods for these fishermen-farmers and point out that the World Bank's own advisory group has doubts about the effectiveness of the consultation meetings. They conclude that the level of comprehension about the project and its impact on affected villagers is low, partly because of the reliance on international NGOs as proxies for local people in the process. ${ }^{93}$ There is greater controversy over the indirect impact of hydropower projects and their mitigation and compensation procedures. This has become a high-profile issue in the region because of the precedent set by the Pak Mun dam in Thailand, where, because of good opportunities and channels for civil organization, 3,000 affected villages have staged a six-year public campaign to demand compensation from the Thai government and the World Bank for lost fisheries. ${ }^{94}$ In the Mekong Basin, there is a similar ongoing dispute at the Theun-Hinboun project in Laos, which was completed in 1998. NGO field studies and pressure forced the dam developers to admit that the project's EIA was inadequate, and that it had led to extensive damage to fisheries and the livelihoods of 53 villages in the basin. ${ }^{95}$ However, the power consortium has refused to compensate local communities, and the ADB, which has acted as a de facto regulator on the project, has stated that forcing the company to pay additional costs would damage investor confidence in Laos. ${ }^{96}$ The responsibility now apparently falls on the Lao government, which reportedly, on legal advice from the ADB, signed an agreement with the power company in 1996 that absolved the latter from any further obligation to assist with mitigation or compensation measures for the life of the project. ${ }^{97}$ The issue remains unresolved, although recent reports suggest that the ADB has now indicated that the power company should pay some of the compensation out of its revenues. ${ }^{98}$

The experiences of local communities in Laos and Thailand adversely affected by hydropower development impacts can be expected to be replicated in downstream Cambodia and Vietnam in coming years, not only from projects within these countries, but also as the downstream impacts of upper-stream developments begin to take effect. If anything, the impacts downstream will be even more severe, as more communities here are more directly dependent on the river for subsistence and have fewer opportunities for civil mobilization to protest and seek compensation.

\section{Institutional redress?}

Can solutions to these disaffections and disputes between local communities, hydropower developers, and central governments be found within regional institutional frameworks? It would seem that key existing institutions such as the ADB are in fact contributing to these disputes. On the other hand, there may be scope for redress within the framework of 
the MRC, which is a regional institution explicitly dealing with integrated river basin planning. The discourse of "sustainable development" is prominent within the MRC mandate, and the commission has an active environment programme, which attracts the bulk of overall donor support. Major donors, such as Denmark, the Netherlands, Sweden, and UN agencies, have long-standing interests in "soft" sector projects, such as fisheries, agriculture, watershed protection, and public participation. However, the MRC's environment programme remains focused on the collection of data and monitoring of hydrological and ecological systems. While this work is crucial, given the dearth of such basic data, there is an urgent need for the employment of this data, for instance, in more sophisticated simulation models of the system's capacity to absorb cumulative impacts of water development projects. ${ }^{99}$ At the same time, the commission has made little progress in one of its main stated aims of setting up a uniform process with procedures for EIA in the Mekong Basin in conjunction with national environmental institutions in the riparian states. ${ }^{100}$

Part of the problem is that the MRC has an increasingly limited technical scope in Mekong development because the task of coordinating major water development projects has been taken over by the ADB. The latter launched its Greater Mekong Subregion (GMS) programme in 1992, to foster closer regional economic linkages and cooperation, focusing especially on infrastructure development. ${ }^{101}$ One of its key aims is to promote and coordinate energy production and consumption in the GMS, centred around supplying the Thai market. Because it has financed almost all the hydropower studies and projects carried out since 1992 and is seeking funds for many others, the ADB is now the MRB's premier water resource development organization. ${ }^{102}$

As a regional lending institution, the ADB has been heavily criticized for its lack of accountability and focus on economic profit for private organizations. However, the ADB appears to be taking some of these criticisms seriously. High profile social problems associated with current hydropower projects seem to have affected the viability of subsequent projects - the ADB recently indicated that it would not fund further controversial dam projects in Laos. ${ }^{103}$ The GMS environment working group also undertook a study on lessons to be learnt from hydropower projects in Laos and took careful note of most of the criticisms about EIA, consultation, and compensation procedures to date. ${ }^{104} \mathrm{~A}$ similar presentation was also made to the GMS Electric Power Forum. The ADB has commissioned a project to formulate best practice procedures for assessing costs and benefits of new large dams and maintaining existing ones. ${ }^{105}$ At the same time, there appears to be an increasing awareness of the importance of environmental protection and the need to 
support community development within ADB projects for the protection of critical wetlands in the lower Mekong Basin, and poverty reduction and environmental management in remote watersheds.

There are limits to these efforts, however. There is no guarantee that the best practices will be followed, and attempts to link environment to development are subject to fundamental flaws. For instance, the watershed protection and poverty reduction programme assumes that shifting cultivators - rather than commercial loggers - are primarily responsible for large-scale deforestation and that settlement and "modernization" of these communities will solve the problem. ${ }^{106}$

The problem is fundamentally exacerbated by governments that are driven by economic development imperatives. The Lao government, for instance, blames poverty and local populations for deforestation and asserts that "hydropower development is inexorably linked with environmental protection and development of rural areas and the alleviation of poverty". ${ }^{107}$ Government ministers have been adamant that projects such as Nam Theun 2 are vital to national development and must go ahead in spite of socio-environmental costs. As the minister in charge of Nam Theun 2 put it, "[we] put economic value before environmental and social values", and Laos is "not going to be a zoo for the rest of the world". ${ }^{108}$

\section{Conclusions and recommendations}

This chapter has described and analysed three key ways in which a quintessential transboundary environment/resource issue can lead to conflict and instability among and within states. It has discussed traditional interstate security in terms of upstream/downstream water allocation conflicts in the Mekong Basin; economic security in terms of national economic vulnerability, bilateral relations, and international financial arrangements in big water development projects; and human security in terms of the implications of hydropower projects for ecological and human communities. It has demonstrated that "environmental security" in the Mekong context represents a salient mixture of traditional and non-traditional security issues. In the process, it has thrown up three complex and difficult questions, which should guide the development of institutional capacity to ensure environmental security in the region:

- How can the asymmetries of power that exacerbate the innate geographical disadvantage of downstream states be redressed?

- How can the dependent, newly developing riparian states be protected against their economic vulnerability?

- How can socio-environmental "externalities" be incorporated into economic cost-benefit analyses in water development projects? 


\section{Conceptual contributions}

This chapter provides a largely conceptual starting point, arguing and demonstrating the case for drawing tighter and clearer links between environment quality and resource utilization; and economic, political, and human security at the national and regional levels. So how has framing the issue of managing a vital transboundary resource in "security" terms helped? At a basic level, "securitizing" the environment lends the issue an urgency that aids access to policy makers and institutions. Conceptually, it helps because, by establishing the relationship between the security of the environment, the security of continued economic growth, and the security and stability of political units, we can begin to reconfigure cost-benefit calculations for development policies and projects.

The most obvious way to do this is through reconstructing "economic" value - factoring environmental externalities into the price of development. As discussed above, social costs, particularly in terms of lost livelihood and substituting resources, can be calculated. This is what lies behind the local campaigns for reparation and also the provisions in the old Mekong joint declaration for inter-riparian negotiations on compensation for the effects of mainstream projects. Increasingly, well-organized civil groups are exerting pressure on international institutions such as the World Bank, if not on national governments, to take the issue. The next step would be to institutionalize the practice and procedures of compensation, not just for local communities but for affected areas in other downstream states as well. In the longer term, taking account of environmental costs must involve the attempt to reflect "true" costs of environmental degradation in terms of complex ecological losses such as biodiversity. This relates to the complicated issue of defining long-term sustainability, which is still subject to intense ethical and technical debate within environmental economics. ${ }^{109}$

However, central to building regional institutional capacity to deal with basin-wide environmental security is the political question of why other riparian states should be concerned about the environmental vulnerabilities of particular riparian states. The concept of security in Southeast Asia retains the individual state and state interest as its key referents. This reflects a fundamental obstacle to cooperation: the Mekong regime is basically a regulatory one governing water allocation; the riparian states do not share obvious common ecological interests on which an institution for environmental protection may be built. Yet, the Mekong states do share the common aspiration of economic development and the attendant belief that the ensuing economic interdependence would generate and maintain regional political stability and security. This liberal security paradigm will be threatened, however, by environmental externalities and unsustainable development. This chapter 
has elucidated the links between environmental quality and social stability and the relationship between economic and environmental vulnerabilities. It is precisely the weaker Mekong states that are particularly subject to these problems. Yet, in the regional political and economic context, this gives them a measure of negative bargaining power. In an era in which Southeast Asian unity and identity are being emphasized in the wake of almost 20 years of war in Indochina, a significant weakening of these vulnerable states' social and economic fabric by the degradation of the Mekong system could be construed as a threat to regional development and stability. Environmentally vulnerable Mekong states have political value as integral regional actors in that they can adversely affect the interdependence, norms, and expectations particular to the region.

The recent expansion of ASEAN to include all the Indochinese states and Myanmar highlights the deliberate construction of an enlarged East Asian entity bound by the ASEAN ideals of consensus, preventive diplomacy, and security through economic development. Economic development has long been seen as the major contributor to regional security - first as the means to offset domestic insurgency and instability and then as the liberal "interdependence-for-peace" argument - and governments have readily invoked the economics and security link. This should form a good basis to expand their conceptions of security into environmental and other cross-border issues. ${ }^{110}$ Environmental and economic instability in some of the new member states, especially those induced by activities of neighbouring states, would challenge the current economic development and cooperation paradigm. As the region becomes more economically interdependent in terms of attracting investments in the region, and joint growth projects and resource demand and supply interconnections, these stakes will rise. This is the politico-economic equivalent of the ecological "interdependence" argument.

For these reasons, riparian states will find it in their interests to cooperate to strengthen institutional frameworks for managing developments in the Mekong Basin in ways that protect environmental security.

\section{Building institutional capacity}

The conceptual linkages suggested above should underpin the efforts of regional institutions in dealing with conflicts arising from shared use of the Mekong. This concluding section offers two key suggestions for building institutional capacity in more concrete terms.

First, there is an urgent need for inclusivity. The upper and lower Mekong riparian states must be brought together within an institutional framework that deals specifically with river resource management, so as to provide an effective forum for disputes arising from upstream/ 
downstream allocation issues. China has begun to be more responsive to multilateral institutions in recent years, and may yet be persuaded to join the MRC. However, in view of the geopolitical realities, China's relatively strong position within the Mekong Basin offers few incentives for it to play a cooperative role within such a regime. The strength of the persuasion would lie more in the need to foster regional norms, stability, and harmony, which would only be effective when its neighbours became stronger and more visibly committed to the Mekong regime.

Second, institutional structures and processes for ensuring environmental security in the Mekong Basin must be clarified and strengthened. The key problem that must be resolved is the unsatisfactory division of labour that currently exists between the MRC and the ADB. The MRC is the most relevant institution in that it has a mandate specifically related to integrated river basin planning, but its effectiveness is seriously hampered by its lack of influence. The ADB, on the other hand, exercises the greatest sway over riparian governments because it can provide or raise the funds for water development projects but is essentially a financial institution with little environmental interest. The two institutions currently work together in some projects, but the relationship is an unequal one, with the MRC providing largely technical input. There is an urgent need to find some way of strengthening and formalizing the MRC's specific concerns with sustainable river basin management in tandem with the ADB-led economic development plans in the region.

The MRC's central advantage is clearly its role as a coordinator for the sustainable development of the Mekong Basin. Its credibility must be strengthened by stronger leadership and links to international institutions, such as the UN, and by the deployment of more influential national riparian officials to the commission. In terms of specific tasks, there are two crucial areas to which the MRC could potentially contribute: as the official arbiter overseeing the planning and implementation of hydropower projects, and as the agency responsible for post-construction socio-environmental monitoring of projects. The commission possesses experience and technical expertise in hydrology, ecology, and environmental impact assessment, does not hold as much of a direct stake in development projects as the $\mathrm{ADB}$ and could be an effective monitoring agency. It would be able to mobilize its existing donor programmes, and be an acceptable contact point for a network of community groups and NGOs in the field.

Such structural changes must be accompanied by the institutionalization of planning processes, beginning with the codification of standard operational procedures, such as EIAs. There is already a trend in the World Bank and other international institutions towards adopting international environmental standards, and the $\mathrm{ADB}$, as a major financier or 
guarantor of projects, could require developers to adopt European, and preferably Nordic, EIA standards. This is not as difficult as it may sound, as most of environmental consultants subcontracted to perform EIAs are European. At the same time, such assessments and monitoring procedures must be conducted transparently and widely reported to governments, donors, NGOs, affected community groups, and the academic community.

Ultimately, these challenges lie at the doors of the respective riparian governments because only they can ensure the authority and accountability of regional institutional frameworks. The greatest task is to convince these governments of the links between environmental and economic and political security, in order that they might make crucial changes, for instance, in establishing national environmental regulatory bodies and legislative protection, and, importantly, with the means to exact compliance. This will also be reflected in the nature of bureaucratic appointments: environmental issues must have representation in the most influential ministries such as finance or energy, and appointees to institutions such as the MRC should be ministers who can make and effect decisions. These factors will be crucial to building regional institutional frameworks to protect environmental, economic, and human security in the Mekong Basin.

\section{Notes}

1. The Mekong is the twelfth longest river and the eight largest in terms of discharge in the world. Its river basin covers $800,000 \mathrm{sq} \mathrm{km}$, making it the largest river system in Southeast Asia.

2. "Sustainability" is a much-contested concept, but at its most basic, it refers to the capacity for future self-perpetuation of a system at a desired level of efficacy and efficiency. For a concise discussion, see Andrew D. Basiago (1995) "Methods of Defining 'Sustainability'", Sustainable Development 3: 109-119.

3. For a survey and analysis of these three cases, see Nurit Kliot (1994) Water Resources and Conflict in the Middle East, London: Routledge.

4. Richard Ullman (1983) "Redefining Security", International Security 8(1, Summer): 129-153; Jessica Tuchman Mathews (1989) "Redefining Security", Foreign Affairs 68(2, Spring): 169-171; Robert Kaplan (1994) "The Coming Anarchy", Atlantic Monthly 273(2, February): 44-76; Peter Gleick (1993) "Water and Conflict: Fresh Water Resources and International Security", International Security 18 (1, Summer): 79-112. For critical views, see Daniel H. Deudney (1990) "The Case Against Linking Environmental Degradation and National Security", Millennium 19: 461-476; Simon Dalby (1996) "The Environment as Geopolitical Threat: Reading Kaplan's 'Coming Anarchy." "Ecumene 3(4): 472-496; Marc A. Levy (1995) "Is the Environment a National Security Issue?" International Security 20(2, Fall): 35-62.

5. Barry Buzan (1991) People, States and Fear: An Agenda for International Security Studies in the Post-Cold War Era, New York: Harvester Wheatsheaf, p. 132. See also 
Joyce Starr (1991) "Water Wars", Foreign Policy 82(Spring): 17-36; Norman Myers (1993) Ultimate Security: The Environmental Basis of Political Stability, New York: Norton.

6. On the former, see Peter Beaumont (1997) "Water and Armed Conflict in the Middle East - Fantasy or Reality?", in Nils Gleditsch, ed., Conflict and the Environment, Dordrecht: Kluwer, pp. 355-374; Daniel H. Deudney (1999) "Environmental Security: A Critique", in Daniel H. Deudney, and Richard A. Matthew, eds., Contested Grounds: Security and Conflict in the New Environmental Politics, Albany: State University of New York Press, pp. 210-214. On the latter, see Miriam R. Lowi (1993) "Bridging the Divide: Transboundary Resource Disputes and the Case of West Bank Water", International Security 18(1, Summer): 113-138; Thomas Homer-Dixon and Valerie Percival (1996) Environmental Scarcity and Violent Conflict: Briefing Book, Toronto: AAAS, p. 9.

7. On this conceptual gap, see Lorraine Elliot (1996) "Environmental Conflict: Reviewing the Arguments", Journal of Environment and Development 5(2, June): 149-167.

8. For this reason, Myanmar is not discussed at any length in this chapter.

9. The monsoon causes major differences in seasonal flow levels in the Mekong lowlands, and the Tonle Sap system naturally evens out this anomaly: in the dry season, the Tonlé Sap river drains the Great Lake towards the Mekong River, supplementing the low flow; in the wet season, rather than flooding its banks, the Mekong River reverses its flow up the Tonle Sap river to fill the Great Lake and its surrounding swamp forests. For further details, see V.R. Pantulu (1986) "Fish of the Lower Mekong Basin", in B.R. Davies, and K.F. Walker, eds., The Ecology of River Systems, Dordrecht: W. Junk.

10. The other is the Red River Delta.

11. Interim Mekong Committee Secretariat (1992) Fisheries in the Lower Mekong Basin, Bangkok: IMCS; "In the Reaches of the Dragon", The Nation, 8 March 1996.

12. It is worth noting, however, that delta degradation may originate from land use within the delta itself. For instance, unsuitable methods of cultivation or varieties of crops may have led to increased soil acidification in the delta in recent years.

13. This is the Kong-Chi-Mun project. See Biwater plc (1987) Kingdom of Thailand: Green E-Sarn: Investigation and Preparation of a Water Resource Development Programme for Northeast Thailand, Surrey: Biwater Plc; Prachoom Chomchai (1994) The United States, the Mekong Committee and Thailand: A Study of American Multilateral and Bilateral Assistance to Northeast Thailand since the 1950s, Bangkok: Chulalongkorn University Institute of Asian Studies, pp. 91-93.

14. "RID Warns of Failure to Implement Project", The Nation, 21 February 1997; "B50bn Water Diversion Project is to be Revived: Kok-Ing-Nan Revival Linked to Dam Delay", Bangkok Post, 21 February 1997. The Kok-Ing-Nan project involves costly and complex engineering and is dogged by controversy about its environmental impact.

15. Kristina Egan (1996/7) "From Megawatts to Negawatts: Demand Side Management in Thailand", Watershed 2(2, November 1996-February 1997): 54-56; Chuong Phanrajsavong, and D. L. Nguyen (1995) "The Lower Mekong Basin: Hydropower Potential and Development Opportunities", MRCS Hydropower Unit paper presented at Hydropower into the Next Century Conference, Barcelona, 5-8 June.

16. "Laos Gears for Hydropower Exports", The Nation, 16 July 1994; "MoU to be Signed with Cambodia on Dam Construction", Bangkok Post, 5 June 1996; "Thailand Plays Major Role in Supply of Power to Region Rich in Potential", The Nation, 2 August 1996; Report of the Fifth Meeting of the ADB Greater Mekong Subregional Electric Power Forum, 1998, http://www.adb.org/gms/epf5.asp.

17. Odendall and Torrell, pp. 120-123. 
18. Chuong Phanrajsavong, Chief of Water Resources Unit, MRCS, pers. comm., July 1997.

19. Report of the Fourth Meeting of the ADB Greater Mekong Subregional Electric Power Forum, 1997, http://www.adb.org/gms/epf4.asp.

20. Cambodia's Mekong hydropower potential is estimated at about 2,200 MW by the MRCS. See Phanrajsavong and Nguyen, p. 5.

21. "Cambodian Watershed", The Nation, 1 November 1996.

22. For a good discussion, see Fiona Miller, "Environmental Threats to the Mekong Delta", Watershed, 17 February 2000, http://www.nextcity.com/ProbeInternational/ Mekong/articles/000217b.html

23. See, for instance, J.C. van Dam and J. Wesel, eds. (1992) Transboundary River Basin Management and Sustainable Development, Volume 1, proceedings of international symposium, Delft University of Technology, 18-22 May; Chris Brady (1993) "Southeast Asia: The Mekong River", in Carol Thomas, and David Howlett, eds., Resource Politics: Fresh Water and Regional Relations, Buckingham: Open University Press; R.T. Maddock (1995) "Environmental Security in East Asia", Contemporary Southeast Asia 17(1): 20-37; Prachoom Chomchai (1995) "Management of Transboundary Water Resources: A Case Study of the Mekong", in Gerald H. Blake, H. Hildesley, M. Pratt, R. Ridley, and C. Schofield, eds., The Peaceful Management of Transboundary Resources, London: Graham and Trotman.

24. China was excluded because it was not a member of the UN, and Myanmar was not interested in joining.

25. ECAFE, now renamed the Economic and Social Commission for the Asia-Pacific Region (ESCAP).

26. The Declaration of the Interim Committee stated that the Mekong Committee would resume "once all members of the committee have decided to participate in that organization" (Art. 3), providing for Cambodia's automatic readmission once it had an internationally recognized government. For an overview of the Mekong Committee before 1995, see IMCS (1989) The Mekong Committee: A Historical Account (1957-89) Bangkok: IMCS,; Jeffrey W. Jacobs (1995) "Mekong Committee History and Lessons for River Basin Development", Geographical Journal 161(2): 135-148.

27. The Joint Declaration of Principles for Utilisation of the Waters of the Lower Mekong Basin. Three key Articles are:

Article X: "Mainstream waters are a resource of common interest not subject to major unilateral appropriation by any riparian state without prior approval by the other Basin States through the committee".

Article XVII: "The Basin State ... which undertakes the project shall present well in advance to the other Basin States for formal agreement prior to the project implementation a detailed study on all possible detrimental effects including short and long term ecological impacts which can be expected within the territory of other Basin States as a result of the proposed mainstream project. The procedures and amounts of damages compensation shall be included in the above study."

Article XXI: "A tributary recognized by all Basin States as a Major Tributary shall be ... governed by the provisions of the present Declaration of Principles applicable to the Mainstream."

28. Grainne Ryder (1993) "An Introduction to the Potential Environmental Effects of the Kong-Chi-Mun Diversion Project on the Lower Mekong River Basin”, Probe International Briefing Paper, May.

29. "Water Plan May Hit Mekong Neighbours", The Nation, 2 August 1994.

30. "Strong Distrust Delays Cooperation in Mekong", The Nation, 27 March 1992; "Dead in the Water?" The Nation, 28 October 1994. 
31. S. Tefft (1991) "Southeast Asians Face Off Over Mekong Dam Plan", Christian Science Monitor 83: 123.

32. "Thailand Wants Restructure of Mekong Committee", Bangkok Post, 8 March 1992; "Strong Distrust Delays Cooperation in Mekong", The Nation, 27 March 1992.

33. "The Mekong: More of a Liability than an Asset?" Bangkok Post, 21 March 1992; "Hanoi Sounds Warning Ahead of Mekong Talks", The Nation, 11 March 1994.

34. For the text of the Agreement for the Cooperation for the Sustainable Development of the Mekong Basin, see http://www.mekongforum.org/95agree.htm.

35. "Mekong Committee Sheds its Shackles", The Nation, 26 January 1995.

36. Agreement for the Cooperation for the sustainable Development of the Mekong Basin, Article 5.

37. Ibid., Article 26.

38. Ibid., Article 6.

39. "China Dams on Mekong 'Beneficial': Claims They Reduce River Water Rejected", Bangkok Post, 12 April 1997.

40. "Thailand Hesitant to Notify Neighbours on New Project", The Nation, 3 November 1995. In fact, only the first phase involving the rehabilitation of existing irrigation works, building spillways and irrigation works and the construction of one dam, one pumping station, and one diversion canal had been approved by the Thai cabinet.

41. "Thai Water Diversion Idea Takes Vientiane by Surprise", The Nation, 9 April 1995; Kate Geary, of the NGO TERRA, Phnom Penh, pers. comm., July 1997.

42. An annual catalogue produced by the MRCS with summary details of proposed projects and programmes seeking funds from donors.

43. "Fundamental Flaws Lie Below MRC's Surface", The Nation, 5 April 1996; "Officials Hope to Settle Water Use Row", The Nation, 24 July 1996. Thailand fears that as the most industrially developed riparian state, it stands to lose from any specific water quantity rules restricting and penalizing pollution of the river, Chomchai, pers. comm., July 1997.

44. Article 7: "every effort to avoid, minimize and mitigate harmful effects".

45. "In the Reaches of the Dragon", The Nation, 8 March 1996; "China Balks at Taking the Plunge", The Nation, 18 March 1996.

46. "China: Confronting an Unwieldy Future", The Nation, 5 December 1993; Mekong Development Research Network (MDRN) (1994) Development of the Mekong Basin in the 1990s: A Regional Perspective, Bangkok: MDRN, p. 12.

47. E.C. Chapman, and He Daming (1996) "Downstream Implications of China's Dams on the Lancang Jiang and their Potential Significance for Greater Regional Cooperation" and Wang Shui, and E.C. Chapman (1996) "The Lancang Jiang Basin: Steps Towards the Realization of Sustainable Development", both in B. Stensholt, ed., Development Dilemmas in the Mekong Subregion Workshop Proceedings, 1-2 October, Clayton: Monash University Asia Institute,.

48. MDRN (1993) Investigation and Study of the Current Status of the Lancang RiverMekong River in Yunnan, People's Republic of China, Kunming, Yunnan: MDRN,.

49. "China: Confronting an Unwieldy Future", The Nation, 5 December 1993; "Mekong Committee Sheds its Shackles", The Nation, 26 January 1995.

50. Prachoom Chomchai (1995) "Transboundary Protection of the Environment: A Mekong Perspective", paper presented at conference on International Boundaries and Environmental Security, Singapore, 14-17 June.

51. Chapman and He, p. 14.

52. "Friends in the Upper reaches", The Nation, 10 November 1995.

53. "Mekong Commission: In Search of a Purpose", The Nation, 17 February 1995; "Vietnam, Laos Want to See Master Plan for Management of Lower Mekong Basin", 
The Nation, 17 February 1995; "Indochina Poised to Sign Away River Safeguards", The Nation, 27 March 1995; "China: Hydro Plant Not Damaging Environment", Bangkok Post 5 November 1995.

54. Chapman and He, p. 14; Tyson R. Roberts, and I.G. Baird (1995) "Traditional Fisheries and Fish Ecology on the Mekong River at Khone Falls in Southern Laos", Natural History Bulletin of the Siam Society 41: 105-133.

55. Note the underlying problem with the "minimum flow" concept: guaranteed uniform water levels, or blanket releases, cannot sustain ecosystems and human systems that have adapted to natural flood cycles. See Thayer Scudder (1988) The African Experience with River Basin Development: Achievements to Date, the Role of Institutions and Strategies for the Future, New York: Clark University,.

56. "Academic: China Will Not Join Mekong Body", Bangkok Post, 24 April 1996; "Mekong Committee Sheds Its Shackles", The Nation, 26 January 1995.

57. UN, "General Assembly Plenary - 5/6 - Press Release GA/9246 99th Meeting", 21 May 1997.

58. An initiative first announced by Thai Prime Minister Chatichai Choonhavan in 1988.

59. Zachary Abuza (1996) "International Relations and Vietnam", Contemporary Southeast Asia 17(4): 406-419.

60. Phanrajsavong and Nguyen, p. 13. Thailand has 1,000 MW; Vietnam 2,000 MW; and Cambodia 2,200 MW

61. See Jonathan Rigg (1996) "Managing Dependency in a Reforming Economy: The Lao PDR", Contemporary Southeast Asia 17(2): 147-172.

62. For instance, a typical remark by the Vice-Minister of Industry and Handicrafts that "[h]ydropower is the priority sector in the Lao programme of socio-economic development ... we have a lot of water ... let's make use of it", quoted in "Flute Playing Aside, Dam Plan Forges On”, Bangkok Post, 12 May 1997.

63. "Hydropower Holds Key to Laos' Progress", The Nation, 26 May 1997.

64. Chairman of the Laos National Economic Committee, quoted in The Nation, 29 May 1995.

65. Marc Innes-Brown, and Mark J. Valencia (1993) "Thailand's Resource Diplomacy in Indochina and Myanmar”, Contemporary Southeast Asia 14(4): 332-351.

66. Grainne Ryder (1996/7) "The Rise and Fall of EGAT: From Monopoly to Marketplace?" Watershed 2(2, November 1996-February 1997): 13-25.

67. See Robert O. Keohane, and Joseph S. Nye (1977) Power and Interdependence: World Politics in Transition, Boston: Little, Brown.

68. "Laos Discovers True Cost of Power", The Nation, 20 September 1996.

69. "Egat to Postpone Power Buys", The Nation, 1 May 1998; "Viability of Four Export Projects in Question: Funding Plus Reduced Thai Demand Cited", Bangkok Post, 18 June 1998.

70. "Power to the People Could Cost", The Nation, 7 October 1999; "Battery of Asia May Ruin Flat: Thailand's Economic Crisis is Raising Questions over the Energy Exporting Hopes of Neighbouring Laos", Financial Times, 6 April 1998.

71. "The Gas-fired Threat to South East Asian Hydro Power", Water Power and Dam Construction, 31 August 1998; "Thai NGOs Call on Thai Prime Minister to Reject Electricity from Nam Theun 2", Foundation for Ecological Recovery Press Release, Bangkok, 15 June 1998. See also Thai presentations at the annual meetings of the ADB GMS Electric Power Forum since 1997, in http://www.adb.org/gms/epf5.asp.

72. "Thailand and Laos: The Search for Mutual Respect", The Nation, 27 November 1995; "Electricity Purchases", Bangkok Post, 16 August 1999.

73. Foundation for Ecological Recovery Press Release, "Thai NGOs Call on Prime Minister to Reject Electricity from Nam Theun 2, 15 June 1998, http://www.nextcity.com/ 
ProbeInternational/Mekong/articles/98b0615.htm. They wrote: "The relationship between Thailand and Laos ... is ... very fragile in terms of the futures of both countries. If cooperation by both governments can bring about real benefits for the peoples of both nations, this delicate relationship will become strengthened. It is the governments' consideration of people that is an essential impetus for insuring sustainable friendship and political stability".

74. "Laos Dam in a Logjam", Financial Times, 15 May 1996; "Well, Answer These Dam Questions", The Nation, 14 February 1997.

75. For details, see Grainne Ryder (1996) "The Political Ecology of Hydropower Development in the Lao People's Democratic Republic", unpublished master's thesis, York University, Ontario, Canada, http://www.nextcity.com/ProbeInternational/Mekong/ laohydro.htm); Tyson R. Roberts (1996) “An Independent Environmental Assessment of the Nam Theun 2 Hydropower Project in Laos, with Particular Reference to Aquatic Biology and Fishes", working paper, Bangkok.

76. "Egat, Laos in Price Deal on Dam Power", The Nation, 26 April 2000; "Nam Theun 2 Hydropower Project: At What Price Electricity?" Bangkok Post, 30 October 1999.

77. High rates of siltation are certainly a common problem with Lao dams - Laos contributes a quarter of the Mekong's total sediment load.

78. Grainne Ryder, and Steve Rothbert (1994) "Rent-a-River, Build a Dam", International Rivers Review 9(4): 8-9. See also International Rivers Network (1999) Power Struggle: The Impacts of Hydro-Development in Laos, Berkeley: IRN, chapter 4.

79. Andrew Nette, "Stepping in Where Banks Fear to Tread", The Nation, 10 June 1997; Nette, "No Guarantees for Local Communities", The Nation, 11 June 1997.

80. Nette, pers. comm., June 1997.

81. "World Bank Says No Backing for Laos Dam until Reforms Take Place", AFP, 22 February 2000.

82. On the concept of human security, see Peter Stoett (1999) Human Security and Global Security: An Exploration of Terms, Toronto: University of Toronto Press; Lloyd Axeworthy, "Human Security: Safety for People in a Changing World", http://www.dfaitmaeci.ca/foreignp/Humansecurity/secur-e.htm.

83. See particularly, Thomas F. Homer-Dixon (1994) "Environmental Scarcities and Violent Conflict: Evidence from Cases", International Security 19(1, Summer): 20-31.

84. Michael Renner (1997) Fighting for Survival: Environmental Decline, Social Conflict, and the New Age of Insecurity, London: Earthscan, pp. 135-153; Jon Barnett (2000) "Destabilizing the Environment-Conflict Thesis", Review of International Studies 26(2, April): 280-284.

85. See, for instance, World Bank/IUCN (1997) Large Dams - Learning from the Past, Looking at the Future, Workshop Proceedings, Gland, Switzerland.

86. The most active environmental organizations working on the Mekong are: Californiabased International Rivers Network (IRN), Toronto-based Probe International, and Bangkok-based Towards Ecological Recovery and Regional Alliance (TERRA).

87. On EIA procedures, see Peter Wathern, ed. (1988) Environmental Impact Assessment: Theory and Practice, London: Routledge.

88. See International Rivers Network (1997) "IRN Letter to the President of the Asian Development Bank", 29 October, http://irn.org/programs/mekong/aviva971029.html; Peter Mortensen (1997) "Mekong River Basin: Towards Establishment of an Integrated Planning Process", paper presented at MRC seminar on Integrated River Basin Development and Management, Cha-am, Thailand, 13-16 May.

89. IRN, Power Struggle - see Introduction on http://www.irn.org/programs/mekong/ps. intro.shtml.

90. “Logging Worsens Dam’s Toll”, Bangkok Post, 3 February 1997. 
91. Andrew Nette (1998) "Double Jeopardy for Laos: Logging Interests and Hydro Developers Join Forces to Dam Mekong Tributary", World Rivers Review 13(1, February) on http://www.irn.org/pubs/wrr/9802/xekaman.html.

92. "Laos Dam Resettlement Plan Approved", Business Day (Thailand), 22 January 1999.

93. IRN (1997) "IRN Letter to the President of the Asian Development Bank, 29 October 1997, on http://irn.org/programs/mekong/aviva971029.html.

94. See IRN (1999) The Struggle for the Mun River, Berkeley: IRN.

95. Bruce Shoemaker (1998) "Trouble on the Theun-Hinboun: A Field Report on the Socio-Economic and Environmental Effects of the Nam Theun-Hinboun Hydropower Project in Laos", IRN paper, April, available on http://www.irn.org/programs/mekong/ threport.html.

96. "The Theun-Hinboun Power Company's Mitigation and Compensation Program", available at http://www.adb.org. See also Probe International Mekong backgrounder \#10, "Power Company Off the Hook for damaging Fisheries in Lao PDR: Government or Foreign Aid Should Pay for restoration, ADB Says", 28 July 1998, http://www. nextcity.com/ProbeInternational/Mekong/backgrounders/mk10.html.

97. Aviva Imhof (1998) "Lao Dam Harms Fishing Communities", World Rivers Review 13(2, April), http://www.irn.org/pubs/wrr/9804/laos.html.

98. IRN, Power Struggle, chapter 2.

99. A point acknowledged by field and secretariat staff. See Mortensen (1997).

100. MRCS (1996) EIA Process and Procedures for the Mekong River Commission, Bangkok: International Environmental Management for MRCS; A. Yoohoon et al. (1997) "State of the Art Report on EIA for Lower Mekong River Basin", Bangkok: MRCS.

101. The GMS was the first and only economic or development initiative to encompass all six Mekong countries. There is only one other framework that involves all six riparian states: the Mekong Development Research Network (MDRN), which is an academic research network that spans the six countries.

102. It is estimated that the ADB has spent about US $\$ 170$ million on hydropower projects in the Mekong basin so far, mostly in Laos. It is considering spending another US $\$ 400$ million by this year through country programmes. See Aviva Imhof (1997) "The ADB's Role in Dam Building in the Mekong Region", IRN working paper; "ADB Slammed for Funding Mekong Project", The Nation, 13 May 1997.

103. "Controversial Dam Projects May Lose Development Bank Funding", South China Morning Post, 24 April 1999.

104. ADB GMS, "Fifth Meeting of the Working Group on Environment", 11-12 May 1999, Kunming, China, http://www.adb.org/gms/wge5.asp.

105. ADB GMS, "Sixth Meeting of the Subregional Electric Power Forum", 28-29 October 1999, Phnom Penh, Cambodia, http://www.adb.org/gms/epf6.asp.

106. See ADB GMS, "Project Profiles - Poverty Reduction and Environmental Management in Remote GMS Watersheds", http://www.org/gms/pp_env7.asp.

107. "Laos to Hold More Public Discussions Next Month", Bangkok Post, 30 January 1997; "Nam Theun 2: Biodiversity, Hydropower", Vientiane Times, 2-4 April 1997.

108. Vice-Minister for Industry and Handicraft, Khammone Phonekeo, quoted in "Hydropower Holds Key to Laos' Progress", The Nation, 26 May 1997; "Lao Dam Plan Wins Support of Environmentalist", The Nation, 8 March 1997.

109. David W. Pearce, and Kerry R. Turner (1990) Economics of Natural resources and the Environment, London: Harvester Wheatsheaf; Kerry R. Turner (1995) Sustainable Environmental Economics: Principles and Practice, Chichester: Wiley. For a flavour of the technicalities, see articles in Sustainable Development.

110. Ramesh Thakur (1997) "From National to Human Security", in Stuart Harris, and Andrew Mack, eds., Asia-Pacific Security: The Economics-Politics Nexus, New South Wales: Allen and Unwin, pp. 31-51. 


\section{Part IV Institutional security perspectives}



10

\title{
Alternative security models: implications for ASEAN
}

\author{
William T. Tow
}

\section{Introduction}

As a new century unfolds, the fate of institutionalism in Asia and beyond remains uncertain. Dire predictions advanced at the end of the Cold War about regional and international organizations yielding to new statecentric rivalries that would fuel incessant and widespread conflict have hardly been validated. Yet, those organizations appear powerless to regulate violence, modify the forces of globalization, or touch the lives of ordinary citizens. At best, they have appeared sluggish in responding to recent economic and humanitarian crises; at worst, they have seemed largely irrelevant in the resolution of these crises. Critics assert that institutions such as the Association of Southeast Asian Nations (ASEAN) are nothing more than instruments of manipulation by their member countries, effective only when the most powerful of these states deem institutional collaboration to coincide with their own national interests. ${ }^{1}$

Asia's recent financial crisis, political turbulence in Indonesia, intensifying Sino-American tensions and, most importantly, increased intraASEAN political differences have generated rising scepticism about institutionalism's future relevance to Southeast Asia's regional security. ${ }^{2}$ Such pessimism is largely derived from the application of realist criteria as a measure of institutional performance. It is also, however, a reflection of growing disillusionment over what many liberal analysts had previously assumed was ASEAN's genuine adherence to (and development 
of) norms that collectively were known as the "ASEAN way". 3 ASEAN's identity and sense of community is now under threat from its affiliates' inability to achieve consensus on key foreign policy issues and to sustain its traditional practice of speaking as one voice to the outside world.

As they have evolved to date, ASEAN and the ASEAN Regional Forum (ARF), in principle, represent non-traditional approaches to regional security politics. They clearly must function in a developing-regional context rather than in a European or Western setting, where centuries of diplomatic and legal precedent shape the form and parameters of institutional interaction. Unlike traditional security alliances, moreover, they try to advance strategic reassurance in the region through transparency and confidence building rather than by perpetuating more traditional modes of security behaviour, such as power balancing, deterrence, and crisis manipulation. ${ }^{4}$

Yet the security behaviour of ASEAN states often belies this idealistic image. Intra-ASEAN consultation is becoming more difficult to sustain as Southeast Asian polities are consumed with domestic political crises and economic survival. A substantial number of ASEAN and ARF members, moreover, are affiliated with either formal security pacts or, more commonly, informal but substantial bilateral or multilateral defence ties with larger powers. Under these circumstances, the fate of institutionalism in the region may well hinge on Southeast Asia's policy-makers finding and implementing alternative security models to breathe new life and credibility into ASEAN/ARF inter-workings.

Three alternative security approaches will be considered here, including constructivism, securitization, and human security. All three have been recently introduced into international security debates in academic circles. At least one of them (human security) has been adopted by various developed states (such as Canada, Norway, and Japan) as hallmarks of their official foreign policies. This particular model has captured the attention of Asian policy officials and analysts, especially within the policy corridors of ASEAN states and Australia.

None of these three models is inherently superior to more traditional realist or liberal explanations for how institutions play (or fail to play) a role in Southeast Asia's security politics. There is, however, clearly insufficient current analysis that employs alternative security models as bases for assessing how that region's security politics may be enhanced. The major argument of this chapter takes this premise even further: institutionalism's best chance for surviving as a viable political entity in Southeast Asia is to incorporate a judicious mix of realist, liberal, and alternative security approaches. Key features of the three alternative security approaches will be discussed herein in relation to Southeast 
Asian institutionalism. A short conclusion will consider what "mix" of these alternative security models might be best applied to strengthen Southeast Asia's regional security future.

\section{Constructivism}

The Cold War's demise shocked many international relations analysts, who lamented their inability to predict it. ${ }^{5}$ One explanation for their embarrassment was the West's failure to consider how social change in the USSR and its Eastern European satellites was affecting their ability to preserve long-standing structural components that sustained the "Soviet bloc's" existence. Existing political structures were challenged by the "new thinking" of Mikhail Gorbachev - a self-acclaimed modern man intent on finding shared values and interests with his country's traditional antagonists as a means of underwriting the USSR's survival. His miscalculation was that this change in social emphasis proved to be far more powerful, and thus less controllable, than he imagined, leading to the unleashing of both nationalist and liberal forces throughout the Soviet bloc, which hastened its downfall. ${ }^{6}$

Constructivist scholars have rejected the idea that material capabilities, such as power and resources, are the key components in determining whether war or peace will occur. They instead argue that the forces of social change now shape contemporary international security politics, undermining both realist and liberal assumptions. Constructivism assumes that institutions are primarily an expression of socio-cultural derived knowledge and practices rather than responses to anarchical regional or international security demands. ${ }^{7}$

While not denying that material factors play a role in international security behaviour, constructivists view "structure" in international relations as comprised of both material and value-oriented components. They posit that institutional formation and behaviour are socially derived and socially contingent rather than evolving only from states that structures can be transformed by knowledgeable groups known as "agents". State identities and interests can thus be changed, constructivists assert, by these groups.

Although the work of constructivists has been prominent in international relations literature for nearly a decade, analysts were slow to apply it to Southeast Asian security issues. This can be attributed to the comparatively recent experiences of decolonization and nation-building endured by most ASEAN states, and the natural preoccupation of their regional elite with preserving their countries' newly won sovereignty. Constructivist theories, such as shared knowledge or "collective iden- 
tity", seem foreign in a region where authoritarian rule and the pursuit of national "self-reliance" often prevail. As importantly, constructivism may be seen by the Asian elite as underwriting values that are largely European rather than attuned to their own traditions.

Two recent assessments linking constructivist thought to ASEAN security relations, however, have prompted debate among Asian analysts. Amitav Acharya has argued that ASEAN is an "imagined" security community, meeting constructivist expectations - that, far from reflecting a neo-utilitarian vision of cooperative rationalism, ASEAN evolved from a "conscious, socio-psychological and 'imaginative' dynamic" of cooperation, underwritten by a collective sense of vulnerability relative to the region's great powers. ${ }^{8}$

ASEAN's collective identity, in this view, is not that of a "mature" security community, predicated upon extensive military cooperation or mutual threat perceptions. It is, rather, regarded as a "nascent" security community based on the elite's common perceptions (i.e. shared knowledge) of the so-called ASEAN way non-interference in one another's internal affairs, pacific settlement of intra-regional disputes, respect for one another's independence and respect for one another's territorial integrity. ${ }^{9}$

Another noteworthy effort to apply constructivist logic to Southeast Asian security politics has been offered by Nikolas Busse. He notes that its founding members to sustain an acceptable regional balance of power may have created ASEAN as a realist strategy, but it has since established a regional code of conduct predicated on the norms of the ASEAN way. Accordingly, such realist strategies as alliance building and deterrence have been shelved in the context of intra-ASEAN relations. War between any ASEAN members is now largely unthinkable. ASEAN's collective identity has thus been strong enough to preclude any one group of the national elite from using it as a scapegoat when experiencing their own domestic political crises. ${ }^{10}$

There is little doubt that a case can be made that constructivism highlights the "socializing" of the ASEAN way as a framework for regional security norms and behaviour. The value of informal consultation and diplomacy applied in a gradual and low-key manner, and the need for negotiating parties to save face while reconciling their differences, have become embodied as integral aspects of ASEAN's diplomatic style.

There is room for dissent, however, against the notion that the ASEAN way has been a powerful impetus for norm compliance and regional identity. Recent efforts by Thailand, for example, to introduce the idea of "flexible engagement" as a means of softening the ASEAN-way's previously hard-line posture on non-interference in the domestic affairs of other member states exposed serious cracks in Southeast Asian regime politics. Flexible engagement was resisted vigorously and successfully by 
Malaysia, Indonesia and Singapore as well as the Indo-Chinese states (the Philippines supported it).

The ASEAN way has remained in force, however, in regard to institutional relations with extra-regional actors. A clear example of this was ASEAN's response to US Vice President Al Gore's criticism of Malaysia's policies surrounding the dismissal and subsequent incarceration of that country's deputy prime minister, Anwar Ibrahim, at a pre-APEC Business Summit convened in Kuala Lumpur in November 1998. Gore's remarks were considered remarkably callous by the Malaysian government and by other ASEAN states. They were viewed in particular, as overly aggressive in imposing American "democratic values" on the politics of an ASEAN state. They prompted ASEAN diplomats to return to the ASEAN way as the fundamental element of its political identity. Economic interaction was still encouraged, however, to sustain regional investment by American firms and other foreign concerns. This "dual track" formula was embodied as official policy at ASEAN's summit in Hanoi convened in December 1998. ${ }^{11}$

Sceptics of the constructivist line conclude that these recent events are less a reiteration of ASEAN's security identity than a rationalization by that institution for preserving an increasingly fragile set of norms. Criticism of Anwar's arrest by the Philippine and Indonesian presidents, a Thai initiative to enhance institutional transparency and the generation of the "Vision 2020" document produced at the Hanoi Summit all point to growing fragmentation within ASEAN ranks.

ASEAN norm compliance has also been questioned by at least one recent study of how closely twenty recent episodes of ASEAN foreign policy adhered to intra-mural deliberations consistent with the ASEAN way. ${ }^{12}$ In at least seven of those instances, norms of principle or procedure usually linked to the ASEAN way were either ignored or failed to be sufficiently predominant to confirm shared policy outlooks. Episodes, such as the 1980 Kuantan Declaration, subsequent Thai diplomatic initiatives towards Indochina and Malaysia's campaign to create an East Asia Economic Caucus (EAEC), were all examples of individual ASEAN actors ignoring the "due process" of quiet consultation and consensus building usually associated with the ASEAN way. Collectively, such episodes intensify doubts as to what extent norms and collective identity guide the decision making of ASEAN states.

Perhaps the most interesting test case of ASEAN's "constructivism identity" relates to Vietnam's 1995 accession into ASEAN. From a constructivist viewpoint, the recent history of Vietnamese-ASEAN relations underscores the key role of ideational factors in institutional politics. Constructivists would argue that two major factors were instrumental in convincing Hanoi's leadership to join rather than confront ASEAN: 1) the loosening of Cold War constraints on the efforts of Southeast Asian 
states to build regional stability and to maximize national wealth and development; and 2) Vietnam's gradual recognition that the strengthening of consultative and consensus-building processes in conjunction with other ASEAN members represented its best chance to modernize and compete in an increasingly geo-economic world. More fundamentally, ASEAN membership would signify that Vietnam had arrived and was fully accepted by its Southeast Asian neighbours in an emerging regional system as a partner for economic growth.

Realists contest most of this interpretation. The history of Vietnamese-ASEAN relations during the Third Indochina War, they insist, is nothing more than an era of intermittent competition and cooperation based on fluctuating national interests. ASEAN was hardly the unified actor that constructivists would like to portray. As one realist has since argued, "the nuances of ASEAN's corporate policy ... and state-centric behaviour are significant in assessing the degree of alienation between Vietnam and its ASEAN neighbours" during the Cambodian conflict. ${ }^{13}$ Later realist assessments, while conceding that ASEAN does cultivate a shared belief in the positive relationship between economic development and security, nonetheless deny that this orientation has been converted to a distinct strategy of regional peace building. ${ }^{14}$

In summarizing constructivism's applicability to Southeast Asia's institutional experience, ASEAN's pursuit of regional collective identity through the ASEAN way or through other, related, norms may be one important factor for understanding that institution's diplomatic style and security agendas. However, it has not been the core component of that organization's security outlooks and postures that ardent constructivists insist is the case. Great power interests and capabilities (what Oran Young has termed "structural power") remain integral to security regime building in Southeast Asia, as ASEAN has recognized by spearheading the creation of ARF in $1994 .{ }^{15}$ US bilateral security relationships, moreover, remained valued by most ASEAN states as power balancing mechanisms, underwriting the opportunity for ASEAN norms and principles to mature as components of regional identity. Until the regional elite are able to command greater consensus within their own polities as to what norms and values are to be universally accepted, such a balancing mechanism is needed to supplement any constructivist ethos that may be gradually evolving within the ASEAN network.

\section{Securitization}

Like constructivism, "securitization" wrestles with the problem of collective identity. Securitization was introduced by the so-called "Co- 
penhagen School", a group of political scientists at that city's Centre for Peace and Conflict Research during the early 1990s. Its two best-known proponents are Barry Buzan and Ole Waever, but a number of other prominent scholars also collaborated. ${ }^{16}$

Unlike constructivism, this security model focuses on "societal security", conceived as existing within borderless communities rather than within state sovereignties:

Securitization is concerned with how the idea of security is conceived and how it is "politicised" or assigned within a specific "objectivist" framework. It is thus a set of ideas and practices that identify individuals as members of a social group ... society is about identity, about the self conception of communities and of individuals identifying themselves as members of a community. ${ }^{17}$

The idea underpinning securitization is to refine our understanding of why a particular issue is "securitized" by any element of society (including a "state" or a "community") and differentiated from other, more routine, political issues. It is a socially constructed concept because it stipulates that any social referent can be deemed "threatening" to a social organization (i.e. a state, a community, or some other type of collective polity) if the elite declare it to be so. A "securitizing actor" or elite can win recognition or legitimacy for its threat designation if that elite gains society's approval to take measures against the referent that has been deemed to be "threatening". Analysis of whether a specific threat has been correctly deemed dangerous to a society's collective identity, however, is only verifiable in hindsight. Security thus becomes a "selfreferential" practice "because it is in this practice that the issue becomes a security issue - not necessarily because a real existential threat exists, but because the issue is presented as such a threat". ${ }^{18}$

This gives the elite or policy-makers considerable discretion in identifying what constitutes a security problem. It also provides them with a convenient link between identifying a "threat" and rationalizing possible intervention to neutralize it on the basis of "security". Waever argues that redefining or expanding the security referent often leads a nation's elite to claim a "special right" to intervene against that source in a variety of policy situations. This prerogative constitutes what he terms a "speech act" - by merely calling something a "security problem", it is; "the utterance itself is the act". ${ }^{19}$ Non-military acts of humanitarian intervention assume the logic of war or survival and justify such initiatives as national mobilization, militarization or even just heightened vigilance against perceived encroachments on sovereignty by a security referent.

Such perspectives have interesting connotations in studying Southeast Asian institutionalism as it has recently developed. Malaysian Prime 
Minister Mahathir's recent claims that Wall Street's hedge traders conspired against developing state economies during the Asian financial crisis might well be regarded as an example of securitization. So too might various aspects of the so-called "Asian values debate", which have highlighted alleged Western efforts to "democratize" Asian states in ways they have deemed inimical to their cultures and identities.

Elite management of security language and discourse is also applied in Singapore in ways that are regarded as consensual or democratic in that city-state. Singaporeans recognize various issues (e.g. religion and race) as "out-of-bound (OB) markers", where "an unspoken consensus has developed between the elite and the citizenry" to prevent such issues from jeopardizing public peace and order. The practice is "democratic" in a Singaporean context because the elite's right to demarcate such issues is linked to a widely desired outcome by the population at large: the preservation of an environment where economic and political development can proceed in an unimpeded fashion. ${ }^{20}$ Unbridled democracy, it is posited, could have negative connotations for the relatively smooth course of Singapore's national development. Controversial issues are thus either better left understated or raised only with great sensitivity. In this context, OB markers are synonymous with security because boundaries or limits are imposed on citizen participation in the shaping of political discourse. These "boundaries of consent" are mandated to Singapore's government by most of its populace, even if such parameters are not always demarcated as clearly as some critics of the practice might suggest.

The Copenhagen Group's theory of security definitions applies to all these examples and notes that issues having international dimensions or implications tend to be more readily designated as security issues. ${ }^{21} \mathrm{In}$ dividual state governments often seize the opportunity to classify such issues as national security matters. As Waever points out, "national security" is usually a subjective concept, understood by a society to be a measure of its identity and defined by the social elite. Security can thus be manipulated by the elite in the context of preserving their preferred version of that identity. ${ }^{22}$

Apart from the obvious point that the location of the Copenhagen School prejudices its analysis along Eurocentric lines, several more substantive aspects of this approach appear to make its relevance to Southeast Asian security affairs somewhat questionable. First, although securitization claims to prioritize society as its key referent, its actual focus on the state tends to belie the claim and to render it nothing more than national security-realism in different trappings. As Muthiah Alagappa and other analysts have argued, the rhetoric of national security may be used by governments "to maintain a certain identity and impose 
an order that privileges some segments while threatening others", perpetuating what has been termed "structural violence" against marginalized sectors within their own societies (i.e. the poor, political dissidents, or ethnic minorities). ${ }^{23}$ Modern Asian history is laden with such examples. The now displaced Suharto government was perhaps the most conspicuous recent example. Here, the concept of a "New Order" was merely a subterfuge justifying government monopoly and ensuring the perpetuation of a highly personalized oligopoly.

Second, and emanating from the above consideration, if collective identity is a matter of "we are who we want to be" rather than "we are who we are", securitization should be about processes of negotiation and change occurring within various social strata of individual Southeast Asian societies. ${ }^{24}$ The perception and demarcation of what are threats would change according to what social aspirations are being realized or impeded at a given time. There is little evidence that such sophisticated processes are occurring in most ASEAN states. Much of the socio-political decision making remains in the hands of the bureaucratic or political elite, constituting a small portion of the national population. Alternatively, political anarchy may prevail (currently throughout much of Indonesia, in the Mindanao province of the Philippines and in large portions of border regions spanning Thailand, Myanmar and Laos) to an extent that social aspirations simply cannot be systematically addressed or pursued. In the latter instances, identity crises rather than identity enhancement are the usual outcome.

A major purpose for applying securitization in an ASEAN context might be to sensitize regional analysts and populaces as to how the state can rationalize "national security" actions on the basis of fulfilling a realist agenda and claim any amount of social resources to achieve them. ${ }^{25}$ In fact, ASEAN institutions would do well to explore means of desecuritization - reducing the scope of security identity and regulating militarization long perpetuated by various ASEAN states. In this sense, the concept of securitization would be modified by institutions, such as ASEAN and ARF becoming viewed as legitimate competitors to or even replacements for states as referent bases for security politics, basing that competition on norm identification and confidence building rather than militarization and security dilemmas.

\section{Human security}

Perhaps the broadest alternative security model in recent years is the idea of "human security". This concept highlights the individual's welfare. That is, the security reference (the object of security or that which is 
to be secured) shifts from the state to the individual. As the definitive 1994 United Nations Development Programme (UNDP) Report on Human Development has noted, the concept of security is thus expanded to encompass "the legitimate concerns of ordinary people who [seek] security in their daily lives". ${ }^{26}$ It is important to note that the meaning of human security is hardly amorphous (it does not intend to encompass every "bad" or "good" thing that impacts on every human being). It focuses on the aggregation of human security, or insecurity, as it relates to the state, an international order, an international regime or the broader international community. ${ }^{27}$

Factors, such as the pace and scope of technological change and the internationalization of markets and finance (together often characterized as "globalization"), have underscored the problem of how the fate of individuals is radically affected by forces beyond the control of traditional state-centric structures of governance. ${ }^{28}$ This remains true notwithstanding the recent focus placed on human security problems by the governments of at least some developed states. Canadian Foreign Minister Lloyd Axworthy, for example, capped his long support for implementing human security as a hallmark of his country's foreign policy with the release of a definitive concept paper on the subject in April 1999. He concludes that, while "security between states remains a necessary condition for the security of the people", the much greater frequency of intra-state conflict since the end of the Cold War mandates "a more comprehensive and systematic approach to enhancing the security of people". ${ }^{29}$ Japan's late prime minister, Keizo Obuchi, established a "Human Security Fund" under the United Nations (initially totalling JPY500 million or US\$4.2 million) to support development projects in Asia. Obuchi referred to two kinds of human security imperatives that needed to be addressed: 1) different types of "non-state threats", including environmental problems, transnational crime, refugee and migration flows, possible pandemics, such as AIDS, and terrorism; and 2) intensifying pressures on the "socially vulnerable" - the poor and the elderly, women and childrenwho are unable to cope with the forces of globalization on their own. ${ }^{30}$ The Norwegian government has also been an active promoter of human security. Norway's Minister of Foreign Affairs Knut Vollebaek has designated anti-personnel landmine eradication, small arms nonproliferation, the welfare of children, the advancement of human rights, anti-transnational crime measures, and conflict prevention as key human security elements. ${ }^{31}$

Advocates of the human security approach point to "practice having led theory" in this case, as grass-roots organizations work in tandem with more "progressive" governments to meet a broadening range of transnational concerns and to neutralize the human costs of violent intra-state conflict. They insist, however, that human security cannot supplant 
national security and that ideally, state security and human security are "mutually supportive". As Axworthy has observed, building an effective democratic state that values its own people and protects minorities is a central strategy of promoting human security: "When states are externally aggressive, internally repressive, or too weak to govern effectively, they threaten the security of the people". ${ }^{32}$

The human security concept, while widely acclaimed in many quarters, has hardly commanded universal support. A major criticism relates to the ongoing "cultural relativism" debate perpetuated by various Asian analysts. The International Monetary Fund (IMF) was criticized sharply by many Asian elite during their region's financial crisis in 1997/8 for imposing social and political reforms, under the guise of "human security", that were alien to the intended recipients' cultures and values. ${ }^{33}$ At the policy level, critics have labelled human security advocates' promotion of "progressive values" as nothing more than the ideology that is integral to the foreign policy identities of those countries most active in advancing the concept. Canada has thus used human security to advance itself as a progressive middle power; Japan has seized on it as a vehicle to "soften" its historical image and to lay the groundwork for its coveted status as a permanent voting member of the UN Security Council, and Norway has been lobbying for a Security Council seat for 2001-2003.

Realists also point to the problem of implementing strategies to protect individuals against physical violence regardless of the level at which it may be inflicted (interstate war or various intra-state conflicts). Resistance by local authorities in a target area, costs and risks of humanitarian intervention, the unanticipated and unintended exacerbation of local rivalries in the process of implementing such intervention (e.g. Kosovo), and the difficulty of enforcing conditions of humanitarian assistance funds exemplify implementation problems. ${ }^{34}$

Most fundamentally, it is far from clear that "globalist-driven" international security agendas can replace more traditional, state-centric ones. The world's most powerful states continue to ascribe to very realist foreign policy designs and to support and defend their own national interests when making calculations about how to behave in the contemporary international environment. The rallying against a pax Americana, which many outside the United States view as having emerged, has its supporters in the most powerful councils of France, Russia, China, and India. It is unclear whether proponents of the human security approach can apply the necessary policy leverage to prevail over such forces and trends.

\section{Human security and ASEAN}

This uncertainty is especially pertinent to the ASEAN region. Writing in the mid-1990s, Barry Buzan and Gerald Segal observed that nation- 
building was still relatively underdeveloped in many Southeast Asian polities that they labelled "weak states". The notions of civil society, pluralism, and democracy remained tested by authoritarian military rule in Indonesia and Myanmar (and the threat of such rule was still present in Thailand). Prospects of economic squalor and widened insurgencies were still strong in the Philippines, while ethnic divisions, boundary disputes, and episodes of "deeply institutionalized corruption" occurred throughout the region. All these underscored the challenge of building stronger state structures, notwithstanding the general lack of "intense competing foreign interventions" that pervaded during the Cold War. ${ }^{35}$

Nearly seven years later, the likelihood of the ASEAN elite to shift their focus from traditional security postulates (state-centric territorial, diplomatic and territorial concerns) to a broader set of referents incorporating "unstructured" threats (those emanating from beyond boundaries or state structures) of a non-military and personal nature remains questionable. To apply the terminology of securitization to the human security problem, there is little evidence that ASEAN's current national leaders have embraced socially constructed concepts that reflect greater orientation towards the welfare of the individual.

The Indonesian elite, for example, are consumed with preserving the legitimacy of their state's identity and structure in the face of intensifying communal violence and secessionist threats in Kalimantan, Aceh, Malukus, Irian Jaya, and other parts of the country. Under such conditions, power struggles for state supremacy among various nationalist factions, a weakened but still formidable Indonesian military, and forces for civil supremacy continue to rage. Insufficient socio-political consensus exists within the Indonesian state to meet the preconditions for genuine human security agendas: a concentration on human welfare goal provisions and on linking of governance with the objective of overcoming human vulnerabilities. ${ }^{36}$

The fate of human security in East and Southeast Asia over the longer term is most likely to be determined by the extent to which it becomes an integral part of regional institution building. Implementation of such agendas at this level circumvents, to at least some extent, the historical manoeuvring that has dominated zero-sum diplomatic behaviour of the so-called "progressive" ASEAN states, under the human security rubric, at the international level. As regional institutions confront and respond to human security issues, they may eventually develop and sustain norms that inhibit individual members from pursuing exclusively state-centric interests.

Yet, cultural and political barriers remain ensconced within ASEAN polities. These may work to undermine their willingness to derive and apply collective solutions to human suffering and deprivation across na- 
tional boundaries for some time to come. Sceptics emphasize the "realist baggage" that accompanies any collectivist ethos that ASEAN projects and that encumbers a substantial deepening of institutional cooperation. ${ }^{37}$ Widely-shared concepts, such as national self-reliance, an ingrained belief in global anarchy or chaos, ethnocentrism and power balancing, are all inherent to Southeast Asia's historical and cultural legacy (derived in large part from the Hindu-Brahmanic idea of mandala). They often work to impose structural biases into the thinking and decision-making of the ASEAN elite. The process of norm formation, essential to raising the status of individual needs within the policy hierarchy's sense of priorities, is confronted by centuries of power-driven interests and behaviour that have shaped Southeast Asia's cultural and political landscape. This results in ASEAN lacking a normative base with which to shape a distinctive collective identity. As Jürgen Rüland has observed, constructed norms cannot form a normative foundation directed towards alleviating human insecurity, or pursuing any other shared social objective, unless a true collective identity is developed during periods of substantial historical transformation. For ASEAN, the form of government, or national values, matters less as a criterion of membership than do mere geography and material success. ${ }^{38}$ Intra-state political change will need to precede inter-state collective identity formation.

Nevertheless, recent efforts by individual ASEAN members to build at least a modest basis for collective identity are significant in human security terms. The importance of norm formation at the institutional level, promoting more liberal values, is reflected in recent efforts by some ASEAN members (most notably Thailand) to incorporate aspects of human security into that institution's agenda. In December 1997, ASEAN incorporated some aspects of human security into its Vision 2020 programme adopted at the heads of state summit in Kuala Lumpur. ${ }^{39}$ That declaration called for Southeast Asia to become a:

community of caring societies [where a] socially cohesive and caring ASEAN [would be bound by a common regional identity, where] hunger, malnutrition, deprivation and poverty are no longer basic problems, where civil society is empowered and gives special attention to the disadvantaged, disabled and marginalised, and where social justice and the rule of law reign.

The key issue, of course, is how ASEAN states will match such rhetoric with concrete results. ASEAN states have adhered to the principle of non-interference ever since they forged that organization's founding document in Bangkok over three decades ago. However, the equally compelling need for Southeast Asia's "regional resilience" has recently contended for primacy, as the legitimacy of several ASEAN member- 
state governments has come under challenge from economic crises, increasingly obvious human rights transgressions and environmental disasters.

The human security problematic was especially highlighted by the East Timor episode. One of ASEAN's previously most stable political infrastructures - the Suharto government in Indonesia - was unravelled by the Indonesian's population's rising consensus that it was no longer able to govern in ways that promised the long-standing trade-off of economic development for a "collectivist" approach to human rights. Indonesia's economy, savaged by the Asian financial crisis, had never recovered its momentum. Suharto proved to have little idea how to reconcile the special interest groups, which had underpinned his power for over 30 years, with the imperatives of national reconstruction. The demise of his regime was soon followed by his successor's decision to subject the long-standing dispute over sovereignty in East Timor to a provincial referendum, a development that produced an overwhelming vote by East Timor's residents for independence.

Regional resilience and human security issues emerged, at odds with non-interference, when ASEAN was forced by events to participate in the International Force for East Timor (INTERFET). The new Indonesian government had invited an international peacekeeping operation to deploy on its own territory. Four other ASEAN countries (Malaysia, Singapore, the Philippines, and Thailand) contributed assistance. Military operations conducted by the troops of ASEAN countries in the territory of another ASEAN state were unprecedented and could well mark a major turning point in ASEAN security politics. Although operating under a UN mandate rather than as a region-specific military contingent, and couching their participation as individual states rather than as an ASEAN-wide decision, the principle of non-interference had been challenged at the heart of its rationale - the nation-building process. ASEAN states proved that they were willing to intervene on human security grounds to check the documented atrocities of militias who were fighting for those who feared Indonesia's sovereign fragmentation. The sanctity of state boundaries was violated on the basis of saving lives. Human security may yet take a significant place in future ASEAN agenda setting. ${ }^{40}$

\section{Implementing the alternative security models}

Southeast Asia's post-war history is marked by the preoccupation of the elite with sustaining their political power (an intra-state security preoccupation) and by minimizing their sovereignties' vulnerability to external aggression (an inter-state security orientation). These two character- 
Table 10.1 Selected alternative security models

\begin{tabular}{|c|c|c|}
\hline & Core characteristics & Applicability to ASEAN \\
\hline Constructivism & $\begin{array}{l}\text { - } \text { state-centric } \\
\text { focuses on inter- } \\
\text { subjective social } \\
\text { structures ("shared" } \\
\text { knowledge and } \\
\text { understandings about } \\
\text { how politics works) } \\
\text { - rejects realist premise } \\
\text { that structural change is } \\
\text { based solely on configu- } \\
\text { ration or redistribution } \\
\text { of material capabilities }\end{array}$ & $\begin{array}{l}\text { - justifies "Asian values" } \\
\text { and the ASEAN Way } \\
\text { contests "structural } \\
\text { power" as an outlook, } \\
\text { and serves as means to } \\
\text { rationalize institution } \\
\text { building }\end{array}$ \\
\hline $\begin{array}{l}\text { Securitization/ } \\
\text { desecuritization }\end{array}$ & $\begin{array}{l}\text { - } \text { socially constructed } \\
\text { within a specific polity } \\
\text { (i.e. a community or } \\
\text { state) } \\
\text { - facilitates or reinforces } \\
\text { social hierarchies by } \\
\text { "justifying" national } \\
\text { mobilization and } \\
\text { referent objects viewed } \\
\text { as threats }\end{array}$ & $\begin{array}{l}\text { - largely Eurocentric } \\
\text { can support "realist", } \\
\text { agendas of the ASEAN } \\
\text { elite for marshalling } \\
\text { national resources and } \\
\text { pursuing key political } \\
\text { agendas }\end{array}$ \\
\hline Human security & $\begin{array}{l}\text { - safety from chronic } \\
\text { threats at the individual } \\
\text { and community levels of } \\
\text { interaction } \\
\text { - non-institutionalized } \\
\text { - targets against } \\
\text { unstructured violence } \\
\text { - multilateral policy } \\
\text { management }\end{array}$ & $\begin{array}{l}\text { - justifies and promotes } \\
\text { ASEAN epistemic } \\
\text { communities } \\
\text { - can supplement regional } \\
\text { institution building by } \\
\text { linking norms to } \\
\text { functional policy tasks } \\
\text { - tests and modifies } \\
\text { ASEAN identity through } \\
\text { changes in discourse and } \\
\text { norms }\end{array}$ \\
\hline
\end{tabular}

istics remain embedded as key security referents throughout most of the region, with recent events in Indonesia reinforcing the first concern and with China's rising power base and its aspirations directed towards the South China Sea underscoring the latter. Security dilemmas remain easily concocted within such a framework, either through suspicions that the tools of violence will be readily employed either by political rivals within a nation's own boundaries or by predator states outside of them.

All three security models (see table 10.1) that have been reviewed here have something to offer in terms of modifying this obsessively brutal outlook. Constructivism invites policy-makers and analysts alike to delve 
beneath perceived (or misperceived) interests and intentions of potential opponents. Southeast Asians are not predestined to be ethnically divided or to be geo-political enemies if they are able to fashion a regional security order, based as much on mutual social and cultural respect as on historical interests or values that may no longer be applicable. In the aftermath of Indochina's incorporation into ASEAN, that institution's relentless commitment to community building appears to offer a better formula for conflict prevention than any power-balancing formula currently available to the ASEAN states. The latter approach would only reinforce the Asia-wide security dilemma, which is in danger of intensifying between China and the United States, if those two countries' engagement postures fail to endure beyond the end of the Clinton and Jiang presidencies. The ultimate measure of constructivism's effectiveness in Southeast Asia, however, will hinge on how amenable both the United States and China are to reconstituting their own preferences for an ASEAN security environment. Ideally, this environment would be less influenced by great power prerogatives and more shaped by ASEAN's own agenda.

Greater understanding of how securitization might work in a Southeast Asian context could be the first step in modifying ASEAN relations with external actors. Like constructivism, securitization evolves around distinguishing "we-ness" from "other-ness". Unlike constructivists, however, those who embrace securitization may endorse divisions as a means to perpetuate power, distorting incentives for building collective identity and squandering opportunities to face structural change through coalition building. ASEAN would have been better served, for example, to desecuritize the Indonesian military's role in East Timor far sooner than it did, rather than adhering to its long-standing habit of viewing that entity as a guardian of "nation-building". East Timor was, above all, a problem of political socialization - securitization within a contested sovereign boundary, rather than a state security concern.

It is the human security model, however, that posits the most significant challenge to traditional security referents in Southeast Asia. Ultimately, security is about all of us and each of us, regardless of how we may choose to organize institutions or instruments at a given time to achieve it. This model supplants the collective human rights concept. For example, in the aftermath of Asia's financial crisis, the argument that individuals' sacrifices will lead to more prosperous and fulfilling lives for their descendants would appear to be tenuous, if not fully discredited. It is apparent that, in the ASEAN region and elsewhere, the human security model may represent an essential element in the next decade's security regime.

Efforts to transform these three models into actual policy need to be 
spearheaded at the state level, where most of the resources to do so remain invested. National governments can work within institutional frameworks to implement this process. Three key aspects of such institutional coordination are: 1) provision of early warning mechanisms for human security crises; 2) development of a continuing discourse on regional security, which incorporates constructivist, securitization, and human security implementation elements; and 3) linking of the principles of the three models to traditional, positive approaches to regional security, such as confidence building and preventive diplomacy.

\section{Human security: Early warning mechanisms}

Several human security crises in Southeast Asia in recent years could have been anticipated and addressed more effectively if viable early warning mechanisms had been in place and operative. Persistent haze over Indonesia, Malaysia, Brunei, and Singapore caused by fires in Indonesia tested ASEAN's Cooperation Plan on Transboundary Pollution (implemented in 1995) and found it wanting. ASEAN's "constructive engagement" approach towards Myanmar, adopted in conjunction with that country's entry into the grouping during 1996, has been largely discredited by the elite of that country continuing to observe a hard line against civil society interest groups in Myanmar and other ASEAN states. The 1997 economic crisis exposed the rampant "crony capitalism" evident in many ASEAN economies at the expense of savaging the economic welfare of the region's middle classes. The East Timor crisis has already been assessed here, exposing the principle of non-intervention in its traditional form as an impediment to ASEAN's international credibility. ${ }^{41}$

Any effort to redress the tendency for events flowing from rapid structural change to overwhelm the capacity of the elite or state mechanisms to cope with them (what is commonly labelled a "crisis of governance") must confront "the subjective, relational and normative dimensions of security relations and elucidate the polarizing implications of identity politics". ${ }^{42}$ Long-standing cultural and political practices, such as "saving face", "non-interference in sovereign affairs", and reinforcement of elite power structures, need to give way to greater encouragement of transparency in communication and making human and social considerations core elements of governance in both intra-state and interstate relations.

Achieving these broad objectives by utilizing effective early warning mechanisms will, of course, be no easy task. Yet a number of regional epistemic communities (groups of experts), capable of addressing key areas of human security to identify and shape broad approaches to the problem, already exist. ${ }^{43}$ Some of these are active within the Council for 
Security and Cooperation in the Asia-Pacific (CSCAP) framework. It provides Track Two, non-governmental panels and working groups, including representatives from academe, research institutes, and other leading centres for policy analysis, working on human security-related issues. Mechanisms for environmental monitoring, the control of transnational crime and narcotics traffic, water supply management, and food security have all been proposed by various CSCAP working groups and have been considered or implemented to some degree by ASEAN governments. ${ }^{44}$

Translating these proposals into full policy commitment with requisite funding, however, has proven to be challenging. The policy elite in ASEAN, the Asia-Pacific region, and internationally continue to assign priority to traditional, state-centric security approaches. They have coopted normative concerns, such as humanitarianism, into what Astri Suhrke has aptly labelled "a combined interest-and institutional" perspective or approach. ${ }^{45}$ Human security is often relegated to the realm of development politics, while traditional security retains a powerful centrality in the mindsets of those who rely on state-centric modes of governance for justifying and retaining their own power bases. Such concepts as "vulnerability", "unstructured violence", and "welfare goals" remain superseded by the quest to define and sustain "order" and "resilience", however fragmented or imperfect those latter concepts may be. This relates to the question of whose security is being pursued - i.e. the state as a concept or the collective body of individuals who inhabit our planet? ${ }^{46}$ Or, as one respected Southeast Asian analyst concluded following the ASEAN debate over flexible engagement, "there is no way of compelling a country to change its behaviour if it does not want to". Neither is there any viable enforcement mechanism for compelling any ASEAN (or other Asia-Pacific) state to change its behaviour if it threatens the collective good of the rest. ${ }^{47}$

Nevertheless, opportunities do exist for selected early warning measures to be implemented. Most significantly, existing collaborative mechanisms for environmental and resource management need to be employed more rigorously and in a more integrated fashion than at present to monitor and enhance cooperation in these sectors. The ASEAN Environmental Programme was established in 1978, for example, to promote sustainable economic development. Sixteen years later, the inaugural conference of the APEC environment ministers was convened. It adopted an environmental action programme three years later. Simultaneously, CSCAP has devoted substantial study to these issues. ${ }^{48}$ To date, however, there is little evidence of an ongoing and systematic effort to combine such initiatives in ways that would work effectively either at the state or regional level of policy management. 
The national elite in a number of Southeast Asian states are often hamstrung by the inadequacy of law enforcement or bureaucratic infrastructures in neutralizing those in either the criminal and commercial sectors who openly flout efforts to control their actions. ASEAN and ARF have not assumed primary responsibility for identifying and implementing "grand strategies" to alleviate region-wide environmental concerns, to combat Southeast Asia's growing narcotics problem or to confront its intensifying food and water resource crises. Non-governmental organizations and pressure groups are making limited inroads, however, in checking the power and influence of those who otherwise would continue to prey on the vulnerability of ASEAN populaces. More extensive dialogue and policy coordination between these groups and the ASEAN elite would appear to be an essential step in advancing human security in these policy sectors.

\section{Expanding discourse}

Yet, how to tailor regional security discussions so as to advance this dialogue? By the mid-1990s, an intra-ASEAN consensus had developed over the value of multilateral dialogues for broadening security perspectives and strengthening regional confidence building. ${ }^{49}$ At the turn of the century, this optimistic appraisal had been undermined by a widening divergence among Asian policy-makers and their populaces over the extent to which economic growth and political stability relate to the advance of human security and democratic practices. As previously noted, leaders, the various intellectual elite, and other advocates of Asian values in China, Malaysia, and elsewhere in East Asia reject any such linkage and have instead designated the "West", and particularly the United States, as an adversary to their own collective identities and aspirations.

The prevailing view in ASEAN and beyond is that security must remain state-centric. That view, however, begs the question of how the state should protect its sovereign subjects if the interests of the state elite emerge clearly at odds with those of its citizens. By exercising more care to ensure that knowledge is truly "shared", that freedom from basic deprivation and constant vulnerability is at the forefront in how "security" is defined, and that this concept is not defined arbitrarily or only for the sake of socio-political manipulation, ASEAN policy-makers may well be successful in winning genuine, long-term support from the societies they govern.

In this sense, greater progress is required in moulding national identity into collective or multilateral concepts that define and shape security agendas. At the state level (and as intimated previously), Singapore's 
leadership appears to have been most successful in reaching a compact of understanding about "broader security paradigms" with its electorate. The other ASEAN elite are considerably less advanced in prescribing how to confront such challenges, while simultaneously preserving whatever legitimacy they may have as agents for economic and human security for their constituents. Discourse that has recently evolved at the multilateral level of diplomacy, however, has been more promising. The July 1998 ARF Meeting in Manila was dominated by concerns about "the socio-economic impact of [proposed economic] reforms, particularly its effect on the less privileged sectors of society" as it could "impact on the peace and security of the region".${ }^{50}$ While there may not have been a conscious initiative among the ARF representatives to conceptualize security along alternative security lines, greater interest was clearly directed towards assessing the human implications of non-traditional threats arising from rapid structural and environmental change.

\section{Linking traditional and alternative security}

The realist/liberal legacy, predicating that international security relations are the product of how material capabilities are distributed in an anarchical world, remains embedded in the conceptual framework of most of the ASEAN policy elite. The best to which proponents of alternative security can aspire over the short term is that a workable modus vivendi can be derived to resolve some of the more urgent security problems now challenging Southeast Asia and the entire region.

One area of possible convergence is in the field of conflict prevention. Traditional security practitioners prescribe bargaining coercion, deterrence and power-balancing as time-honoured strategies to achieve some form of regional stability or order that will prevent war. Alternative security proponents attempt to discern and eradicate root causes of conflict, based on economic deprivation, social cleavages, and human suffering. The two approaches converge, however, in pointing to cooperative security (either through the pursuit of common interests or through the achievement of intersubjective understanding) as the preferred means for maintaining peace and stability. There appears to be a basis for at least a limited integration of means to achieve a common objective in this case.

A second linkage relates to the need to reduce the vulnerability of the security subject. ${ }^{51}$ The traditionalists are preoccupied with "order" as a security precondition to overcome anarchy and achieve prosperity and an enduring political identity. This "ideal" of stability or predictability is a transcending concept, as are the ideals of ensuring welfare and attaining greater, more enduring knowledge about ourselves and "others", which 
underscore the alternative security ethos. Again, the language may be different, but the policy ends - to improve the condition of the human race through the pursuit of and adherence to viable norms (based on collective interests or values) - are very similar indeed. The preferred outcome is an international security "community", whether it is based on hierarchy by assent or on reconciliation of different societies and the removal of differentiation. To a traditional security proponent, it matters little if power is invested in a state or in a higher authority, as long as it is wielded efficiently and in the interest of international stability. Alternative security analysts exercise an abiding faith that any structural hierarchy can eventually be transformed into human communities, capable of recognizing and managing a broad array of global threats (see table 10.2).

\section{Conclusion}

A decision for ASEAN governments to invest scarce resources and energy in institutional coordination of the achievement of alternative security goals is hardly routine. Yet, policy creativity and even policy risk can be justified if the payoffs for those they are designed to benefit appear to be reasonably high. ASEAN's current policy-makers might well consider the advantages of integrating traditional and alternative security paradigms to their region's long-term advantage.

The advocates of "standard" security approaches for the conduct of Asia-Pacific relations among states, whether realists or liberals, will not be dissuaded from their traditional approaches by the proponents of alternative security models. However, long-term state and ruling elite self-interests may be best served by the assimilation of elements of such models in their security outlooks. The examples cited in this chapter of the demonstrated adverse effects of a failure to so are enough to convince even the most dogmatic policy-makers of the need to carefully include at least some of alternative security premises into their realist/ liberal approaches to regional security.

The benefits of any such integration will come slowly, as is perhaps appropriate in societies transitioning from third world to developednation status. Any such payoffs will, in any case, be measured by how effective they are in facilitating more positive relationships among the ASEAN governments. The extent to which mutual interests and aspirations develop among the ASEAN elite and those who live and work under their collective tutelage is no less important, however, and will be even more decisive in shaping Southeast Asia's future stability and prosperity. 
Table 10.2 Traditional and "alternative" security: areas of comparison

\begin{tabular}{|c|c|c|c|}
\hline Forging linkages & Policy approaches & Examples of implementation & Relevant mechanisms/institutions \\
\hline \multirow{2}{*}{$\begin{array}{l}\text { strategic reassurance } \\
- \text { (alliance politics) } \\
- \text { (multi-lateral } \\
\text { dialogue and } \\
\text { negotiations) }\end{array}$} & $\begin{array}{l}\text { (Traditional security) } \\
\text { deterrence power } \\
\text { balancing }\end{array}$ & $\begin{array}{l}\text { (Traditional security) } \\
\text { sustaining military parity } \\
\text { forging state-centric alliances }\end{array}$ & $\begin{array}{l}\text { (Traditional security) } \\
\text { bilateral alliances }\end{array}$ \\
\hline & $\begin{array}{l}\text { (Alternative security) } \\
\text { cooperative security } \\
- \text { (confidence building) } \\
\text { - (preventive diplomacy) } \\
\text { collective identity }\end{array}$ & $\begin{array}{l}\text { (Alternative security) } \\
\text { ensuring food and resource } \\
\text { security } \\
\text { resolving territorial disputes } \\
\text { moderating in ethnic/religious } \\
\text { disputes }\end{array}$ & $\begin{array}{l}\text { (Alternative security) } \\
\text { ASEAN (and the ARF) } \\
\text { United Nations }\end{array}$ \\
\hline \multirow[t]{2}{*}{ Reducing vulnerability } & Policy approaches & Examples of implementation & Relevant mechanisms/institutions \\
\hline & $\begin{array}{l}\text { (Traditional security) } \\
\text { projecting state-centric } \\
\text { diplomacy } \\
\text { building military power } \\
\text { (Alternative security) } \\
\text { identifying common norms } \\
\text { and values knowledge } \\
\text { sharing }\end{array}$ & $\begin{array}{l}\text { (Traditional security) } \\
\text { forging a regional power } \\
\text { equilibrium } \\
\text { (Alternative security) } \\
\text { enhancing human welfare } \\
\text { realising a "security } \\
\text { community" }\end{array}$ & $\begin{array}{l}\text { (Traditional security) } \\
\text { summit diplomacy } \\
\text { military alliances and coalitions } \\
\text { (Alternative security) } \\
\text { epistemic communities } \\
\text { institutional diplomacy } \\
\text { development politics } \\
\text { human rights } \\
\text { covenants }\end{array}$ \\
\hline
\end{tabular}




\section{Notes}

1. For a general statement of this position, see John Mearsheimer (1994/5) "The False Promise of International Institutions", International Security 19(3): 5-49. For Southeast Asia-specific assessments adopting the same general line, consult Robin Lim (1998) "The ASEAN Regional Forum: Building on Sand", Contemporary Southeast Asia 20(2, August): 115-136, and John Garofano (1999) "Flexibility or Irrelevance: Ways Forward for the ARF", Contemporary Southeast Asia 21(1, April): 74-94.

2. Accounts of this perspective are provided by John Funston (1999) "Challenges Facing ASEAN in a More Complex Age", Contemporary Southeast Asia 21(2, August): 205219; Jeannie Henderson (1999) Reassessing ASEAN, Adelphi Paper 328, London: Oxford University Press for the International Institute for Strategic Studies; and Greg Sheridan (1999) “ASEAN: An Image Problem", Southeast Asian Affairs 1998 Singapore: Institute of Southeast Asian Studies, pp. 38-44.

3. A sceptical account of the "ASEAN way's" endurance as an organizational norm is offered by Tobias Ingo Nischalke (2000) "Insights from ASEAN's Foreign Policy Cooperation: The 'ASEAN Way', a Real Spirit or a Phantom?", Contemporary Southeast Asia 22(1, April): 89-112.

4. This point is discussed cogently by Khong Yuen Foong (1996) "Evolving Regional Security and Economic Institutions", Southeast Asian Affairs 1995, Singapore: Institute of Southeast Asian Studies, pp. 50-51.

5. See, for example, John Lewis Gaddis (1992/3) "International Relations Theory and the End of the Cold War", International Security 17(2, Winter): 5-58.

6. David Halloway (1988/9) "Gorbachev's New Thinking", Foreign Affairs 68(1, Winter): 66-81, and Charles E. Ziegler (1993) Foreign Policy and East Asia: Learning and Adaptation in the Gorbachev Era, Melbourne: Cambridge University Press.

7. Representative works include Emanuel Adler (1997) "Imagined (Security) Communities: Cognitive Regions in International Relations", Millennium Journal of International Studies 26(2): 249-278; Emanuel Adler (1997) "Seizing the Middle Ground: Constructivism in World Politics", European Journal of International Relations 3(3): 319-363; David Dessler (1989) "What's At Stake in the Agent-Structure Debate?" International Organization 43(3, Summer): 441-474; Ted Hopf (1998) "The Promise of Constructivism in International Relations Theory", International Security 23(1, Summer): 171-200; Friedrich Kratochwil (1989) Rules, Norms and Decisions: On the Conditions of Legal and Practical Reasoning in International Relations and Domestic Affairs, Cambridge: Cambridge University Press; Alexander Wendt (1992) "Anarchy is What States Make of It", International Organization 46(2, Spring): 391-425 and Alexander Wendt (1999) Social Theory of international Politics, Cambridge: Cambridge University Press.

8. Amitav Acharya (1998) "Collective Identity and Conflict Management in SoutheastAsia", in Emanuel Adler and Michael Barnett, eds., Security Communities, Cambridge: Cambridge University Press, pp. 200-201.

9. Ibid. pp. 209, 218-219.

10. This argument is developed by Nikolas Busse (1999) "Constructivism and Southeast Asian Security", The Pacific Review 12(1): 39-60.

11. Jürgen Haacke (1999) "The Concept of Flexible Engagement and the Practice of Enhanced Interaction: Intramural Challenges to the 'ASEAN way'", The Pacific Review 12(4): 603-604.

12. Nischalke, passim.

13. Hari Singh (1997) "Vietnam and ASEAN: The Politics of Accommodation", Australian Journal of International Affairs 51(2, July): 220. 
14. Michael Leifer (1999) "The ASEAN Peace Process: A Category Mistake", The Pacific Review 12(1): 27-28.

15. Oran Young (1991) "Political Leadership and Regime Formation: On the Development of Institutions in International Society", International Organization 45(3, Summer): 281-308. For an application to the ARF, see William Tow and Richard Gray (1995) "Asia-Pacific Security Regimes: Conditions and Constraints", Australian Journal of Political Science 30(3, November): 436-451.

16. The major contributors included Barry Buzan, Jaap de Wilde, Morten Kelstrup, Pierre Lemaitre, and Ole Waever. Key works include Buzan's (1991) People, States and Fear: An Agenda for International Security Studies in the Post-Cold War Era, second edn., Hemel Hempstead: Harvester Wheatsheaf; Ole Waever, Pierre Lemaitre, and Elzbieta Tromer, eds. (1990) European Polyphony: Perspectives beyond East-West Confrontation, London: Pinter; and Ole Waever, Barry Buzan, Morten Kelstrup, and Pierre Lemaitre (1993) Identity, Migration and the New Security Agenda in Europe, London: Pinter.

17. Ole Waever, et al., eds., Identity, Migration and the New Security Agenda in Europe, p. 7. For a critical view of this conceptualization, see Bill McSweeney (1996) "Identity and Security: Buzan and the Copenhagen School", Review of International Studies 22(1, January): 81-93.

18. This concept is further developed by Melissa G. Curley (forthcoming) "Exploring Complex Security Realities: NGOs, Community and State Development Partnerships in Laos", to be published in Asian Perspectives, 2000. Author has rough draft copy on hand.

19. Ole Waever (1995) "Securitization and Desecuritization", in Ronnie D. Lipschutz, ed., On Security, New York: Columbia University Press, p. 55.

20. Ho Khai Long (2000) "Citizen Participation and Policy Making In Singapore", Asian Survey 40(3, May/June): 441.

21. Barry Buzan, Ole Waever, and Jaap de Wilde (1997) Security: A New Framework for Analysis, Boulder: Lynne Rienner, p. 21.

22. Waever, op. cit. p. 51.

23. Muthiah Alagappa (1998) "Rethinking Security: A Critical Review and Appraisal of the Debate", in M. Alagappa, ed., Asian Security Practice: Material and Ideational Influences, Stanford: Stanford University Press, pp. 30-31.

24. McSweeney, op. cit. p.90.

25. David Mutimer (1999) "Beyond Strategy: Critical Thinking and the New Security Studies", in Craig Snyder, ed., Contemporary Security and Strategy, Basingstoke and London: Macmillan, p. 90.

26. Extracts of the UNDP discussion on human security can be found in UNDP (1995) "Redefining Security: The Human Dimension", Current History 94(592, May): 229-236.

27. Michael Wesley (1999) "Human Security in Development and Crisis: How to Capture Human Security in Regional Institutional Arrangements?" The Asia-Australia Papers (2, September): 28.

28. Ibid. p. 27.

29. Lloyd Axworthy, "Human Security: Safety for People in a Changing World", reprinted at www.dfait.maeci.gc.ca/foreignp/HumanSecurity/secur-e.htm.

30. See Shinyasu Hoshino (1999) "How Can Human Security Be Placed on the Regional Collaborative Agenda?" Asia-Australia Papers (2, September): 43-44.

31. "A Perspective On Human Security: Chairman's Summary", Lysøen, Norway, 20 May 1999, reprinted at www.dfait.maeci.gc.ca/foreignp/HumanSecurity/lysøen-e.httm.

32. Axworthy, passim.

33. William T. Tow (2000) "Introduction", in William Tow, Ramesh Thakur, and In-Taek Hyun, Asia's Emerging Regional Order: Reconciling Traditional and Human Security, Tokyo: United Nations University Press, p. 3. 
34. Astri Suhrke (1999) "Human Security and the Interests of States: Reviving the OsloOttawa Axis", Security Dialogue 30(3, September): 274.

35. Barry Buzan, and Gerald Segal (1994) "Rethinking East Asian Security", Survival 36(2, Summer): 17.

36. George Maclean (2000) "Instituting and Projecting Human Security: A Canadian Perspective", Australian Journal of International Affairs 54(3, November): 270.

37. Jürgen Rüland (2000) "ASEAN and the Asian Crisis: Theoretical Implications and Practical Consequences for Southeast Asian Regionalism", The Pacific Review 13(3): 438.

38. Ibid. p. 439.

39. A text of the "ASEAN Vision 2020" statement is on the ASEAN web page at www. aseansec.org/summit/vision97.htm.

40. For analysis, see the National Institute for Defense Studies, Japan (2000) East Asian Strategic Review 2000, Tokyo: NDS), pp. 36-41. For an argument that "non-interference" remains a viable ASEAN principle in its original context, see Robin Ramcharan (2000) "ASEAN and Non-Interference: A Principle Maintained", Contemporary Southeast Asia 22(1, April): 60-88.

41. A good synopsis of these general trends is by Daljit Singh (2000) "Southeast Asia in 1999: A False Dawn?" Southeast Asian Affairs 2000, Singapore: Institute of Southeast Asian Studies, pp. 3-25.

42. Joseph A. Camilleri (2000) "The Security Dilemma Revisited: Implications for the Asia-Pacific", in William Tow, Ramesh Thakur, and In-Taek Hyun, eds. Asia's Emerging Regional Order: Reconciling Traditional and Human Security, Tokyo: United Nations University Press, p. 315.

43. See especially Sung-Han Kim (2000) "Human Security and Regional Cooperation: Preparing for the Twenty-First Century", in William Tow, Ramesh Thakur, and In-Taek Hyun, eds., Asia's Emerging Regional Order: Reconciling Traditional and Human Security, Tokyo: United Nations University Press, pp. 295-299.

44. For a recent and excellent overview of CSCAP activities and reports, see Desmond Ball (2000) The Council for Security Cooperation In The Asia Pacific, Canberra Papers on Strategy and Defence No. 139, Canberra: Strategic and Defence Studies Centre, Research School of Asian and Pacific Studies, The Australian National University. An assessment of how such Track Two activities can be incorporated to pursue human security more directly is offered by Toshiya Hoshino (2000) "Pursuing 'Informal' Human Security: A 'Track II' Status Report”, in William Tow, Ramesh Thakur, and In-Taek Hyun, eds., eds., Asia's Emerging Regional Order: Reconciling Traditional and Human Security, Tokyo: United Nations University Press, pp. 267-288.

45. Suhrke, p. 268.

46. A point raised by Camilleri, p. 317.

47. Singh, p. 7.

48. Alan Dupont (1998) The Environment and Security in Pacific Asia, Adelphi Paper 319, London: The International Institute for Strategic Studies, p. 78.

49. Andrew Mack, and Pauline Kerr (1995) "The Evolving Security Discourse in the AsiaPacific", Washington Quarterly 18(1): 123-140. Also see Graeme Cheeseman (1999) "Asian-Pacific Security Discourse in the Wake of the Asian Economic Crisis", The Pacific Review 12(3): 334.

50. Chairman's Statement at the Fifth Meeting of the ASEAN Regional Forum, 27 July 1998. Reprinted at www.dfat.gov.au/arf/arf5.html. Also see Cheeseman, p. 345.

51. William Tow and Russell Trood (2000) "Linkages Between Traditional and Human Security”, in William Tow, Ramesh Thakur, and In-Taek Hyun, eds., Asia's Emerging Regional Order: Reconciling Traditional and Human Security, Tokyo: United Nations University Press, p. 22. 
11

Seeking non-traditional security in "traditional" ways: Northeast Asia and emerging security challenges

\author{
Richard W. Hu
}

The discussion on non-traditional security issues is getting momentum among policy-makers as well as academics in recent years. This new phenomenon appears in a context where the significance of military power in international relations is on decline after the Cold War. National threat perceptions are changing. The impacts of globalization, accompanied by democratization, regionalization, and fragmentation are increasingly transforming security concerns and the ways to conceptualize security issues. Security is no longer a one-dimensioned issue focused on military defence of states. Instead, states must consider a much wider set of security challenges, such as drug trafficking, terrorism, organized crime, environment degradation, civil and ethnic conflict, poverty, and resources scarcity. The connotation of security becomes broadened and inclusive. As one scholar puts it, there is a horizontal extension of security policy parameters to include a larger set of security problems as well as a vertical extension of the traditional referent object of security policy to above and below the level of nation-state. ${ }^{1}$

Nevertheless, the security referent shift and security threat "widening" raise some interesting questions: How should nation-states address nontraditional security issues in their national strategies in the contemporary era? Have states changed their strategies to address non-traditional security issues? Have states begun to deal with non-traditional security issues in "non-traditional" ways or still in "traditional" ways? Expanding the focus of security has both advantages and disadvantages. The good 
news is that governments have become more attentive to issues about which they used to have less concern. However, we need to note that none of the non-traditional security issues raised so far are purely "new" issues. Rather, they are old issues that have existed for a long time, but they are "new" because of who and what are increasingly considered to be "security threats". As the relative importance of non-military security increases in national strategy, we have to ask a more fundamental question: Is security policy still part of public policy or has public policy become a part of security policy? The default line on what is a security issue becomes very blurred when we try to draw an artificial line between traditional and non-traditional security.

However, this chapter is not about how we should define security. Rather, it concerns how Northeast Asian states conceive and address non-traditional security issues in their national strategies. In this chapter, I attempt to advance the following three arguments: first, compared with Southeast Asia and developing countries in general, Northeast Asian states still view security problems more "traditionally" than Southeast Asia and other developing countries. While Northeast Asian leaders have increasingly appreciated the importance of non-traditional security issues in national strategy, they tend to approach non-traditional security issues in more "traditional" ways. While Southeast Asia and other developing countries began to be concerned about economic security and human security issues, Northeast Asia is still preoccupied with national security and international security. Second, related to the first observation, the external environment has a strong shaping effect on Northeast Asia's security conception and threat perception. Given the political and traditional security problems in the region, ranging from territorial disputes and military rivalry to the divided nation problems, multilateral cooperation on non-traditional security issues has proven to be just as difficult as that on traditional security issues. Without stable political relations, cooperation on non-traditional security issues cannot be sustained and, sometimes, is vulnerable to the fluctuation in political relations. Northeast Asia, though a geographic referent, is far from a political and economic community. Third, the state is still considered the primary referent of security as well as the means to achieve security goals, including nontraditional security goals. This is because the state still plays the dominant role in society and people look to the state for solutions of security problems, traditional and non-traditional. Different from the state-society relations in other parts of the world, the Northeast Asian internal order exists in a hierarchically organized society, where the state is considered the solution to security problems. Therefore, the relative importance given to traditional and non-traditional security concerns must be considered from cultural and ideational perspectives. 


\section{The concept of security and non-traditional security challenge}

After the Cold War "security" became perhaps the most contested concept in international relations and foreign policy studies. The debate between the advocates for a limited definition of security and an expanded definition is largely centred on "security of whom" and "security of what". Realists believe the state is the primary actor in all aspects of social life, protecting and promoting liberty, prosperity, and life at home and defending rights of its people and sovereignty externally. At the opposite end of the spectrum, the state-centric view is challenged by a more diversified view of security. ${ }^{2}$ The process of globalization transcends political boundaries and makes perceptions of threat no longer centred on state and regime security. A more radical school of thought challenges the traditional conception of security. Under the name of "human security" it argues that security has been interpreted too narrowly: as security of territory from external aggression, or protecting national interests in foreign relations, or a global security of world war or nuclear devastation. Instead, it argues security is about people and individual human beings. Too often the needs of individual human beings are neglected and sacrificed in the name of "national interests". ${ }^{3}$

To illuminate the conceptual debate on security, Alaggapa produces an organizational map of security definition which is very useful for this discussion (see Alaggapa 1998, Appendix) The concept of security, according to him, can be viewed by four elements: (1) the referent object (security of whom); (2) the core values to be secured (security of what); (3) types of threat (nature of security); and (4) how security is achieved (security approaches). ${ }^{4}$ Looking at Alaggapa's map, we can find the default line between traditional and non-traditional line is getting blurred. The broadening of the focus of security helps to integrate development studies to security studies. The focus shift from state-centric to society focus, from external threat to domestic threat, from political and military problems to economic, environment, and even cultural concerns has changed the perception that the state is the only referent of security. Instead, it coexists with other referents of security at sub-national and international levels. When non-traditional security prevails in national agenda, the referents at the sub-national level may take priority over the state. National survival is an ultimate goal of the state, but challenges to political survival of the state could come from within the state.

Nevertheless, although the state is no longer the sole referent of security, it is still the most important and relevant referent of security. Human security cannot equate to national security, though it is the most fundamental security for a populace. Multiple and, sometimes, competing ob- 
jects of security, however, make it difficult to distinguish non-traditional security from traditional security. Considering security on different levels of analysis makes it further complicated. It is true that, if we multiply referents of security, the scope of security concerns gets broadened, making it go beyond national survival to encompass economic, environment, societal, and even cultural threats that can endanger core values. But the indiscriminate broadening may lose focus of national security strategy. As Baldwin argues, if security becomes too broad, it will lose the meaning of the label. For last forty years, designating something as a security issue has been synonymous with asserting its importance in national strategy. The term "national security" is not just another label, it is a powerful political symbol. ${ }^{5}$ As Edward Kolodziej observes, security studies now have gradually shifted from a theory of strategy to a theory of security and global governance. ${ }^{6}$

The non-traditional security challenge raises several interesting questions: (1) Has security become too broad? How can we distinguish it from other public policy issues? (2) Do we still have a subfield in IR called "security studies"? Does it overlap too much with other fields and disciplines? (3) More important, how would policy-makers respond to this challenge when they make national policy? How would they incorporate non-traditional security issues into national strategy?

\section{Security concept and security practice}

Security practice differs from state to state. In studying non-traditional security issues in East Asia, we must examine the relative importance given to non-traditional security issues in national strategy on a countryby-country basis. When comparing Northeast Asia with Southeast Asia, however, a general observation can be drawn from their security practices. That is, although both Northeast and Southeast Asian states have given more attention to non-traditional security issues in their national strategies, one can hardly miss the difference between Northeast and Southeast Asia in their security practices and the relative importance they give to non-traditional security issues on their national agendas. The difference is largely attributed not only to the balance of power at the international level or external environment, but also to the ways they conceptualize security. The security conceptualization or reconceptualization is closely linked to perceptions, strategic culture, state-society relation, and even cultural and ideational sources such as historical experiences, ideas, norms, and expectation, which help the state to interpret the security reality and shape the policy agenda.

How different are they? First, in Northeast Asian countries the state is 
still considered as the paramount referent of security. Although the salience of sub-national entities as security referents is increasing in both regions, the paramount nature of the state in Northeast Asia is still intact. Most Southeast Asian states are what Barry Buzan calls "weak states" that is, the role of the state in society is not the same as in Northeast Asia. Second, Southeast Asian nations are more concerned about domestic security and governance issues than their Northeast Asian counterparts. While socio-economic issues are poised as more important security threats in Southeast Asia, Northeast Asian countries are still preoccupied with external security issues. Third, in regard to security approaches, Northeast Asian states tend to address non-traditional security issues more in "traditional" ways (such as comprehensive national power, big power diplomacy, and the developmental state), while Southeast Asian states tend to assign more security implications to non-traditional security issues.

These observations may be rather general and perhaps even arbitrary. But the point is that they do approach non-traditional security issues differently because of their different external and social environments, the role of the state, nation-state-building process, and economic development.

\section{Security practice as social construction}

Security strategy is traditionally viewed in terms of the use, threat, or control of force in international relations. ${ }^{7}$ This narrowly focused thinking is based on political realism, which emphasizes the state as the primary referent and means of security, and national security as the fundamental goals of foreign policy. All system-level theories (such as neo-realism and neo-liberalism) see state security behaviour as a set of rational responses to the constraints and pressures created by international security. The end of security is taken as a given, and national interests are just "institutional scripts" of international order and a country's position in the international order.

Built on the constructivist challenge to international relations studies, we have to address the ideational source of the security strategy when we compare the security practices of Northeast Asia and Southeast Asia. From this perspective, security strategy and practice is viewed as a social constructive process, in which decision-makers and elite decide how to incorporate non-traditional security elements in the national security strategy and how to balance different objectives of security.

Constructivism, at the international level, views the structure of the international system as a network of shared norms, principles, knowledge, and state practice, as well as a structure based on the material dis- 
tribution of capabilities. Karl Deutsch's security community is best understood as a socially constructed mechanism that transforms security policies of states. State actors might see security as achievable through community and socialization rather than through power struggle. Security is thus something that can be constructed.

At the domestic level, constructivism explains security policy by drawing upon the power of culture, ideas, and identity. Culture could be broadly understood as enduring and widely shared beliefs, traditions, attitudes and symbols. Historical experiences (such as national humiliation or glory), values, belief, national identity, and strategic culture (historically rooted strategic preferences) are important components of cultural factors that affect security perception and practice. The underlying assumption is that cultural-institutional factors affect not only the incentives for national security practice, but also empower identity building. Identity is socially contingent, and so is national interest. National security interests, according to Katzenstain, are defined by actors who respond to cultural factors and other social determinants. ${ }^{8}$ That does not mean that power, which is conventionally understood as being material capability, is unimportant for national security. Instead, states are still primary actors and they define national interest in a social building process in which policy-makers and elite derive meanings out of the intersubjective and culturally established concept of "security". In this social constructive process, they understand the meaning of security, balance different objectives of security, and prioritize them in a national strategy. Too often the social constructs are missing in our security analysis, but they are important factors in explaining the differences between Northeast and Southeast Asia.

\section{Northeast Asian security practice}

Traditional Northeast Asian security is largely driven by ideological conflict (as in the Cold War), the balance of power among major states in the region, and historical territorial disputes. With the end of the Cold War, new apprehensions, rivalries, and tensions arose due to the uncertainties of the future and relative positions of major players in the region. The United States, as an intervening player in the region, still plays a pivotal role in regional security. But the rapid growth of China and the sluggish Japanese economy all contribute to long-term apprehensions in the region concerning whether China will substitute Washington as the dominant player there and whether a stable regional structure is obtainable based on a multiple balance of power of major states.

Northeast Asian states face similar non-traditional security challenges 
as in other parts of the world. These challenges include terrorism, illegal immigration, trafficking in arms and narcotics, the spread of infectious diseases, and cross-border environmental depredations. Many of these issues have gone beyond protection of a state's territorial integrity, political independence and sovereignty, and are traditionally public policy issues. Northeast Asian states, as with states in other parts of the world, have to grapple simultaneously with problems of external threats, internal social cohesion, regime capacity and vulnerability, economic development, structural adjustment, gender relations, ethnic identity, and transnational and global problems like AIDS, drug trafficking, terrorism, and environmental degradation.

However, Northeast Asian states tend to address non-traditional security issues differently from their Southeast Asian counterparts. They tend to deal with non-traditional security issues more in "traditional" ways. The state is considered and held as the primary referent of security and the means for maintaining security. In my view, there are at least three factors we can use to explain the different security practices: (1) security culture; (2) the state-society relations (or political institution); (3) national identity.

Security culture, as one scholar argues, is the enduring and widelyshared beliefs, traditions, attitudes, and symbols that collectively formulate a state's interests and values with respect to security, stability, and peace. ${ }^{9}$ In Northeast Asia the tradition of "Rich Nation, Strong Army" (Fuguo Qiangbing) is perhaps the most important belief policy-makers and elite have carried through over a long time. This belief has been reinforced by their experiences in modern history. In this cultural writ, the end and means of security are clear and so are the relations between them. In the state-society relation, the societal patterns of authority in Northeast Asia differ significantly from those in Southeast Asia and other parts of the world, including Western societies. The Northeast Asian internal order exists in a hierarchically organized society, where the state still plays the dominant role and people look to the state for solutions to security problems. The cultural influences have a large effect on how a state chooses to pursue its security. On non-traditional security issues, cultural factors inform policy-makers where to draw the line on the security agenda and how to formulate security strategy.

\section{Governance problem or security issue?}

Northeast Asia still treats security problems in narrow and traditional ways. Governments tend to treat non-traditional security issues more as governance problems. Policy-makers in Northeast Asia believe in a hier- 
archical order of security goals, with national survival and security from military threats as the highest order of the goal system. Although the importance of economic security and environmental security are rising, they still believe that a multidimensional approach to security may distract attention from the most important security needs of a nation. They agree that non-traditional security concerns are legitimate, but they argue that they should be items of public policy and addressed on economic and social development agendas, rather than in national security strategy. Broadening national security to incorporate non-traditional security issues could have the effect of de-emphasizing traditional security issues. Nontraditional security issues are better dealt with as governance problems, rather than "real" security issues.

\section{Conclusion}

Most of the non-traditional security issues discussed here are not "new" issues; they are old issues that have existed for long time. They are "new" because their importance is increasingly considered a "security threat". As the relative importance of non-military security increases in national strategy, we have to ask a more fundamental question: Is security policy still part of public policy or has public policy become a part of security policy? The default line on what is a security issue becomes very blurred when we try to draw an artificial line between traditional and non-traditional security. Northeast Asian states tend to address nontraditional security issues in more traditional ways. Compared with Southeast Asia, Northeast Asian states still view security problems more "traditionally". While Southeast Asia and other developing countries have begun to focus on economic security and human security issues, Northeast Asia is still preoccupied with national security and conventional international security. This security practice is largely attributed to the external environment and its shaping effect on Northeast Asia's security conception and threat perception, as well as cultural and societal factors such as state-society relations.

\section{Notes}

1. Paul B. Stares (1998) "Introduction", in Paul B. Stares, ed., The New Security Agenda: A Global Survey, Tokyo: Japan Centre for International Exchange, p. 15.

2. See, for example, Barry Buzan (1991) People, States and Fear, second edition, Boulder, Colorado: Lynne Rienner.

3. See United Nations Development Programme (1994) Human Development Report 1994, Oxford: Oxford University Press. 
4. Muhiah Alagappa, ed. (1998) Asian Security Practice, Stanford, CA: Stanford University Press, pp. 16-17.

5. David Baldwin (1995) "Security Studies and the End of the Cold War", World Politics 48(October): 139.

6. Ibid.

7. Stephen Walt (1991) “The Renaissance of Security Studies”, International Studies Quarterly 35(2): 212.

8. Peter J. Katzenstein, ed. (1996) "Introduction", The Culture of National Security, Columbia University Press, pp. 14-15.

9. Keith Krause (1999) "Cross-Cultural Dimensions of Multilateral Non-Proliferation and Arms Control Dialogues: An Overview", in his edited volume Culture and Security: Multilateralism, Arms Control and Security Building, London: Frank Cass, p. 15. 


\title{
Cooperation and institutional
} transformation in ASEAN: Insights from the AFTA project

\author{
Helen E.S. Nesadurai
}

\section{Introduction}

The Association of Southeast Asian Nations (ASEAN) is best known as a regional diplomatic community that works on the basis of a limited form of institutionalization, which stresses processes of socialization and consensus building and employs minimal rules. ${ }^{1}$ The ASEAN member states arguably prefer such institutional forms owing to their preoccupation with national sovereignty and domestic policy autonomy. ${ }^{2}$ Thus scholars and ASEAN watchers expect ASEAN institutions to remain weak and informal, with little prospect for a shift to rule-based or centralized institutional forms. ${ }^{3}$ Rule-based and centralized institutions would impose additional constraints on national behaviour that the individual ASEAN governments would not endorse or accept. ASEAN is thus a hard case for rule-based institution building.

This chapter challenges these views and shows that partial institution building involving rule-based institutional forms has taken place throughout the 1990s in ASEAN in the field of regional economic cooperation through the ASEAN Free Trade Area (AFTA) project. Why has this area of multilateral cooperation witnessed this form of institutional transformation, contrary to the prevailing wisdom about the prospects for such developments in ASEAN? The chapter suggests that the presence of politically and economically significant non-state constituencies, as well as distributional concerns between domestic social groups, will alter 
the dynamics of cooperation and could well make rule-based institution building necessary to advance cooperative processes. This is because institutions are as much about attempting to influence the behaviour of non-state actors, including business actors, as they are about influencing national governments to cooperate through the informational and distributional functions that institutions perform. ${ }^{4}$ Rules and procedures can play a significant role in this regard.

Non-state constituencies and distributional considerations that are common in economic issue areas are also prevalent in issue areas such as the environment and human security - the realm of non-traditional security concerns. This chapter's insights about economic cooperation and institution building in AFTA will, therefore, be able to shed new light on the prospects for institution building in non-traditional security issue areas because of these shared characteristics. This is not to argue that institution-building dynamics will be identical across the range of nontraditional security issue areas and with the field of economic cooperation. How these non-state constituencies matter to the issue area at hand and to national governments will ultimately determine the dynamics of cooperation and institution building. Nevertheless, the presence of these shared characteristics suggests that processes of cooperation and institution building in these issue areas are likely to share certain similarities.

Moreover, economic cooperation in ASEAN could itself be considered to be a non-traditional security issue. In the majority of the ASEAN states, domestic politics is best conceptualized as a system of elite governance, with political competition usually restricted to the elite and governance generally the function of "a narrow set of interlocking elite interests". 5 Elite governance is most usefully regarded as a project whose principal aim is to maintain elite power, autonomy, and exclusivity, with economic growth the means most often employed by the elite to maintain elite rule as well as the stability of the regime. ${ }^{6}$ This suggests that any disruptions or anticipated disruptions to economic growth could well be perceived as potentially threatening to elite rule and the stability of the domestic regime. ${ }^{7}$ As Mohamed Ayoob notes, security in developing states is best regarded in terms of both "external and internal vulnerabilities that threaten or have the potential to bring down or weaken state structures, both territorial and institutional, and governing regimes". ${ }^{8}$ Economic growth has long been a key instrument of elite governance and regime stability and security in the ASEAN states and thus fits Ayoob's conception of security.

The security dimension of economics has been clearly demonstrated in Indonesia since 1998, where political turmoil quickly followed financial and economic troubles as a result of the Asian financial crisis that began in mid-1997. Malaysia too has witnessed substantial elite cleavages as a 
result of the financial crisis, although an emergent mass challenge to the ruling elite has been contained. ${ }^{9}$ To the extent that economic cooperation is a crucial means of ensuring economic growth in the ASEAN states, then it is logical to regard it as a non-traditional security issue.

The main aim of this chapter is to examine whether and to what extent ASEAN economic cooperation in AFTA has been accompanied by an increase in the level of institutionalization, what form this has taken, and why. The analysis covers the period from AFTA's formal inception in 1992 to December 2000. It also focuses on the core ASEAN states of Brunei, Indonesia, Malaysia, the Philippines, Singapore, and Thailand. These states were responsible not only for initiating AFTA but also for being instrumental in determining the way AFTA evolved through the 1990s. Moreover, major disputes in AFTA over implementation were between two or more of these states.

The first part of this chapter provides a historical survey of ASEAN economic cooperation in AFTA between 1992 and December 2000. The next section develops the framework to analyse institutional forms, while the following section uses this framework of institutionalization to provide a more precise characterization of institutions and institutional transformation in AFTA. Based on this, the final section explains why institutional transformation has occurred in AFTA over the years.

\section{ASEAN cooperation in AFTA: A brief historical survey ${ }^{10}$}

The AFTA project can be divided into three stages (table 12.1). Stage one from 1991 through 1995 may be termed the initial consolidation stage. AFTA was officially launched in January 1992 at the Fourth ASEAN Summit in Singapore, and aimed to reduce tariffs on intra-ASEAN trade in manufactured goods and processed agricultural products to between 0 and 5 per cent within 15 years, starting from January 1993. Unprocessed agricultural products were not covered in the original agreement. The Common Effective Preferential Tariff (CEPT) became the primary mechanism to implement AFTA. Unfortunately, AFTA got off to a bad start as some member governments began rethinking their AFTA commitments as a result of domestic political changes and growing domestic business opposition to AFTA. ${ }^{11}$ Moreover, the staggered implementation plan, which allowed some states to delay the start of AFTA tariff cuts, led to tensions among members. Nevertheless, after serious negotiations, the ASEAN governments recommitted themselves to AFTA by the end of 1995, with certain improvements to the AFTA programme. ${ }^{12}$

First, the staggered implementation programme was replaced in favour of a common start-up date - 1 January $1994 .{ }^{13}$ Second, the time frame for 
Table 12.1 The three stages of the AFTA Project

\begin{tabular}{|c|c|}
\hline STAGE 1 & Free trade area by 2008 \\
\hline $\begin{array}{l}\text { Initial consolidation } \\
\text { stage (1991-1995) }\end{array}$ & $\begin{array}{l}\text { Tariffs on manufactured products targeted at } 0-5 \% \text {; } \\
\text { Excludes unprocessed agricultural products and } \\
\text { services; } \\
\text { Staggered implementation start-up date allowed; } \\
\text { Acceleration of AFTA by } 2003 \\
\text { 0-5\% tariff target; } \\
\text { Unprocessed agricultural products included; } \\
\text { Services and investment included; } \\
\text { Implementation date fixed at January 1994; } \\
\text { Includes programme for NTBs and trade facilitation; } \\
\text { DSM adopted }\end{array}$ \\
\hline $\begin{array}{l}\text { STAGE } 2 \\
\text { Initial expansion } \\
\quad \text { stage }(1996-1997)\end{array}$ & $\begin{array}{l}\text { First round of services negotiations launched in } 7 \text { priority } \\
\text { sectors, 1996-1998 } \\
\text { Package 1: Dec 1997; } \\
\text { Package 2: Dec 1998; } \\
\text { AICO scheme launched } \\
\text { Requires minimum } 30 \% \text { national equity; } \\
\text { AIA initiative } \\
\text { Initial consultations, 1996-1998 }\end{array}$ \\
\hline $\begin{array}{l}\text { STAGE } 3 \\
\text { Financial crisis and } \\
\text { post-crisis stage } \\
(1998-2000)\end{array}$ & $\begin{array}{l}\text { New flexible deadline of } 2002 \text { ( } 0-5 \% \text { tariff) } \\
\text { Formal deadline } 2003 \text {; } \\
\text { Protocol on sensitive and highly sensitive agricultural } \\
\text { products } \\
\text { Completion date - 2010; } \\
\text { Complete elimination of tariffs } \\
\text { By 2010/2015 for original/new members; } \\
\text { AIA Framework Agreement signed, October } 1998 \\
\text { Binding commitments; } \\
\text { Original deadline of } 2010 \text { for national treatment and } \\
\text { market access for ASEAN investors revised to } 2003 \text {. } \\
\text { Notification Procedures adopted } \\
\text { Second round of services negotiations } \\
\text { All other service sectors; } \\
\text { Negotiations over } 1999-2001 ; \\
\text { Short-term Investment Enhancement Measures* } \\
\text { ASEAN Surveillance Process* } \\
\text { Voluntary } \\
\text { Adopted Protocol on CEPT Delays }\end{array}$ \\
\hline
\end{tabular}

Note: * Not directly a part of the AFTA project. Nevertheless, they are part of the programme of ASEAN economic cooperation and should, therefore, be regarded as supplementary to the AFTA project.

AFTA's completion ${ }^{14}$ was shortened to ten years. Third, ASEAN member governments also agreed to commit unprocessed agricultural products, services, and investment to joint liberalization. Fourth, procedures 
governing the temporary exclusion of products from AFTA disciplines were tightened. Finally, an AFTA-Plus programme for trade facilitation and non-tariff barriers (NTB) was introduced.

Stage two, the initial expansion stage of AFTA, covers the years 1996 and 1997 and is the period when detailed negotiations on services and investment liberalization got underway. A Dispute Settlement Mechanism (DSM), also agreed to at the Fifth Summit in 1995, was formally adopted by ASEAN member states in November 1996.

Stage three, covering 1998 through 2000, represents the financial crisis and post-crisis period. This was a time when existing initiatives were consolidated and a number of new initiatives were undertaken in direct response to the crisis. ${ }^{15}$ Other programmes begun earlier under AFTA were also consolidated. At the Sixth Summit in Hanoi in 1998, the ASEAN leaders agreed to bring forward the date of completion of AFTA by a year to 2002 where possible, although the formal deadline remained 2003. A year later, economic ministers set 2015, subsequently revised to 2010, as the target date for the complete elimination of all tariffs when a zero tariff AFTA would be realized. ${ }^{16}$ In addition, ASEAN economic ministers also tightened the conditions for exempting agricultural products under AFTA. ${ }^{17}$

The ASEAN economic ministers also launched the ASEAN Investment Area (AIA) in October 1998. This agreement binds member governments to gradually eliminating investment barriers, liberalizing investment rules and policies, granting national treatment and allowing market access initially in the manufacturing sector and later in other sectors. ${ }^{18}$ The most significant aspect of the Agreement was the extension of national treatment and market access to all ASEAN investors by 2010, later revised to 2003, and to all other foreign investors by 2020 . Despite these advances, this period was also marked by a number of ASEAN countries attempting to delay on their AFTA commitments, arguing that domestic industries were already badly affected by the regional financial and economic crisis could suffer further if subject to the AFTA liberalization.

\section{AFTA: A new phase in ASEAN economic cooperation?}

Contrary to predictions of its failure, ${ }^{19}$ AFTA has not only persisted, it has also been accelerated and its scope widened. Although negotiations in the new areas have not been easy, especially over agriculture and services liberalization, what is significant is that the ASEAN member states actually committed these potentially contentious sectors to joint decision-making. Moreover, ASEAN's attempts to develop a regional regime for investment liberalization, market access, and national treat- 
ment goes beyond the Trade Related Investment Measures (TRIMs) agreement of the General Agreement on Tariffs and Trade (GATT).

Tariff liberalization on goods trade within AFTA is essentially on schedule. Since its relaunch in 1994 after a disastrous start, or non-start, member governments have each year lowered tariffs on a range of products under the CEPT framework, with these reductions gazetted in national annual legal customs enactments. On approximately 98 per cent of all tariff lines in the core, six ASEAN states are projected to reach the targeted $0-5$ per cent by $2002 / 3$. In the tariff reduction package for 2000 submitted by the core ASEAN states, a total of 89.7 per cent of the total 42,724 tariff lines are in the $0-5$ per cent band, 8.9 per cent of the total are above 5 per cent while 1.39 per cent are excluded. ${ }^{20}$ The final instalment of products in the temporary exclusion list was moved to the inclusion list at the start of 2000 and tariffs on these products brought down to 20 per cent, after which the rates will be reduced to $0-5$ per cent by 2002/ 3. Only automobiles in Malaysia and petrochemicals in the Philippines remain temporarily excluded from AFTA. ${ }^{21}$ The point is, despite the early setbacks and disputes over some agenda items, including the most recent case of automobiles, AFTA has advanced considerably since 1992, compared to both the first unsuccessful phase of ASEAN economic cooperation during the 1970s and 1980s and Asia Pacific Economic Cooperation (APEC).

One of the most important indicators of AFTA's significance is that foreign and domestic corporate executives acknowledge that they are now making investment and production decisions based on calculations involving a functioning AFTA market. ${ }^{22}$ This is noteworthy since, as will be shown below, AFTA has become a key tool of the ASEAN member governments to participate in global and regional production chains as well as to attract foreign investors to the ASEAN region. Nevertheless, the key question from the point of view of this chapter is whether economic cooperation in AFTA has been accompanied by simultaneous institution building.

\section{A framework to characterize institutions}

This section develops a simple framework to characterize institutions (table 12.2) based on four dimensions of institutionalization. Each dimension of institutionalization is presumed to vary in two ways, respectively reflecting low and high levels of institutionalization. If institutions ${ }^{23}$ are defined as sets of practices, rules and procedures that constrain activity, shape expectations and prescribe acceptable forms of behaviour, then by definition a higher level of institutionalization in- 
Table 12.2 Framework of institutionalization

\begin{tabular}{|c|c|c|}
\hline \multirow{2}{*}{$\begin{array}{l}\text { Dimensions of } \\
\text { institutionalization }\end{array}$} & \multicolumn{2}{|c|}{ Level of institutionalization } \\
\hline & Low & High \\
\hline \multicolumn{3}{|l|}{$\begin{array}{l}\text { Nature of constitutional } \\
\text { documents }\end{array}$} \\
\hline - Degree of formality & Informal; & Formal; \\
\hline $\begin{array}{l}\text { - Nature of } \\
\text { commitments }\end{array}$ & Non-binding; & $\begin{array}{l}\text { Binding; } \\
\text { Detailed agreement }\end{array}$ \\
\hline $\begin{array}{l}\text { Form of the } \\
\text { agreement }\end{array}$ & $\begin{array}{l}\text { Joint communiqué or } \\
\text { vaguely-worded } \\
\text { statement of intent. }\end{array}$ & \\
\hline \multicolumn{3}{|l|}{$\begin{array}{l}\text { Decision-making } \\
\text { procedures }\end{array}$} \\
\hline - Voting style & Consensus. & $\begin{array}{l}\text { Majority voting or partial } \\
\text { easing of consensus } \\
\text { requirements }\end{array}$ \\
\hline \multicolumn{3}{|l|}{ Modality of cooperation } \\
\hline - Substantive policy & Absent or ambiguous; & Present and transparent; \\
\hline targets (rules) & Nationally determined & Multilaterally/jointly \\
\hline - If present: & Absent or ambiguous. & determined. \\
\hline $\begin{array}{l}\text { - Procedural rules } \\
\text { Nature of coordination }\end{array}$ & & Present and transparent. \\
\hline - Decision-making & Ad-hoc or crisis-driven. & $\begin{array}{l}\text { Regularized and/or } \\
\text { centralized. }\end{array}$ \\
\hline - Monitoring & $\begin{array}{l}\text { Decentralized/Inter- } \\
\text { governmental. }\end{array}$ & Third-party/centralized. \\
\hline - Enforcement & $\begin{array}{l}\text { Decentralized/Inter- } \\
\text { governmental. }\end{array}$ & $\begin{array}{l}\text { Third-party/centralized } \\
\text { with delegated powers. }\end{array}$ \\
\hline
\end{tabular}

volves stronger constraints on, as well as more explicit prescriptions for, national behaviour.

The chapter does not, however, posit any causal relationship or direct correlation between the level of institutionalization and cooperative outcomes. The empirical record so far with regard to other cooperative projects is too mixed to allow any firm conclusions to be drawn. ${ }^{24}$ The chapter is merely interested in whether there has been a shift from lower to higher levels of institutionalization in AFTA, particularly since this would represent a hard case for ASEAN.

\section{Nature of constitutional documents}

The nature of the constitutional documents that frame regional cooperation is presumed to shape its institutional form. ${ }^{25}$ Three aspects are relevant in this regard: the extent of formality of these documents, whether they are binding on signatories, and the form that such agreements take. 


\section{Degree of formality}

A formal agreement is defined as one that enjoys the state's most authoritative imprimatur, namely, ratification, while informal agreements do not. ${ }^{26}$ Institutions governed by informal agreements are presumed to reflect a lower level of institutional constraint on national governments compared to those based on formal agreements. This is simply because informal agreements can be more easily abandoned at lower cost than formal agreements, although this is not always the case. Charles Lipson cautions against presuming that formal, ratified treaties somehow legally bind states to their promises. ${ }^{27}$ In an anarchic world with no higher international authority, states must act for themselves in enforcing bargains made with other states. Imperfect information and incentives to defect apply to all kinds of international agreements, whether formal or informal.

Nevertheless, the language of "binding commitments" that is found in formal agreements are instances of diplomatic communication aimed at other signatories or third parties, revealing states' intentions, at least, to adhere to a particular commitment. ${ }^{28}$ Their effect is to raise the costs of non-compliance. These costs are incurred largely in terms of loss of reputational capital if parties are seen to be reneging on "binding" agreements to which they had committed, making future cooperation less likely as other governments become increasingly wary of engaging in cooperation with the recalcitrant partner. In the case of economic agreements designed to influence economic actors, reneging on formal agreements by governments also carries economic costs if economic actors decide not to engage in the economic activity the agreement was designed to promote due to the lack of credibility of the participating governments.

\section{Nature of commitments}

A higher level of institutionalization is associated with cooperative agreements that stipulate binding commitments over non-binding ones for reasons similar to those above. The constraints that binding commitments place on participating members are greater if adequate monitoring and enforcement mechanisms are also present.

\section{The form of agreements}

The form by which an agreement is expressed, whether as an elaborately written document, a joint communiqué, a verbal commitment, or even a tacit bargain, further helps to shape the institutional form of cooperation. For this paper, detailed agreements that are clear and transparent are presumed to represent a higher level of institutionalization than vaguely worded agreements or simple joint statements of intent. The former im- 
pose a larger constraint on signatories than the latter, since they specify more clearly promises about future national behaviour.

It is also important to remember that international agreements are frequently designed to be flexible, since governments, often uncertain about the distribution of future benefits under a particular agreement, are naturally reluctant to conclude long-term, inflexible agreements. ${ }^{29}$ For instance, international agreements, whether formal or informal, may be designed to be of limited duration in order to allow signatories to calculate their costs and benefits more confidently and to legitimately allow parties to reassess their commitment in the future. Agreements could also be devised in ways that allow signatories to partially withdraw without risk to reputations, a prime example being the GATT escape clauses that allow for post-agreement protection. ${ }^{30}$ While this chapter accepts flexibility as an important attribute of institutions, flexible agreements in which caveats or escape clauses are well-defined and clearly expressed, including the conditions under which they can be invoked, are presumed to reflect a higher level of institutionalization.

\section{Decision-making procedures}

Decision rules within institutions can affect the constraints that an institution imposes on its members. ${ }^{31}$ Consensus decision-making allows the party least inclined to accept constraints on its behaviour to veto other parties that are willing to accept more stringent constraints. Mechanisms such as majority voting, easing consensus requirements for particular decisions, delegating responsibilities to technical experts, setting clear time limits for particular procedures, especially in dispute settlement, and establishing a clear organizational core to which some collective responsibilities could be devolved enhance institutional control on members' behaviour. ${ }^{32}$ Such forms of decision-making are assumed to reflect a higher level of institutionalization, while consensus decision-making in this chapter is associated with weaker constraints on national behaviour.

\section{Modality of cooperation}

Coordination within an institution can follow substantive or procedural rules, with Miles Kahler distinguishing between substantive and procedural institutions. ${ }^{33}$ The former feature explicit and detailed rules on substantive policy targets, such as maintaining a fixed exchange rate, an ending tariff rate, the date by which a particular tariff rate has to be reached, or a precise timetable for tariff reductions. Procedural institutions feature a set of procedural rules that are used to suggest a course of action under certain specified conditions. 
At one level, the presence of explicit or detailed rules and injunctions or substantive policy targets is assumed to reflect a higher level of institutionalization since the degree of constraint imposed on members will be higher in such instances. At a second level, institutions in which substantive policy targets or rules are jointly determined rather than decided unilaterally by each member are presumed to represent a higher level of institutionalization. When national governments are allowed to determine substantive policy targets unilaterally, they are not obliged to consider joint gains for the system as a whole. Jointly determined rules or substantive policy targets are expected to impose a higher degree of constraint on members relative to unilaterally determined targets since it is assumed that the former will consider the needs of the system as a whole. ${ }^{34}$ Nevertheless, the presence of consensus decision-making qualifies this argument since a party unwilling to accept a higher degree of constraint on its behaviour would be able to determine the agenda for all members.

As for procedural institutions, this chapter considers the presence of procedural rules as reflecting a higher degree of institutionalization since such rules compel members to adopt a course of action in the event of disruption or potential disruption to cooperation. Thus procedural rules may trigger either dispute settlement processes or at least an obligation for members to consult with one another on problems that arise in the course of cooperation. In such instances, institutional members must, at the very least, jointly consider or debate any departures from the cooperative agreement to which individual states have committed.

\section{Nature of coordination}

This chapter focuses on three aspects of institutional coordination: decision-making, monitoring, and enforcement. These three aspects of coordination can vary along the centralized/decentralized continuum, reflecting higher and lower levels of institutionalization, respectively.

Stronger institutions are defined as those that display regularized and centralized decision-making in which decisions on collaboration are made jointly rather than on an ad-hoc basis or only when crises strike. The assumption is that regularized decision-making meetings raise the chances for cooperative outcomes over purely ad-hoc forums since the former raise the shadow of the future. ${ }^{35}$ Decentralized or inter-governmental monitoring and enforcement are assumed to reflect weaker institutions compared to third party or centralized arrangements provided with delegated or independent powers. The former raises the possibility that institutional constraints on behaviour may be negotiated downwards through inter-governmental compromises. Third party arrangements, such as panels of technical experts, rarely allow for the downward renegotiation of in- 
stitutional commitments. Instead, such panels usually uphold institutions by providing rulings on whether institutional commitments have been breached and often also specify the countervailing actions that need to be taken in the event of such breaches. The effect of such panels on behavioural outcomes depends, however, on the way panel results are treated within the institution.

\section{Institutional transformation in AFTA: 1992-2000}

Using the framework outlined in the previous section, this chapter turns to characterizing institutions in AFTA and to the question of whether institution building has taken place.

\section{Nature of the constitutional documents}

Apart from the initial agreements made among the ASEAN governments in 1992 that launched AFTA and the Summit Declarations of 1995 and 1998, all other agreements signed between the ASEAN member governments are formal and binding, requiring domestic ratification by national legislatures (table 12.3). ${ }^{36}$ Table 12.3 shows a progressive increase in the level of institutionalization in ASEAN/AFTA when focusing on the nature of the constitutional documents underpinning AFTA.

The initial AFTA agreements of 1992, the Framework Agreement and the CEPT agreement containing ten articles provided only general guidelines on tariff reduction schedules, with few specific details. The CEPT agreement as it was originally designed allowed enormous flexibility in tariff liberalization. Senior officials subsequently worked out implementation details during the course of 1992. These were detailed in three documents, the Operational Procedures for CEPT, Rules of Origin for CEPT, and Interpretative Notes to the Agreement on the CEPT Scheme for AFTA. ${ }^{37}$ Moreover, protocols on procedural matters were also adopted, notably on dispute settlement in 1996, on notification procedures in 1998, and on modification of CEPT concessions in 2000.

The point to note is that after 1995 , the constitutional documents pertaining to AFTA became formal and binding on signatories, while the level of detail provided also increased. It is clear that there has been a progressive institutionalization of AFTA since 1992 as far as the nature of the constitutional documents is concerned. While vaguely worded initial statements of intent in the form of Framework Agreements were initially adopted, these were followed by negotiations to firm up commitments and obligations of participants.

Contrary to popular perception, this approach to AFTA - cynically dubbed Agree First Talk After - is not unique. It is an approach com- 
Table 12.3 Nature of the constitutional documents

\begin{tabular}{|c|c|c|c|}
\hline Agreements (signed) ${ }^{a}$ & $\begin{array}{l}\text { Degree of } \\
\text { formality }^{b}\end{array}$ & $\begin{array}{l}\text { Type of } \\
\text { commitments }^{c}\end{array}$ & Form of agreement ${ }^{d}$ \\
\hline Singapore Declaration (28-1-92) & Informal & Not applicable & Statement of Intent \\
\hline Bangkok Declaration (15-12-95) & Informal & Not applicable & Statement of Intent \\
\hline Hanoi Declaration (16-12-98) & Informal & Not applicable & Statement of Intent \\
\hline $\begin{array}{l}\text { Framework Agreement on Enhancing Economic Cooperation } \\
(28-1-92)\end{array}$ & Informal & $\begin{array}{l}\text { Not clearly } \\
\text { stated }\end{array}$ & Vague; few specifics \\
\hline $\begin{array}{l}\text { Protocol to Amend the Framework Agreement on Enhancing } \\
\text { ASEAN Economic Cooperation (15-12-95) }\end{array}$ & Formal & Binding & $\begin{array}{l}\text { Completion period set at } 10 \text { years; Allows } \\
\text { accession of new members }\end{array}$ \\
\hline Protocol to Amend the CEPT Scheme for AFTA (15-12-95) & Formal & Binding & More details provided than original agreement \\
\hline $\begin{array}{l}\text { Protocol Regarding the Implementation of the CEPT Scheme } \\
\text { Temporary Exclusion List (23-11-2000) }\end{array}$ & Formal & Binding & $\begin{array}{l}\text { Detailed procedures provided on modification } \\
\text { of CEPT concessions }\end{array}$ \\
\hline Protocol on Dispute Settlement Mechanism (DSM) (26-11-96) & Formal & Binding & Detailed procedures provided \\
\hline Protocol on Notification Procedures (8-10-98) & Formal & Binding & Detailed procedures provided \\
\hline $\begin{array}{l}\text { Protocol on the Special Arrangement for Sensitive and Highly } \\
\text { Sensitive Products (30-9-99) }\end{array}$ & Formal & Binding & Substantive targets and procedures outlined \\
\hline ASEAN Framework Agreement on Services (FAS) (15-12-95) & Formal & Binding & Statement of Intent \\
\hline $\begin{array}{l}\text { Protocol to Implement the Initial Package of Commitments } \\
\text { under ASEAN FAS (15-12-97) }\end{array}$ & Formal & Binding & Commitment details provided in annexes \\
\hline $\begin{array}{l}\text { Protocol to Implement the Second Package of Commitments } \\
\text { Under the ASEAN FAS (16-12-98) }\end{array}$ & Formal & Binding & Commitment details provided in annexes \\
\hline $\begin{array}{l}\text { Framework Agreement on the ASEAN Investment Area } \\
(8-10-98)\end{array}$ & Formal & Binding & $\begin{array}{l}\text { Statement of Intent, providing procedures for } \\
\text { future negotiations }\end{array}$ \\
\hline
\end{tabular}

a. Other agreements signed but excluded from this table are agreements on intellectual property rights, facilitation on goods in transit within ASEAN, industrial cooperation, customs harmonization, electronic commerce, and mutual recognition arrangements.

$b$. Ratification is required for formal agreements; informal agreements do not require ratification.

c. Whether binding or non-binding.

$d$. Whether detailed or vaguely worded/statement of intent. All agreements/protocols relating to AFTA and economic cooperation are available from the ASEAN Secretariat website at www.asean.or.id 
monly adopted in international agreements. As Christer Jonsson and Jonas Tallberg note, many international agreements are developed from general framework agreements that become increasingly specific protocols through a sequence of bargaining processes. ${ }^{38}$ For instance, in the case of the European Free Trade Area (EFTA), the initial Stockholm Convention establishing EFTA in 1960 was an open agreement whose details were filled in later, a striking parallel to AFTA. ${ }^{39}$ Global cooperation in services negotiated under the Uruguay Round of GATT initially took the form of a broad framework agreement signed in 1993, which outlined only generalized commitments to negotiate on services and lacked specific details. It was only subsequently that a series of detailed negotiations and hard bargaining in different services categories were conducted to try and obtain specific commitments and other details on global services liberalization. Similarly, the Montreal Protocol on Substances that Deplete the Ozone Layer was signed in 1987, following two years of negotiations to flesh out the initial framework agreement concluded in 1985, which set out the broad commitments to reduce emissions.

\section{Decision-making procedures}

Consensus decision-making operates in AFTA at all levels, resulting in a weakly institutionalized AFTA as far as this dimension is concerned. A simple majority voting procedure is, however, incorporated within the settlement procedure outlined in the Protocol on DSM. In the event that a panel is established by the Senior Economic Officials Meeting (SEOM) to examine a dispute, the SEOM is to make a ruling on the panel's report based on a simple majority vote. Thus far the DSM has yet to be invoked, with member governments preferring to engage in negotiations among themselves to resolve disputes.

\section{Modality of coordination}

ASEAN member governments have been engaged in the progressive tightening of rules and procedures in AFTA since 1992, but especially in the period after 1995. These rules and procedures cover a range of issues, including how to conduct future negotiations, schedules for tariff liberalization, modification of concessions already made, dispute settlement and notification procedures, emergency safeguards, and how to treat exemptions. Substantive policy targets and procedural rules were made more transparent, while new rules and procedures were introduced where previously none existed. While flexibility continues to be a feature, the conditions governing flexibility were made more transparent and stringent. Clearly AFTA has undergone a gradual process of institutionalization through rule building since its inception. 


\section{Strengthening rules and procedures: General CEPT implementation}

Although some policy targets were initially indicated in AFTA for the liberalization of goods trade, these were not clearly specified, with individual member states able to determine their respective rates of reduction within the end tariff rates and the 15-year time period stipulated in the original CEPT agreement. Annual tariff reduction schedules were thus nationally rather than jointly determined. The starting date for tariff reductions could be later than 1 January 1993 provided the target dates were reached on schedule. Moreover, no clear procedures governed the treatment of exclusions.

In 1994/5, ASEAN member governments undertook to introduce and/ or tighten rules and procedures for the CEPT. First, the target date for AFTA was set at 2003. Second, rules and procedures governing the temporary exclusion list were tightened and stipulated that member governments would have to transfer on an annual basis 20 per cent of the items in the temporary list to the CEPT inclusion list between 1996 and 2000. Where previously the temporary exclusion list was only to be reviewed in 2000 , the amendments meant that the list would effectively cease to exist in 2000, when all products, except those in the General Exception List, ${ }^{40}$ would be subject to AFTA tariff liberalization. ${ }^{41}$

\section{Strengthening rules and procedures: Unprocessed agricultural products}

The ASEAN member governments also undertook to formally tighten rules and procedures for the temporary exclusion of unprocessed agricultural products by signing a protocol on sensitive and highly sensitive agricultural products in September $1999 .{ }^{42}$ The protocol stipulates that the original six ASEAN members are to begin phasing agricultural products on their sensitive lists into the CEPT scheme between January 2001 and January 2003. The deadline is 2010 when tariffs on these products have to be at the $0-5$ per cent level. Highly sensitive products are to be phased in between January 2001 and January 2005, but to be completed by January 2010 although the end tariff rates could remain at a maximum of 20 per cent. Indonesia, Malaysia, and the Philippines were the only countries to submit a list of highly sensitive products, essentially rice and rice-related products. They were allowed the flexibility to determine the final tariff rates for highly sensitive products although the protocol capped this at 20 per cent. ${ }^{43}$

\section{Establishing procedures for dispute settlement}

The 1992 CEPT agreement did not include any mechanism for dispute settlement, only specifying in Article 8 that member states should try to amicably settle any disputes arising from implementation of AFTA 
through consultations. In November 1996, ASEAN member states adopted a protocol on DSM. Comprised of 12 articles, this protocol specifies in some detail the procedures that member governments need to follow in the event of a dispute. Five stages in the dispute settlement process were detailed: consultation, elevation of dispute to the SEOM, appeal of SEOM ruling to the ASEAN Economic Ministers (AEM), implementation of decision of the SEOM or AEM, and compensation or suspension of concessions.

While the protocol encourages consultations between disputing parties to find an amicable solution as in the 1992 agreements, the protocol specifies in some detail the procedures under which consultations are to be carried out. The protocol also allows for the formation of a panel to hear disputes, specifying the duties and obligations of the panel, including the maximum period allowed for panel deliberations. The protocol also specifies how panel results are to be treated and the procedures for appeal.

Thus far the DSM has yet to be invoked, although a number of disputes have arisen in the course of AFTA. ASEAN member states have preferred to address these disputes, most notably in agriculture and most recently in automobiles, through diplomatic consultations and bargaining. Senior officials from Indonesia, Singapore, Thailand, and Malaysia interviewed between July and September 2000 reiterated that invoking the DSM could jeopardize political relationships in ASEAN, something that all member governments wished to avoid. Nevertheless, the DSM was established to make available at least a framework of procedures and rules in the event it became needed. Although the ASEAN preference for diplomatic consultations to resolve disputes seemingly reflects the ASEAN cultural preference for diplomacy over legalistic forms of cooperation, the cultural argument should not be exaggerated. Kahler notes that this preference exists in many international forums. ${ }^{44}$ Again, the European experience in EFTA is strikingly similar. Although a ministerial council had been established in EFTA to rule on disputes between member states, only very minor conflicts were brought to the council for resolution. Major disagreements between EFTA member states were settled bilaterally or multilaterally through consultation so as not to jeopardize the political relationships between these states. ${ }^{45}$

\section{Specifying notification procedures}

Prior to 1998 when a protocol on notification procedures was adopted, there were no specific procedures for notification. This protocol details member states' obligations if they intend taking any measures that may nullify or impair any benefit accruing to any other member state directly or indirectly under any ASEAN economic agreement. The protocol does 
not, however, apply to actions taken under the emergency or safeguard clauses in the CEPT agreement. Its adoption creates a more predictable and rule-based AFTA, as member states and economic actors can now be warned in advance of possible changes to AFTA concessions. Member governments decided to adopt such a procedure in response to concerns that some countries had occasionally modified or withdrawn their AFTA concessions without informing other members, thereby creating problems for firms in the aggrieved states who were unaware of the alteration. For instance, Indonesia raised its import tariffs on petrochemicals in 1996 from 5 per cent to 40 per cent without informing the ASEAN Secretariat as required under the CEPT agreement. ${ }^{46}$

\section{Introducing procedures for the modification of CEPT concessions}

The ASEAN economic ministers signed a protocol in November 2000 that provides rules and procedures to govern a more flexible implementation of the CEPT. The protocol enables member governments facing real economic difficulties to delay the transfer of a product from the temporary exclusion list to the inclusion list or to temporarily suspend concessions on products already transferred to the inclusion list. Modifications are, however, limited to the final tranche of temporary exclusion list products required to be moved to the inclusion list by 1 January 2000. The protocol also provides for compensatory adjustment from the offending party to other members on a most-favoured nation (MFN) basis. The ASEAN protocol is closely based on Article XXVIII (Modification of Schedule) of the GATT 1994. It was developed in response to Malaysia's request that it be allowed a two-year delay in shifting automobiles onto the inclusion list and subjecting them to CEPT tariff reductions.

\section{Nature of coordination}

Decision-making, monitoring and enforcement in AFTA remain decentralized, revealing ASEAN's preference for inter-governmental mechanisms as opposed to third party or centralized modes of coordination. This approach to cooperation is, however, not unique to ASEAN. ${ }^{47}$

Decision-making in AFTA occurs at three principal levels, the SEOM, the AEM, and the leaders' summits. Prior to 1995, leaders' summits were held infrequently, with only four held between 1967 when ASEAN was formed and 1992. In 1992 at the Singapore Summit, the leaders agreed to hold formal summit meetings every three years. At the Bangkok Summit in 1995, ASEAN leaders agreed to meet annually on an informal basis to help advance AFTA. Thus leaders now meet either formally or informally at least once each year. The AEM meets at least twice annually, once formally and the second time informally. Between July 1998 and 
June 1999, the AEM, in fact, met six times. The SEOM meets more frequently each year, with 11 such meetings held between July 1998 and June $1999 .{ }^{48}$ Both the formal and informal AEM as well as the various SEOMs involve serious negotiations, consultations, and ultimately decision-making on outstanding issues, including implementation issues. The process can be cumbersome and time-consuming, though, with difficult issues transferred to the higher-level meeting. Nevertheless, there clearly is a commitment to working through problems and outstanding issues in AFTA rather than deferring or avoiding them altogether, a charge often levelled at ASEAN.

Monitoring is also carried out in a decentralized manner, with firms and national governments providing the main source of information on problems in AFTA. Firms may notify the AFTA units located within each national government or the AFTA unit in the ASEAN Secretariat of any problems they may have experienced with regard to impediments to AFTA. Enforcement is also decentralized, with the SEOM or the AEM the final arbiters on disputes in AFTA.

Although coordination in AFTA is carried out in a decentralized manner, nevertheless the inter-governmental mechanisms for decisionmaking, monitoring, and enforcement are well institutionalized rather than being ad hoc or crisis driven. At the very least, they provide an institutionalized arena for negotiations and bargaining, which has helped to advance the AFTA process on many occasions. Their presence does not, however, guarantee that the decisions that are made in these different forums will hasten implementation of AFTA. On a number of occasions, these institutionalized mechanisms have served as the arena in which compromises resulting in a lower level of compliance were worked out. Nevertheless, as all ASEAN senior officials and scholars of ASEAN interviewed between July and September 2000 have pointed out, it is unlikely that AFTA could have advanced as far as it has done without these compromises. ${ }^{49}$

\section{Explaining institutional transformation in ASEAN/AFTA}

The previous section has shown that partial institution building has taken place in AFTA since 1995. While consensus decision-making and the decentralized nature of coordination limit the constraints imposed on member states, the tightening of existing rules and procedures, as well as the articulation of new rules and procedures to govern issues where none existed previously, has strengthened the institutional foundations of AFTA. These rules and procedures were articulated through fairly detailed, binding protocols that required domestic ratification. The AFTA 
process also includes clear agendas for negotiations as well as negotiated timetables. ${ }^{50}$ While flexibility continues to be a feature, the conditions governing flexibility were made more transparent and stringent. Although decision-making, monitoring, and enforcement remain decentralized, decision-making processes, in particular, have been regularized, particularly at the level of leaders' summits. The interesting question is, of course, why this has occurred. To understand this, this chapter draws on insights from the scholarly literature on institutions as well as on postagreement or compliance bargaining.

\section{Explaining how institutions work: Informational and distributional models}

Lisa Martin and Beth Simmons identify two models of how institutions work - informational and distributional - based on the two central problems in international cooperation: how to prevent cheating and how to resolve distributional conflict. ${ }^{51}$ Informational models stress the role of international institutions in providing information to help overcome the fear of cheating that is regarded as the primary impediment to collaboration. Institutions facilitate cooperation by undertaking to provide information, thus improving the transparency of state actions. This facilitates the negotiation of cooperative agreements, the monitoring of agreements made, and allows compliance (or non-compliance) to be more easily observed. Distributional models, on the other hand, address the problem of the unequal distribution of gains and losses that impedes cooperation, particularly by trading benefits and costs between participants.

\section{Incorporating process: Compliance bargaining}

While these models are instructive, they ignore process and what happens in the event of non-compliance. The literature on post-agreement or compliance bargaining provides useful insights in this regard. ${ }^{52}$ Postagreement or compliance bargaining between states refers to all those bargaining and negotiation processes that follow from the conclusion of international agreements, a trend that is quite common in international negotiations. ${ }^{53}$ This perspective suggests that compliance problems need to be analysed within a bargaining framework in which bargaining strategies are adopted by both the "guardians" and "violators" of agreements. This is particularly true for self-help situations in which a third party enforcer or prosecutor is absent, a situation that characterizes ASEAN.

What kind of bargaining strategies are likely to be adopted during the 
course of compliance bargaining? Here, the compliance-bargaining approach draws on international relations literature that treats compliance as a management rather than an enforcement problem. In such instances, compliance-bargaining strategies adopted by treaty guardians may include persuasion in addition to or instead of threats to impose sanctions or mobilize social and political pressure. The violator's main bargaining strategy may also consist of persuasion, apart from promises of rewards in return for tolerance of deviant behaviour or threats of retaliation. The management school does not regard non-compliance as a deliberate decision by states to violate an agreement. Instead, it regards non-compliance as the outcome of ambiguities in the agreement, the limited technical capacity of states to comply with the agreement, or unexpected social, economic, or political developments that make compliance difficult to achieve. ${ }^{54}$ The use of built-in sanctioning or punishment measures in agreements (the enforcement approach) is rejected in favour of managerial solutions. ${ }^{55}$

Mutual consultation and analysis, technical and financial assistance, enhanced transparency, improved dispute resolution, and other procedural rules are the primary mechanisms employed to deal with non-compliance problems in the managerial approach. ${ }^{56}$ Institutional transformation occurs as a result of these processes. The essence of the management school is persuasion, or "jawboning" - the effort to persuade the violator to alter its behaviour. In such instances, the search for mutually acceptable solutions might entail compromises that do not fully conform to the original agreement. This will be especially true when partners in the agreement lack the means of forcing violators into compliance, as in the case of ASEAN where the members are fairly evenly matched in terms of power. In such instances, partners may decide to accept a lower level of compliance rather than risk the cooperative agreement in total. ${ }^{57}$ Thus a lower level of compliance is more likely in self-help situations involving managerial solutions among a group of fairly evenly matched states. ${ }^{58}$

\section{Institution building in AFTA as a process phenomenon}

This framework demonstrates clearly that institution building in AFTA is a process phenomenon. It is the outcome of compliance bargaining involving the managerial as opposed to the sanctioning approach. Institutions emerged out of the process of implementing AFTA; they were not created ex ante when the agreement to form AFTA was initially made. When problems emerged among the ASEAN states on particular AFTA agenda items, especially with regard to implementation or agreement ambiguities, a process of negotiation and bargaining between these states was set in motion. The presence of regularized inter-governmental 
mechanisms for decision-making - such as the meetings of senior officials, ministers, and leaders - facilitated this process by providing an institutionalized arena where negotiations could take place. While persuasion was the principle means employed to resolve problems, threats of retaliation have also been used by one or another ASEAN member state, in a clear departure from the "ASEAN way" of inter-state relations. ${ }^{59}$

For instance, Indonesia in early 1995 backtracked on its earlier decision to commit 15 unprocessed agricultural products to liberalization by 2003. The product groups withdrawn by Indonesia included rice, sugar, garlic, cloves, and wheat. Rice has always been a politically sensitive crop, given that Indonesia has a large rice-farming rural community. Sugar production was dominated by inefficient state-owned enterprises that were, nevertheless, politically important, while the import and sale of cloves, garlic, and wheat were governed by monopolies involving state trading enterprises and conglomerates of President Suharto's family or business/political allies. ${ }^{60}$ These explain the Indonesian government's refusal to budge from its position.

After intense discussion, a compromise was finally reached a year later that allowed Indonesia to continue to protect the 15 items but only until 2010, rather than indefinitely as Indonesia had originally wanted. Moreover, rules were drawn up to tighten the conditions under which agricultural products could be temporarily exempted from AFTA in the form of a Protocol on the Special Arrangement for Sensitive and Highly Sensitive Products, which was finally signed by all member states in 1999. The placing of unprocessed agricultural products into the new temporary exclusion list was also limited to products controlled by state trading enterprises, and thus designed to be consistent with GATT/WTO rules on state trading enterprises. This episode is clearly an instance of compliance bargaining, in which both persuasion and threats were employed by the disputants. In the end, a compromise was reached, which represented a lower level of compliance over the original commitment. Member states, nevertheless, tightened up loopholes and introduced rules and procedures to govern the treatment of agricultural products. It may, however, prove difficult for the ASEAN member governments to make Indonesia meet the new 2010 deadline, or to prevent any other ASEAN state from reneging as well.

A more recent and essentially similar event relates to the dispute over liberalization of the automobile sector. In early 1999, Malaysia requested that it be allowed to delay until 2005 the transfer of automobiles from the temporary exclusion list to the inclusion list, citing the problems experienced by Malaysia's national car project as a result of the 1997/8 financial crisis. The national car project, part of the Malaysian prime minister's heavy industries programme that had been initiated in the early 1980s, 
was aimed at creating an indigenous technological and industrial capability in the country. Malaysia's move led to tensions with Thailand, poised to be the regional hub for foreign/global automobile producers who had plans to produce and export to the rest of ASEAN from Thailand if a free trade area in automobiles were in place. ${ }^{61}$ This episode also involved threats of retaliation between Thailand and Malaysia, as well as offers of rewards and persuasions.

While Malaysia has been granted the delay, a protocol was introduced based on GATT Article XXVIII on the modification of concessions to govern the delay process. The protocol includes an annual review process and clear guidelines on its scope, as well as procedures governing compensation and retaliation by aggrieved parties. Malaysia itself was said to have been keen to develop a rule-based framework to govern the review of concessions. ${ }^{62}$ Nevertheless, ASEAN officials are sufficiently realistic to acknowledge that they have very little means to prevent any further delays by Malaysia in liberalizing the automobile sector under AFTA, even though the protocol aims to raise the cost of doing so through rule building. ${ }^{63}$ Although member governments have little rule-enforcement powers apart from diplomacy, they are clearly attempting to limit requests for delays from members through the protocol by making the process of modifying concessions sufficiently restrictive and costly to members.

These two episodes illustrate the process nature of institution building in AFTA. Institution building has essentially involved increasing transparency and predictability of cooperation through strengthening substantive policy targets as well as procedures. While flexibility continues to be a feature of economic cooperation, rules and procedures are used to inject a higher degree of certainty into AFTA. The outcome of compliance bargaining between the evenly matched core ASEAN states has, however, resulted in compromises that are based on a lower level of compliance than that associated with the original commitments. What is significant, however, is that the outcome of compliance bargaining has involved imposing additional constraints on national governments through institution building. The ASEAN states appear more willing to be bound by institutions than in the past. The question is, why? To answer this, the role that AFTA plays in the calculations of national governments in the core ASEAN states needs to be examined.

While the initial decision to establish AFTA in 1992 was influenced by a variety of factors, including political ones, the evidence shows that the one sustaining motivating force behind AFTA's continuation, its acceleration, and its expansion is globalization. AFTA represents a means by which the ASEAN states can respond to the competitive pressures generated by globalization. ${ }^{64}$ AFTA is a means for the ASEAN states to 
maintain or augment their participation in global trade and production networks. Most significantly, AFTA is regarded as an instrument to attract international investment in an era of enhanced competition for internationally mobile capital through the strategy of the large market. ${ }^{65}$ Institution building in AFTA through tightening rules and procedures signals member states' commitment to AFTA to economic actors, such as firms and investors, who are vital to national economic growth, and through that for regime security and political legitimacy of the ruling elite. Although monitoring and enforcement remain decentralized, with consultations and amicable solutions preferred over sanctioning, including invoking the DSM, the strengthening of rules and procedures, nevertheless, raises the credibility of AFTA and of national governments' commitments to liberalization.

For instance, the protocol on modification of concessions helps to signal to global automobile corporations that Thailand remains an attractive investment site, despite the temporary protection of the Malaysian automobile market. Malaysia itself may be aided by the presence of a rulebased framework governing its delay of automobile liberalization if it signals to foreign investors Malaysia's continued commitment to AFTA. This informational component of AFTA institutions thus helps member governments to signal their commitments to AFTA, not only to each other, but also to economically important business actors. There is also a distributional component to these institutions since gains and losses have been traded between states when post-agreement bargaining resulted in a lower level of compliance than originally intended.

\section{Conclusion}

Using the framework of institutionalization developed in this chapter, it is evident that institution building has occurred through the years in AFTA, especially after 1995 through the articulation and tightening of rules and procedures, often through formal, detailed binding protocols. The aim was clearly to influence the behaviour of governments in AFTA, as well as to signal to economically important non-state actors, notably foreign investors, members' commitment in realizing AFTA. Nevertheless, some degree of domestic autonomy has been maintained by retaining consensus decision rules and decentralized decision-making, monitoring, and enforcement mechanisms.

Institution building in AFTA has essentially been undertaken to sustain and implement AFTA as a means of coping with globalization, a key external challenge for the ASEAN states. Through the processes of compliance bargaining, involving the managerial approach, and institu- 
tion building, the ASEAN member states have managed to resolve disputes between themselves over particular AFTA agenda items. Although a lower level of compliance has prevailed than the original commitments would have entailed, nevertheless intra-ASEAN tensions have been diffused. At the same time, rules and procedures in AFTA have been tightened to signal to governments and to economic actors, members' commitments to AFTA, thereby influencing the inflow of economic resources to the ASEAN/AFTA region.

A survey of 150 firms in the East Asian region conducted for the Economist Intelligence Unit in 1997 revealed that these firms regarded AFTA as the regional project most likely to be realized or implemented compared to APEC and East Asia Economic Caucus (EAEC). A significant proportion of those surveyed acknowledged that they had incorporated AFTA as a factor in their investment strategies. ${ }^{66}$ A survey conducted among regional business executives by the Far Eastern Economic Review revealed essentially similar results. ${ }^{67}$ Studies by Japan's Export-Import (EXIM) Bank, the Japan External Trade Organization (JETRO), and the Nomura Research Institute also revealed that an increasing number of firms, especially Japanese firms, were undertaking investment strategies and regional operations based on a potential AFTA market, especially in automobiles, automotive components, and electrical and electronic sectors. ${ }^{68} \mathrm{~A}$ wide range of multinationals, including Southeast Asian firms, in sectors, such as food and beverages, cosmetics, petrochemicals, automotive components, automobiles, jewellery, electrical items, textiles, and apparel, have developed regional production and investment strategies based on calculations involving AFTA. ${ }^{69}$

This suggests that the ASEAN member governments, despite the problems and setbacks experienced by AFTA in its initial years, have managed to convey their commitment to AFTA and thus of the AFTA project's viability to economic actors. Economic actors are beginning to incorporate AFTA into their business and production decisions, thereby influencing the flow of economic resources into the AFTA region, notwithstanding the fall in investment inflows due to the regional financial crisis. Although it is not possible to attribute these positive developments solely to rule-based institution building in AFTA, it is clear that business actors would not have factored AFTA into their corporate strategies if they had not been convinced of the project's credibility. Institution building in AFTA may well have played a significant role in this process.

The analysis suggests that national governments may be willing to accept a higher level of institutional constraints on their behaviour in AFTA if that means they are able to influence the behaviour of other members to realize AFTA jointly, as well as to influence non-state actors who are economically important. Nevertheless, it is important to recog- 
nize that, while these institutional arrangements perform a signalling and distributional function, they do not cause cooperation and compliance. Rather, it is the importance of AFTA in national responses to globalization that drives the regional commitment to AFTA. Institutions are, nevertheless, used in this process to alter the incentives (through raising costs) facing states to defect from AFTA when domestic political economy factors intervene. They are also put in place to convince economically important non-state actors to make business decisions based on a potential single AFTA market. It is this underlying dynamic that has driven the process of institution strengthening in AFTA.

\section{Notes}

1. Amitav Acharya (1999) "Realism, Institutionalism, and the Asian Economic Crisis", Contemporary Southeast Asia 21(1): 18-19.

2. On the primacy of sovereignty, see Jeannie Henderson (1999) "Reassessing ASEAN", Adelphi Paper No. 328, p. 42.

3. On the primacy of sovereignty, see Greg Sheridan (1998) "Where are Asia's Institutions?", Asian Wall Street Journal, 2 April.

4. Lisa Martin and Beth Simmons (1998) "Theories and Empirical Studies of International Institutions", International Organisation 52(4): 740-741.

5. Duncan McCargo (1998) "Elite Governance: Business, Bureaucrats and the Military", in Richard Maidment, David Goldblatt, and Jeremy Mitchell, eds., Governance in the Asia-Pacific, London: Routledge/Open University, p. 126.

6. William Case (1996) Elites and Regimes in Malaysia, Clayton, Australia: Monash Asia Institute, pp. 4-20.

7. "Regimes" in the context of this paper are best regarded as "basic patterns in the organization, exercise and transfer of state positions and power". Case, p. 4.

8. Mohammed Ayoob (1995) The Third World Security Predicament, Boulder: Lynn Rienner, p. 9.

9. Helen E.S. Nesadurai (2000) “In Defence of National Economic Autonomy? Malaysia's Response to the Financial Crisis", The Pacific Review 13( 1): 96-104.

10. This section draws heavily on the author's Ph.D. dissertation in which more details are available. Helen E.S. Nesadurai (forthcoming) The Political Economy of the ASEAN Free Trade Area, Coventry, UK: University of Warwick.

11. Richard Stubbs (2000) "Signing on to Liberalisation: AFTA and the Politics of Regional Economic Cooperation", The Pacific Review 13(2): 306-307. Also see The Asian Wall Street Journal (hereafter AWSJ), 15 April 1993.

12. ASEAN Secretariat (1995), AFTA Reader Volume III, Jakarta: ASEAN Secretariat.

13. Brunei would begin tariff cuts in July 1993 due to national administrative laws. See AWSJ, 6 October 1993.

14. Unless specifically mentioned, AFTA's completion is taken to mean the time when intra-ASEAN tariff rates reach the $0-5$ per cent level, and not when they are set to reach zero.

15. These are detailed in Nesadurai, The Political Economy of the ASEAN Free Trade Area.

16. Joint Press Statement, Thirteenth Meeting of the AFTA Council, 29 September 1999, Singapore. 
17. Joint Press Statement, Thirty-First ASEAN Economic Ministers Meeting, 30 September 1999, Singapore.

18. The second meeting of the ASEAN Investment Area (AIA) Council in September 1999 expanded the scope of the AIA Agreement to cover services incidental to manufacturing, agriculture, forestry, fisheries, and mining. See Joint Press Statement, Second Meeting of the AIA Council, 29 September 1999, Singapore.

19. Walter Mattli, for instance, suggests that AFTA is unlikely to succeed. Walter Mattli (1999) The Logic of Regional Integration: Europe and Beyond, Cambridge: Cambridge University Press, p. 169. Lesyek Buszynski raises the possibility that AFTA is more likely to result in weakening rather than strengthening ASEAN owing to the diverse economic interests of member countries. Lesyek Buszynski (1997) “ASEAN's New Challenges", Pacific Affairs 70( 2): 565-569.

20. Data from the ASEAN Secretariat.

21. Some unprocessed agricultural products that are governed by a different tariff reduction schedule remain protected.

22. See the Conclusion to this chapter.

23. Keohane defines international institutions as "persistent and connected sets of rules (formal and informal) that prescribe behavioural roles, constrain activity and shape expectations", Robert O. Keohane (1989) International Institutions and State Power: Essays in International Relations Theory, Boulder: Westview Press, p. 3.

24. Kahler stresses this point based on his study of a variety of international institutions. Miles Kahler (1995) International Institutions and the Political Economy of Integration, Washington, DC: Brookings Institute,

25. Joseph Grieco (1997) "Systemic Sources of Variation in Regional Institutionalisation", in Edward D. Mansfield and Helen V. Milner, eds., The Political Economy of Regionalism, New York: Columbia University Press, p. 165.

26. Charles Lipson (1991) "Why are Some International Agreements Informal?", International Organisation 45(4): 498.

27. Ibid., pp. 508-509.

28. Ibid., p. 508.

29. Ibid., pp. 518-519.

30. Kahler has, in fact, attributed the success of GATT to such flexibility. See Kahler, passim.

31. Kahler, passim.

32. Ibid.

33. Kahler, p. 4.

34. Tommaso Padoa-Schioppa (1985) "Rules and Institutions in the Management of MultiCounty Economies", in Loukas Tsoukalis, ed., The Political Economy of International Money, London: Royal Institute of International Affairs, pp. 266-268.

35. Miles Kahler (1988) "Organisation and Cooperation: International Institutions and Policy Coordination”, Journal of Public Policy 8: 388.

36. The Protocol Regarding the Implementation of the CEPT Scheme Temporary Exclusion List signed on 23 November 2000 does not explicitly mention ratification, although Article 12 stipulates that the protocol becomes effective on signing.

37. ASEAN Secretariat (1993) AFTA Reader: Volume I , Jakarta: ASEAN Secretariat, pp. $40-71$.

38. Christer Jonsson, and Jonas Tallberg (1998) "Compliance and Post-Agreement Bargaining”, European Journal of International Relations 4( 4): 372.

39. Victoria Curzon (1974) The Essentials of Economic Integration: Lessons of EFTA Experience, London: Macmillan, p. 45.

40. Products on the General Exception List are exempted from AFTA on the grounds that 
their unrestricted trade could endanger national security and public morals or lead to the loss of national historical treasures.

41. Joint Press Statement, Twenty-sixth ASEAN Economic Ministers Meeting, Thailand, 2223 September 1994.

42. These categories are distinct from those covering the original products targeted for AFTA, namely manufactured goods and processed agricultural products.

43. The Philippines, however, continues to demand the right to impose a 70 per cent tariff on these products.

44. Kahler, International Institutions, passim.

45. Curzon, pp. 51-55.

46. Bangkok Post, 11 July 1997.

47. Kahler, International Institutions, p. 121.

48. ASEAN Secretariat (1999) ASEAN Annual Report 1998-99, Jakarta: ASEAN Secretariat, p. 113.

49. Stubbs makes a similar point, although he argues that this was primarily the result of the norm or culture of the "ASEAN way". See Stubbs, p. 312. I prefer an interest-based rather than a cultural argument.

50. As Acharya notes, "formal agendas, structured meetings, and legalistic procedures are quite evident in ASEAN's approach to political and economic cooperation, particularly in the development of the ASEAN Free Trade Area". Amitav Acharya (1998) "Collective Identity and Conflict Management in Southeast Asia", in Emanuel Adler and Michael Barnett, eds., Security Communities, Cambridge: Cambridge University Press, p. 212.

51. Martin and Simmons, pp. 739-742.

52. Jonnson and Tallberg, passim.

53. Post-agreement bargaining is prevalent in international politics, including in the European Union, see Jonsson and Tallberg, pp. 387-397.

54. Abram Chayes, and Antonia Handler Chayes (1993) "On Compliance", International Organisation 47(2, Spring): 188. Also see Jonnson and Tallberg, pp. 382-383.

55. On the contrary, the enforcement school treats non-compliance as a deliberate decision by a member state to violate its commitments under the cooperative agreement. In this approach, cooperation is facilitated by the provision of effective enforcement and sanctioning mechanisms that deter potential violators. A study of 125 international treaties showed that sanctioning authority is rarely granted by treaty, rarely used when granted, and likely to be ineffective when used, see Abram Chayes and Antonia Handler Chayes (1995) The New Sovereignty: Compliance with International Regulatory Agreements, Cambridge: Harvard University Press, p. 32.

56. Jonnson and Tallberg, p. 375.

57. Chayes and Chayes, p. 184.

58. Jonnson and Tallberg, pp. 384-85.

59. The "ASEAN way" approach stresses discreteness and non-confrontational bargaining styles over the "adversarial posturing" that is seen to characterize "Western multilateral negotiations", Amitav Acharya (1997) "Ideas, Identity and Institution-Building: From the 'ASEAN Way' to the 'Asia-Pacific Way'?", The Pacific Review 10( 3): 329.

60. Interview with Dr. Hadi Soesastro, Executive Director of the Centre for Strategic and International Studies (CSIS), Jakarta, July 2000. See also Didik J. Rachbini (1999) "Growth and Private Enterprise", in Richard W. Baker, M. Hadi Susastro, J. Kristiadi, and Douglas E. Ramage, eds., Indonesia: The Challenge of Change, Singapore: Institute of Southeast Asian Studies, pp. 11-39.

61. See for instance, The Bangkok Post, 5 October 1998; The Nation, 14 February 1999; and AWSJ, 30 March 1999. 
62. Interviews with senior officials from the governments of Malaysia, Singapore, Thailand, and Indonesia, July-September 2000.

63. Interviews with government officials from Indonesia, Thailand, and Singapore.

64. The theoretical/conceptual relationship between globalization and regionalism is discussed in detail in Nesadurai, The Political Economy of the ASEAN Free Trade Area. The dissertation also presents detailed evidence to support this argument for AFTA.

65. Interviews conducted in Indonesia, Singapore, Thailand, and Malaysia and with officials from the ASEAN Secretariat confirm this point.

66. The Jakarta Post, 2 June 1997.

67. Far Eastern Economic Review, 7 August 1997, p. 39.

68. ASEAN Secretariat (1999) ASEAN Investment Report 1999, Jakarta: ASEAN Secretariat, p. 16.

69. From various issues of The Nation, The Bangkok Post, The Business Times (Singapore), and The New Straits Times (Malaysia). 


\title{
Non-traditional security cooperation in Northeast Asia
}

\author{
Tsuneo Akaha
}

\section{Introduction}

The changing balance of power in post-Cold War Asia has prompted debate on the future security architecture for the region. At issue is what regional security framework will serve best to contain or resolve existing conflicts in Asia, particularly the North-South Korean stalemate, nuclear and missile development in North Korea, the PRC-Taiwan conflict, and territorial disputes involving China, Japan, Korea, Russia, and Southeast Asian countries. Some analysts have explored the possibility and desirability of transferring European models of multilateral security and cooperation to this region, such as the Organization for Security and Cooperation in Europe (OSCE), but there are no such prospects in Northeast Asia at the beginning of the twenty-first century. ${ }^{1}$ Others have persuasively argued against uncritical applications of Western concepts and institutions of security and confidence-building measures that ignore the lasting historical legacies and dominant cultural norms in Asia. ${ }^{2}$ It is important to place security issues in the context of the history and culture of each country. ${ }^{3}$ Various forms of balance of power, great-power concert, and multilateral cooperation have been proposed as alternative approaches to managing rivalries and avoiding conflicts among the region's great powers in the post-Cold War period. However, no consensus has yet to emerge.

Further complicating the future of Northeast Asia is the fact that it is 
increasingly clear that traditional concepts of national and international security are woefully inadequate, misleading, or even counterproductive in addressing the myriad security issues facing this region. The shortcomings of the state-centric conception of national security have been acknowledged not only by observers of Northeast Asia but by those focused on other parts of the world as well. In response, the International Relations community has introduced such concepts as "non-traditional security", "alternative security", "cooperative security", and "comprehensive security". Traditional security issues are understood to be primarily of a military nature, with threats to the stability and legitimacy of the state and the regime considered the core concerns in discussion and policy. On the other hand, non-traditional security problems usually, but not always, relate to non-military threats and the protection of nonmilitary values. They include issues of economic security, environmental security, information security, development, public health, and poverty. They encompass issues of importance both to the state and to international institutions, transnational organizations, sub-national communities, as well as to the individual. ${ }^{4}$

Many analysts have proposed a more radical shift in the central focus of security discourse and policy development toward the individual and away from the state and interstate relations and introduced the concept of "human security". ${ }^{5}$ This concept is focused on questions of livelihoods and human development. ${ }^{6}$ It is true that "human security" marks a major departure, at least in the academic international relations (IR) and foreign policy communities, from the conventional preoccupation with state security institutions and focuses our attention on those problems that threaten the individual's well-being, be they physical, mental, or spiritual. It is also true that in many instances institutions and resources dedicated to the traditionally conceptualized national security problems may be seen as either real or potential threats to human security.

In this analysis, however, I will employ the concept of "non-traditional security" for three reasons. First, the distinction between traditional and non-traditional security is important in the context of contemporary Northeast Asia. There is a growing list of non-military security problems in this region that neither the state and its institutions nor the international community can ignore. Second, the state plays such a dominant role in both domestic and foreign affairs in this region - as both a source and target of security threats and as a means of combating those threats that many security problems can be more appropriately defined and addressed through the dichotomy between traditional and non-traditional security. Third, an exclusive focus on "human security" would ignore many non-traditional security issues that affect in important ways the interests of the state and its institutions, as well as their responses to those 
issues. We should be mindful, however, of the persuasive argument of the advocates of "human security" that we should not lose sight of those issues which tend to be overlooked or even ignored by the state and its institutions but which are real and threaten individual security. For these reasons, the term "non-traditional security" will be used to capture the range of issues encompassing both security issues of concern to the state but which have either been neglected by the state until recently or emerged more recently, as well as those issues of central importance to human security. As will be made clear in the present analysis, these issues include economic security, environmental security, societal security, and human security.

It is a fact that in this part of the world traditional and non-traditional security issues exist side by side, demanding equal attention from the policy-makers and analysts in all the countries of the region, both big and small. It is also true that the state controls the major portion of the institutions and resources that can be devoted to the combating of security threats of both traditional and non-traditional kinds. It is also important to recognize that both state and non-state actors in the region understand their security concerns in the context of their history, geography, and culture. One should not impose a uniform categorization of traditional and non-traditional security issues, therefore, on the analysis of each country's or each community's interests and perspectives regarding security. What may be an emerging security concern - therefore a "nontraditional" security issue - to some actors may be a problem that has been recognized and addressed by others as a security issue for quite some time. For example, the Japanese government and public embraced the concepts of "economic security", "energy security", "food security", and "comprehensive security" in the 1970s in the wake of the first "oil shock" of 1973-1974. ${ }^{7}$ For Japan, therefore, these are not necessarily "non-traditional" security issues but continuing problems. For most other Northeast Asian countries, however, these issues are more recent additions to their national security agenda, in the context of deepening economic interdependence in East Asia generally since the mid-1980s. ${ }^{8}$ Japan has also been the first country in this region to embrace "human security" as a legitimate concern of the nation's foreign policy.

The purpose of this chapter is twofold. First, I will offer an explanation of why multilateral cooperation has been limited in Northeast Asia. I will do so by briefly introducing some key factors that have informed the process of regional economic cooperation in other parts of the world, namely, in Western Europe, North America, Southeast Asia, and AsiaPacific. A comparative perspective helps us to identify the main characteristics of Northeast Asia as a region and how those features are likely to affect cooperation in non-traditional security fields in this region. Sec- 
ondly, on the basis of the understanding thus gained, I will be able to explore the prospects of multilateral regional cooperation in nontraditional security matters. I will introduce non-traditional security issues in Northeast Asia for which multilateral cooperation is desirable. This will be followed by a brief examination of the various multilateral cooperation schemes that have appeared in Northeast Asia since the 1990s. They include the Tumen River Area Development Programme, the Northeast Asia Economic Forum, and the Northeast Asia Cooperation Dialogue. I will also briefly look at two other multilateral cooperation efforts that are particularly relevant to Northeast Asia, namely, the Council for Security Cooperation in the Asia Pacific (CSCAP) and the ASEAN plus Three. I will conclude with an assessment of the prospects for multilateral regional cooperation in non-traditional security areas in the foreseeable future.

\section{Regional cooperation in other parts of the world}

The experience of the EU, NAFTA, APEC, and ASEAN suggests factors that inform the scope, level, and direction of multilateral regional cooperation. The key factors are: (1) the distribution of power within the given region, (2) the role of the state in domestic and international economic processes, (3) the role of the market in those processes, and (4) the perspectives of the participants in regional cooperation regarding multilateral cooperation. ${ }^{9}$ It is beyond the scope of this analysis to provide a detailed review of each case. Suffice it to point out the main characteristics of each regional experience in terms of these factors. ${ }^{10}$

Regional integration in Western Europe has been shaped by the combination of several factors. Enlightened political leadership has been essential, particularly regarding the Franco-German relationship in postwar Europe and the functionalist approach to regional integration, as exemplified by the establishment of the EURATOM, the European Coal and Steel Community (ECSC), and the European Economic Community (EEC). Second, the common civilizational background among the countries of the region facilitated their collective effort. Third, the region's leaders shared common national security concerns during the Cold War era and developed the North Atlantic Treaty Organization (NATO). Finally, the European leaders have found it difficult, but possible, to cooperate in developing a common strategy to deal with the dramatically altered political, security, and economic landscape in the wake of the collapse of the Soviet Union and the end of the Cold War. They have done so by enlarging the EU membership, adopting a common European currency, and expanding NATO eastward. These factors have con- 
tributed to the development of ingenious mechanisms of integration, the establishment of elaborate organizational structures, and the timely expansion of membership. As a result, the participants in European integration have successfully developed a "security community" in which no war is expected and there are no preparations for war between members.

In comparison, Northeast Asia has lacked enlightened political leadership that might see long-term mutual interests in regional cooperation to overcome the legacies of the past, particularly with respect to Japan and its relations with the neighbouring countries. The region does not represent a common civilizational space, particularly as Russia is geographically a part of the region and the United States has an important presence in the region.

In the case of NAFTA, the US hegemonic power has been essential for the emergence and evolution of the free trade project. The US economy is so much more productive than that of either Canada or Mexico that the US-led regional scheme offers substantial benefits to producers and consumers in the neighbouring countries as well as those in the United States. In contrast, there is no economic hegemony in Northeast Asia that is both willing and able to lead the other regional powers in forging a multilateral regional framework. Japan and China cooperate as much as they compete for regional leadership, politically and, more recently, economically as well.

The experience of APEC shows a slow, deliberate, and informal process of region-building. The so-called "APEC process" is attributable to the great diversity in the region, in the degree of economic development, social and political systems, and cultures. ${ }^{11}$ Asia-Pacific does not represent a common civilizational space. APEC does not purport to forge a common political identity. Nor is it anchored on any sense of common security. Modest expectations and pragmatic attitudes have guided the APEC process rather than an overarching ideology or strategic vision.

The evolution of ASEAN is similarly shaped by the diversity in Southeast Asia and guided by political pragmatism. The absence of a dominant regional power, the relatively weak states, the legacy of historical animosities within and between the countries of the region, and the cultural diversity of the countries have prevented the heavy institutionalization one sees in Europe or the fast-paced market integration one witnesses in North America. Equally important is the fact that the Southeast Asian economies are closely linked to major economies outside the region, particularly the Japanese and US economies. An important achievement of the ASEAN countries is the development of the ARF process. Although it has not been able to resolve important problems, such as the territorial and jurisdictional disputes in the South China Sea, the regional forum has facilitated security dialogue among the re- 
gion's leaders and between them and other major powers, including the United States, China, Japan, and Russia. North Korea has also joined the regional security forum.

\section{International relations of Northeast Asia}

Multilateral regional cooperation, in both traditional and non-traditional security fields, has been difficult to develop in Northeast Asia. This is largely attributable to the nature of international relations in the region. ${ }^{12}$ First, memories of history weigh heavily on the contemporary mutual perceptions among the region's powers, with animosity and suspicion more often the norm than a spirit of reconciliation and cooperation. Second, major power relations in the area are in flux, with their policies towards each other dominated by global and broader regional (Asia-Pacific) strategic considerations. This is particularly the case with respect to the strategic interaction among the United States, China, and Russia. Third, the regional power structure is complicated by the fact that the foundations of power of the region's countries and the source of their international influence are quite different, uneven, and shifting at different rates. Fourth, the power of the state continues to prevail over the influence of civil society institutions, with authoritarian tendencies restricting democratic yearnings and state intervention inhibiting the liberalizing and integrative effects of transnational economic exchanges and social interactions. Fifth, nationalism remains a powerful force and continues to hamper internationalist initiatives by non-governmental agents. A related characteristic of the region is that international cooperation is severely constrained by the presence of traditional issues of nationalism, including territorial disputes and conflicts over maritime jurisdiction. Sixth, the region represents a full range of political systems and societal structures, as well as wide disparities in economic development. ${ }^{13}$

Consequently, Northeast Asia remains a geographic referent, not a political unit, nor an integrated economic area. As such, the region lacks an institutional framework for multilateral cooperation, most efforts at policy coordination taking place through bilateral channels. Multilateral dialogue involving all the major powers of Northeast Asia has no historic precedent.

Moreover, as noted at the outset, traditional and non-traditional security issues exist side by side in Northeast Asia. The growing economic power of China has given rise to the spectre of the "China threat" in the United States and elsewhere. At the same time, however, there are growing signs of ethnic tension and social fissure resulting from the growing disparities in income and economic opportunities and the fast 
pace of social change accompanying economic reform. Moreover, internal and cross-border migration of hundreds of thousands, if not millions, of Chinese has become a major challenge to both Beijing and the capitals in the neighbouring countries, as well as to the affected local communities. The political and economic crises in post-Soviet Russia have caused precipitous economic decline and serious social dislocation in the Russian Far East, exposing its woefully inadequate social and environmental safety net. Even Japan, heralded in the 1980s as an economic superpower and model of economic development, has experienced a long and deep economic recession since the bursting of its economic bubble in 19891990, with no sign of sustainable recovery. At the same time, Japan's effort to upgrade its defence capabilities within the framework of its security alliance with the United States has invited Chinese charges of Japanese military resurgence. Even the United States - arguably the sole superpower in the post-Cold War world - has not yet developed a longterm strategic vision for the region, with the balance between political, security, and economic policy priorities shifting from time to time. Consequently, there is much uncertainty in US relations with its Cold-War adversaries - China and Russia - and its relationship with Japan is also coming under closer scrutiny in both those countries. The massive starvation problem in the economically crippled North Korea, with its possibility of implosion or explosion, demands the attention of the international community as much as does the nuclear and missile threat that Pyongyang poses. The Asian financial crisis of 1997-1998 caused serious damage to South Korea's economy, forcing its political and business leaders to swallow the bitter pills of administrative and economic reforms, affecting literally millions of workers and households. The leaders have not been able to focus exclusively on the resulting economic and social problems as they continue to face the possibility of armed conflagration on the Korean Peninsula. ${ }^{14}$ Mongolia continues to struggle with its domestic reforms after the demise of its Communist-controlled and Soviet-tied economy in the late-1980s.

As a result, it is extremely difficult to develop a regional framework for addressing all matters of security in the region, be they traditional or non-traditional issues, bilateral or multilateral, historical or of more recent origin.

\section{Shifting balance of power in Northeast Asia}

The balance of power in Northeast Asia is in a state of flux and there is no multilateral mechanism for managing its great power relations. Because Northeast Asia remains a region dominated by state-centric international relations, with limited transnational integration, the changing 
power of its major countries exerts important influences on the stability of the region. Russia's economic decline after the break-up of the Soviet Union, China's spectacular economic rise since the late 1970s, and Japan's sluggish performance since the bursting of its economic bubble in 1989-1990 present major challenges to the future stability of Northeast Asia. The presence of the United States in the region - through its economic involvement, bilateral alliances with Japan and South Korea, strategic interaction with China and Russia, and engagement with North Korea - is a stabilizing factor. ${ }^{15}$ On the other hand, the strong US presence also serves as a brake on multilateralism in Northeast Asia.

Various indicators show that Russia's power has declined precipitously since the demise of the Soviet Union. Its GDP experienced a real decline every year from 1990 to 1996 , the biggest drop (14.5 per cent) coming in 1992. ${ }^{16}$ In 1997, the economy experienced a real growth of 0.8 per cent, but in 1998 it declined again, by 4.6 per cent. Russia's population also declined from 148.54 million in 1990 to 146.33 million in 1998. Its economic decline is even more noticeable on a purchasing power parity (PPP) basis with its GDP per capita about one-fifth that of the Japanese. The GDP per capita of China, with a population nearly ten times that of Russia, is almost US $\$ 1,000$ lower than Russia's and about one-seventh that of Japan.

Russia is also facing serious international challenges. NATO's eastward expansion, the Kosovo crisis, the protracted war in Chechnya, and the rouble crisis of August 1998 have exposed Russia's inability to control developments affecting its national security. Russia has tried to forestall a further decline of its military might, but Putin's government has had to pare down its military in the face of the nation's serious economic woes. Russia's nominal defence spending in rouble terms has continued to increase since 1992, but the precipitous decline in the nation's currency and continuing high inflation have meant that there are less resources available to the military. Moscow's budget shortfalls have severely constrained allocation of funds to the Far Eastern forces, weakening the preparedness of all troops except the strategic nuclear force. Further reductions in Russia's Far Eastern forces are expected. ${ }^{17}$ The deteriorating force levels are attributable to the general economic decline, the reduced tension vis-à-vis the United States in the Pacific, and improved military relations with China. ${ }^{18}$

In contrast, China's national power has grown substantially and this growth is expected to continue. Since economic reforms began in the country in the late 1970s, China's economy has grown dramatically. Its real GDP growth rates ranged from 14.2 per cent in 1992 to 3.8 per cent in 1990, and its population growth ranged between 1.45 per cent in 1990 and 0.96 per cent in 1998. The nominal GDP of China far exceeds that of 
Russia, which in 1998 was a mere 7.3 per cent of Japan's, while its nominal GDP per capita was about 3 per cent of the Japanese; the Chinese nominal GDP per capita is currently about half that of the Russian figure. China's defence spending has grown by more than 10 per cent each year since 1989 - its leadership considers defence modernization and build-up should be in line with the nation's economic growth as a matter of policy, and Beijing regularly under-reports its defence expenditures. ${ }^{19}$ Moreover, China continues to view international relations from the traditional perspective of power, conflict, and threats, and relies on the development of military strength for national security. ${ }^{20}$

Japan's economy grew slowly from 1990 to 1997, with its nominal GDP growth rate ranging between 7.5 per cent in 1990 and 0.8 per cent in 1995. In 1998 the economy contracted by 2.5 per cent, ${ }^{21}$ and its longest post-war recession continues. The nation's population, which is a rapidly ageing one, grew slowly during the 1990s, from 123.54 million in 1990 to 126.49 million in 1998. Japan has increased its defence spending steadily over the recent decades and today its defence budget is the second largest in the world. However, the economic recession in the last decade has curtailed Tokyo's ability to boost its defence spending, which dropped by 0.2 per cent in 1998 , and was scaled down by a further 0.2 per cent in 1999. An economic turnaround is likely to reverse this trend, as Tokyo appears readier today than at any time in the post-war period to expand its international security role. ${ }^{22}$ Japan currently possesses some of the most sophisticated defence weapons in Asia. Following the adoption of the new guidelines for US-Japan defence cooperation in 1997, the Japanese parliament approved legislation to enable Tokyo to meet its expanded logistic obligations under the new arrangement with Washington. Its parliament is also reviewing its war-renouncing Article 9 - a prospect that was unthinkable only a few years ago. Public support for constitutional revision is growing. ${ }^{23}$

As will be seen in the next section, the importance of the United States to the region's economic development, political stability, and security environment cannot be over-emphasized. This was the case during the Cold War and continues to be the case today. The new Bush administration in Washington has stressed the importance of the US-Japan alliance for the region's stability; it has adopted a harder line against Beijing, particularly with respect to the PRC-Taiwan relations; and it has virtually ignored Russia as a security factor in the region. With the "strategic partnership" between Russia and China having no demonstrable effect on US policy in the region, the near-term security environment in Northeast Asia will be influenced predominantly by US policy towards Japan and China. Assuming stability in the US-Japan alliance, the only uncertain element in the uneven strategic quadrangle in the region is the relationship between the United States and China. 


\section{Uneven economic ties in the region}

The economic relations among the Northeast Asian countries are quite varied. Some regional economies are increasingly interdependent and intra-regional trade is becoming a very important part of their global trade. Equally significant, however, is that some economies are extensively integrated with economies outside the region, while other regional economies are fairly contained within it, with one economy - that of North Korea - virtually self-contained.

In 1996, the eight Northeast Asian economies, counting Hong Kong and Taiwan separately from China and excluding the United States, conducted well over US $\$ 733$ billion in trade within this region, or 20 per cent of their total trade. Their trade with the United States nearly matched that sum (see table 13.1).

The Asian currency/financial crisis of 1997-1998 demonstrated the importance of trade ties among the Northeast Asian economies and also highlighted the importance of the United States as a trading partner in the region's economies. As tables 13.1 and 13.2 show, in dollar terms, the total intra-regional trade fell from US\$733,710 million in 1996 to US $\$ 655,843$ million in 1998. In fact, during this period intra-regional trade shrunk for every regional economy except Taiwan. Excluding the United States, the proportion of the combined international trade of the eight regional economies that was conducted within the region declined from 20.8 per cent to 18.5 per cent. If we include trade with the United States, however, the Northeast Asian economies' trade increased from US $\$ 1,439,248$ million ( $40.8 \%$ of their global trade) to US $\$ 1,457,027$ million $(41.1 \%)$. This clearly demonstrates the importance of US markets for Northeast Asian traders. For China, trade with the United States was particularly important. While its trade with the other Northeast Asian economies dropped from US $\$ 192,711$ million to US\$152,116 million during this period, its trade with the United States grew as much as 42 per cent, from US $\$ 38,709$ million to US $\$ 54,998$ million. The impact of the Asian crisis on Japan's trade pattern was also significant: its trade with the other Northeast Asian economies declined from US\$180,769 million in 1996 to US\$149,216 million in 1998, but its trade with the United States grew from US $\$ 180,710$ million to US $\$ 187,235$ million. ${ }^{24}$

As the region's economies become increasingly interdependent, disparities in trade laws and practices, trade imbalances, and industrial restructuring and other domestic adjustments are likely to become major concerns that require policy coordination and cooperation on a multilateral basis. However, it is evident from the following tables that the importance of intra-regional trade to the Northeast Asian economies is quite uneven. For the major trading powers of the region. - i.e. China, Japan, and South Korea - trade with other regional economies is very impor- 
Table 13.1 Trade in Northeast Asia, 1996 (in US\$m.)

\begin{tabular}{lccccc}
\hline Trade with & $\begin{array}{l}\text { Northeast Asia } \\
\text { excluding US }\end{array}$ & $\begin{array}{l}\text { Northeast Asia } \\
\text { including US }\end{array}$ & $\begin{array}{l}\text { World total } \\
\text { US/World total (\%) }\end{array}$ & $\begin{array}{l}\text { Northeast Asia including } \\
\text { US/World total (\%) }\end{array}$ \\
\hline US & & 328,051 & $1,494,066$ & & 22.0 \\
China & 192,711 & 231,420 & 412,056 & 46.8 & 56.2 \\
Japan & 180,769 & 361,479 & 773,833 & 23.4 & 46.7 \\
Hong Kong & 167,210 & 219,535 & 229,583 & 34.8 & 95.6 \\
South Korea & 87,783 & 136,131 & 251,728 & 38.9 & 60.9 \\
Taiwan & 87,505 & 136,941 & 224,783 & 10.9 & 16.6 \\
Russia & 15,177 & 23,101 & 139,003 & 61.0 & 61.0 \\
North Korea & 1,960 & 1,961 & 3,215 & 65.5 & 69.2 \\
Mongolia & 595 & 629 & 909 & 20.8 & 40.8 \\
Total & 733,710 & $1,439,248$ & $3,529,176$ & \\
\hline
\end{tabular}

Source: Calculated from data in IMF (1998) Direction of Trade Statistics Yearbook, Washington, D.C.: International Monetary Fund. 
Table 13.2 Trade in Northeast Asia, 1998 (in US\$m.)

\begin{tabular}{lccccc}
\hline Trade with & $\begin{array}{l}\text { Northeast Asia } \\
\text { excluding US }\end{array}$ & $\begin{array}{l}\text { Northeast Asia } \\
\text { including US }\end{array}$ & $\begin{array}{l}\text { World total } \\
\text { US/World (\%) }\end{array}$ & $\begin{array}{l}\text { Northeast Asia including } \\
\text { US/World (\%) }\end{array}$ \\
\hline US & & 399,710 & $1,627,032$ & 47.0 & 24.6 \\
China & 152,116 & 207,114 & 323,894 & 22.3 & 64.0 \\
Japan & 149,216 & 336,451 & 668,411 & 54.8 & 50.3 \\
Hong Kong & 196,424 & 250,891 & 358,493 & 29.4 & 40.0 \\
South Korea & 66,274 & 109,684 & 225,595 & 39.1 & 64.3 \\
Taiwan & 81,240 & 133,740 & 207,908 & 6.9 & 13.5 \\
Russia & 9,190 & 17,990 & 133,092 & 46.2 & 46.4 \\
North Korea & 908 & 913 & 1,967 & 60.0 & 67.7 \\
Mongolia & 475 & 534 & 789 & 18.5 & 41.1 \\
Total & 655,843 & $1,457,027$ & $3,547,181$ & & \\
\hline
\end{tabular}

Source: Calculated from data in IMF (1999) Direction of Trade Statistics Yearbook, Washington, D.C.: International Monetary Fund. 
tant. In 1998, excluding the United States, China conducted 47 per cent of its trade in this region, Japan about 22 per cent, and South Korea almost 30 per cent. Hong Kong's trade within the region accounted for more than half of its global trade. For North Korea and Mongolia, the two smallest economies of the region, intra-regional trade accounted for 46.2 per cent and 60.0 per cent of their total trade, respectively. Russia was the least dependent on trade within the region, with less than 7 per cent of its global trade being conducted in Northeast Asia. If we include trade with the United States, Northeast Asia represents a much more important region for each country.

The economic importance of the United States clearly has political implications as well. To the extent that the domestic political stability of Northeast Asian countries depends on healthy economic growth, access to US markets remains very important. In addition, the United States holds the key to the place of Northeast Asian countries within the global trading system. Washington clearly recognizes its weight in the global trade regime. It played its WTO card vis-à-vis Beijing by linking China's human rights record to the normal trading status it accorded to China in 2000, paving the way for China's entry into the WTO. Likewise, access to US markets is very important to Japan. As the world's second largest economy, it conducts almost one-quarter of its international trade with the United States.

\section{Conflicting national perspectives on multilateral cooperation}

Multilateral cooperation in Northeast Asia is complicated further by the fact that the region's countries have different interests and perspectives on the issue.

Russia (and the Soviet Union before it) has been the most outspoken advocate of multilateral security cooperation in the region. However, Japan and other regional powers viewed with suspicion Moscow's repeated call for a regional security framework during the Cold War. Russia has so far failed to persuade the United States, China, and North and South Korea to enlarge the four-power talks over the Korean peace into a six-party framework to include Russia and Japan. Russia was left out of the KEDO process based on the 1994 US-DPRK Agreed Framework, and is clearly aware of its limited influence in regional affairs. While it is preoccupied with domestic economic and political reforms, it relies more on diplomacy than on military or economic foundations of power in pursuing its regional interests.

Russia has expressed interest in multilateral initiatives in Northeast Asia, including the Tumen River Area Development Programme (discussed below), but has been unable to follow through with the necessary 
material contributions. The downward spiral of its economy since the early 1990s through to the financial crisis in 1998 has had painful consequences for Far Eastern Russia. Dwindling federal subsidies, scarce capital investments, and shrinking defence contracts have crippled industrial and agricultural production in the region. There is little doubt, however, that industrial and commercial modernization in the Russian Far East will require expanded international trade and foreign investment. ${ }^{25}$

Moscow's new foreign policy doctrine highlights its desire to strengthen Russia's ties to the dynamic economies of Asia-Pacific. The doctrine states, "Asia enjoys a steadily growing importance in the context of the entire foreign policy of the Russian Federation, something which is due to Russia's direct affinity with this dynamically developing region and the need for an economic upturn in Siberia and the Far East". ${ }^{26}$ In the absence of any multilateral political or security framework in Northeast Asia, Russia is eager to improve bilateral ties in the region. Most important in this context are Moscow's relations with Beijing. Moscow and Beijing share the common objective of constraining the dominance of the United States in the region's strategic environment. Although there are limits to the "strategic partnership" between Russia and China, Moscow is determined to expand cooperation with Beijing for political, strategic, and economic purposes. ${ }^{27}$ Moscow is making similar efforts to improve its ties with Tokyo, but so far this bilateral relationship has received only secondary priority. Moreover, the irreconcilable territorial dispute with Japan constrains Russia's economic opportunities with that country. China's current foreign policy has four priorities. ${ }^{28}$ First, it seeks relationships that advance its domestic goal of rapid economic development. Second, China opposes what it views as US-centred unipolarism, although it wants to maintain economic ties with the United States to meet its developmental needs. Third, China stands firm on its territorial claims, most importantly with respect to Taiwan, but also over offshore territories claimed by its neighbouring countries. Fourth, China is seeking to develop a more even balance between bilateralism, which it has traditionally favoured, and multilateralism, which it finds increasingly beneficial to its strategic and economic interests.

The PRC leaders believe that the success of regional multilateral organizations will depend on healthy bilateral relations. Nationalism remains a powerful force behind Chinese foreign policy in this region and elsewhere. Since the reform policy began in the late 1970s and in the aftermath of the Cold War, the Chinese leadership has increasingly turned to nationalism as the glue to hold the nation together while, at the same time, pursuing a pragmatic approach to the expansion of international economic ties. Territorial disputes, human rights issues, military development, and non-proliferation issues all touch the nationalist nerves of 
the power centre in Beijing. Chinese leaders are not averse to multilateralism if benefits far outweigh potential costs and, especially, if multilateral engagement will directly benefit their top priorities. This is evident in China's push to join the World Trade Organization. China has also been a strong supporter of the Tumen River Area Development Programme. ${ }^{29}$

Japan's superior power, except in the military field, gives it a broader base of international influence than Russia or China, particularly in the economic and technological fields, and its membership in such forums as the World Bank, IMF, G-8, and APEC gives it a more prominent global and regional profile. However, Japan views Northeast Asia from a longterm perspective and can "bide its time at little domestic cost". ${ }^{30}$ Japan pursued a predominantly bilateral mode of diplomacy in Northeast Asia during the Cold War and continues to use existing bilateral ties to pursue its political and security interests in the region. ${ }^{31}$ The only exception is the Washington-Tokyo-Seoul coordination of policy regarding North Korea, including its supportive role in KEDO. ${ }^{32}$ This contrasts sharply with Tokyo's active diplomacy to promote multilateral dialogue and cooperation in Southeast Asia, including the hosting of international conferences in support of Cambodian settlement and post-conflict assistance, as well as high profile participation in the ASEAN post-ministerials and active promotion of the ASEAN Regional Forum (ARF). ${ }^{33}$

Prospects for multilateral engagement involving Japan appear much brighter on the economic front than in the security realm. Tokyo and Seoul have initiated discussion of a free trade agreement. If the two countries are successful in establishing a free trade area between them, it will improve the prospects for a natural economic territory (NET) encompassing Japan, South Korea, and areas of Northeast China, where Japanese and South Korean firms are already investing heavily. ${ }^{34}$

South Korea is eager to play a key role in Northeast Asian affairs but its resource base and international influence are substantially smaller than those of the larger regional powers. ${ }^{35}$ On the one hand, the potentially explosive situation on the Korean Peninsula forces both North and South Korea to maintain a high level of political attention and resource commitment. On the other hand, this same conflict draws to both regions a higher level of political attention and material support from the international community than they might otherwise attract.

In South Korea there are both liberal voices in support of greater international engagement and economic interdependence and nationalist concerns about the influence of foreign powers on peninsular affairs and dominance in its economy. ${ }^{36}$ The liberals maintain that South Korea should fill the gap created by the absence of Japanese or Chinese leadership in regional cooperation. ${ }^{37}$ The nationalist sentiment is a product 
of the long history of foreign dominance and interference on the peninsula, as well as an expression of South Koreans' national security concern in the fragile security environment they face. This sentiment is clearly more pronounced among the North Koreans, who have had no choice but to follow the dogmatic and isolationist world-view dictated by their Leninist leaders. To all intents and purposes, liberal views are nonexistent in North Korea.

Mongolia is one of the most active supporters of regional cooperation in Northeast Asia. ${ }^{38}$ From the Mongolian perspective, it is advantageous to align itself with the Northeast Asian countries and place itself under the "economic umbrella" of technologically advanced countries like Japan, South Korea, and the United States. ${ }^{39}$ Landlocked and in need of unimpeded access to international commerce, Mongolia needs to develop bilateral relations with its immediate neighbours, the Russian Far East, Northeast China, and North Korea. Access to Mongolia is possible only through Russia and China. The Tumen River Area Development Programme, discussed below, offers Mongolia that access and, therefore, Ulaan Baatar is actively participating in the multilateral project. At the same time, however, Mongolia must avoid economic or political subordination to either its Cold War protector, the former Soviet Union, or its dynamic but dominant neighbour, China. Therefore, Mongolia actively supports multilateral cooperation that will involve Japan, South Korea, the United States, and other members of the international community. These countries can also provide Mongolia with the necessary capital and technological assistance to sustain its economic reform and development. In order to avoid high inflation, bad commercial loans, and high interest rates, Mongolia needs international financial aid and investment.

\section{Non-traditional security issues in Northeast Asia}

What are the security issues that are begging for multilateral cooperation in Northeast Asia? Some of the problems predate the Cold War, others have Cold War origins, and still others are issues of more recent vintage or issues that existed during the Cold War but which had no prospect of settlement during that period. In the first group we can include territorial disputes involving China, Japan, Russia, and Korea. Problems of Cold War origin include the division of China and Korea, as well as the military threats Cold War antagonists continue to pose even in the post-Cold War era. The last group of security issues includes some military security problems, such as proliferation of weapons of mass destruction, as well as issues of a non-traditional nature. 
Non-traditional security issues in Northeast Asia include:

- environmental deterioration and its deleterious effects on human health and transboundary pollution problems;

- growing pressures on natural resources due to expanding market demand, particularly with respect to forestry and fishery resources;

- legal and illegal migration and resulting ethnic tensions in and around China;

- increasing gaps in wealth and income within and between neighbouring regions in part as a result of international and transnational economic exchanges;

- illegal drug trafficking; and,

- mismanagement of national economies and their vulnerability to the intensifying forces of globalization, resulting in major economic and social dislocations among the local populations.

What institutional mechanisms are there to deal with these non-traditional security problems in the region?

In recent years we have seen a proliferation of international conferences on environmental problems in Asia-Pacific but very few of these are focused specifically on Northeast Asia. ${ }^{40}$ Examples include the APEC environmental ministers' meetings since 1994 and the series of meetings organized by the Economic and Social Commission for Asia and the Pacific (ESCAP) since 1978. There have also been a few international conferences focused on environmental problems in Northeast Asia. One example is the annual conference involving working-level officials from Japan, South Korea, China, and Russia. Begun in 1997, the conferences have discussed areas for regional cooperation, such as information sharing, collaborative research and training, and joint surveys. Another example is the series of meetings on environmental cooperation since 1993 involving senior officials from the United Nations Environment Programme (UNEP), ESCAP, and UNDP. These processes have produced a myriad of programmes and action plans but their implementation is left to each member country and depends heavily on the availability of international financial and technological assistance. At the technical level, as well, there is growing multilateral cooperation. An example is the cooperation among China, Japan, South Korea, and Russia in monitoring and exchanging information on acid precipitation in each country. Northeast Asian countries are yet to develop a multilateral environmental agreement with legal force. Instead, they continue to rely mostly on national and local means of pollution abatement and environmental protection and on voluntary international programmes. It should be noted, as well, that Japan has become an important donor of environmental assistance, but most of this aid is disbursed bilaterally through Tokyo's ODA programmes, with China being the largest recipient. 
In the natural resources sector, most problems have been addressed unilaterally. The only exception is a series of bilateral treaties on fisheries involving Japan, China, South Korea, and Russia since the 1950s. Most of these treaties include provisions for principles, rules, and procedures for resource conservation and dispute resolution regarding fishing in areas under each coastal state's jurisdiction. ${ }^{41}$ These legal regimes have reduced the level of conflict between the coastal and fishing states over the years and today provide a degree of predictability to their fishery relations. However, the bilateral arrangements have been inadequate in dealing with resource depletion and illegal fishing problems. Where there are territorial and jurisdictional disputes, political expediency has dictated that treaties be established in such a way that they would not jeopardize each state's sovereignty claims. ${ }^{42}$

Energy security has also been recognized as an important issue for Northeast Asian countries, with their energy demand and dependence on Middle Eastern oil expected to continue to grow. ${ }^{43}$ The current and near-term energy production and oil reserves in the Northeast Asian countries are likely to be inadequate to meet their future energy demands. Energy imports of these countries, particularly those of China, are expected to continue to grow, pushing up their dependence on Middle Eastern oil. Of particular importance are the large reserves of oil and natural gas in Siberia and the Russian Far East, and their potential exports to China, South Korea, and Japan. This is an issue that is attracting increasingly focused attention in all Northeast Asian countries. In fact, the APEC energy ministers' meeting in 1998 endorsed the "Natural Gas Initiative" prepared by its energy working group. The APEC Natural Gas Initiative calls for the promotion of investment in the development of natural gas supplies, infrastructure, and trade network in APEC member countries. It states that the development of a natural gas trade network composed of domestic and cross-border pipelines, LNG terminals, and a distribution system will expand the cooperation and trade among APEC members and promote regional economic development and growth. ${ }^{44}$ If successfully developed, this initiative will enhance the region's cooperation in this important sector as well as Russia's influence in energy diplomacy. ${ }^{45}$

There is no formal bilateral or multilateral mechanism in Northeast Asia to deal with transborder human flows that may have serious implications for relations between ethnic groups within and between countries. There are two potentially serious problems in this area - Chinese migration and settlement in the Russian Far East and North Korean refugees in the case of a crisis on the Korean Peninsula. Against the background of deepening economic difficulties in the Russian Far East and the burgeoning Chinese economy and population, many residents in Far 
Eastern communities feel vulnerable to Chinese influence. ${ }^{46}$ Since the early 1990s, the influx of large numbers of Chinese traders and labourers and poorly regulated border trade have raised the spectre of a Chinese invasion of Far Eastern territories "by peaceful means". The tightening of visa control in the winter of 1993/4 alleviated much of the problem of migration, but it also caused a drastic drop in border trade. Although bilateral trade has since recovered, the Russian fear of Chinese influence remains unabated. Moreover, although Russia and China have managed to resolve most of their border demarcation issues since 1991, regional leaders in the border areas of the Russian Far East have exploited, and will continue to do so for political purposes, the nationalist sentiment among the local residents over these issues.

The potentially devastating effect of a massive flow of refugees from North Korea into South Korea, China, or Russia is on the minds of many government officials in the neighbouring countries. However, to date, the issue has not been officially broached in any international forum, reflecting the very sensitive nature of the problem. Nor have experts in Korean affairs seriously discussed policy options available to the neighbouring countries. ${ }^{47}$

There is no regional forum for addressing the impact of growing transnational economic ties for the welfare of the local communities. On the one hand, the growing trade and other economic activities across national borders between China and Russia and between Mongolia and Russia, as well as international investments in these countries, are creating pockets of new wealth and opportunities in each country. On the other hand, most members of these communities have seen little or no benefits resulting from the growing interdependence. ${ }^{48}$

Illegal drug trafficking is another potentially serious security concern for which there is no regional forum. The problem is currently being addressed through bilateral channels, such as between Japan and Russia.

Finally, the management of national economies in Northeast Asia is strictly a matter of national control. In the Asian currency/financial crisis of 1997-1998 we saw what devastating effects could result from the mismanagement of national economies or the economies' exposure to the inexorable forces of globalization. The crisis created serious difficulties in South Korea and equally profound problems in Russia. Japan also felt the impact on its business presence in East Asia. Fortunately, unlike in many Southeast Asian countries, the state in each of the Northeast Asian countries was strong enough to prevent the intense and even violent social tensions and political conflicts that were seen in Southeast Asia. As will be noted below, some efforts are underway within the framework of "ASEAN Plus Three" to prevent the recurrence of a similar crisis in the future, but obviously much more needs to be done. Additionally, Japan 
and South Korea have been conducting discussions on a bilateral freetrade agreement. If successfully concluded, it would be a major step forward in regional cooperation in Northeast Asia. However, any similar arrangements that included PRC, Taiwan, and Russia would be very difficult to forge.

\section{Institutionalized multilateral cooperation in Northeast Asia}

There are two notable multilateral cooperation schemes in Northeast Asia that are concerned with issues of economic development, but neither deals explicitly with non-traditional security. The first is the Tumen River Area Development Programme based on international treaties and the second is the non-governmental Northeast Asia Economic Forum. Another multilateral cooperation scheme that exists in Northeast Asia is the Northeast Asia Cooperation Dialogue (NEACD), but its primary focus is traditional security issues. Together, these three frameworks illustrate the challenges facing multilateral cooperation in non-traditional security in the region.

\section{The Tumen River Area Development Programme ${ }^{49}$}

The Tumen River programme has the potential to evolve into a framework for multilateral cooperation involving all Northeast Asian countries. The current participants are Beijing, Moscow, Pyongyang, Seoul, and Ulaan Baatar. Unfortunately, competing national and local priorities and interests have proved formidable.

China has been the most enthusiastic participant in this project, making by far the most visible and substantial investments in the development of transportation and communication infrastructure. Progress has been very slow on the Russian side due to domestic economic chaos and disagreements between Moscow and the regional governments in the Russian Far East. There are serious local concerns about the economic and environmental impact of the multilateral project. North Korea has focused almost exclusively on the development of its own projects, particularly the special economic zone in Rajin-Sonbong. Pyongyang's international isolation has also limited the international community's involvement in the project. Furthermore, the absence of diplomatic ties between Pyongyang and Tokyo has prevented Japanese participation in the Tumen programme.

The multilateral project has had difficulty attracting large international investments, which are essential to its success. The prospects of international capital have been hurt further by Japan's protracted recession and 
the Asian financial crisis. Given the paucity of financial resources in the Tumen Region, the multilateral programme must attract international capital. The earlier proposal to establish a Northeast Asia Development Bank has proved unrealistic so far. The most recent effort by the Tumen Secretariat in Beijing is the proposal to establish a Northeast Asia/ Tumen Investment Corporation (NEATIC).

The Tumen River programme is increasingly turning its attention to the protection of the environment. If effectively promoted, cooperation in this area will help the participating countries develop a habit of cooperation and sensitivity to the consequences of domestic developments for their neighbouring countries. Particularly important is the international support for the environmental mitigation efforts in north-east China.

There is no question that, without the involvement of the United Nations Development Programme (UNDP), it would have been impossible for the participants to develop the close consultations they currently conduct. The UNDP not only provided financial assistance for some of the feasibility studies for the development programme but also played a key role as coordinator and organizer of the project in its early phases. Given the politically sensitive issues yet to be resolved and the equally daunting task of attracting capital investment required for the project, the support of the UNDP remains critical.

Finally, the international environment surrounding the Tumen River programme must continue to improve. This means, at a minimum, that the Korean conflict must be contained, if not settled, and this requires consensus among the four major powers about the need to engage North Korea, prevent its collapse, and expand North-South contacts. This in turn calls for an understanding among the great powers about a desirable multilateral framework for managing their competing political and security interests. Multilateral cooperation in economic and non-traditional security issues will improve the chances of favourable developments along these lines.

\section{Northeast Asia Economic Forum $(N E A E F)^{50}$}

The origins of the Forum were in a scientific meeting at the East-West Centre in 1987 and a series of conferences in the region in subsequent years. Among the issues addressed in the early conferences were international cooperation for the management of ocean resources, development of marine transport, and environmental protection. One of these conferences, held in Changchun, China in 1990, generated interest in the concept of the Tumen River development. It was also at this conference that the Northeast Asia Economic Forum was established. The Forum has since been held in Pyongyang, Vladivostok, Yeongbyong, Niigata, Honolulu, Ulaan Baatar, and Tianjin. ${ }^{51}$ 
The Tianjin conference in 1999 discussed regional economic cooperation, transportation networks, the Tumen Region as a model for Northeast Asian economic cooperation, energy resources in the region, and environmental issues in the energy sector. Also on the agenda were financial issues and capital mobilization for infrastructure development, cooperation in the telecommunications sector and the electric power sector. ${ }^{52}$ In other words, economic and technical issues have become the central focus of the annual gatherings.

The Forum remains an informal, non-governmental process, similar to the Pacific Economic Cooperation Council (PECC) that paved the way for the establishment of APEC. The Forum also tries to mobilize both national and international support for its mission by holding its conference in each participating country on a rotation basis. This has also facilitated a sense offairness and equality among the participating countries. Participation has also been open to any and all actors, governmental or non-governmental, regardless of national identity. That is, inclusiveness has been a hallmark of the Forum.

The limitations of the Forum have also become evident. The mobilization of sufficient financial, technical, and other resources for many of the needs identified by the Forum requires official support of Japan and other developed countries, but as long as the North Korean regime remains reclusive and suspicious of others, the necessary international support for the Tumen Project is unlikely. As long as the Forum remains focused on economic and technical issues, it is unlikely to develop into a useful mechanism for addressing, much less managing, non-traditional security issues. Its most notable weakness, from the perspective of implementation, is the absence of strong central government participation.

\section{Northeast Asia Cooperation Dialogue (NEACD)}

The Northeast Asia Cooperation Dialogue was established by the University of California's Institute on Global Conflict and Cooperation (IGCC) as a supplement to broad regional bodies such as ASEAN. The NEACD's goal is to promote cooperative dialogue among the six most influential states in Northeast Asia: Japan, China, South Korea, Russia, North Korea, and the United States. Such dialogue is encouraged through the group's informal Track Two status that allows representatives to air concerns independent of official state policy. Meetings involve government officials from the foreign and defence ministries, uniformed military officers, and participants from private research institutions.

Each meeting of the NEACD focuses on one area of possible cooperation, contains a session devoted to national and military perspectives on security, and addresses current topics in Northeast Asian security. The first meeting, held in California in October 1993, focused primarily on 
security issues. However, participants quickly agreed that promoting cooperation on less confrontational issues might build the trust necessary for productive discussions on security concerns. Attendees decided that the NEACD should focus on several confidence-building measures, including maritime and nuclear policy, crisis prevention centres, and transparency.

The NEACD has endeavoured to identify new areas in which to foster regional cooperation. The group has studied the security implications of energy issues in Northeast Asia, including regional demand and nuclear fuel cycle issues, and the role of agriculture production and trade. Later sessions have examined potential cooperation in maritime shipping and trade, and regional cooperation on the civilian use of nuclear energy. Working groups and study projects report their findings in these areas at every NEACD meeting. One of the NEACD's major projects is the Defence Information Sharing study project. The DIS stemmed from the Dialogue's exploration of CBMs and seeks to increase transparency in Northeast Asia. This study project is the first multilateral, military-tomilitary dialogue in the North Pacific. The group focuses on post-Cold War changes in the security environment, including the increased importance of economic security and the growing use of cooperative security in resolving disputes. The importance of considering inter-state relations and peacekeeping when formulating state security policy is also discussed.

One setback in the organization is North Korea's failure to attend any of the sessions, although North Korean officials did agree to the organization's establishment. They remain involved in agenda discussion for each meeting, however, and are provided with the proceedings of each dialogue. The other representatives remain hopeful that North Korean officials will begin actively participating in the discussions.

Among the multilateral cooperative efforts focused on Northeast Asia, the NEACD offers the greatest promise for addressing security issues, but its primary concern relates to traditional security problems and confidence-building measures, and its limited size and resources are likely to limit the scope of issues it can address. In addition, the US-based forum may come under closer scrutiny, particularly from its Asian participants, as it pushes forward with a more ambitious agenda.

\section{The Council for Security Cooperation in the Asia Pacific (CSCAP)}

The CSCAP was formally established under the Kuala Lumpur Statement in June 1993. Its founding members were security and international studies institutes with government ties in Australia, Canada, Indonesia, Japan, South Korea, Malaysia, the Philippines, Singapore, Thailand, and the United States. ${ }^{53}$ The organization was designed to hold workshops to 
be attended by academics, business leaders, and former or current officials from ministries of defence and foreign affairs. In accordance with this objective the Council was made open to all countries and territories in the Asia-Pacific region interested in promoting regional security cooperation.

The CSCAP Charter was adopted in December 1993 in Lombok, Indonesia and later amended in August 1995. The Charter outlined seven functions the organization was to undertake. In addition to promoting dialogue and cooperation on security issues, the Charter called for links to be established with other institutions and organizations throughout the world for exchanging information and producing publications relevant to regional security issues. The CSCAP has been expanding steadily since its establishment and, in addition to the founding members, New Zealand, Russia, North Korea, Mongolia, India, Cambodia, Papua New Guinea, the European Union, China, and Vietnam have also become full members. With this broad membership the CSCAP is hoping to establish solid links to the ASEAN Regional Forum.

The CSCAP currently has five working groups. The first four were established in 1993 and 1994 and dealt with maritime cooperation, North Pacific/Northeast Asia security cooperation, confidence and securitybuilding measures, including transparency, and cooperative and comprehensive security. The fifth group, dealing with transnational crime, was granted full working group status at the 1997 Steering Group Committee Meeting in Tokyo. The working groups are the most productive portion of the CSCAP and have been conducting relevant and useful research. At the eighth meeting of the Comprehensive and Cooperative Security Working Group, held in October 2000, topics related to the theme "Implications of Globalization for Security Cooperation in the Asia Pacific" were discussed during five sessions. The first session was an overview of the impact of globalization on security in the Asia Pacific. It highlighted the fact that increased globalization has made traditional tools of security policy less appropriate and the emphasized a need for "trans-sovereign" security policies. The other sessions dealt with globalization and sovereignty, the impact of the technological revolution on the balance of power, and the role of multilateral institutions in managing globalization. Some of the issues raised at this event were the need to develop an Asian perspective on ideas such as human security rather than allowing the West to impose its own concepts on the region, the promotion of more South-South cooperation, and the development of stronger cooperation between multilateral institutions.

While the working groups have been successful in promoting dialogue, the extent to which such discussions have been transformed into policy is unclear. Working group meetings generally end with suggestions for 
further discussions rather than suggesting how their ideas might be implemented. The extent to which attending government officials attempt to incorporate the suggestions into their policy recommendations is not discussed.

From the perspective of non-traditional security cooperation, the CSCAP shows the greatest promise as a forum for research and dialogue. With its inclusiveness in terms of membership, agenda, and ties to institutions elsewhere, the group offers some definite advantages over the other forums discussed in this chapter. However, how successful it will be in addressing some of the specific non-traditional security issues in Northeast Asia remains to be seen. In particular, its ability will be seriously tested if it decides to develop policy recommendations concerning some of the sensitive human security issues on the Korean Peninsula and China, the presence of ethnic minorities in China and the Russian Far East, and cross-border migration involving China.

\section{ASEAN plus Three}

ASEAN plus Three, comprising the ASEAN states and Japan, South Korea, and China, has been meeting informally since 1997. A drive to increase cooperation between Northeast and Southeast Asian states was brought about by what many Asian states viewed as an inadequate response by the West and the IMF to the financial crisis of 1997. This sentiment bolstered support for stronger regional bodies in order to reduce economic dependence on the West.

In May 2000, ministers from ASEAN met with officials from Japan, China, and South Korea to discuss developing a joint approach to WTO and APEC discussions, regional economic recovery, and creating an expanded regional free trade area.

ASEAN plus Three held its first official summit meeting in Manila in November 1999. In attendance were the foreign ministers, trade and industry ministers, finance ministers, deputy central bank governors, and senior officials from various sectors of each participating state. The members stated that increased East Asian interaction was improving chances for cooperation and collaboration with each other and strengthening the potential for promoting peace and stability in the region. They also agreed to promote dialogue and deepen efforts to increase mutual understanding and trust in East Asia and beyond through existing cooperative processes and joint efforts. In accomplishing these goals, members agreed to follow guidelines set out in the UN Charter, the Five Principles of Peaceful Coexistence, the Treaty of Amity and Cooperation in Southeast Asia, and universally recognized principles of international law. Principles for promoting cooperation in economic, social, and political areas were also proposed. 
In the economic sphere, promoting trade, investments, technology transfer, and cooperation in industry, agriculture, and monetary policy were agreed upon. The importance of developing social and human resources was highlighted, as well as the need for the association to cooperate in development programmes. In the political and security areas they agreed to continue dialogue and cooperation to increase mutual understanding and trust. No firm plans for attaining these objectives were established.

At the second summit meeting in November 2000 the establishment of an East Asian free trade zone with an institutional link with Northeast Asia was proposed. At the time Prime Minister Goh of Singapore suggested the group would likely focus on economic and social issues, but that expansion into political issues was possible. Around this time the ten ASEAN states and Japan, China, and South Korea started referring to themselves as the East Asian states.

Despite being criticized as a "talk-shop", ASEAN plus Three has made surprising advancements in promoting financial cooperation since the November 2000 summit. By January 2001 the thirteen East Asian states were establishing a network of bilateral swap and repurchase agreements to assist each other in the event of another financial difficulty. In the case of development, much of the group's energy has thus far gone into promoting development in the Mekong River Basin. Mechanisms for cooperating in trade, investments, technology-transfer, and e-commerce were still being discussed. To assist in accelerating the integration process, an East Asian Vision Group composed of respected intellectuals from the region was established.

Table 13.3 summarizes the main characteristics of the institutionalized multilateral cooperation efforts reviewed above and their current and potential relevance to the development of non-traditional security cooperation in Northeast Asia.

\section{Conclusions}

The distribution of power in Northeast Asia is uneven and in a state of flux today. The state, the most dominant actor in the region, has performed its central roles to varying degrees of success in cultivating a national identity among its people, integrating economic processes within its borders, forging a national strategy for economic development, and providing for national security. In each Northeast Asian country, nationalism remains a powerful force that commands the loyalty of its citizens. There are multiple territorial disputes, jurisdictional conflicts, and ethnic animosities. The states in the region lack experience in collective problem-solving; they are suspicious of each other; and they rarely encourage 
Table 13.3 Main characteristics of multilateral cooperation institutions

\begin{tabular}{|c|c|c|c|c|c|}
\hline & $\begin{array}{l}\text { Governmental vs. } \\
\text { non-governmental }\end{array}$ & Membership & Main agenda & $\begin{array}{l}\text { Current } \\
\text { relevance to } \\
\text { non-traditional } \\
\text { security } \\
\text { cooperation }\end{array}$ & $\begin{array}{l}\text { Potential } \\
\text { relevance to } \\
\text { non-traditional } \\
\text { security } \\
\text { cooperation }\end{array}$ \\
\hline Tumen Project & governmental & limited & economic & medium & medium \\
\hline NEAEF & non-governmental & broad & economic, technical & low & low-medium \\
\hline NEACD & non-governmental & limited & $\begin{array}{l}\text { traditional security, } \\
\text { economic security }\end{array}$ & medium & medium \\
\hline CSCAP & non-governmental & broad & $\begin{array}{l}\text { traditional security, non- } \\
\text { traditional security }\end{array}$ & medium & medium-high \\
\hline ASEAN plus Three & governmental & limited & economic & low & low-medium \\
\hline
\end{tabular}


their citizens to engage with one another across national borders without their direct control or monitoring.

The private sector has historically been subservient to the dominant interests and institutions of the state in all Northeast Asian countries. With the development of democracy and market capitalism, however, Japan and South Korea have seen a dramatic and progressive growth in multi-party competition, civil society institutions, and powerful commercial enterprises. In Russia and Mongolia, authoritarian habits at the state level are competing for citizens' loyalty against nascent civil society groups, fledgling commercial interests, and other private agents of change, including underground enterprises and criminal organizations. In China, the economy is straddling the not-so-clear public-private divide, but the Communist Party dictatorship continues to control the state apparatus of the country. Only North Korea remains a virtually unchanged society since the earlier decades, but even in the reclusive regime in Pyongyang there are signs of interest in engaging the international community, albeit selectively and cautiously, to salvage the nation's faltering economy.

Given the diversity among the Northeast Asian societies, it is highly unlikely that their governments will quickly develop a common political or security agenda. Nor can we expect the state in each country voluntarily to surrender its control over the level and direction of transnational economic exchanges.

Further complicating regional cooperation in Northeast Asia is the widely ranging degree of dependence of the individual economies on trade and investment opportunities outside this region. The US market has been particularly important to the growth and expansion of Japanese, South Korean, and, more recently, Chinese economies. Southeast Asian markets have also played an important role in the growth of these Northeast Asian economies. More recently, European markets too are becoming an important source of capital and markets for Northeast Asian exports.

What rules should guide the institutionalization of multilateral cooperation in Northeast Asia? The most realistic approach to multilateral decision-making in Northeast Asia would resemble the procedural rules practiced by the ASEAN, namely, consensual decision-making based on the least common denominator. The Northeast Asian countries that participate in the ARF may be able to transfer their experience as dialogue partners in that process to a future Northeast Asian security forum. The recent establishment of ASEAN plus Three gives testimony to this logic.

Initial emphasis in multilateral security cooperation in Northeast Asia will likely be placed on the process of dialogue and consultation rather than on formal decisions involving firm commitments. Consensus will be required for all issues that entail substantial domestic adjustments. How- 
ever, some non-controversial issues may be put to a majority vote as a package to develop a habit of cooperation, collective decision-making, and bargaining through issue linkage.

The experience of the Tumen River Area Development Programme suggests that as long as the states remain the key participants in a multilateral cooperation scheme in the region, their political and security interests will dictate the manner of cooperation and the pace of progress. The record of the Northeast Asia Economic Forum indicates that nonstate participants are unwilling or unable to take on traditional security issues. However, as transnational linkages among civic society groups grow and their security implications are more widely realized, those linkages cannot but contribute to the recognition of the importance of multilateral approaches to confidence-building, problem-solving, and crisis management or prevention. In this process, non-governmental organizations can play an important role in promoting the development of trust, elimination of prejudices, and cultivation of a sense of shared future among the peoples of Northeast Asia. Ultimately, however, official support and participation will be required to meet the specific requirements of regional cooperation, be they infrastructure development, capital investment, removal of customs barriers, or implementation of environmental programmes or measures in other non-traditional security fields.

The experience of the NEACD testifies to the importance of the role of intellectual communities in facilitating multilateral security dialogue when political leaders cannot overcome obstacles to governmentallevel cooperation. The CSCAP, with its greater readiness to add nontraditional security issues to its agenda and its more inclusive approach to membership, has a more promising potential to become an important facilitator of multilateral cooperation in non-traditional security issues. ASEAN Plus Three has begun to articulate an Asian voice in the management of regional economic issues, but it faces the daunting task of going beyond dialogue. Moreover, the group's relevance to non-traditional security issues specific to Northeast Asia remains to be established.

Whatever institutional mechanism or mechanisms Northeast Asian countries employ in addressing the challenges of non-traditional security issues, they must keep in mind the six main characteristics of the region that were noted at the outset of this chapter. They are: the memories of history; the shifting balance of power; the disparate foundations of national power; the dominance of the state in domestic and international affairs; strong nationalism; and diversity in terms of political systems, societal structures, and economic development. Civil society institutions and private businesses must be encouraged to promote the integrative effects of transnational economic, social, and cultural exchanges, which will also facilitate the development of tolerance towards diversity. How- 
ever, successful regional cooperation will depend on the authority and resources of central governments.

Given the strong national sensitivities and sensibilities in the region, security cooperation can only begin in areas that do not threaten national sovereignty but which offer promises of mutual benefits. Promising candidate issues include environmental protection, resource conservation and development, coordination of migration policies, and effective management of cross-border flows of goods and people. Finally, cooperative schemes must employ non-threatening rules and procedures, allowing for a gradual building of consensus, eschewing, at least initially, demanding political compromises or major resource commitments.

\section{Notes}

1. In 1990, Australian Foreign Minister Gareth Evans proposed an Asian version of CSCE, which he called CSCA (Conference on Security Cooperation in Asia) (Gareth Evans (1990) "What Asia Needs is a Europe-style CSCA", International Herald Tribune, 27 July, p. 5), but the proposal was met with widespread scepticism in Asia (Trevor Findlay (1996) "Disarmament, Arms Control, and the Regional Security Dialogue", in Gary Klintworth, ed., Asia-Pacific Security: Less Uncertainty, New Opportunities?, New York: St. Martin's, p. 229.) In a 1991 publication, an Asian security analyst stated, "In the longer term, something similar to the Helsinki process in the Asia-Pacific region - a Conference on Security and Cooperation in Asia - is needed" (Stuart Harris (1991) "The End of the Cold War in Northeast Asia: The Global Implications", in Stuart Harris and James Cotton, eds., The End of the Cold War in Northeast Asia, Boulder, Colorado: Lynne Rienner, p. 273), but there are no such prospects at the beginning of the twenty-first century.

2. See, for example, James C. Hsiun (forthcoming) ed., 21st Century World Order and the Asia Pacific: Value Change, Exigencies, and Power Realignment, New York: Palgrave.

3. For a series of insightful analyses that contextualize national security agendas in Asia, see Muthiah Alagappa, ed. (1998) Asian Security Practice: Material and Ideational Influences, Stanford: Stanford University Press.

4. For a succinct and useful discussion of the relationship between "traditional security" and "non-traditional security", as well as the concept of "human security", see Melissa G. Curley (2001) "Cooperation between Multilateral Institutions and NGOs on Nontraditional Security Issues in East Asia", paper presented to Inter- and Intra-Regional Security Cooperation and Institutions Research Group, Singapore, 25-26 May, pp. 3-8.

5. For a comprehensive review of competing approaches to security and advocacy of "human security" to overcome the conceptual and empirical limitations of national security, see Ramesh Thakur (1997) "From National to Human Security", in Stuart Harris and Andrew Mack, eds., Asia-Pacific Security: The Economics-Politics Nexus, Sydney: Allen and Unwin, pp. 52-80.

6. Curley, "Cooperation between Multilateral Institutions and NGOs", p. 7.

7. See, for example, Tsuneo Akaha (1991) "Japan's Comprehensive Security policy: A New East Asian Environment", Asian Survey 31(4, April): 324-340.

8. See, for example, Susan L. Shirk and Christopher P. Twomey, eds. (1996) Power and Prosperity: Economics and Security linkages in Asia-Pacific, New Brunswick, NJ: Transaction Publishers. 
9. Edward D. Mansfield and Helen V. Milner (1998) "The Political Economy of Regionalism: An Overview", in Edward D. Mansfield and Helen V. Milner, eds., The Political Economy of Regionalism, New York, NY: Columbia University Press, pp. 1-19.

10. For a fuller comparison of the regional experiences, see Tsuneo Akaha (1999) "Northeast Asian Regionalism: Lessons from Europe, North America, Asia-Pacific, and Southeast Asia", Global Economic Review 28(2): 28-49.

11. For a succinct discussion of the APEC experience and its relevance to Northeast Asia, see Ippei Yamazawa (2000) "Hokutoajia Chiiki Keizai Kyoryoku no Kinmitsuka ni Mukete: PECC-APEC no Shiten kara" (Towards a Closer Regional Cooperation in Northeast Asia in the Context of PECC and APEC), ERINA Report 36 (October): pp. 1-8.

12. For a comprehensive examination of Northeast Asia as a region, see Tsuneo Akaha (1999) ed., Politics and Economics in Northeast Asia: Nationalism and Regionalism in Contention, New York, NY: St. Martin's Press.

13. For a similar characterization of Northeast Asia as a region, see Gilbert Rozman (2000) Restarting Regionalism in Northeast Asia, North Pacific Policy Papers No. 1, Vancouver, Canada: Program on Canada-Asia Policy Studies, Institute of Asian Research, University of British Columbia, pp. 3-4.

14. See Tsuneo Akaha, ed. (forthcoming) The Future of North Korea, London: Routledge.

15. See Ralph A. Cossa and Jane Khanna (1997) "East Asia: Economic Interdependence and Regional Security", International Affairs 73(2): 219-234, and Yong Deng (1998) "The Asianization of East Asian Security and the United States' Role", East Asia 16(3/4, Autumn/Winter): 87-110.

16. Unless otherwise noted, the statistics used in this section come from ERINA Report 30 (October 1999): 46-49.

17. In November 2000, Russian Defence Minister Igor Sergeyev stated his government would cut its troop levels in the Far East by 20 per cent. ("Russia to Cut Military Strength in Far East by 20 Percent", Agence France Presse, Russia Today News (http:// www.russiatoday.com/news.php3?id=224797\&section=default (accessed on 28 November 2000)).

18. Boeicho, ed. (1999) Boei Hakusho (Defence white paper), Tokyo: Okurasho Insatsukyoku, pp. 55-56.

19. Ibid., pp. 68-69.

20. See, for example, Gakushu Shidori (1997) "Bei-chu-ro Sankyokukozo no Keisei to AjiaTaiheiyo Chiiki no Anzenhosho" (The formation of US-China-Russia tripolar structure and security in the Asia-Pacific region), in Nihon Gakujutsu Kyoryoku Zaidan, ed., Reisengo no Ajia no Anzenhosho (Security of Post-Cold War Asia), Tokyo: Okurasho Insatsukyoku, pp. 121-125.

21. Japan 2000: An International Comparison, Tokyo: Keizei Koho Center, 2000, p. 14.

22. In his inaugural speech to the Diet in April 2000, Prime Minister Mori said that his government might propose legislation that would allow Japanese soldiers to carry weapons abroad and take part in UN peacekeeping operations. Mori also said that eventually, Japanese forces also might be permitted to take action against ships that violate Japan's territorial waters. (Michael Zielenziger (2000) "Japanese Leader Hints of Bigger Role for Military", Knight Ridder News Service, 8 April; cited in Northeast Asia Peace and Security Network Daily Report, Berkeley, California, 10 April 2000.)

23. According to a Yomiuri Shimbun survey in March 2000, 60 per cent of respondents supported proposals to revise the constitution, while 27 per cent were opposed. When the same newspaper polled 95 lawmakers who sat on the Research Commission on the Constitution, about 70 of them, including representatives from the Liberal Democratic Party and Minshuto (Democratic Party of Japan), said that they favoured constitutional 
reform ("Survey: 60\% Support Revising Constitution", The Daily Yomiuri, 15 April 2000; cited in Northeast Asia Peace and Security Network Daily Report, Berkeley, California, 21 April 2000.).

24. The share of Japan's international trade within Northeast Asia declined slightly from 23.4 per cent to 22.3 per cent of its global trade, but if we include trade with the United States, Japan's regional trade went up from 46.7 per cent to 50.3 per cent. The proportion of intra-regional trade dropped more visibly for Hong Kong (from $72.8 \%$ to $54.8 \%$ ), for South Korea (from $34.9 \%$ to $29.4 \%$ ), for Russia (from $10.9 \%$ to $6.9 \%$ ), North Korea (61.0\% to $46.2 \%$ ), and Mongolia (from $65.5 \%$ to $60 \%$ ). In contrast, intraregional trade became slightly more important for Taiwan (from $38.9 \%$ to $39.1 \%$ ).

25. Vladimir I. Ivanov (1999) "Prospects for Russia's Energy Diplomacy in Northeast Asia", Global Economic Review 28(2): 96-113.

26. "Foreign Policy Concept of the Russian Federation Approved by the President of the Russian Federation V. Putin, 28 June 2000" (unofficial translation from the Russian, 10 July 2000; accessed at the Russian Foreign Ministry homepage).

27. See Sherman W. Garnett (1998) Limited Partnership: Russia-China Relations in a Changing Asia, Report of the Study Group on Russia-China Relations, Washington, D.C.: Carnegie Endowment for International Peace; Li Jingjie (2000) "Pillars of the Sino-Russian Partnership", Orbis 44(4, Fall): 527-539; and Gilbert Rozman (2000) "A New Sino-Russian-American Triangle?", Orbis 44(4, Fall): 541-555.

28. Robert A. Scalapino (1999) The People's Republic of China at Fifty, NBR Analysis 10(4, October): $15-16$.

29. See Weixing Hu (forthcoming) "Economic and Security Cooperation in Northeast Asia: A Chinese Perspective", in Akaha, ed., Politics and Economics in Northeast Asia.

30. Gilbert Rozman (1997) "Cross-national Integration in Northeast Asia: Geopolitical and Economic Goals in Conflict”, East Asia 16(1/2, Spring/Summer): 6-43.

31. Stephen J. Anderson (forthcoming) "Japan's View of Northeast Asia Regional Economic Cooperation: Bilateral Priorities and Multilateral Experiments", in Akaha, ed., Politics and Economics in Northeast Asia, pp. 85-108.

32. Takashi Inoguchi (1999) "Globalization and Japan's Foreign Policy", Japan Review of International Affairs 13(3, Fall): 163.

33. For a detailed analysis of Japan's diplomacy to promote ARF, see Paul Midford (2000) "Japan's Leadership Role in East Asian Security Multilateralism: The Nakayama Proposal and the Logic of Reassurance", Pacific Review 13(3): 367-398.

34. Robert Scalapino coined the term "natural economic territory", see Scalapino (1991/ 1992) "The United States and Asia: Future Prospects", Foreign Affairs 50(5, Winter): $19-41$.

35. For an explication of South Korean views on regional cooperation, see Jaewoo Choo, Kap-Young Jeong, and Ku-Hyun Jung (1999) "Regional Cooperation in Northeast Asia: Beyond the Economic Crisis", Global Economic Review 28(2): 114-132.

36. Chung-in Moon and Dae-Won Ko (forthcoming) "Korea's Perspective on Economic and Security Cooperation in Northeast Asia", in Akaha, ed., Politics and Economics in Northeast Asia, pp. 177-206.

37. Choo et al., p. 39.

38. See Tsegmid Sukhbaatar (2000) "Mongolia and Tumen Area Cooperation", in Regional Economic Cooperation in Northeast Asia: Proceedings of the Ninth Meeting of the Northeast Asia Economic Forum, 26-29 October 1999, Tianjin, China, Honolulu: Northeast Asia Economic Forum, pp. 122-125.

39. See Tsedendambyn Batbayar (forthcoming) "Mongolian Perspectives on Northeast Asian Regional Development", in Akaha, Politics and Economics in Northeast Asia, pp. 207-223. 
40. For a review of the emerging environmental cooperation in Northeast Asia, see Miranda A. Schreurs (1998) "Environmental Cooperation in the Northeast Asian Region", in Kap-Young Jeong and Jaewood Choo, eds., Towards New Dimensions of Cooperation in Northeast Asia, Seoul: Institute of East and West Studies, Yonsei University, pp. 143-162.

41. Tsuneo Akaha (1996) "Fishery Relations in Northeast Asia", in Dalchoong Kim et al., eds., UN Convention on the Law of the Sea and East Asia, Seoul: Institute of East and West Studies, Yonsei University, pp. 143-165.

42. See, for example, Tsuneo Akaha (2000) "The Japan-South Korea Fishery Treaty of 1998", in Harry H. Scheiber, ed., The Law of the Sea: The Common Heritage and Emerging Challenges, The Hague: Netherlands: Kluwer Law International, pp. 249263.

43. Hokutoajia Enerugii-Kankyo Kyodotai e no Chosen (A challenge for a Northeast Asia energy-environment community), Tokyo: NIRA, 2001, pp. 12-37.

44. Nijuisseiki, Kyakko wo abiru Ajia no Tennengasu Enerugi: Enerugi Anzenhosho, Kankyo Hozen, Keizai Seicho no Doji Tassei ni mukete (Natural Gas Energy in Asia Receiving Heightened Attention in the Twenty-First Century: Towards a Simultaneous Achievement of Energy Security, Environmental Protection, Economic Growth), Tokyo: Tsushosangyhosho Enerugicho Chokankanbo Kokusaishigenka Sekiyubu Kaihatsuka, 1998, p. 106.

45. For an examination of Russia's energy diplomacy in Northeast Asia, see Vladimir I. Ivanov, "Prospects for Russia's Energy Diplomacy".

46. See, for example, Mikhail Alexseev (2000) "Chinese Migration in the Russian Far East: Security Threats and Incentives for Cooperation in Primorskii Krai", a paper prepared for the project of the National Bureau of Asian Research, "Security Implications of Political and Economic Development in the Russian Far East".

47. Reflecting the traditional realist conceptualization of security, a 1998 collection of analyses by some of the best-known experts in North Korean affairs includes only one minor reference to the issue of North Korean refugees, see Dae-Sook Suh and Chae-Jin Lee, ed. (1998) North Korea after Kim Il Sung, Boulder, Colorado and London: Lynne Rienner.

48. See, for example, Tsuneo Akaha and Anna Vassilieva (2000) "Environmental Consciousness in Sakhalin: Background and Views on the Sakhalin Offshore Oil-Gas Development", in Takashi Murakami and Shinichiro Tabata, eds., Russian Regions: Economic Growth and Environment, Sapporo: Slavic Research Centre, Hokkaido University, pp. 215-248.

49. See Tsuneo Akaha (2001) "The Tumen River Area Development Programme and International Political Economy", in Yuji Masuda, ed., Nijuisseiki no Hokutoajia to Sekai (Northeast Asia and the World in the Twenty-first Century), Tokyo: Kokusaishoin, pp. 179-211.

50. For a summary description of the evolution of the forum, see Mark J. Valencia (1999) "The Northeast Asia Economic Forum: Achievements and Future Prospects", in Tsuneo Akaha, ed., Politics and Economics in Northeast Asia: Nationalism and Regionalism in Contention, New York: St. Martin's Press, pp. 315-328.

51. The forum held two conferences in October 2001, one in Hong Kong and one in Anchorage, Alaska.

52. See Regional Economic Cooperation in Northeast Asia: Proceedings of the Ninth Meeting of the Northeast Asia Economic Forum, 26-29 October 1999, Tianjin, China, Honolulu: Northeast Asia Economic Forum.

53. They are: Strategic and Defense Studies Centre, Australian National University, Australia; University of Toronto-York University Joint Center for Asia Pacific Studies, 
Canada; Centre for Strategic and International Studies, Indonesia; Japan Institute of International Affairs, Japan; The Seoul Forum for International Affairs, Republic of Korea; Institute of Strategic and International Studies, Malaysia; Institute for Strategic and Development Studies, Philippines; Singapore Institute of International Affairs, Singapore; Institute for Security and International Studies, Thailand; and the Pacific Forum/CSIS, USA. 


\section{Contributors}

Tsuneo Akaha, Professor and Director, Center for East Asian Studies, Monterey Institute of International Studies, Monterey, California

Jennifer Bennett, Director, Population and Environment Communication Center (PECC) housed at the Sustainable Development Policy Institute( SDPI), Pakistan

P.R. Chari, Director, Institute for Peace and Conflict Studies, New Delhi

Melissa G. Curley, Research Officer, China-ASEAN Project, Centre of Asian Studies, University of Hong Kong

Ajaya Dixit, Founder of Nepal Water Conservation Foundation and Editor of Water Nepal, Kathmandu, Nepal

Evelyn Goh, Assistant Professor, Institute of Defence and Strategic Studies, Singapore
Dipak Gyawali, Nepal Water Conservation Foundation (NWCF), member of the Royal Nepal Academy of Science, Kathmandu, Nepal

M. Shamsul Haque, Senior Lecturer, Department of Political Science, National University of Singapore, Singapore

Richard W. Hu, Associate Professor, Department of Politics and Public Administration, Hong Kong University

Kanishka Jayasuriya, Senior Research Fellow, the Southeast Asia Research Centre, City University of Hong Kong

Adil Najam, Assistant Professor, Department of International Relations, Center for Energy and Environmental Studies, Boston University 
Helen Nesadurai, Assistant Professor, Institute of Defence and Strategic Studies, Singapore

Edward Newman, Academic Officer, Peace and Governance Programme, United Nations University, Tokyo

Paikiasothy Saravanamuttu, Executive Director, Centre for Policy Alternatives, Sri Lanka

Ramesh Thakur, Senior Vice-Rector of the United Nations University, Tokyo, and UN Assistant SecretaryGeneral.

\section{William T. Tow, Professor} International Relations, University of Queensland's School of Politics and International Studies, Brisbane, Australia

Jayadeva Uyangoda, Senior Lecturer, Department of History and political Science, University of Colombo, Sri Lanka

Qingxin K. Wang, Assistant Professor, the Department of Politics and Public Administration, Hong Kong University 


\section{Index}

Note: emboldened page numbers indicate main text entries

acid rain $176-7,180,182,183,184,187$, 188; Northeast Asian cooperation 322

ADB see Asian Development Bank administrations, politization of 107

Afghanistan, and Pakistan drug-trafficking 112-13

Africa, and global trade 24

AFTA see ASEAN Free Trade Area

Agreement on Cooperation in the Field of Environmental Protection (1993): Korea-Japan 183

Agreement on Environmental Cooperation (1993): Korea-China 183

Agricultural Bank of China 88

agriculture: in Mekong River Basin 213; in

Nepal 201-2; subsidies 53, see also

irrigation issues; water resources

AIA see ASEAN Investment Area

air pollution 177-80; Indonesia's smoke pollution 261

Alagappa, Muthiah 252-3, 272

APEC see Asia Pacific Economic Cooperation

arms smuggling: and human security 114,

276; and terrorist linkages 103
Arun III hydropower project (Nepal) 2045, 207

ASEAN+3 see ASEAN plus Three (China, Japan, and South Korea)

ASEAN see Association of Southeast Asian Nations

ASEAN Free Trade Area/Agreement (AFTA) 68

ASEAN Investment Area (AIA) 283

ASEAN plus Three (China, Japan, and South Korea) (ASEAN+3) 68, 309, 324, 330-1, 332, 333

Asia Pacific Economic Cooperation (APEC) 47, 51-2, 284, 301, 309, 310, 320, 327; and East Asia 68; and environmental issues/programmes 262, 322; expansion 234; Natural Gas Initiative 323; and open regionalism $60-2$

Asia-Pacific 310; economies 319; environmental issues 322 ; financial crisis 245,252 , 280-1, 312, 315, 324, 326, 330 ; international relations 311 ; nontraditional/regional security 322,329 ; per capita income 25; regional economic cooperation 308; and Western democratization 252 
Asian Development Bank (ADB) 27, 38, 88; and Greater Mekong Subregion (GMS) programme 231; and Mekong River Basin developments 227, 230, 232 , 235

Asian economic crisis 47, 61-2

Association of Southeast Asian Nations

(ASEAN) 309, 310-11; China's membership 223; collective identity/interests 248 , 257, 263-4, 265; and constructivism 24850; critics 245; economic cooperation 279-81, 283-4; Economic Ministers (AEM) 293; Environmental Programme (1978) 262; and institutionalization 253, 279-80; and International Force for East Timor (INTERFET) 258, 260; Kuantan Declaration (1980) 249; and law enforcement 263; Myanmar: constructive engagement approach 261; political differences 245 ; and securitization/desecuritization 253,260 ; security politics $258,260,263$, 264-5; Senior Economic Officials Meeting (SEOM) 293; and US/the West 250, 263; Vision 2020 programme 257 Association of Southeast Asian Nations (ASEAN) Regional Forum (ARF) 47, 246, 253, 263, 310-11, 320; Common Effective Preferential Tariff (CEPT) mechanism 281, 289, 292, 294; constitutional documents 285-6, 289-91; cooperation/coordination modality 287-9, 291, 294-5; and CSCAP 329; decisionmaking procedures 287, 291, 333; Dispute Settlement Mechanism (DSM) 283, 2923; and economic cooperation 279, 281-4; formal agreements 286-7; GATT/WTO rules 298, 299; and globalization 299-301, 302 ; institution building 280, 281, 297-8, 299, 310-11; institutional transformation 289-300; institutionalization framework 284-9, 300; non-tariff barriers (NTB) 283; notification procedures 293-4; Protocol on the Special Arrangement for Sensitive and Highly Sensitive Products 298; rules and procedures $280, \mathbf{2 9 2}$; tariff liberalization programme 281-4

Australia 86, 328; and human security model 246

Australian Agency for International Development (AusAID) 87 authoritarianism, German 50 automobiles: in Northeast Asia 179; production/tariffs 298-300, 301

Axworthy, Lloyd (Canadian foreign minister) 254, 255

Ayoob, Mohamed 280

Baldwin, David 273

Bangkok (Thailand) 215, 219, 220

Bangladesh 157; ethnic conflict 108; role of military 106; security/insecurity threats and sources 104, 160, 162

Bank of Agriculture (China) 89

Beeson, Mark 48

Beijing International Workshop on Social Development 82

Bello, W. 25

Bhutan 104, 157

Birendra, King (Nepal) 207

black money: in South Asia 111, 115

block regionalism 61

Bowrie, Alasdair 59

Bretton Woods institutions 19-20, 73;

Washington consensus 80,82

Brock, L. 150, 151

Buddhism/Buddhists: Sangha (clergy) 127, 132, 133-5; in South Asia 109

build-operate-transfer (BOT) ventures 227

Busse, Nikolas 248

Buzan, Barry 211, 251, 255-6, 274

Cambodia 329; hydropower development 215-16; and Mekong Committee 219; and Mekong River Basin hydro-politics 20936; Tonlé Gap (Great Lake) 213, 219 , 220, 222

Canada 310, 328; and human security 246, 255

Canada Fund 86

carbon dioxide emissions 176, 177, 182, 188

Caribbean: per capita income 25

Cerny, Philip 53

Chakma movement (Bangladesh) 108

Chang (Yangtze) River, flooding 177

Chao Phraya River (Thailand) 214, 215

China 329; agriculture/rural development $82,83,84,85,86,87,91$; banks/banking 89-90; country programmes 85 ; defence budget 185; economic development/ reforms $78-9,83,91,275,313-14,333$; environmental issues $84,176-7,178,183$; ethnic minorities 330; Foreign Capital 
China (cont.)

Management Centre (FCPMC) 88;

foreign investment/economic assistance

24, 80, 82-5; human rights 318,319 ; and

IGOs 78, 85-7, 91-2; infrastructure

development 82, 84, 90; and Japan 310;

Lancang Basin hydropower project 221-

2; and Malaysia 58-9; Mekong River

Basin development 209-36; micro-finance

technique 84, 87, 91-2; Ministry for

Foreign Trade and Economic Cooperation (MOFTEC) 87-8; National 8-7 Poverty Reduction Plan $82,83,88$, 91, 92; National People's Congress 83; nationalism 319-20; nuclear power 177, 182; population expansion 179,189 ; poverty and alleviation programmes 82 5, 88-9, 187, 189; and regional security 259, 311; and Russia relationship 319-20; social services (health/education) 82,83 , 85, 86; State Planning Commission (SPC) 82, 83; and Taiwan 306, 314; technical assistance 85,86 ; trade: regional/ international 315-18; Training Programme for Cadres in Poor Areas 92; and UNDP assistance 87-8; urbanization 178; and US relationship 190-1, 245, 260; water supplies and irrigation issues 79 , 82, 84, 86, 90; Western Poverty Reduction Project (WPRP) 84; and World Bank 83-4, 92; and WTO entry 318; Yunnan Province hydropower developments 216

China International Centre for Economic and Technical Exchanges (CICETE) 87

Chinese Academy of Social Sciences (CASS) 91

chlorofluorocarbon (CFC) emissions 176

CICETE see China International Centre

for Economic and Technical Exchanges

civil services, in South Asia 107

civil society: and authoritarianism 256, 333; in Nepal 205-8; in Northeast Asia 311, $333,334-5$; and poverty alleviation $77-8$; in Sri Lanka 121, 137-8; suppression 122 clientalism, of Northeast Asia 57 Climate Change Secretariat 175

coalitions: political 50,115, see also domestic coalitions

Cold War demise 245, 247; and European integration 309-10; and Northeast Asia
$275,306,321$; and security issues 270 ,

272

Colinvaux, P.A. 149

collective identity/interests $248,250-1,253$, 257, 263-4, 265

colonialism: decolonization 247; in South

Asia 120

Commission on Global Governance (CGC) 155

Committee for Coordination of Investigations of the Lower Mekong Basin see Mekong Committee

Common Effective Preferential Tariff (CEPT) mechanism 281

communities: and environmental issues 9 , 86 ; and governance 7 ; security issues 2,6 , 11,76

conflicts: civil 270; and environmental issues 149-50, 152, 154, 161, 165; interstate 165; over transboundary rivers 209-10, 211, 212 ; and poverty issues 77 ; resolution 124-8; and security issues $164,216-32$; and water supplies 159 , see also ethnic conflicts

constructivism: and ASEAN 248-50; and poverty alleviation 78 ; and security models/strategy 246, 247-50, 259-60, 274-5; theories 247-8

Convention on Biological Diversity 175

Convention to Combat Desertification 175

Copenhagen Declaration and Program of Action (1995) 82

Copenhagen School 250-1; security definitions 252

corruption: in South Asia 102, 108, 111-14, 115, 117; in Southeast Asia 256; in Sri Lanka 127, 136, 141; in Thailand 64

Council for Security Cooperation in the Asia-Pacific (CSCAP) 261-2, 309, 32830, 332, 334; and ASEAN Regional Forum 329; Track Two 262, 327

crime 124; politization in South Asia 11117 ; and security 270; smuggling offences in South Asia 103, 111, 114; transnational 254, 262, 329

cross-border migration $181,312,322,323-4$, 330

cross-border security 72, 103, 181, 187

CSCAP see Council for Security and Cooperation in the Asia-Pacific 
culture 174,310 ; definition 275 ; political $120,122,123,126-7,133,138,142$; security 276,306 ; Sinhala 134

Cumings, Bruce 51

Dabelko, G. 155, 161, 163

Dalada Maligawa bomb attack (Sri Lanka, 1998) 128

Dandeldhura District Development Committee (Nepal) 196

deforestation: in Laos 232; in Mekong River Basin 229; in Northeast Asia 176, 177, 180, 184

democracy/democratization: and authoritarianism 256; and globalization 270; and poverty alleviation 74; social foundations of 50; in South Asia 116-17 desecuritization 253,260

desertification 177, 181

Deutsch, Karl 275

developing countries: security/insecurity threats and sources 160; structural adjustment policies and debts $24-5$; and trade deficits 42

Development International Desjardins (Canada) (DID) 87

dictatorships: social foundations of 50

Diehl, P.F. 149

disease(s) 156, 276; control and prevention 23, 37; in Pakistan 33

Dispute Settlement Mechanism (DSM) 283 disputes: in ASEAN countries 283, 292-3, 310-11; fishing 181, 210, 213, 226, 230, 322, 323; maritime 187-8, 311; territorial 306, 311, 321, 331

domestic coalitions: and embedded mercantilism 48-54; and international strategies 47-69; and nomenklatura capitalism 60, 68; in Southeast Asia 65-6

drought 181, 213

drug-related issues: and security 75,114 ; and terrorist linkages 103; trafficking 112-13, 270, 276, 322, 324

dual economies 58-9; and deregulation 645; East Asian 61

EAEC see East Asia Economic Caucus Earth Summit see United Nations Conference on Environment and Development (1992)
East Asia: coalitions 56, 68-9; and Cold War structures 51; domestic savings 63 ; dual economies 61; financial crisis 62-3; and human security 256, 308-9; newly industrializing countries 55 ; political economy 63-4; trade 61

East Asia Economic Caucus (EAEC) 68, 249, 301

East Asian free trade zone 331

East Asian miracle 39

East Asian Vision Group 331

East China Sea 177

East Timor crisis 258, 260

Eastern Europe: per capita income 25 ecological issues: and human security 210 ; and transboundary rivers 209-10

economic crises: and policy responses $66-7$ economic development: and environmental issues 178-80; Mekong Basin states 214; and populism 121

economic issues: agriculture-based 39-40; currency movements 55, 57; deregulation 64-5; high debt equity ratios 63 ; and international terrorism 77; liberalization 50; loans 19; national debts 160; NETs (natural economic territories) 320; parallel economies in South Asia 111; reform policies $52,65-8$; strategies 49 50; structures 53, 76, 203

economic security 5-7, 76, 307; and hydropower development in Laos 223-4; and Indonesia 280-1; and poverty 75

Economic and Social Commission for the Asia-Pacific Region (ESCAP) 322

Ecoviolence (Homer-Dixon and Blitt) 1512, 159-60

ECSC see European Coal and Steel Community

education: Northeast Asia 82, 83, 85, 86, 189; Pakistan 31-2; South Asia 103, 158

Eelam movement (Sri Lanka) 108, 125

EFTA see European Free Trade Area

EGAT see Electricity Generating Authority of Thailand

Ehrlich, A.H. 150, 151

Ehrlich, P.R. 150, 151

EIAs see environmental impact assessments elections/electoral systems: in South Asia 113-14, 115-17; Sri Lanka 128

Electricity Generating Authority of Thailand (EGAT) 225 
Elliott, Lorraine 155

embedded liberalism 52-4

embedded mercantilism 47; and domestic

coalitions 48-54; and globalization 62-5;

open regionalism 61; in Southeast Asia

54-60

endangered species 177, 226

energy issues 148, 187; EGAT and MoUs

negotiations 225-6; generation/electricity

supplies/costs 204, 222, 224, 225; and

Greater Mekong Subregion (GMS)

programme 231; hydropower projects

196-9, 200, 215-16; natural gas 226, 323;

in Northeast Asia 177, 179, 182, 187, 323, 328; oil reserves 323; scarcity 175

Environmental Cooperation Treaty: ChinaJapan (1994) 183

environmental degradation 103, 149, 155 ,

159, 161, 164, 166, 276; and cross-border migration 181, 276; and human security 228, 270; and interstate tensions 211; in

Northeast Asia 322

environmental disorders $187-8$; biodiversity loss 176, 177, 180, 187, 233; biological system threats 175 ; and economic expansion 178-9; external policy options 190-2; indicators and causes 175-80; internal policy options 188-9; and interstate tensions 180-4; policy limits and flaws 184-7; remedial policies 180-1, $182-4,188$

environmental impact assessments (EIAs) 229-30, 231, 235

environmental issues: action programmes 262 ; and civil violence 161 ; and conflicts 152, 154, 165; governance of 164-5; and human development 159; and international standards 235-6; interstate cooperation 165-6, 167; literature 15960 ; in national security contexts 159 ; and poverty-security links $157-61$, 164-5; and security links 148-57; water development and human security $228-30$ environmental resources: and civil violence 161; scarcity 151-2, 178, 180, 181, 187, $189,270,322$

environmental security: concept $210-11$, 307; conferences and symposia 174-5; and industrialization 177-80; major forms of insecurity 175-6; in Mekong River Basin 183; in Northeast Asia 174-92; policies 182-7; and population expansion 179-80; and poverty $75,76,157-61$; and reductionism 186, 187; and urbanization 178

ESCAP see Economic and Social

Commission for the Asia-Pacific Region ethnic conflicts: in Northeast Asia 311, 322, 324, 330, 331; and security 270; South Asia 108-11; Sri Lanka 104, 123, 124-8, 134

ethnic minorities, China and Russian Far East 330

ethnicity, definition of 108

EURATOM (European Atomic Energy Agency) 309

Europe: and FDI 24; multilateral security models 306; post-Cold War 309-10; and US 310, see also Western Europe/the West

European Coal and Steel Community (ECSC) 309

European Economic Community (EEC) 309

European Free Trade Area (EFTA) 291, 293

European Union (EU) 309, 329

Export-Import (EXIM) Bank of Japan 301

family planning: in India $37-8$

Far Eastern Economic Review 301

FCPMC see Foreign Capital Management Centre (China)

financial crises, East Asia 62-3, 65

Finland: aid to China 87

fish stocks/fishing disputes: in Laos 226,

230; in the Mekong River Basin 210, 213, 222; in Northeast Asia 181, 322, 323

Five Principles of Peaceful Coexistence 330

Five-Year development plans: China 83; India 38

flexible engagement concept 248-9

floods/flooding: China 177, 181; in Mekong Basin 214, 222; Nepal 202-4

"flying geese" model of investment 56 food aid: in China 86

food baskets: as poverty line measure 79 food security: and environmental issues 159 ; and human security issues 76,103 , 175

Foreign Capital Management Centre (China) (FCPMC) 88 
foreign direct investment (FDI) 21, 24, 179

former Soviet Union (FSU) 25, 74

Framework Convention on Climate Change 175

free trade 36; New Zealand-Singapore treaty 69; in Northeast Asia 179

fundamentalism: in South Asia 109

G-8 (Group of Eight) 320

Galtung, J. 150

Gandhi, Indira 102

GATT see General Agreement on Tariffs and Trade

General Agreement on Tariffs and Trade (GATT) 52; principle of MFN status 60; principle of reciprocity 61; Trade Related Investment Measures (TRIMs) 284;

Uruguay Round 25, 291

George, Susan 26

geotectonics 206

Gerschenkron, A. 50

Gleditsch, N.P. 149, 152-3

Gleick, Peter 150

global integration: dynamics of 21-3; and human development 23-6

global political economy 74, 78

global warming 176, 178

globalization 19; and embedded mercantilism crisis 62-5; and human security linkages 39-41; and security issues 270, 272; and South Asia 102, 111; and structural reforms 41

Goh Chok Tong (Singapore prime minister) 331

Gorbachev, Mikhail 247

Gore, Al (US) 249

governance 7-9; corruption in South Asia 99-117; crisis of 261; democratic 124-8; environmental 164-5; global 52-3, 273; humane 101; in plural societies 115; and security linkage 100-1; in Sri Lanka 11942; structures 254

Greater Mekong Subregion (GMS) programme (ADB, 1992) 231

greenhouse gas emissions: Northeast Asia $176,182,184,187,188$

Halle, Mark 148-9

Hanoi (Vietnam) 221

Hassan, Shaukat 150, 166
Health Corporation Holdings (Singapore) 60

health provisions: and human security 76 ; in India 37-8; public spending (of GNP)

160; urban sanitation 160

Heginbotham, Eric 62

Hernandez, C.G. 178, 181-2, 184

Hindus, in South Asia 109-10

Homer-Dixon, Thomas 150, 153, 159-60

Hong Kong: FDI 55; regional/international trade 315-18

human development: concept and definition 155-6, 307; and economic development 39; and environmental degradation 159; and global integration 23-6; and human security relationship 155-6; sustainable $81,82,159$

Human Development reports (UNDP) 80 1, 123, 154-6, 161; Crisis in Governance in South Asia (1999) 124-5, 138, 139; Human Development in South Asia (1997) 157-8

human rights 72, 155; and China 318, 319; and security issues 75; in Sri Lanka 124, 135

human security: as alternative model/ approach 246, 253-8, 259; and ASEAN 255-8; concept and definitions 76, 93, 155, 228, 255, 307; cultural relativism debate 255; discourse and dialogue 263-4; early warning mechanisms 261-3; and ecological issues 210; and environmental impacts of water development 228-30; focus on 154-7; and globalization linkages 39-41; and human development 155-6; and insecurity $155,157-61,254$; and international politics 76 ; key elements 254; literature 228; and national security 100, 272-3; non-traditional framework 76-7; and Northeast Asia 330; and poverty $72, \mathbf{7 5}-\mathbf{7}, 92$; and social stability 228; and South Asia 102; and the state 307-9; and sustainable development 155 , 162; threats to 76,101 ; and UNDP $80-1$, see also water resources

Human Security Fund (UN) 254

humanitarianism: and international security 262; and interventions 255

hydro-politics 209-36

hydrogeology 206 
hydropower development projects: in China 221-2; in India 196, 197-9, 200; in Laos

223, 232; mega-dams 222; in Mekong

River Basin 209-36; in Nepal 196, 197-9, 204-5, 207; social impact of 229-30

Ibrahim, Anwar (Malaysia) 249

IGOs see international government organizations

illiteracy: adult 160; South Asia 158

IMF see International Monetary Fund India 157, 329; Administrative Reforms

Commission Report 107; economic development 33-7, 39; electoral process 113, 116; employment 36-7, 38; and environmental issues 165-6; ethnic conflict 108; external debts 34; FiveYear Plans 38; food-grain output 36; governance 102; grain trade losses 35-6; health budgets and policies 37-8; and IGOs 78; intervention in Sri Lanka 124; middle classes 102 ; military expenditure 158; and multiculturalism 115; political corruption 111,112 ; poverty and malnutrition 37,38 ; security/insecurity 104, 105, 160, 162; social development 37-9; and Structural Adjustment policies 20-1; Vohra Committee Report 112 Indian Economic Survey Reports 35 Indian Peace Keeping Force 124 Indo-Sri Lanka Accord (1987) 124, 134 Indochina: and ASEAN 234, 260; and Chinese Lancang Basin development 222; and flexible engagement concept 248-9

Indonesia 245, 328; and authoritarianism 256; and deregulation 65; dual economy 58; East Timor dispute 258, 259; economic/industrial growth 57-8; economy 258; and flexible engagement concept 248-9; Japanese FDI 55-6; oil boom phase (1973-1982) 57-8; and political anarchy 253 ; smoke pollution episode 261; sugar production 298; and tariff liberalization 298

Indus Water Treaty $165-6$ industrial waste pollution 177, 183 inequality: GINI index 160; in Northeast Asia 180, 187; and terrorism 77

infectious diseases: Indian control programme 37
INGOs see international non-governmental organizations

insecurity 254 ; and poverty 161 ; roots and sources 156, 159, 160; and violent conflict 164-5

institutional perspectives $12-14$

institutions/institutionalism: ASEAN framework 284-9; in Asia 245-7; compliance bargaining 296-7; for environmental governance 164-5, 175, 182-3, 184, 186, 191; and Mekong Basin states 233, 234-6; models 296; and non-traditional security 322-31; in Northeast Asia 333-4

Integrated Treaty on the Mahakali River (India-Nepal) 196, see also Mahakali Treaty

Intellectual Property Rights (IPRs) 23

Interim Mekong Committee (IMC) 218

International Centre for Trade and Sustainable Development 175

International Force for East Timor (INTERFET) 258

international government organizations (IGOs): and China's poverty alleviation programmes 78-92; and poverty alleviation $73, \mathbf{8 0 - 2}$

International Monetary Fund (IMF) 19-20, 320; and Asian financial crisis 62-3, 255, 330; environment-related programs 175 international non-governmental organizations (INGOs): implementation of UNDP programmes in China 87-8; and poverty alleviation 73

international organizations (IOs) 245 international relations (IR): and Northeast Asia 311-21; poverty studies 74; security studies 274,307

international security 271 ; state-centric conceptions 307; and terrorism 77

Interpol report on drugs-army nexus in Pakistan 114

interstate issues: borders 72, 181-2; cooperation 185-6, 190, 191-2; and environmental management $165-6,181$ 2, 183-4

intervention: humanitarian 255 irrigation issues: in China 84, 90; in Nepal 201-2, 205; and pollution 202

Janata Vimukthi Peramuna (People's Liberation Front, Sri Lanka) (JVP) 123 
Japan 86, 328; and China 310; defence policies 185, 312; economic growth/ problems 178-9, 275, 312, 314, 324-5, 333; and embedded mercantilism 53; environmental issues $176-7,178$; foreign direct investment 24, 51-2, 55-6; and human security $246,255,307$; nuclear power 177,182 ; regime shifts $50-1$; regional cooperation/influence 320; trade: regional/international 315-18; and US military factor 190, 312

Japan External Trade Organization (JETRO) 301

Jonsson, Christer 291

Kaplan, Robert 153

Kashmir conflict 108, 158

Katzenstain, Peter J. 275

KEDO (Korean Peninsula Energy Development Organization) process 318 , 320

King, Gary 76

Koirala, Girija Prasad (Nepalese prime minister) 196

Kolodziej, Edward 273

Kong-Chi-Mun project (Thailand) 219, 220

Korea, and agricultural subsidies 53

Korea-China Environmental Cooperation Joint Committee 183

Korea-Japan Environmental Cooperation Joint Committee 183

Korean Peninsula: human security issues 330; KEDO process 318 , 320; tensions 185, 312, 320, 323

Kornai, J., and East Asian financial crisis 63-4

Kumaratunga, Chandrika Bandaranaike (Sri Lankan president) 126, 129

Kyoto Protocol 175

Lancang Basin hydropower project (China) 221-2

land: degradation 176, 180, 184, 187, 202; rights 205

Langjung Electricity Development Company (LEDCO), Nepal 204

Laos: hydropower projects 215, 223-6, 229; and Mekong River Basin hydro-politics 209-36; and memoranda of understanding (MoUs) 225, 229; Nam Theun 2 project 226, 227, 228, 229, 232; National
Biodiversity Conservation Areas 226; and political anarchy 253; and Thai hydropower market 224-6; Theun-Hinboun project 230

Latin America 25

LDP see Liberal Democratic Party

least developed countries: share of world trade $24-5$

Lee, Shin-Wha 187

legislation: in South Asia 106-7

Levy, Marc 151, 153

Li Kai 179

Li Peng (Chinese premier) 82

liberal democracy 102, 119

Liberal Democratic Party (LDP) of Japan

51

Liberation Tigers of Tamil Eelam (LTTE) $124-5,128,129,141$

life expectancy figures 160

Lipson, Charles 286

literacy levels: in India 38

Lodgaard, S. 149

Lonergan, S. 155, 161, 163

Lower Mekong Basin Development

Programme 183

LTTE see Liberation Tigers of Tamil Eelam

Mack, Andrew 76

McMichael, A.J. 149, 150

McNamara, Robert (WB President) 80

Mahakali River (India-Nepal) 197, 198

Mahakali Treaty (India-Nepal) 197-9, 207

Mahathir bin Mohamad (Malaysia prime minister) 251-2

Mahbub ul Haq, Dr. 161

Malaysia 328; and Asian financial crisis 66, 281; and Chinese 58-9; economic growth/ policies 57-9; and flexible engagement concept 248-9; Japanese FDI 55-6; national car project 298-9; new economic policies (NEPs) 58; and rent-seeking practices 53-4; and tariff liberalization 284; and Thailand relationship 299 the Maldives 104, 157 malnutrition: in India 38 marine pollution: exclusive economic zones 184; Northeast Asia 177, 180, 183, 184, 187,188

maritime issues: disputes 187-8; fish stocks/ fishing 181; in Northeast Asia 311; sealevel rise 181, 187 
market economy: strategic understanding of 48-9

market liberalization 42

Marshall Plan 73

Mathews, J.T. 150

Matthew, R. 155, 161, 163

media: Colombo Declaration of Media

Freedom and Social Responsibility (April 1998) 137; legislation 136; Sri Lanka 133 5

mega-cities: in China 178

Mekong Agreement (UNDP, 1995) 220, 222-3

Mekong Committee 218, 219-20, see also Interim Mekong Committee (IMC)

Mekong River Basin 183, 209-36, 331; conflict and security issues 216-32; economic rivalry 219 ; and environmental security 210-12, 235; geopolitics and resources 212-16, 217; hydropower and economic growth 215-16, 223-4; institutional frameworks 230-2, 233, 234-6; integrated planning 221-3; international financing and national debt 227-8; and interstate cooperation 218; riparian states 210, 211-12, 213; Tonlé Gap (Cambodia) 213; UNDP Agreement (1995) 220, 222-3; Upper Mekong Forum 219; upstream/downstream tensions 216-32; Vietnam Delta 213-14; water allocation disputes 218, 219-21; water development projects 214-15; water quality monitoring 221; water utilization rules 218, 219-21

Mekong River Commission (MRC) 218, 220, 221; and Asian Development Bank 231, 235; and Chinese membership 221, 223 ; environment programme 231 ; and sustainable development 231

memoranda of understanding (MoUs) 225, 229

mercantilism see embedded mercantilism Mexico 310

migration, cross-border 103, 181, 187, 312, 322, 323-4, 330

militarization: expenditure 158; nuclear capability 158; South Asia 106

Ministry for Foreign Trade and Economic Co-operation (China) (MOFTEC) 87-8

minorities: in South Asia 108-11, 115; in Sri Lanka 121, 123 modernization: in South Asia 102

MOFTEC see Ministry for Foreign Trade

and Economic Co-operation (China)

money-laundering: security implications 114; and terrorism 103

Mongolia 179, 183, 189, 312, 329, 333; and regional cooperation 321; trade: regional/ international 316, 317, see also Tumen

River Area Development Programme

Montreal Protocol on Substances that

Deplete the Ozone Layer 175, 291

Moore, Barrington 49-50

MRC see Mekong River Commission

Mujahideen, arms supplies 113

multiculturalism: and Northeast Asia 191;

and South Asia 114-15

multilateral donor institutions 19

multilateral security 306

multinational companies (MNCs) 22

Murray, Christopher 76

Muslims, in South Asia 109-10

Myanmar 234; ASEAN's constructive engagement approach 261; and authoritarianism 256; and Mekong River Basin hydro-politics 212-16; and political anarchy 253

Myers, N. 149, 150, 154

NAFTA see North American Free Trade Agreement

Nair, K.R. 34-5

Nam Theun 2 hydropower project (Laos) 226, 227, 228, 229, 232

Narmada Bachao Andolan (NBA), India 200

nation-building 247

nation-states/state-nation problem 120-3

National Movement Against Terrorism (Sri Lanka) (NMAT) 134

national security: and human security issues 272-3; and Northeast Asia 271; in South

Asia 101, 103; state-centric conceptions 307 ; threats to 103

nationalism: China 319-20; in Northeast

Asia 311

NATO see North Atlantic Treaty

Organization

natural environment 9-11; hazards and disasters 202-4, 205

NEACD see Northeast Asia Cooperation Dialogue 
NEAEF see Northeast Asia Economic Forum

NEATIC see Northeast Asia/Tumen Investment Corporation

neo-liberalism 78

neo-Marxian analysis 74

neoclassical economics $62-3,80$

Nepal 157; coalition governments 105-6; degradation and pollution 202; energy issues 204-5; ethnic/caste-based violence 109; floods/flooding 202-4; hydropower development projects 196, 197-9, 204, 207; irrigation schemes and systems 2012; Kalapani/Mahakali issue 197, 199; Maoist movement 106; natural disasters 203, 205; role of military 106; security issues 104, 160, 199-201, 205-8; social solidarity 205-8; water-related livelihoods 201-2

Nepal Communist Party United MarxistLeninists (UML) 196

nepotism: in South Asia 102

New Zealand 86, 329

newly industrializing countries (NICs) 55, 56

NGOs see non-governmental organizations

NMAT see National Movement Against Terrorism (Sri Lanka)

nomenklatura capitalism 48, 54, 57-8; and

domestic coalitions 60; and open regionalism 60-2; in Southeast Asia 64-5

Nomura Research Institute (Japan) 301

non-governmental organizations (NGOs):

Chinese 90; environmental 175; and Nam Theun 2 project 229, 230; and World Bank-assisted projects 90

non-tariff barriers (NTBs) 283

non-traditional security: applying 3-5; and nation-states 270-1; in Northeast Asia 270-7, 306-35; and security concept 272-3, 307-8; and the state $2-3,307$

North America 24

North American Free Trade Agreement (NAFTA) 309; and East Asian trade 61 North Atlantic Treaty Organization (NATO) 153, 309, 310; expansion 313

North Korea 329; economy 315, 333; environmental issues 176-7, 183; and NEACD 328; nuclear missile development 306,312 ; poverty and inequality $187,189,312$; and regional cooperation 321, 325, 326; trade: regional/international 315-18; and US military factor 190-1, see also Tumen River Area Development Programme

Northeast Asia: authoritarian regimes 311,333 ; civil society institutions 311 , $333,334-5$; cross-border migration 181 , 312, 322, 323-4, 330; defence budgets and military security $185,187,190-2$; deforestation 176, 177, 180, 184; democratization and capitalization 333 ; economic growth/relations 178-9, 186-7, 188, 315-18; education and social welfare 189 ; energy issues $177,179,182,187,323$, 328 ; environmental disorder indicators and causes 175-80; environmental security 174-92, 322-3; ethnic conflicts $311,322,324,330,331$; foreign investment 179,188 ; industrialization effects 177-80, 186-7; international relations 311-21; interstate tensions and remedial policies 180-4, 190-2; marine pollution 177 ; nationalism issues 311,327 ; and non-traditional security 307-9, 311, 321-5, 334; population expansion 179-80; poverty and inequality $180,187,189$; power balance 312-14; regional cooperation 308-9, 311-12, 318-21, 325-31, 333-5; security issues 174, 185, 270-7; security practice $\mathbf{2 7 5}-\mathbf{6}$; statecentrism 185-6, 272, 273-4, 276-7; territorial disputes $306,311,321$, 331; trade: regional/international 315-18; urbanization effects $178,186-7$; US military presence 186-7, 190, 313, 314

Northeast Asia Cooperation Dialogue (NEACD) 309, 325, 327-8, 332, 334; Defence Information Sharing (DIS) study project 328

Northeast Asia Economic Forum (NEAEF) 309, 325, 326-7, 332, 334

Northeast Asia Environment Programme 183

Northeast Asia/Tumen Investment Corporation (NEATIC) 326

Northeast Asian Conference on Environmental Cooperation (1992) 183 
Northwest Pacific Action Plan 183

Norway: and human security 246, 254; involvement in Sri Lankan-LTTE talks 130, 141

nuclear energy: military capability 158 ; power plants accidents $177,182,188$; radioactive waste disposal 177, 182, 184, 187,188

Obuchi, Keizo (Japanese prime minister) 254

OECD see Organisation for Economic Co-operation and Development oil spills 177,182

open regionalism 47; effects of Asian crisis 68; and nomenklatura capitalism 60-2; and security strategies 62

Opschoor, J.B. 150

Organisation for Economic Co-operation and Development (OECD) 25; Development Assistance Committee (DAC) 82

Organization for Security and Cooperation in Europe (OSCE) 306

Ottawa Conference on Conservation and Development (1986) 174

ozone layer depletion 176

Pacific Economic Cooperation Council (PECC) 327

Pak Mun dam (Thailand) 230

Pakistan 21, 26-33, 157; development model 42-4; drugs-army nexus and trafficking 112-14; economic growth 27-30; education expenditure and programmes 31-2; and environmental issues 165-6; foreign direct investment 30 ; governance 102; health expenditure/ statistics 31-3, 33; military expenditure 158 ; and national security 104 ; poverty 30 ; role of military 106; security/ insecurity threats and sources 160, 162; social development 30-3

Pakistan Economic Surveys 27, 28, 29

Pakistan Narcotics Control Board (PNCB) 112, 113

Pancheswar Multi-Purpose Dam Project, Nepal 196, 197, 199, 207

Papua New Guinea 329

Paris Development Forum on Sri Lanka (2000) 140
PECC see Pacific Economic Cooperation

Council

Pempel, T.J. 50-1, 53

Peoples Alliance (PA) Sri Lanka 126

People's Bank of China 88

People's Republic of China (RPC) see

China

personal security issues 76

the Philippines 328; and authoritarianism

256; bilateral aid 56; and flexible engagement concept 248-9; and political anarchy 253; and tariff liberalization 284

Phnom Penh (Cambodia) 220

Plaza Accord (1985) 55

plural societies: governance in 104, 119-42; and multiculturalism 114-15

pluralism: and authoritarianism 256

political clientalism 53

political economies: East Asia 63-4; global

74, 78; Southeast Asia 61-2

political instability: and human security 166 political security 76

politics: criminalization in South Asia 11117

pollution: air 177-80; industrial waste 177 ,

182; and irrigation issues 202; marine 177 , 180,182 ; transboundary 181,322 ; water supplies 183, 188, 202, 205

Poornagiri Dam, Nepal 196

populations: China 179, 189; cross-border movements of 103, 181-2; growth rates 160, 179-80; Mekong Basin states 214

populism: and economic development 121 post-Cold War era: and poverty issues 74 ,

see also Cold War demise

post-structuralism 74

postmodernism 74

Poudel, Ram Chandra (Nepal) 204

poverty $72-3$; as an international issue

$77-8$; in China 82-5, 88-9, 187, 189; and economic growth 80 ; and environmentsecurity links 157-61; as human security issue $72, \mathbf{7 5}-\mathbf{7}, 92,154-5,270,307$; in

India 37,38 ; in international relations studies 73-8; in Laos 232; measuring systems 79; in Northeast Asia 180, 187; of Southern debtor countries 26; and structural reforms 41 ; studies 74 ; as threat to regime instability 74

Poverty Alleviation and Development Offices, China (PADOs) 89 
poverty alleviation (PA) 39; Chinese-IGO collaboration 78-92; civil-society-driven model 77-8; conceptual models 72-3; and democracy 74; and IGOs 73, 77-8; international collaboration models 77-8; and micro-finance technique $84,87,91-2$; "Samurdhi"' (Sri Lankan government programme) 140; in Sri Lanka 137

poverty eradication: in China $79,83,85$; and IGOs 81-2

PPLG see Provincial Poverty Leading Group (China)

Prabhakaran (LTTE leader) 126, 141

Provincial Poverty Leading Group (China) (PPLG) 88-9

Qomolongma Nature Preserve (China) 87

radioactive waste $177,182,184,187,188$, 191

Ratwatte, General (Sri Lanka) 139

Reagan, Ronald (US president) 80

Redefining Security (Brown) 175-6

refugee problems $74,174,181,254,323-4$

regional issues: cooperation $165-7,184$,

308, 309-11; environment-led tensions

181-2; environmental security 163, 192;

institutions 233; security politics 246, 264

regionalism: block 61 ; open $60-2$

regionalization 270

religious fundamentalism, in South Asia 109-10

Renner, M. 149

rent-seeking practices: in East Asia 53-4; in Nepal 206

rentier classes: in South Asia 102

research: poverty (WB) 75; securityenvironment links 151-3, 157, 161, 162-3

research and development $(\mathrm{R} \& \mathrm{D})$, and WTO rules 23

Reserve Bank of India, annual reports 34 resources: control and security 149-50; degradation 151-2, 178; depletion/ scarcity $151-2,178,180,181,187,189$, 270, 322; and governance 164-5; of Mekong River Basin 212-16, see also fish stocks/fishing disputes; water resources riparian states: in the Mekong River Basin 210, 211

Rodan, Garry 60
Rosen, S. 23

Ruggie, J. 52, 54

Rüland, Jürgen 257

Russia 183, 325, 329, 333; and China relationship 319-20; economic decline 312, 313, 319, 324; and regional development/cooperation 318-19; regional/international trade $315-18$; and security issues 313

Russian Far East 312, 313, 319, 325; ethnic minorities 330; migration problem 323-4

SAARC see South Asian Association for Regional Cooperation

Sahi, Gajendra 196

Sambor Dam hydropower development (Cambodia) 216

Samuels, Richard 62

Sangha (Buddhist clergy) 127, 132, 133-5

Sardar Sarovar Project, Narmada (India) 200

Schwartz, D.M. 152-3

Sea of Japan 177, 182

Seattle Ministerial Conference (WTO, 1999) 23

Secretariat of the Convention on Biological Diversity 175,183

Secretariat of the Convention to Combat Desertification 175, 183

sectarian problems/violence: in South Asia 109-10

securitization: as alternative security model/ approach 246, 250-3, 259; Asian values debate 252; and collective identity 250-1, 253; and societal security 251

security: alternative approaches 245-66; concept and definitions 147-8, 149, 151, 154, 210, 233, 252, 254, 271; constructivist model/approach 246, 247-50; economic perspective 5-7; and governance linkage 100-1; implementing alternative models 258-65; integration of traditionalalternative approaches 264-5, 265-6; international politics 247; and natural resources 149-50; non-traditional 174, 175, 184, 185, 272-3; and organized crime 270; and pax Americana 255; policies 271; regional 166; and socio-economic issues 5-7, 274; and the state 271; studies 273; traditional 93, 163, 166, 184, 256, 264-5, see also human security 
security models: alternative $245-66$; constructivist 246, 247-50, 259; human security 253-8, 259; securitization/ desecuritization 250-3, 259

security practice: in Northeast Asia 275-6; and security concept $\mathbf{2 7 3}-\mathbf{4}$; as social construction 274-5

security strategies: and open regionalism 62; traditional concept 274

security-environment links 148-57; arguments for 150-1; conceptual debates 151, 153, 156-7; five key lessons 162-7; insecurity sources 156, 159, 160; literature 149-50, 154, 157, 161; and political instability 166; and poverty 157-61; research $151-3,157,161,162-3$; research methodology 152-3, see also water resources

Segal, Gerald 255-6

Self-Financing Irrigation and Drainage Districts (China) (SIDDs) 90

Sen, Amartya 72

senas (private armies in South Asia) 109, 112

Shanxi Poverty Reduction Project (China) 90

Shias, in Pakistan 110

Shiva, V. 36

Sikhs: in South Asia 109-10

Singapore 328; government-linked companies (GLCs) 59-60; Japanese FDI 55-6; out-of-bound (OB) markers 252

Singapore Technologies 60

Sinhala Commission (1998) 134

Sinhala Urumaya (Sinhala Heritage) party 134

Sino-American tensions 245, 260

social action programmes (SAPs) 23-4

social issues: conflict and human security 103; poverty and security $75, \mathbf{1 5 7}-\mathbf{6 1}$,

163-7; security perspectives 5-7; stability 228; welfare and dharma 100

societies: instability and poverty issues 77 ; plural 119-42; politicization of 121; and role of the state 119-20

socio-economics: of Mekong Basin states 214-15; and security issues 274

soil erosion 177,181

Soroos, Marvin 150, 151

South Asia: alienation of minority populations 108-14; caste-based issues
109-10; civil services 107; coalition governments 105-6; colonial legacy 120; democracy/democratic institutions 102 ,

105-8; economic reforms 111; education 103 , 158, 160; electoral systems $113-14$, 115-16; enclaves and insurgency 105; environment-security-poverty links 157-61, 163-7; fundamentalism 109; and globalization 102; and governance crisis/ corruption 99, 101-5, 116-17; health care 103, 158; illiteracy 158; legislation 106-7; militarization 106, 158; and multiculturalism 114-15; political corruption 111-14; poverty issues $103,157-61$; regional tensions/conflicts 163,245 ; security/insecurity issues 102,104 , 157-61, 162-7, 245; senas (private armies) 109, 112; and sustainable development 159; and transnational conflict 103

South Asian Association for Regional Cooperation (SAARC) 114, 157, 166-7

South China Sea 177, 259, 310

South Korea 328; economic issues 178-9, $312,324,333$; environmental issues 176-7, 178, 183; foreign direct investment 55-6; nuclear power 177, 182; poverty and inequality 187,189 ; and regional cooperation 320-1; trade: regional/ international 315-18; and US military factor 190

South Pacific Regional Environment Programme 183

Southeast Asia 310-11; coalition types 66-7; cooperation 264; and domestic cartels 57; dual economies 54-5; and economic growth/security 57,271 ; and economic reform policies $65-8$; embedded mercantilism 54-60; and foreign direct investment 55-6; and human security $256-7,271$; institutionalism 246-7, 250; and law enforcement 263; and nationalist/ internationalist coalitions 50-4; and political anarchy 253; political economy 61-2; post-crisis 65-6; security concept/ issues 233-4, 252, 260, 264-5, 271

Sri Lanka 157; civil society $121,122,131$, 136, 137-8; colonial legacy 120; Constitution/Thirteenth Amendment 124, 130-1; constitutional reforms $125,126-7$, 
130-3; Dalada Maligawa bomb attack (1998) 128; defence budget 124-5; democratic governance 102, 119-42; economic/civic governance 139-41, 142; elections/electoral system reforms 128 , 129, 131-3, 138-9; ethnic conflict and terrorism 104, 108, 110, 123, 124-8, 133, 134; human rights abuses 124,135 ; independence 121-2; independence and sovereignty 121 ; Indian intervention 124, 130; Jaffna peninsula issue 128, 130; Jayasikuru campaign 128; language policy 121, 124, 134; LTTE 124-6, 128-30, 141; media (state-controlled/private) 133-5, 135-7; military role $106, \mathbf{1 2 8}-\mathbf{3 3}$; minorities 121,124 ; and national security 104; PA-UNP talks 130-3; political scene 128-33; poverty alleviation 137 , 139-40; Prevention of Terrorism Act (1979) 125; and role of state 120-3; Sangha (Buddhist clergy) 127, 132, 133-5; security/insecurity threats and sources 160 ; sovereignty $121-2$; Tamils and devolution 104, 124, 125-7, 130

State Planning Commission (China) (SPC) 82,83

state(s): authoritarian 50,121, 256; collaboration with IGOs 93; and nation-state/ state-nation problem 120-3; role of 122; and security issues $2-3,270-7$; "weak" 256, 274

Stockholm Convention (EFTA) 291

strategy(ies): economic 48-50; international 47-69; theory of 273

structural adjustment loans (SALs) 19-20

structural adjustment policies 24-5

structural reforms: and globalization 41

structuralism 74

Stubbs, Richard 56

sub-Saharan Africa 25

Suharto family 58, 298

Suharto government 253, 258

Suharto, President (Indonesia) 258

Suhrke, Astri 155-6, 262

sulphur dioxide emissions 176-7, 180, 182, 188

Sunnis, in Pakistan 110

sustainability 210

sustainable development 81,82 ; and human security $155,159,162,165$; and Mekong Basin project 231
Taiwan: and China 306, 314; economic growth 178-9, 315; environmental disorders 176, 178; foreign direct investment 55-6; military expenditure 185 ; nuclear power 177,182 ; trade: regional/international 315-18; and US military factor 190

Tallberg, Jonas 291

Tamil people: Bindunuwewa rehabilitation camp massacre 125; Eelam movement 108, 125; and ethnic conflict 124

Tamil United Liberation Front (TULF) 127 tariff liberalization 281-4

Tehri Dam Project, Garhwal (India) 199

Temasek Holdings (Singapore) 60

terrorism/terrorists: linkages to drugs/arms smuggling 103; Prevention of Terrorism Act (Sri Lanka) 125; religious 110; and security 270, 276; in Sri Lanka 126

Thailand 328; and authoritarianism 256; Chao Phraya River Basin 214, 215; and Chinese Lancang Basin development 222; economic issues 57, 66, 215; and flexible engagement concept 248-9; and foreign investment 299-300; and human security 257; hydropower 215; industrialization 215; Japanese FDI 55; Kong-Chi-Mun project 219, 220; and Lao hydropower market 224-6; and Malaysia 299; and Mekong River Basin hydro-politics 209-36; NGOs 226; Pak Mun dam 230; and political anarchy 253; and Vietnam 219-20; and World Bank 64

Thatcher, Margaret (UK prime minister) 80

Theun-Hinboun project (Laos) 230

Thimpu Principles (Sri Lanka) 129

third world: and poverty issues 74

Tigno, V. 178, 181-2, 184

Tonlé Gap (Great Lake, Cambodia) 213, 219, 220, 222

Torres, C.G. 178, 181-2, 184

Tow, William T. 74-5

toxic waste disposal 178, 180

trade barriers 60

trade deficits 42

trade liberalization 36

Trade Related Aspects of Intellectual Property Rights (TRIPs) 23

Trade Related Investment Measures (TRIMs) 284 
Training Programme for Cadres in Poor Areas (China) 92

transborder tensions 176 , see also crossborder migration; cross-border security transboundary rivers: conflicts 209-10,211, 212; environment/resource issues 232

transport, water 210, 213, 219

Treaty of Amity and Cooperation in Southeast Asia 330

Trood, Russell 74-5

Truman Doctrine 73

TULF see Tamil United Liberation Front

Tumen River Area Development

Programme 183, 309, 318, 320, 321, 325-6, 327, 332, 334

Ullman, R.H. 150, 151

Ultimate Security (Myers) 154

UMNO see United Malays National Organization

UNDP see United Nations Development Programme

unemployment: and human security 103 ; and structural reforms 41

UNEP see United Nations Environment Programme

UNICEF see United Nations Children's Fund

unilateral trade liberalization, and open regionalism 60

United Kingdom (UK) 86

United Malays National Organization (UMNO) 58-9

United National Party (Sri Lanka) (UNP) 123, 127; and human rights abuses 135

United Nations 73, 330; Human Security Fund 254; and International Force for

East Timor (INTERFET) 258; and security-environmental links 153 ; Social Development Summit Preparatory Committee 82

United Nations Children's Fund (UNICEF) 26; support in China 86

United Nations Commission on Sustainable Development 175, 183, 184

United Nations Conference on Environment and Development (1992) 174-5

United Nations Conference on the Human Environment (1972) 174
United Nations Convention on the Law of the Non-Navigational Uses of International Watercourses (1997) 223

United Nations Development Programme (UNDP): and Chinese country programmes 87-8, 322; Human Development report (1990) 80-1; Human Development report (1994) 154-5, 254;

Human Development report (1997) 157; Human Development report (1999) 123, 124-5, 138; Human Development reports 139, 161; and Mekong Basin Committee 220; and non-traditional security issues 184 ; and poverty alleviation 78,87 ; and sustainable human development 81 ; and Tumen River Area Development Programme 326

United Nations Economic Commission for Asia and the Far East 218

United Nations Environment Programme (UNEP) 175, 182, 322

United Nations Security Council 150, 184

United Nations Symposium on the Global Environment in the Twenty-first Century (1997) 175

United States (US): bilateral security relationships 250; Bureau of Reclamation 218; and China 245, 260, 311; and CSCAP 328; Department of Defense 153; foreign policies 74; Japanese alliance 61 , 314; military presence in Northeast Asia 186-7, 190-1; and Northeast Asia 275, 311, 312, 313, 314, 316, 317, 333; pax Americana 255

Universal Declaration of Human Rights 23

University of California, Institute on Global Conflict and Cooperation (IGCC) 327

University of Toronto: Peace and Conflict Studies Program 151

UNP see United National Party (Sri Lanka)

US-DPRK Agreed Framework 318

Veneroso, F. 62-3

Vienna Convention for the Protection of the Ozone Layer 175

Vientiane (Laos) 220, 222, 224

Vietnam 329; and ASEAN 249-50; hydropower development projects 216 ; and Mekong River Basin hydro-politics 
209-36; and MRC negotiations 221; and Thailand 219-20

Vollebaek, Knut (Norwegian minister) 254

Wade, Robert $62-3$

Waever, Ole 251, 252

Wallerstein's World System theory 74

Wanasinghe, Shelton 141, 142

war see conflicts

Washington Consensus 80, 82

water resources: in China $79,82,84,86$,

90; and environmental issues 228-30;

hydropower dam projects 196-201; and

interstate conflicts 159; Mekong River

Basin hydro-politics 209-36; in Nepal

196, 197-9, 205-8; in Northeast Asia

181; pollution $183,188,202,205$;

related livelihoods 201-2; and security

issues 199-202, 228-30; transport and

navigation 219 , see also irrigation issues

welfare states: use of term 53

Western Europe/the West: and Asian financial crisis 330; regional integration $309-10$; security concepts and institutions 306

Westing, Arthur 150

wetlands protection 213, 232

Wickremesinghe, Ramil (Sri Lanka) 129

World Bank (WB) 19, 25, 73, 320; and

Arun III hydropower project (Nepal)

204-5, 207; and economic growth in

Northeast Asia 178-9; environment- related programs 175; and international environmental standards 235-6; marketcentric approach to development 80-1; and Mekong River Basin developments 227, 233; Nam Theun 2 project (Laos) 227-8, 229; and poverty alleviation in China 83-4, 88-90; poverty research and measurement 75, 79; Project

Management Offices (PMOs) 89; Sri Lankan report (2000) 140; structural adjustment programmes 78 ; and Thailand 64; World Development reports 81

World Commission on Environment and Development 149, 162

World Economic Forum (Davos, 2003) 23

World Food Programme, work in China 86

World Summit on Social Development (WSSD) (Copenhagen, 1995) 81-2, 175

World Summit on Sustainable

Development (2002) 175

world trade: and least developed countries 24-5

World Trade Organization (WTO): China's entry 318, 320; establishment 19-20, 24; and global trade practices 22 ; and traditional security issues 184

Yellow Sea 177, 182, 183

Young, Oran 250

Yunnan Province (PRC) 212, 214, 216, 217

Zysman, J. 49 
